\title{
Psychogenic non-epileptic seizures : a separate disorder or part of a continuum?
}

Citation for published version (APA):

Bodde, N. M. G. (2013). Psychogenic non-epileptic seizures : a separate disorder or part of a continuum? [Doctoral Thesis, Maastricht University]. Maastricht University. https://doi.org/10.26481/dis.20131031nb

Document status and date:

Published: 01/01/2013

DOI:

$10.26481 /$ dis.20131031nb

Document Version:

Publisher's PDF, also known as Version of record

\section{Please check the document version of this publication:}

- A submitted manuscript is the version of the article upon submission and before peer-review. There can be important differences between the submitted version and the official published version of record.

People interested in the research are advised to contact the author for the final version of the publication, or visit the DOI to the publisher's website.

- The final author version and the galley proof are versions of the publication after peer review.

- The final published version features the final layout of the paper including the volume, issue and page numbers.

Link to publication

\footnotetext{
General rights rights.

- You may freely distribute the URL identifying the publication in the public portal. please follow below link for the End User Agreement:

www.umlib.nl/taverne-license

Take down policy

If you believe that this document breaches copyright please contact us at:

repository@maastrichtuniversity.nl

providing details and we will investigate your claim.
}

Copyright and moral rights for the publications made accessible in the public portal are retained by the authors and/or other copyright owners and it is a condition of accessing publications that users recognise and abide by the legal requirements associated with these

- Users may download and print one copy of any publication from the public portal for the purpose of private study or research.

- You may not further distribute the material or use it for any profit-making activity or commercial gain

If the publication is distributed under the terms of Article $25 \mathrm{fa}$ of the Dutch Copyright Act, indicated by the "Taverne" license above, 


\section{Psychogenic non-epileptic seizures}

a separate disorder or part of a continuum? 


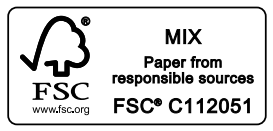

N.M.G. Bodde Psychogenic non-epileptic seizures: a separate disorder or part of a continuum

Layout: $\quad$ Tiny Wouters

Cover design: Painting of "St. Anastasia" by Friedbert Andernach

Permission of the Museum for epilepsy and the history of epilepsy in Kork, Germany

Print: $\quad$ Ipskamp Drukkers, Enschede

ISBN:

978-94-6191-870-3

The printing of this thesis was financially supported by the Nationaal Epilepsie Fonds, the Department of Research and Development Kempenhaeghe and the School for Mental Health and Neurosciences (MHeNS), Maastricht University. 


\title{
Psychogenic non-epileptic seizures
}

\author{
a separate disorder or part of a continuum?
}

\author{
PROEFSCHRIFT \\ Ter verkrijging van de graad van doctor aan de Universiteit Maastricht, \\ op gezag van de Rector Magnificus, Prof. dr. L.L.G. Soete, \\ volgens het besluit van het College van Decanen, \\ in het openbaar te verdedigen \\ op donderdag 31 oktober 2013 om 16.00 uur
}

door

Nynke Maria Gerharda Bodde 


\section{Promotores}

Prof. dr. R.J. van Oostenbrugge

Prof. dr. K.E.J. Vonck, Universitair Ziekenhuis Gent (België)

\section{Copromotores}

Dr. R.H.C. Lazeron, Kempenhaeghe (Heeze)

Dr. A.J.A. de Louw, Kempenhaeghe (Heeze)

\section{Beoordelingscommissie}

Prof. dr. F.R.J. Verhey (voorzitter)

Prof. dr. G.A. Baker, Walton Centre for Neurology and Neurosurgery and University of Liverpool (United Kingdom)

Prof. dr. E. Thiery, Universitair Ziekenhuis Gent (België)

Dr. M.C.G. Vlooswijk 


\section{Contents}

$\begin{array}{lll}\text { Chapter } 1 & \text { General introduction } & 7\end{array}$

Part $1 \quad$ Setting the scene 13

Chapter 2 Psychogenic non-epileptic seizures - diagnostic issues: a critical review 15 Bodde NM, Brooks JL, Baker GA, Boon PA, Hendriksen JG, Aldenkamp AP.

Clin Neurol Neurosurg 2009;111:1-9

Chapter 3 Psychogenic non-epileptic seizures - definition, etiology, treatment and prognostic issues: a critical review

Bodde NM, Brooks JL, Baker GA, Boon PA, Hendriksen JG, Mulder OG, Aldenkamp AP. Seizure 2009;18:543-53

Part 2 Lessons from current treatment

Chapter 4 Factors involved in the long-term prognosis of psychogenic non-epileptic seizures

Bodde NM, Janssen AM, Theuns C, Vanhoutvin JF, Boon PA, Aldenkamp AP.

J Psychosom Res 2007;62:545-51

Chapter 5 Treatments for non-epileptic attack disorder: a Cochrane Review Baker GA, Brooks JL, Goodfellow L, Bodde N, Aldenkamp

A. Cochrane Database Syst Rev 2007;24:CD006370

Chapter 6 Nondrug treatments for psychogenic non-epileptic seizures:

what's the evidence?

Brooks IL, Goodfellow L, Bodde NM, Aldenkamp A, Baker GA.

Epilepsy Behav 2007;11:367-77

Part 3 Patient characteristics and psychogenic etiology

Chapter 7 MMPI-2 personality profiles of patients with psychogenic non-epileptic seizures

Bodde NM, Bartelet DC, Ploegmakers M, Lazeron RH, Aldenkamp AP, Boon PA. Epilepsy Behav 2011;20:674-80

Chapter 8 Patients with psychogenic non-epileptic seizures referred to a tertiary epilepsy centre: patient characteristics in relation to diagnostic delay

Bodde NM, Lazeron RH, Wirken JM, van der Kruijs SJ, Aldenkamp AP, Boon PA. Clin Neurol Neurosurg 2012;114:217-22 
Chapter 9 Subgroup classification in patients with psychogenic non-epileptic seizures

Bodde NM, van der Kruijs SJ, ljff DM, Lazeron RH, Vonck KE, Boon PA, Aldenkamp AP. Epilepsy Behav 2013;26:279-89

Part $4 \quad$ Somatic vulnerability

Chapter 10 Psychophysiological biomarkers of dissociation in psychogenic non-epileptic seizures

Van der Kruijs SJ, Bodde NM, Aldenkamp AP.

Acta Neurol Belg 2011;111:99-103

Chapter 11 Functional connectivity of dissociation in patients with psychogenic non-epileptic seizures

Van der Kruijs SJ, Bodde NM, Vaessen MJ, Lazeron RH, Vonck K, Boon P, Hofman PA, Backes WH, Aldenkamp AP, Jansen JF.

J Neurol Neurosurg Psychiatry 2012;83:239-47

Chapter 12 General discussion

Summary

Samenvatting

239

Dankwoord

247

Curriculum Vitae 


\section{Chapter 1}

General introduction 
8 Chapter 1 


\section{General introduction}

A psychogenic non-epileptic seizure (PNES) is defined as a clinically observable paroxysmal change in behaviour or consciousness, that resembles an epileptic seizure, but is not accompanied by the typical electrophysiological changes that accompany an epileptic seizure. In these patients there is an absence of any known organic aetiology for the seizures, whereas there is positive evidence or a strong suspicion for the existence of psychogenic factors ${ }^{1-3}$. The incidence of PNES in the general population is relatively low, estimated at about $1.5 / 100,000$ persons per year ${ }^{4,5}$. The actual incidence may be higher because of difficulties in epidemiological studies, such as the requirement for detailed neurological examination to confirm PNES, limiting the possibility to carry out large community studies ${ }^{6}$.Tertiary referral centres estimate a much higher incidence rate. Twenty-five to thirty percent of the patients referred to tertiary epilepsy centres for refractory epilepsy are diagnosed with PNES, with or without co-morbid epilepsy ${ }^{7}$.

Although the correct medical differential diagnosis of PNES versus epilepsy can be challenging, the differential diagnosis has greatly improved during the past thirty years with advanced techniques such as video EEG. Differentiating PNES from epilepsy is important, since misdiagnosing PNES as epilepsy may potentially expose patients to unnecessary antiepileptic medication and other iatrogenic consequences of unnecessary medical treatments 7,8 . However, once the medical diagnosis has been made, patients with PNES comprise a very heterogeneous patient group with regard to the psychological aetiology ${ }^{9}$. It appears not easy to treat these patients adequately and prognosis for at least part of the patients is not that well. With their somatic appearance and underlying psychological or psychiatric problems, PNES patients present on the boundaries of the medical and mental health services. There are potential risks that PNES patients 'shop' through the medical circuit or remain in a 'No Man's Land' without the necessary realization of appropriate psychological or psychiatric treatment ${ }^{10,11}$. Meanwhile, the impact on daily life is substantial, including not being able to engage in society, leading to psychological burden and substantial economic costs ${ }^{12,13}$.

The studies in this thesis aim at exploring the psychological aetiology after the medical diagnosis of PNES has been confirmed. A focus that is in line with recent studies of PNES in the international field. Firstly, the research questions focus on finding psychogenic factors that underlie the onset and the prolongation of PNES. Finding underlying psychological mechanisms is essential to engage in treatment. Secondly, the research questions aimed at exploring possible sub-classifications of PNES that may be helpful to specify treatment for subgroups and to establish prognosis. The studies are mostly based on clinical work with PNES patients diagnosed in the 
specialised Epilepsy Centre Kempenhaeghe and referred to a multidisciplinary expert team involved in the treatment of PNES.

In part 1, introducing the topic, a background for our studies is established by presenting reviews of the existing literature. The first review in chapter 2 focuses specifically on the medical differential diagnosis of PNES and epilepsy. In chapter 3, the review is focused on psychological aetiology, treatment issues and prognosis. Based on these reviews a model is proposed of factors involved in the causation, provocation and prolongation of PNES. This model is used for the interpretation of the findings of subsequent studies. Although this model resembles other models of somatoform disorders, specific factors were added presenting PNES as a unique disorder.

In part $\mathbf{2}$ the current status of subsequent treatment interventions is explored. Is there evidence-based treatment for PNES and what is the long term prognosis? Chapter 4 describes a clinical non-randomized study on the long-term outcome of a group of patients diagnosed with PNES in our center, 4 to 6 years after the diagnosis. A Cochrane review on treatment effects is presented in chapter 5. This was a mutual collaboration with the University of Liverpool. Additional information was used for a separate review that is presented in chapter 6 .

Considering the above described complications in diagnosis and treatment, part $\mathbf{3}$ challenges both the usefulness of the PNES diagnosis for such a heterogeneous patient group and the opinion of PNES as a unique disorder. Patients with PNES may have similar characteristics as patients with other functional neurological symptoms (FNS) or even the broader group of patients with functional somatic symptoms and syndromes (FSSS). In chapter 7 the personality profile of patients with PNES is compared with the profile of patients with insomnia. Chapter 8 includes a descriptive study providing patient characteristics in 90 patients newly referred to the epilepsy center in a 2-year period, including the medical and psychological patient history before seizure onset. Finally, the theoretical model derived from the reviews is used to describe subgroups in a prospective study presented in chapter 9.

In the model that is used in our studies, a specific vulnerability to develop PNES is suggested. This predisposition may involve psychological factors such as personality characteristics. However, biological vulnerability may also be involved in the development of PNES. This is studied in part 4 . Such a vulnerability may not be the single cause of the symptoms, but may contribute to the development of PNES. This in line with the biopsychological model that is used in somatoform disorders. In chapter 10 a specific review is presented, focusing on psychobiological markers for dissociation, one mechanism or process that may cause psychogenic seizures. In a 
final study, described in chapter 11 , functional MRI is used to demonstrate such biological vulnerability.

Finally, in chapter 12, general discussion and conclusion, the results of all studies are discussed by attempting to answer some of the recurring questions about PNES. Central focus of the discussion is whether PNES must be viewed as a separate disorder or part of a continuum with other functional somatic (neurological) symptoms. 


\section{References}

1. Krumholz A, Niedermeyer E. Psychogenic seizures: a clinical study with follow-up data. Neurology 1983;33:498-502.

2. Leis AA, Ross MA, Summers AK. Psychogenic seizures: ictal characteristics and diagnostic pitfalls. Neurology 1992;42:95-9.

3. Marquez AV, Farias ST, Apperson M, Koopmans S, Jorgensen J, Shatzel A, Alsaadi TM. Psychogenic nonepileptic seizures are associated with an increased risk of obesity. Epilepsy Behav 2004;5:88-93.

4. Sigurdardottir KR, Olafsson E. Incidence of psychogenic seizures in adults: a population-based study in Iceland. Epilepsia 1998;39:749-52.

5. Reuber M, Elger CE. Psychogenic nonepileptic seizures: review and update. Epilepsy Behav 2003;4: 205-16.

6. Carson JA, Brown R, David AS, Duncan R, Edwards MJ, Goldstein LH, Grunewald R, Howlett S, Kanaan $R$, Mellers J, Nicholson TR, Reuber M, Schrag A-E, Stone J, Voon V. Functional (conversion) neurological symptoms: research since the millennium. J Neurol Neurosurg Psychiatry 2012;13:1-9.

7. Witgert ME, Wheless, JW, Breier JI Frequency of panic symptoms in psychogenic nonepileptic seizures. Epilepsy Behav 2005;6:174-8.

8. Francis P, Baker GA. Non-epileptic attack disorder (NEAD): a comprehensive review. Seizure 1999;8:53-61.

9. Baslet $\mathrm{G}$, Roiko A, Prensky E. Heterogeneity in psychogenic nonepileptic seizures: understanding the role of psychiatric and neurologic factors. Epilepsy Behav 2010;17:236-41.

10. LaFrance WC, Devinsky O. The treatment of nonepileptic seizures: historical perspectives and future directions. Epilepsia 2004;45:15-21.

11. Reuber M, Elger CE. Psychogenic nonepileptic seizures: review and update. Epilepsy Behav 2003;4:205-16

12. Betts T, Boden S. Diagnosis, management and prognosis of a group of 128 patients with non-epileptic attack disorder. Part I. Seizure 1992;1:19-26.

13. Szaflarski JP, Hughes C, Szaflarski M, Ficker DM, Cahill WT, Li M, Privitera MD. Quality of life in psychogenic nonepileptic seizures. Epilepsia 2003;44:236-42. 


\section{Part 1}

Setting the scene

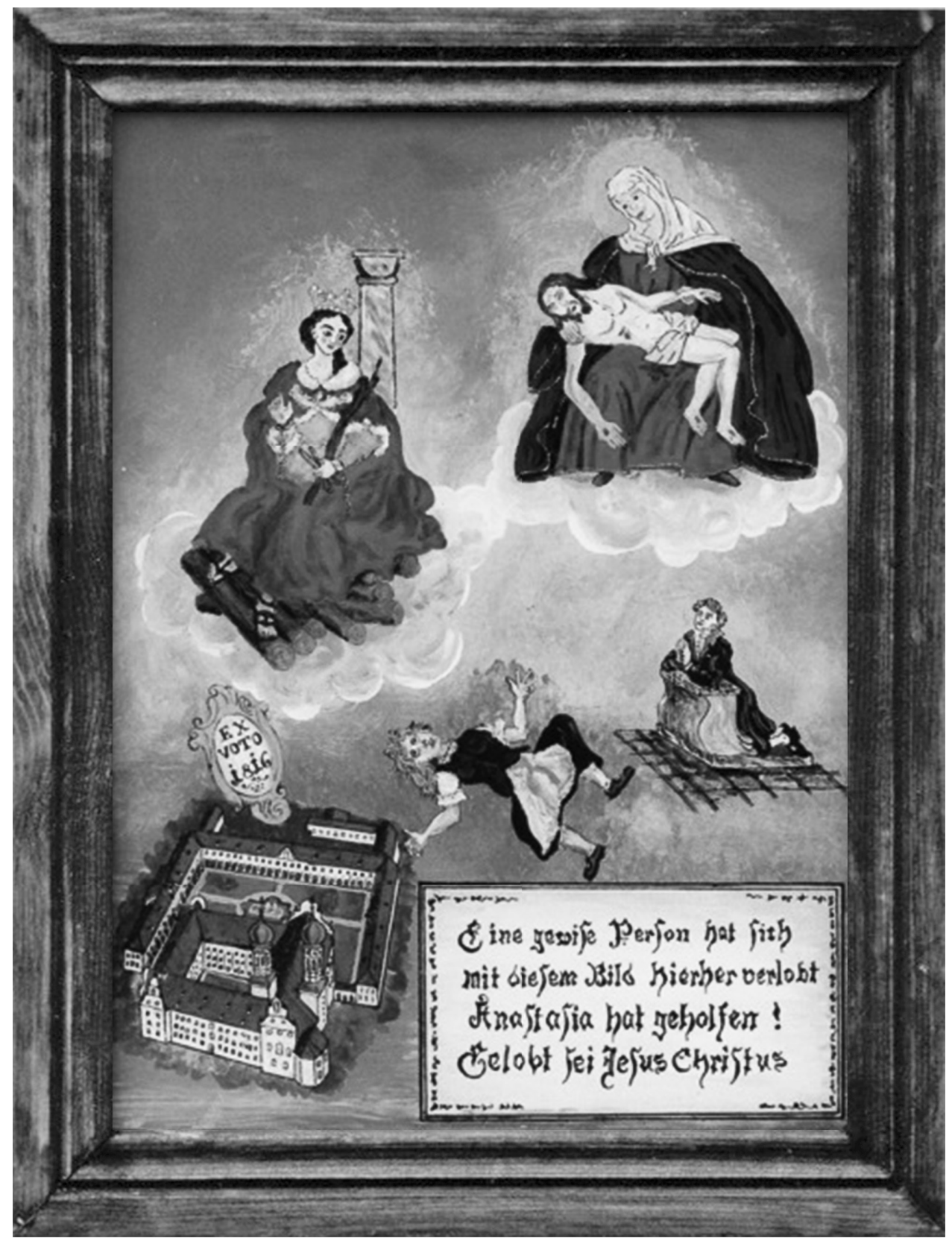


14 


\section{Chapter 2}

Psychogenic non-epileptic seizures Diagnostic issues: A critical review

NMG Bodde, JL Brooks, GA Baker, PAJM Boon, JGM Hendriksen, AP Aldenkamp

Clin Neurol Neurosurg 2009;111:1-9 
$16 \mid$ Chapter 2

\section{Abstract}

In this review we systematically assess our current knowledge about psychogenic non-epileptic seizures (PNES), epidemiology, etiology, with an emphasis on the diagnostic issues. Relevant studies were identified by searching the electronic databases. Case reports were not considered. Articles were included when published after 1980 up till 2005 (26 years). A total of 84 papers were identified; 60 of which were actual studies. Most studies have serious methodological limitations. An open non-randomized design, comparing patients with PNES to patients with epilepsy is the dominant design. The incidence of PNES in the general population is low. However, a relatively high prevalence is seen in patients referred to epilepsy centres (15-30\%). Caution is needed in the clinical interpretation of ictal features suggested to be pathognomic for PNES. Video-EEG is widely considered to be the gold standard for diagnosing PNES. Still the differential diagnosis epileptic/non-epileptic seizures can be difficult. Despite the current available technical facilities, the mean latency between onset of PNES and final diagnosis as being non-epileptic and psychogenic is approximately 7 years. One of the reasons for diagnostic delay is that the diagnosis of PNES is often limited to a 'negative' process and consequently PNES is characterized as a 'non-disease' (i.e. 'not epilepsy'). The psychological diagnosis is thus an important, although not a conclusive, 'second phase' aspect of medical decision making. Specific relations between seizure presentation and underlying psychological mechanisms are not conclusive. A classification between major motor manifestations and unresponsiveness is recognized. With respect to psychological etiology, a heterogeneous set of factors have been identified that may be involved in the causation, development and provocation of PNES. 


\section{Introduction}

Psychogenic non-epileptic seizures (PNES) are paroxysmal changes in behavior that resemble epileptic seizures, have no electrophysiological correlate or clinical evidence for epilepsy, whereas there is positive evidence for psychogenic factors that may have caused the seizure ${ }^{1-3}$. Improved diagnostic capabilities (especially the video-EEG) have shown that PNES are more common than once believed ${ }^{3}$. Patients with PNES are often misdiagnosed as suffering from intractable epilepsy, and are thus potentially exposed to unnecessary anticonvulsant medications and other iatrogenic consequences of unnecessary treatments ${ }^{4,5}$.

Many patients with PNES have a tendency to seek frequently medical attention ${ }^{6}$, and PNES make up a larger share of the workload of neurologists, general physicians and even emergency physicians ${ }^{7}$. In the study by Leis et al. ${ }^{2} 69 \%$ of the patients with PNES were treated pharmacologically with antiepileptic drugs (AEDs), whereas the maximum duration of AED treatment had been longer than 360 months. AEDs prescribed to PNES patients have potentially serious side effects and may even exacerbate the seizures. Failure to recognize pseudostatus epilepticus has a potential hazard of intubation and its morbidity and mortality: a third of the patients with PNES suffer at least one prolonged seizure that could be mistaken for status epilepticus ${ }^{7}$. The failure to recognize the psychological nature of these seizures also delays implementation of appropriate psychological treatment ${ }^{7}$. Social stigma attached to the diagnosis of epilepsy is considerable and patients that suffer such a stigma for a longer period become hostile when the diagnosis changes from epilepsy to PNES ${ }^{8}$.

The clinical relevance of an early diagnosis of PNES is also unequivocal when looking at secondary outcomes: most patients with PNES have substantial social and personal problems; the majority are not in paid employment ${ }^{1,9}$. Most apparent are the problems in family-life. Relatives are often as anxious as the patient. Protectiveness may lead to gross restriction and life-long effects on the social position ${ }^{9}$. Studies also show that PNES patients score significantly lower on quality of life subscales (work, driving, social functioning, etc. $)^{10}$. Szaflarski et al. ${ }^{11}$ showed that 'health related quality of life' for patients with PNES may score about $10 \%$ lower than patients with refractory epilepsy.

Seizures, erroneously diagnosed as epileptic also have an economic impact. The costs of misdiagnosing and treating PNES are staggering: estimates suggest more than 100,000 dollar per patient ${ }^{12}$ to an amount equal to that of intractable epilepsy, which for 1995 was estimated to be as high as \$231,432 per patient ${ }^{11}$. Martin et al. ${ }^{13}$ evaluated the direct medical costs that were on average $\$ 8000$,- per patient for the 6 months period pre-diagnosis. After the diagnoses of PNES was made the costs were $\$ 1300$,- for the 6 months period. There was a $84 \%$ reduction in total seizure-related medical charges in the 6 months period following the PNES diagnosis.

It is therefore clear that the diagnosis of PNES is clinically relevant. Benbadis ${ }^{14}$, however, concludes that in his experience this is a field in which there is a severe 
18 Chapter 2

disconnect between the frequency of the problem and the amount of attention (especially scientific attention) devoted to it. In this review we therefore systematically assess our current knowledge about PNES with an emphasis on the diagnosis of PNES.

\section{Methods}

Relevant studies were identified by searching the electronic databases psycINFO, EMBASE, MEDLINE, PubMed and Online Contents. Articles included in this review were identified by searching the terms: 'non-epileptic seizures'; 'non-epileptic attack disorder'; 'psychogenic non-epileptic seizures'; 'pseudo-epileptic attack disorder'; 'psychogenic pseudoseizures'; 'psychogenic seizures'; 'dissociative episodes', 'hysterical seizures'. In all cases 'seizures' were also replaced by 'fits' and 'attacks'. Titles of articles and abstracts extracted during the search were reviewed for relevance, and if found to be applicable, the full-text article was retrieved. Articles were included if they were published in English, Dutch or German. Case reports were not considered. Articles were included when published after 1980 up till 2005.

\section{Results}

A total of 84 papers were identified; 60 of these were studies and 24 reviews. Table 2.1 provides the main characteristics of the main source articles and Table 2.2 shows the reviews and their topics:

\section{Description of the studies}

Some comments on the results in Tables 2.1 and 2.2 are in order. The dominant type of design in studies on PNES is the open non-randomized comparative study. The studies are therefore not protected against the effects of bias, especially selection bias. Patients with epilepsy are mostly used as the comparator. Although this seems obvious in the light of the fact that the symptoms resemble seizures, but is not logical when studying for example the psychopathology or outcomes in daily life in patients with PNES. In many cases patients with PNES have been in the diagnostic process as 'epileptic patient' for many years. The effect may therefore not be different and patients with epilepsy may not be helpful to study the specific effects or etiologies in patients with PNES. The sample size is mostly rather limited; the majority in the range of 20-30 patients. Given the high variability of the symptoms and underlying characteristics in these patients, it is doubtful whether any of the studies achieves sufficient power. Formal power analyses, have however not been performed. The larger studies are retrospective studies and mostly studies on patient files. The only exceptions are postal questionnaire studies with such a high non-response rate that bias can not be excluded. 
Psychogenic non-epileptic seizures - Diagnostic issues 19

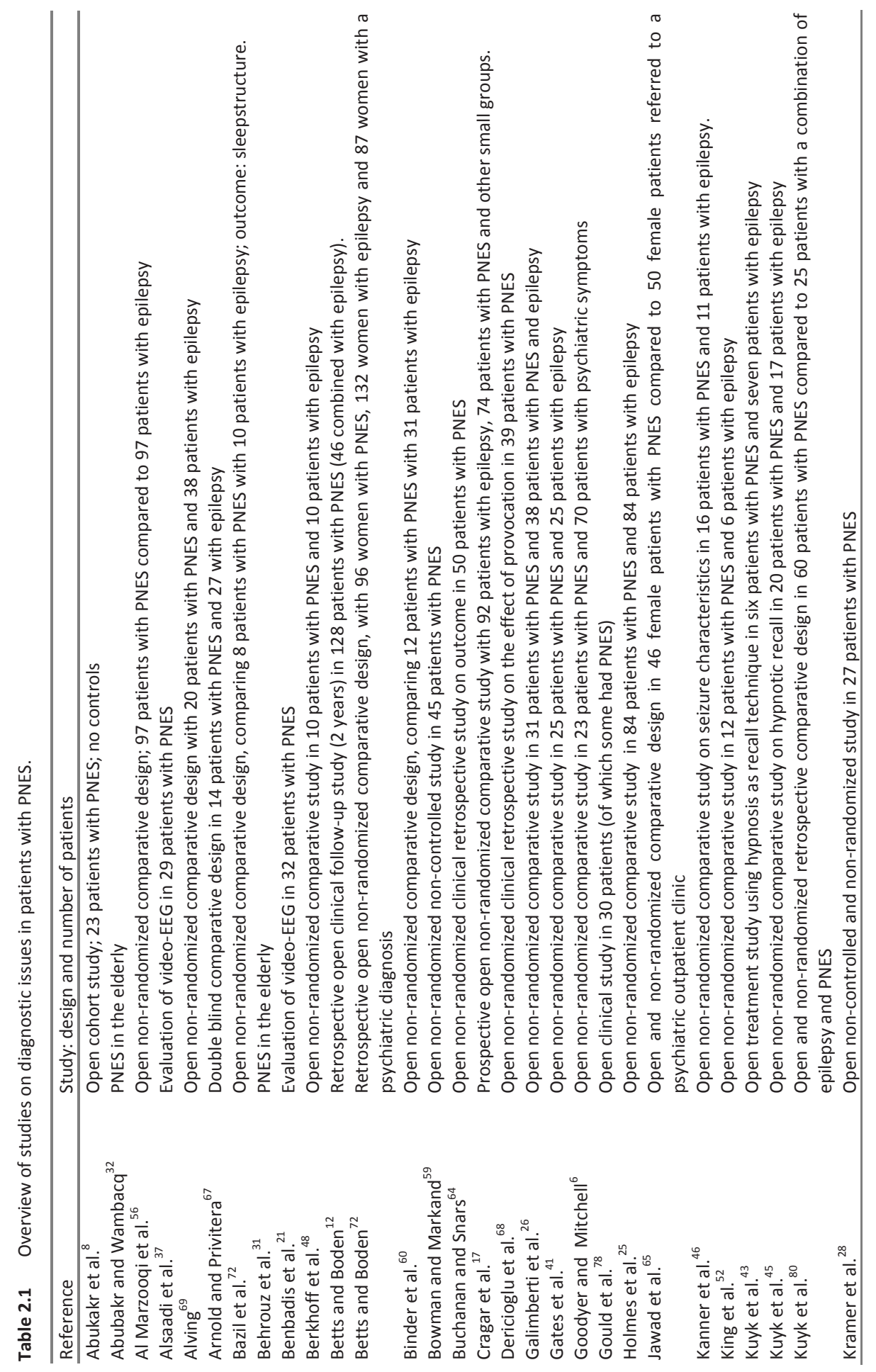


20 $\mid$ Chapter 2

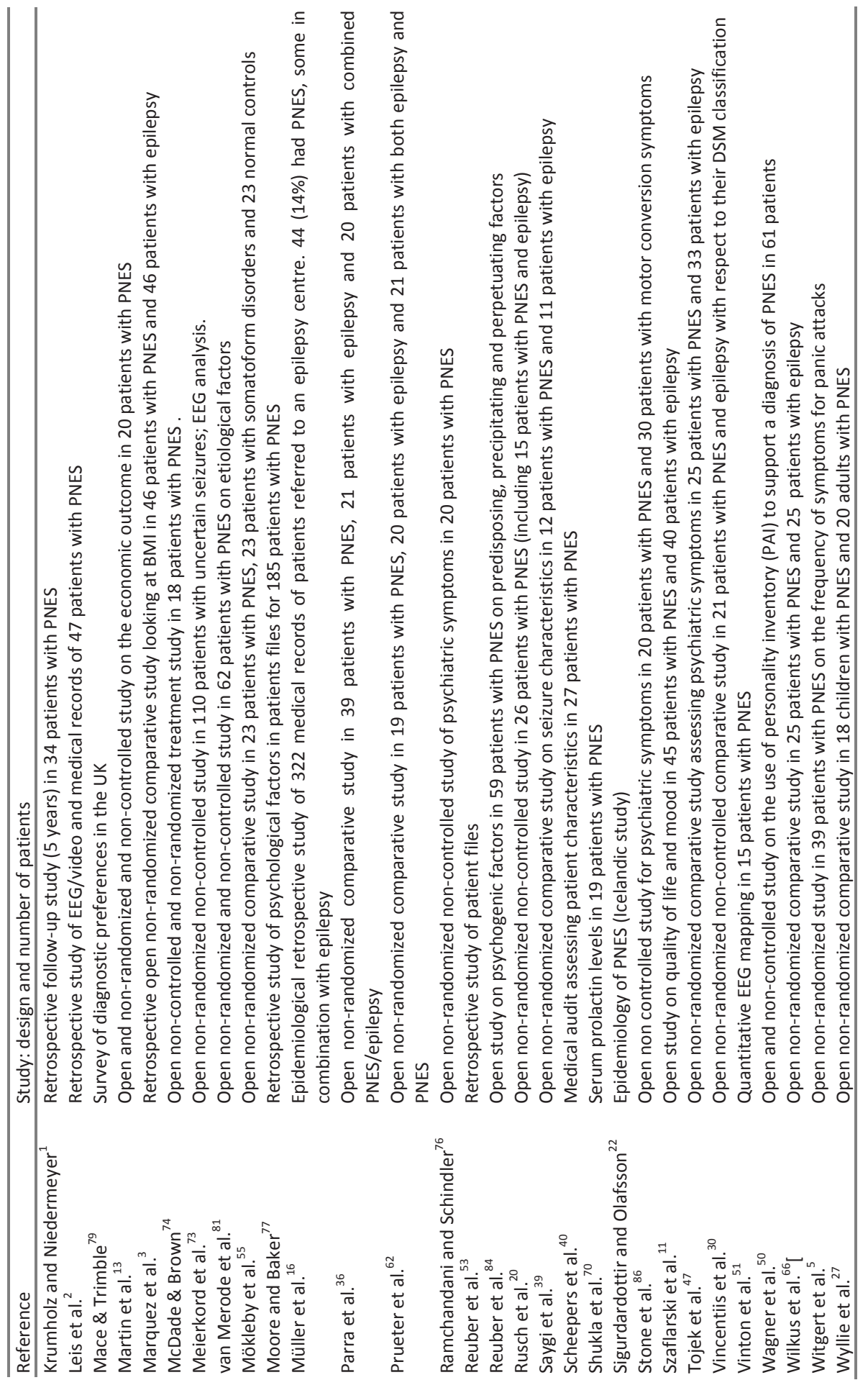


Table 2.2 Overview of reviews on diagnostic issues in patients with PNES.

\begin{tabular}{|c|c|}
\hline Reference & Review topic \\
\hline Alper $^{15}$ & General update \\
\hline Barry and Sanborn ${ }^{63}$ & Psychological factors \\
\hline Benbadis and Hauser ${ }^{21}$ & Epidemiology of PNES \\
\hline Benbadis $^{4}$ & Educational approach \\
\hline Braun $^{82}$ & Dissociation in PNES \\
\hline Chabolla et al. ${ }^{58}$ & Classification \\
\hline Chen et al. $^{71}$ & Use of serum prolactin in the diagnosis \\
\hline Dekkers and van Domburg ${ }^{54}$ & Diagnosis with an emphasis on psychological diagnosis \\
\hline Devinsky ${ }^{42}$ & Differential diagnosis \\
\hline Fejerman $^{38}$ & PNES imitating idiopathic generalized epilepsies \\
\hline Fiszman et al. $^{61}$ & Traumatic events and PTSD in patients with PNES \\
\hline Francis and Baker ${ }^{4}$ & $\begin{array}{l}\text { Description of PNES in an historic and societal context, } \\
\text { terminology, epidemiology, diagnosis and aetiology }\end{array}$ \\
\hline Iriarte et al. ${ }^{10}$ & Diagnosis of PNES \\
\hline Kuyk et al. ${ }^{44}$ & Psychological diagnosis \\
\hline Krumholz ${ }^{49}$ & Diagnosis and management \\
\hline LaFrance and Devinsky ${ }^{85}$ & Treatment of non-epileptic seizures \\
\hline LaFrance and Barry ${ }^{57}$ & Update on treatments of PNES \\
\hline Mackay ${ }^{34}$ & Diagnosis of PNES in children \\
\hline Ramani et al. $^{19}$ & General update \\
\hline Reuber and Elger ${ }^{7}$ & Update on diagnosis and outcome of PNES \\
\hline Reuber and House ${ }^{9}$ & Treatment factors \\
\hline Riggio $^{24}$ & Seizure characteristics \\
\hline Sirven and Glosser ${ }^{23}$ & Epidemiology of PNES \\
\hline Wyllie et al. ${ }^{29}$ & PNES in children \\
\hline
\end{tabular}

\section{Epidemiology}

The epidemiological data have two sources of origin:

(a) Data from tertiary centers, such as epilepsy centers. These data provide us an estimate for the proportion of PNES among those patients that are in assessment for possible epilepsy. Abubakr et al. ${ }^{8}$, Alper ${ }^{15}$ and Witgert et al. ${ }^{5}$ report that in approximately $25-30 \%$ of the patients referred to tertiary epilepsy centers for refractory epilepsy a diagnosis of PNES is obtained. Betts and Boden ${ }^{12}$ report $24 \%$ with PNES per year in a highly specialized psychiatric ward. Müller et al. ${ }^{16}$ report PNES in $14 \%$ of the patients in a specialized hospital. Cragar et al. ${ }^{17}$ reconfirm the prevalence data of up to $33 \%$ of the patients with PNES referred to epilepsy centers, but found this percentage only be true for clinical referrals. Prevalence is much lower (5\%) in outpatient units ${ }^{15}$.

A complicating observation, especially for the patients referred to specialized epilepsy centers is that between 5 and $40 \%$ of the patients with PNES have a concomitant diagnosis of epilepsy or have a past history with epileptic seizures ${ }^{10}$. This finding is confirmed in the study by Bendadis et al. ${ }^{18}$ in which between 9 and $32 \%$ of PNES patients also had epilepsy. It is often claimed ${ }^{12}$ that this patient group is the most challenging for diagnosis and treatment ${ }^{2,19}$, although this claim 
is challenged by others ${ }^{20}$. Müller et al. ${ }^{16}$ report that in most patients PNES started years later than the epileptic seizures; in some cases more than a decade later. No other studies have confirmed this.

(b) Data from population studies, that provide an estimate of the prevalence and incidence of PNES in the general population. Benbadis and Hauser ${ }^{21}$ estimate the point prevalence to be low in the range of one person per 30,000-50,000. In the Iceland population study the incidence of PNES was 1.4 in 100,000 person-years of observation with a maximum age-specific incidence between 15 and 24 years ${ }^{22}$. Szaflarski et al. ${ }^{11}$ report an incidence of 3-4.6 per 100,000 subjects. This incidence rate is equivalent to $4 \%$ of that of epilepsy. Studies based on patients referred to neurological centers for diagnosis have reported an incidence of 1.5 per 100,000 per year $^{7}$. Although these data are reasonably consistent, Sirven and Glosser $^{23}$ point to one specific methodological problem when interpreting these rates. As some patients with PNES may have more or less identical symptoms as other 'movement' or 'conversion-type of symptoms', some patients with PNES are likely to be followed for various other neurologic complaints in a movement disorders centre, headache clinic or chronic-pain program and would be excluded from epidemiologic estimates. They therefore do not exclude the possibility that the current incidence rates underestimate the problem.

When evaluating the specific characteristics, most studies found that $75-80 \%$ of the patients with PNES are female ${ }^{8,24}$. Holmes et al. ${ }^{25}$, however, suggest that the gender factor may be less pronounced than given by the previous figures. Generally, fewer men than women seek medical attention. This may result in an evaluation of only the most severely affected men. This is in line with some reports that suggest more severe psychogenic factors in men compared to women. The true incidence of men with PNES may thus be significantly unrecognized and underreported. The PNES episodes tend to begin in early adulthood in most patients ${ }^{3,8,26}$. Wyllie et al. ${ }^{27}$ have demonstrated that PNES are rare in children under 10 years old. When occurring in the younger age range, the PNES are seldom a 'stand-alone phenomenon' and more often occur as a symptom in a range of other symptoms ${ }^{28,29}$, mostly mannerisms, parasomnias, hyperventilation attacks, breath-holding spells, syncope or movement disorders $^{30}$. On the other hand Behrouz et al. ${ }^{31}$ and Abubakr and Wambacq ${ }^{32}$ have demonstrated that PNES should also be considered as a diagnostic possibility in older patients (60 years of age or older). The actual prevalence of PNES in the elderly is however not known. Moreover a higher incidence is found with lower educational level $^{26}$. Significant psychiatric co-morbidity is found in at least $70 \%$ of the patients, although often the exact definition of the psychiatric disorder is lacking or nonconclusive ${ }^{9,14,21}$.

Among the conversion types of symptoms, PNES is the second most common conversion symptom category exceeded in frequency only by all forms of movement disturbances, including paralysis, weakness, impaired gait, and tremor ${ }^{15}$. 


\section{Diagnosis including differential diagnosis}

In a first phase PNES must be distinguished from organic non-epileptic seizures, such as syncope, migraine or tension headache, hyperventilation, transient ischemic attacks, hypoglycaemia, benign myoclonia, myasthenia gravis, paroxysmal choreoathethosis, seizures due to alcohol abuse and one of the parasomnias ${ }^{7,16,33}$. In children especially the parasomnias are a diagnostic challenge $\mathrm{e}^{29,34}$. All these conditions require specific diagnostic procedures. Next, attention must be paid to non-epileptic emotionally based states that resemble seizures ${ }^{12}$. Especially panic attacks and related anxiety states such as impulse control problems and flashbacks in the context of posttraumatic stress disorder are a major diagnostic confound that must be distinguished from epilepsy ${ }^{7,35}$. Moreover ictal and postictal fear are reported to be common anxiety states in epilepsy and are reported to occur in approximately $10-15 \%$ of the patients with complex partial seizures with a temporal origin ${ }^{15}$. Therefore not all anxiety states are non-epileptic by definition.

Most of the attention during this phase must, however, be paid to distinguishing epileptic from non-epileptic seizures. Such differential diagnosis may be challenging in many cases ${ }^{14,34-37}$ and especially in those cases mimicking idiopathic generalized seizures, such as myoclonic or absence seizures ${ }^{38}$. Various studies demonstrated that many signs that have been considered typical for PNES, appeared not to be specific and can also be found in epileptic seizures, especially in those seizures that originate from the frontal lobe ${ }^{3,39}$. Hence, caution is needed in the clinical interpretation of ictal features that have been considered pathognomonic for epileptic seizures such as tongue biting, or complex movements ${ }^{2,10}$. Sometimes injuries are seen as indicative for epilepsy; however, impressive degrees of self-injury can occur in PNES as well. The frequent occurrence of fractures in patients with PNES are in fact evidence for the capacity of some PNES patients for self-inflicted injury and discomfort. This capacity is perhaps explained by the tolerance of pain conferred by dissociation ${ }^{15}$, which is one of the most common psychological mechanisms in PNES. Autonomic changes can occur with epileptic seizures, but also with PNES (e.g. coughing, palpitations and pupillary dilatation). Many of these signs are simply part of the generalized arousal response attached to panic or other extreme emotional states ${ }^{23,40}$.

Many studies have reported that the clinical diagnosis and careful history making is still essential for the differential diagnosis. The following symptoms have found to distinguish epileptic seizures from PNES:

- PNES are more often composed of purposeful, asynchronous, apparently consciously integrated motor activity such as thrashing movements of the entire body, opistotonic posturing of trunk, out-of-phase limb movements, side-to-side head movements, forward pelvic thrusting ${ }^{10,24,37,41}$. Sirven and Glosser ${ }^{23}$ observed that distinctive patterns of facial muscle activity distinguished PNES from epileptic seizures. PNES patients were more likely to have forceful sustained eye closing at any stage of the seizure and jaw clenching in the tonic phase of convulsive seizures. 
- PNES is often accompanied by moaning and crying (ictal weeping) throughout the events $^{10}$. However a caveat concerns the existence of ictal fear in epilepsy ${ }^{15}$.

- Leis et al. $^{2}$ found in their series that the single most common ictal characteristic of PNES was unresponsiveness without predominant motor manifestations. This is, however, only one seizure type in PNES and hence not a very useful differential characteristic.

- Stereotyped behavior is regarded as more characteristic of epileptic seizures than of PNES $^{15,42}$. So variability in symptoms is regarded a symptom of PNES.

- Also, patients with PNES often describe fluctuating, but more or less continuous, levels of conscious mental activity during their events without the discrete gaps of missing memory that are characteristic of the impaired consciousness during complex partial epileptic seizures ${ }^{15}$. Some studies have tried to use this postictal amnesia as a sign for epileptic seizures, e.g. using hypnosis or a hypnotic recall technique ${ }^{43,44,45}$.

- Agreement appears to exist regarding increased seizure length ${ }^{24}$ and a high degree of affect in the vocalization in PNES ${ }^{39,46}$. Epileptic vocalizations are described as monotonous, with less emotive content than those encountered in PNES ${ }^{15}$.

- Self-reported emotional stress bears a somewhat counter-intuitive relationship to epilepsy and $\mathrm{PNES}^{15}$. Most patients with epilepsy do report having more seizures when they are angry or anxious. Patients with PNES have been reported to more often deny a connection between their events and the subjective experience of emotional stress, possibly because the PNES itself serves to enable psychic discomfort to remain out of conscious awareness ${ }^{15,47}$.

- More often, PNES occur in the presence of others and have a more gradual onset (slow increase of symptoms) $)^{19,23}$ with abrupt recovery ${ }^{1}$.

- Pre-ictal pseudosleep, in which the seizure arises while the patient seems to be asleep despite electrographic evidence of wakefulness, has been reported to be specific for PNES ${ }^{23}$.

Although such seizure characteristics can be important, Reuber and Elger ${ }^{7}$ warn that often the past medical, social and psychiatric history is more helpful in the differentiation of PNES from epilepsy than the description of the seizures themselves. Others warn that a history with clear psychogenic factors does not protect against developing organic problems such as epilepsy ${ }^{48}$. Therefore such a positive history only has meaning in the context of excluding medical causes for the seizures ${ }^{49}$. Wagner et al. $^{50}$ describe the use of a psychological test (the Personality Assessment Inventory, $\mathrm{PAI}$ ) as an effective psychological screening tool to aid in the differential diagnosis of epileptic seizures versus PNES prior to hospital admission for VEEG. Cragar et al. ${ }^{17}$ conclude that, despite a plethora of research on methods for differentiating PNES from epilepsy, seizure recording with simultaneous video EEG monitoring remains the gold standard for differential diagnosis. However, some studies report that despite the most modern investigatory equipment it sometimes may be impossible to decide 
what one is dealing with ${ }^{12,45,51}$. Parra et al. ${ }^{36}$ state that during the initial years of video EEG monitoring neurologists were more prone to misdiagnose PNES as epilepsy ${ }^{52,46}$, but in the last few years clinicians are more likely to suspect and recognize PNES but also 'overdiagnose' atypical paroxysmal events as PNES. In their own study they also found that epileptic seizures were misdiagnosed as PNES more frequently than the reverse (57\% versus $12 \%)$. A worrisome observation is that, despite the current available technical facilities, the mean latency between onset of PNES and final diagnosis as being non-epileptic and psychogenic is approximately 7 years ${ }^{7,9,37,53}$. Müller et al. ${ }^{16}$ therefore conclude that early admission of so-called 'pharmacoresistent epilepsy' to an epilepsy centre (establishing a standard work-up and clarifying the medical terminology) will improve diagnosis (and lead to adequate therapy of PNES as well prevent unnecessary drug treatment). They describe a diagnostic algorithm in which video EEG and clinical observation as well as a close review of the general medical and drug history must be considered as a minimal diagnostic standard. One of the reasons for diagnostic delay is outlined by Dekkers and Domburg ${ }^{54}$ : the medical diagnosis of PNES is often limited to a 'negative' process and consequently PNES is characterized as a 'non-disease' (i.e. 'not epilepsy', 'no cardial disease', 'not an anxiety attack', etc.), which may obstruct a 'positive diagnosis', evaluating the exact psychological mechanisms that have caused PNES in an individual patient.

The psychological diagnosis is thus an important, although not a conclusive, 'second phase' aspect of medical decision making in which the focus will gradually shift to etiological factors. Iriarte et al. ${ }^{10}$ (see also Mökleby et al. ${ }^{55}$ ) emphasize that the diagnosis of PNES requires a multidisciplinary approach. It is not enough to determine that the seizures have a non-epileptic origin, but also to obtain a comprehensive clinical psychological, psychiatric and neuropsychological evaluation that may shed light on potential psychogenic mechanisms of PNES ${ }^{56,57,58}$. Bowman and Markand ${ }^{59}$ advise that after PNES are confirmed a complete assessment should be carried out, requiring at least three components: (a) screen for co-existent neurological disorder; (b) psychological examination; (c) assessment of social/interpersonal problems. Three general types of psychological tests have been used to assess PNES: personality inventories, neuropsychological tests and forced choice malingering detection tests. They are useful methods, and each probably contributes to obtaining unique information that can identify patients who should be monitored. Also multiple measures should provide a more accurate prediction of the seizure type than single measures ${ }^{23,60}$.

Some authors use a classification system for the clinical manifestations of PNES such as the DSM- IV or ICD-10 $20,55,61$. Seizures are then diagnosed as either 'dissociative disorders' (ICD-10) ${ }^{62}$ or on the DSM on either axis I, or axis II or both. The most frequent DSM-IV diagnosis for PNES appears to be somatoform disorder (conversion disorder $)^{24,63}$. The second most common diagnosis was anxiety disorder ${ }^{5,64}$. It is questionable though, whether the seizures should be 'relabeled', since these diagnostic categories on their own tell us comparatively little about the management 
26 Chapter 2

of patients with PNES ${ }^{65}$. Wilkus et al. ${ }^{66}$ even used MMPI profiles to distinguish epilepsy form PNES and report a $80 \%$ success score. This has never been confirmed, though. Moreover Arnold and Privitera ${ }^{67}$ could not distinguish patients with epilepsy and patients with PNES using the DSM classification in a double blind study.

Induction protocols are controversial (e.g. suggestive techniques such as tuning fork or intravenous injection of normal saline solution; Dericioglu et al. ${ }^{68}$ ) because it may negatively influence the patient-physician relationship, but also because induction tests can also induce epileptic seizures or can even cause PNES in patients who might not have had PNES before ${ }^{10,16,44}$. The diagnostic accuracy of serum prolactin levels is less than that of provocation with suggestion during video EEG monitoring ${ }^{15,69,70}$. Although Chen et al. $^{71}$ recommend that elevated serum prolactin assay, when measured in the appropriate clinical setting (at 10-20 min after a suspected event) is a useful adjunct for the differentiation of generalized tonic-clonic or complex partial seizure from PNES among adults and older children .

As mentioned before, the coexistence of epileptic and non-epileptic seizures in the same patient presents a specific diagnostic challenge. Some studies have found that there may be relationships between the two types of seizures, such as symptom modeling and the susceptibility to behavioral dysfunction conferred by neurological illness and behavioral toxicity of $\mathrm{AEDs}^{15}$. Two types of seizures may be especially difficult to differentiate: frontal seizures ${ }^{12,39}$ and minor non-convulsive psychogenic seizures which simulate complex partial epileptic seizures ${ }^{1}$. Bazil et al. ${ }^{66}$ suggest that monitoring the sleep structure may be an helpful additional aid in the differential diagnosis. Patients with PNES have a sleep architecture similar to patients with major depression with an increased percentage of REM sleep.

\section{Seizure characteristics}

Although PNES can imitate any type of seizure event ${ }^{5}$, Abubakr et al. ${ }^{8}$ suggest a division into two seizure types: (a) major motor manifestations and (b) limpness, unresponsiveness, flaccidity. Sometimes this division is made in parallel with the epileptic seizures that they resemble: 'Major' seizures are defined as attacks that resemble most convulsive-type seizures such as the generalized tonic or clonic seizures. 'Minor' seizures resemble absence-like or short partial seizures ${ }^{1}$. A similar division is proposed by Riggio ${ }^{24}$, distinguishing between: a primary motor component type and the second non-motor type in which the event is often characterized by a change in behavior. Meierkord et al. ${ }^{73}$ report that $66 \%$ of the patients presented with excessive motor manifestations and unresponsiveness is a more seldom reported symptom. This is confirmed by McDade and Brown ${ }^{74}$. Leis et al. ${ }^{2}$, however, caution against such conclusions as unresponsiveness may go undetected more frequently. Betts and Boden ${ }^{12,75}$ distinguish three types of seizures: (a) 'Swoons': a relaxed fall to the ground without injury, followed by lying still without convulsion, with eyes closed for various periods of time and apparently unconscious, usually followed by rapid 
recovery with no post-ictal confusion; (b) 'Tantrums': the patient emits a cry, falls, thrashes about with a convulsive struggle if restrained, kicks and may bite (either himself of spectators), and is often noisy, shouting, roaring or crying; (c) 'Abreactive attacks'; there may be initial over-breathing, which may pass unrecognized, followed by sudden movement and stiffening of the body, which is followed by breath holding, gasping, uncoordinated jerking of the body with pelvic thrusting and back arching. There may be screaming or crying, spitting or retching. It bears superficial resemblance to sexual intercourse and may continue for many hours. Alper ${ }^{15}$ distinguishes PNES that are conversion symptoms (conversion PNES) from PNES that are non-conversion and are paroxysmal behavioral features of other syndromes (nonconversion PNES). Another important distinction proposed by Alper ${ }^{15,35}$ is that between consiousness/unconsiousness and intentional/nonintentional. This distinction leads to the following subgroups: (a) PNES as conversion disorder: the patient is not consciously aware of intentionally producing symptoms or of the presumed unconscious conflict or unmet need underlying their occurrence. (b) PNES as factitious disorder: patients are consciously aware of intentionally producing symptoms but not consciously aware of their reason for pursuing the sick role as a dominant motivating theme of their lives. (c) Non-epileptic seizures in the context of malingering: the patient is consciously aware of intentional symptom production and clearly understands his or her agenda, which is specifically identifiable in external incentives. Intentional PNES production distinguishes these disorders from other axis I disorders, which may occasionally manifest unintentional paroxysmal behavioral features that may be suspected of being epileptic seizures, such as anxiety, dissociative or impulse control disorders.

Some specific relationships were reported between seizure presentation and underlying psychological mechanisms. Meierkord et al. ${ }^{73}$ report that pelvic thrusting can occur as prominent feature only in women with a history of childhood sexual abuse. Galimberti et al. ${ }^{26}$ report that PNES mimicking generalised tonic-clonic seizures was associated with a low educational level. Ramchandani and Schindler ${ }^{76}$ found that patients with pseudo complex partial seizures had dissociative symptoms, whereas patients with pseudo tonic-clonic seizures had their illness developed in the context of longstanding personality disorders. Alper ${ }^{15}$ emphasized the importance of distinguishing the subgroup with non-conversion PNES as it may allow identification of a discrete underlying psychiatric disorder, whose specific treatment differs from that of conversion PNES. This is particularly true for axis I disorders that allows specific pharmacotherapeutic approaches such as panic disorder or schizophrenia. Moore and Baker ${ }^{77}$ observed that many of the symptoms described by their patients appear to be anxiety related. Holmes et al. ${ }^{25}$ found a relationship between seizure presentation and gender. Men were more likely than women to have 'convulsive-like' psychogenic seizures, while women were more likely to have 'non-convulsive' attacks. This semiological difference is attributed to 'a more male form of acting out' during forms of PNES associated with dramatic motor activity. 
$28 \mid$ Chapter 2

\section{Psychological etiology}

Freud saw PNES as a 'hysterical fit', being the expression of normal sexual desires, repressed from conscious awareness due to the unbearable affects with which they had become associated. The phenomenological similarity of many patients' seizures to movements common in the context of the sexual act was interpreted as evidence that the seizure was the symbolic expression of a repressed unconscious sexual conflict ${ }^{4,15,58}$. After the abolition of the term 'hysterical neurosis' from the current diagnostic systems, PNES is no longer seen as one discrete disorder ('hysteria') and the term 'hysterical seizures ${ }^{19,78}$ vanished from the literature, although a survey among British neurologists showed that in 1991 the term hysteria was still used in the 'informal contacts' ${ }^{\text {'79 }}$. Sirven and Glosser ${ }^{23}$ conclude that a satisfactory etiologically referenced classification system has been elusive because of many current problems, of which the issue of homogeneity is dominant. PNES are almost infinitely heterogeneous and are quite different from person to person. Even if the PNES behaviors of very different people are morphologically similar, clinical experience reveals that the psychogenic causes may be quite divergent ${ }^{20,44,80}$.

It is helpful when describing psychological etiology also to define the used terms, because one of the major problems is the incoherent use of terminology:

- 'Psychological etiology' or 'psychogenic factors' describe the underlying causation of the seizures; factors such as sexual abuse during childhood ${ }^{81}$. Such psychogenic factors may be compulsory but not sufficient to cause PNES; not all patients that suffered from sexual abuse will develop PNES, although the risk for developing PNES is clearly increased. Other common examples of such psychological etiology may be personality disorders.

- 'Psychological mechanisms' are the actual mechanisms that transfer an emotional state into a seizure. One of the most commonly described psychological mechanisms is dissociation $^{3,8,15,82}$

- A final frequently used term in this context is 'comorbidity', specifically 'psychiatric comorbidity" $7,55,62$. Some authors describe psychiatric comorbidity as an etiological factor. However the term "comorbidity" refers to different disorders than PNES. In this context PNES is considered a separate disorder and psychiatric comorbidity then refers to psychiatric diseases in the same patient, such as depression. The problem in clinical practice and in scanning the literature is that it is often extremely difficult to clarify the relationship between PNES and such comorbid disorders in terms of causation. Often the resulting psychiatric disorders may be a cause as well as the result of PNES or simply an epiphenomenon. For example a depression could be a result of having psychogenic seizures over a long period of time, but a depression could also be a separate disorder. To define psychiatric comorbidity as an etiological factor therefore seems unjustified. 
A wide range of psychogenic factors have been identified that may underlie the occurrence of PNES in individual patients: a history of sexual and physical abuse and post-traumatic stress disorder, malingering, depression or chronic anxiety, dissociation, somatization disorder, including Briquet's syndrome, behaviorally oriented concepts of secondary gain and assumption of the sick role (mainly in intellectually impaired persons), personality disorders, organicity and age $^{8,12,15,27,55,61,63,75,77}$. Elsewhere ${ }^{83}$, we propose a model distinguishing 5 different levels. This model is based on the previous mentioned factors specifically found for PNES. (a) Psychological etiology: factors that are involved in the causation of PNES, such as sexual abuse; (b) Vulnerability: factors that predispose a person to develop psychosomatic symptoms, such as PNES. Many authors have pointed to the specific vulnerability of patients with PNES both in terms of the emotional 'make-up' and their neuropsychological functioning; (c) Shaping factors: factors that can specifically shape the symptoms in the form of 'seizures' (in contrast to for example movement disorders or 'headache-like symptoms'). A shaping factor may be a relative with epileptic seizures (symptom modeling); (d)Triggering factors: create circumstances or situations that provoke PNES such as factors that refer to primary gain. Also psychological mechanisms that transfer an emotional state into a seizure can be part of these triggering factors such as dissociation; (e) Prolongation factors: the previous four factors are specifically important in the development of PNES. Prolongation factors are important in explaining why the seizures persist. Examples are the coping strategy of a patient or secondary gain aspects. This model resembles other models used to explain PNES or other somatisation disorders ${ }^{84-86}$.

\section{Discussion}

In this systematic review we identified papers on diagnostic issues through the period 1980 up to 2005 (26 years), of which 60 were actual studies. The quality of most research is limited, due to serious methodological limitations. Nonetheless, they represent some key data on diagnostic issues related to PNES.

PNES is a condition with a significant burden on the patients involved. First of all, the diagnosis is difficult in many cases; therefore patients with PNES are often misdiagnosed as suffering from intractable epilepsy, and are thus potentially exposed to the iatrogenic consequences of unnecessary treatments. Moreover most patients with PNES have substantial social and personal problems even after a clear diagnosis. In economic terms, the costs of misdiagnosing and treating PNES are staggering: estimates suggest an amount equal to that of intractable epilepsy, which for 1995 was estimated to be as high as $\$ 231,432$ per patient.

The incidence of PNES in the general population is low (about 1.5/100,000 persons per year; about $4 \%$ of the incidence of epilepsy), with a peak in the young adult age range (15-24 years) predominantly in women with a lower educational level. Point 
30 Chapter 2

prevalence rates vary but are probably in the range of one person per 30,000-50,000. However, a much higher prevalence is seen in patients referred to epilepsy centres: $15-30 \%$ of patients referred to tertiary epilepsy centres have PNES, which illustrates the complexity of the diagnosis. A further complicating factor is that PNES frequently occurs in patients with the comorbid diagnosis of epilepsy or a past history with epileptic seizures (estimates vary to $5-40 \%$ of the patients with PNES).

One factor causing differential diagnostic uncertainty is that caution is needed in the clinical interpretation of ictal features that are suggested to be pathognomic for PNES. Large overlap exists with epileptic phenomena, especially when epileptic seizures originate in the frontal lobe. Therefore video-EEG is widely considered to be the gold standard to confirm a suspected diagnosis of PNES. Two caveats are mentioned in the evaluated studies. Firstly when the medical diagnosis of PNES is only focused on excluding epilepsy, the outcome can be a 'negative' process (it is 'not epilepsy', 'no cardial problems', 'no metabolic disorders', etc.) and consequently PNES becomes a 'non-disease'. Such a process may frustrate a 'positive diagnosis' evaluating the underlying psychological mechanisms that have caused PNES in an individual patient. Thus medical and psychological diagnosis must be combined in a multidisciplinary assessment protocol for PNES. In such a protocol the medical diagnosis should be the first phase, since the presence of clear psychogenic factors does not exclude the possibility of epilepsy. A second caveat concerns the observations that despite the currently available technical facilities, the mean latency between onset of PNES and final diagnosis as non-epileptic and psychogenic is approximately 7 years. Such long latency periods increase the risk that patients will be treated with antiepileptic drugs for 'refractory epilepsy' which complicates their later acceptance of the seizures as non-epileptic, which is a precondition for psychological treatment.

Attempts to categorize ictal movements into specific patterns (e.g. clonic, tonic, dystonic, in-phase or out-phase, unilateral or bilateral) proved very difficult if not impossible. Also specific relationships between seizure presentation and underlying psychological mechanisms are not conclusive. The only widely recognized classification is between major motor manifestations and unresponsiveness. Moreover a frequent distinction is between patients with PNES that result from a conversion or dissociative disorder who do not appear to have control over their events, in contrast to malingering.

A wide range of psychogenic factors have been identified that may underlie the occurrence of PNES in individual patients. Not all these factors have the same type of impact; some factors are etiological, others modulating or are precipitating, i.e. 'trigger' seizures. Consequently some studies propose a 'multifactor approach': i.e. one factor is not always sufficient to develop PNES. In most patients several of such factors are active and have to interact to develop PNES, such as the presence of a psychopathological disorder and the influence of a 'general trigger mechanism' or an emotional mechanism such as a higher dissociation tendency or a greater vulnerability of the brain for not tolerating conflictual situations. 


\section{References}

1. Krumholz A, Niedermeyer E. Psychogenic seizures: a clinical study with follow-up data. Neurology 1983;33:498-502.

2. Leis AA, Ross MA, Summers AK. Psychogenic seizures: ictal characteristics and diagnostic pitfalls. Neurology 1992;42:95-9.

3. Marquez AV, Farias ST, Apperson M, Koopmans S, Jorgensen J, Shatzel A, Alsaadi TM. Psychogenic nonepileptic seizures are associated with an increased risk of obesity. Epilepsy Behav 2004;5:88-93.

4. Francis $P$, Baker GA. Non-epileptic attack disorder (NEAD): a comprehensive review. Seizure, 1999;8: 53-61.

5. Witgert ME, Wheless, JW, Breier JI. Frequency of panic symptoms in psychogenic nonepileptic seizures. Epilepsy Behav 2005;6:174-8.

6. Goodyer IM, Mitchell C. Somatic emotional disorders in childhood and adolescence. J Psychosom Res 1989;33:681-8.

7. Reuber M, Elger CE. Psychogenic nonepileptic seizures: review and update. Epilepsy Behav 2003;4:205-16.

8. Abubakr A, Kablinger A, Caldito G. Psychogenic seizures: clinical features and psychological analysis. Epilepsy Behav 2003;4:241-5.

9. Reuber M, House AO. Treating patients with psychogenic non-epileptic seizures. Cur Op in Neurol 2002;15:207-11.

10. Iriarte J, Parra J, Urrestarazu E, Kuyk J. Controversies in the diagnosis and management of psychogenic pseudoseizures. Epilepsy Behav 2003;4:354-9.

11. Szaflarski JP, Hughes C, Szaflarski M, Ficker DM, Cahill WT, Li M, Privitera MD. Quality of life in psychogenic nonepileptic seizures. Epilepsia 2003;44:236-42.

12. Betts T, Boden S. Diagnosis, management and prognosis of a group of 128 patients with non-epileptic attack disorder. Part I. Seizure 1992;1:19-26.

13. Martin RC, Gilliam FG, Kilgore M. Faught E, Kuzniecky R. Improved health care resource utilization following video-EEG confirmed diagnosis of nonepileptic psychogenic seizures. Seizure 1998;7:385-90.

14. Benbadis SR. The problem of psychogenic symptoms: is the psychiatric community in denial? Epilepsy Behav 2005;6:9-14.

15. Alper K. Nonepileptic seizures. Neurologic Clinics (Epilepsy II: special issues) 1994(12):153-73.

16. Müller T, Merschhemke M, Dehnicke C, Sanders M, Meencke HJ. Improving diagnostic procedure and treatment in patients with non-epileptic seizures (NES). Seizure 2002;11: 85-9.

17. Cragar DE, Berry DTR, Schmitt FA, Fakhoury TA. Cluster analysis of normal personality traits in patients with psychogenic nonepileptic seizures. Epilepsy Behav 2005;6:593-600.

18. Benbadis SR, Agrawal V, Tatum WO. How many patients with psychogenic nonepileptic seizures also have epilepsy? Neurology 2001;57:915-7.

19. Ramani SV, Quesney LF, Olson D, Gumnit RJ. Diagnosis of hysterical seizures in epileptic patients. Am J Psychiatry 1980;137(6):705-9.

20. Rusch MD, Morris GL, Allen L, Lathrop LA. Psychological treatment of nonepileptic events. Epilepsy Behav 2001;2:277-83.

21. Benbadis SR, Hauser WA. An estimate of the prevalence of psychogenic non-epileptic seizures. Seizure 2000;9:280-1.

22. Sigurdardottir KR, Olafsson E. Incidence of psychogenic seizures in adults: a population-based study in Iceland. Epilepsia 1998;39:749-52.

23. Sirven JI, Glosser DS. Psychogenic nonepileptic seizures: theoretic and clinical considerations. Neuropsychiatry, Neuropsychol, and Behav Neurol 1998;11:225-35.

24. Riggio, S. Psychogenic seizures. Emerg Med Clin North Am 1994;12: 1001-12.

25. Holmes MD, Dodrill CB, Bachtler S, Wilensky AJ, Ojemann LM, Miller JW. Evidence that emotional maladjustment is worse in men than in women with psychogenic nonepileptic seizures. Epilepsy Behav 2001;2:568-73.

26. Galimberti CA, Ratti MT, Murelli R, Marchioni E, Manni R, Tartara A. Patients with psychogenic nonepileptic seizures, alone or epilepsy-associated, share a psychological profile distinct from that of epilepsy patients. J Neurol 2003;250:338-46. 
32 Chapter 2

27. Wyllie E, Friedman D, Lüders H, Morris H, Rothner D, Turnbull J. Outcome of psychogenic seizures in children and adolescents compared with adults. Neurology 1991;41:742-4.

28. Kramer U, Carmant L, Riviello JJ, Stauffer A, Helmers SL, Mikati MA, Holmes GL. Psychogenic seizures: video telemetry observations in 27 patients. Pediatric Neurology 1995;12:39-41.

29. Wyllie E, Benbadis SR, Kotagal P. Psychogenic seizures and other non-epileptic paroxysmal events in children. Epilepsy Behav 2002;3:46-50.

30. Vincentiis S, Valente KD, Thomé-Souza S, Kuczinsky E, Fiore LA, Negrao, N. Risk factors for psychogenic nonepileptic seizures in children and adolescents with epilepsy. Epilepsy Behav 2006;8:294-8.

31. Behrouz R, Heriaud L, Benbadis SR. Late-onset psychogenic nonepileptic seizures. Epilepsy Behav 2006;8:649-50.

32. Abubakr A, Wambacq I. Seizures in the elderly: video/EEG monitoring analysis. Epilepsy Behav 2005;7:447-50.

33. Roberts R. Differential diagnosis of sleep disorders, non-epileptic attacks and epileptic seizures. Cur Op in Neurol 1998;11:135-9.

34. Mackay M. Fits, faints and funny turns in children. Aust Fam Physician 2005;34:1003-8.

35. Alper K, Devinsky O, Perrine K, Vazquez B, Luciano D. Psychiatric classifications of nonconversion nonepileptic seizures. Arch Neurol 1995;52:199-201.

36. Parra J, Iriarte J, Kanner AM. Are we overusing the diagnosis of psychogenic non-epileptic events? Seizure 1999;8:223-7.

37. Alsaadi TM, Thieman C, Shatzel A, Farias S. Video-EEG telemetry can be a crucial tool for neurologists experienced in epilepsy when diagnosing seizure disorders. Seizure 2004;13:32-4.

38. Fejerman N. Nonepileptic disorders imitating generalized idiopathic epilepsies. Epilepsia 2005;46: 80-3.

39. Saygi S, Katz A, Marks DA, Spencer SS. Frontal lobe partial seizures and psychogenic seizures: comparison of clinical and ictal characteristics. Neurology 1992;42:1274-7.

40. Scheepers B, Budd SCS, Gregory S, Elson S. Non-epileptic attack disorder: a clinical audit. Seizure 1994;3:129-34.

41. Gates JR, Ramani V, Whalen S, Loewenson R. Ictal characteristics of pseudoseizures. Arch Neurol 1985;42:1183-7.

42. Devinsky O. The differential diagnosis of epilepsy. Semin Neurol 1990;10:321-7.

43. Kuyk J, Dunki Jacobs L, Aldenkamp AP, Meinardi H, Spinhoven PH, Van Dyck R. Pseudo-epileptic seizures: hypnosis as a diagnostic tool. Seizure 1995;4:123-8.

44. Kuyk J, Leijten F, Meinardi H, Spinhoven Ph, Van Dyck R. The diagnosis of psychogenic non-epileptic seizures: a review. Seizure 1997;6:243-53.

45. Kuyk J, Spinhoven PH, Van Dyck R. Hypnotic recall: a positive criterion in the differential diagnosis between epileptic and pseudo-epileptic seizures. Epilepsia 1999;40:485-549.

46. Kanner AM, Morris HH, Lüders H, Dinner DS, Wyllie E, Medendorp SV, Rowan AJ. Supplementary motor seizures mimicking pseudoseizures: some clinical differences. Neurology 1990;40:1404-7.

47. Tojek TM, Lumley M, Barkley GB, Mahr G, Thomas A. Stress and other psychosocial characteristics of patients with psychogenic nonepileptic seizures. Psychosom 2000;41:221-6.

48. Berkhoff M, Briellmann RS, Radanov BP, Donati F, Hess CW. Developmental background and outcome in patients with nonepileptic versus epileptic seizures: a controlled study. Epilepsia 1998;39:463-9.

49. Krumholz A. Nonepileptic seizures: diagnosis and management. Neurology 1999;53(Suppl 2): S76-83.

50. Wagner MT, Wymer JH, Topping KB, Pritchard PB. Use of the personality assessment inventory as an efficacious and cost-effective diagnostic tool for nonepileptic seizures. Epilepsy Behav 2007;7:301-4.

51. Vinton A, Carino J, Vogrin S, MacGregro L, Kilpatrick C, Matkovic Z, O’Brien TJ. "Convulsive" nonepileptic seizures have a characteristic pattern of rhythmic artifact distinguishing them from convulsive epileptic seizures. Epilepsia 2004;45:1344-50.

52. King DW, Gallagher BB, Murvin AJ, Smith DB, Marcus DJ, Hartlage LC, Charles Ward L. Pseudoseizures: diagnostic evaluation. Neurology 1982;32:18-23.

53. Reuber M, Fernandez G, Helmstaedter C, Qurishi A, Elger CE. Evidence of brain abnormality in patients with psychogenic nonepileptic seizures. Epilepsy Behav 2002;3:249-54.

54. Dekkers W, Van Domburg P. The role of doctor and patiënt in the construction of the pseudoepileptic attack disorder. Med Health Care Philos 2000;3(1):29-38. 
55. Mökleby K, Blomhoff S, Malt UF, Dahlström A, Tauböll E, Gjerstad L. Psychiatric comorbidity and hostility in patients with psychogenic nonepileptic seizures compared with somatoform disorders and healthy controls. Epilepsia 2002; 43 (2):193-8.

56. Al Marzooqi SM, Baker GA, Reilly J, Salmon P. The perceived health status of people with psychologically derived non-epileptic attack disorder and epilepsy: a comparative study. Seizure 2004;13:71-5.

57. LaFrance WC, Barry JJ. Update on treatments of psychological nonepileptic seizures. Epilepsy Behav 2005;7:364-74.

58. Chabolla DR, Krahn LE, So EL, Rummans TA. Psychogenic non-epileptic seizures; Mayo symposium on epilepsy part II. Mayo Clin Proc 1996;71(5):493-500.

59. Bowman ES, Markand ON. Psychodynamics and psychiatric diagnoses of pseudoseizure subjects. Am J Psychiatry 1996;153(1):57-63.

60. Binder LM, Salinsky MC, Smith SP. Psychological correlates of psychogenic seizures. J Clin Exp Neuropsychol 1994;16:524-30.

61. Fiszman A, Alves-Leon SV, Nunes RG, D’Andrea I, Figueira I. Traumatic events and posttraumatic stress disorder in patients with psychogenic nonepileptic seizures: a critical review. Epilepsy Behav 2004;5:818-25.

62. Prueter C, Schultz-Venrath U, Rimpau W. Dissociative and associated psychopathological symptoms in patients with epilepsy, pseudoseizures, and both seizure forms. Epilepsia 2002; 43(2):188-92.

63. Barry JJ, Sanborn K. Etiology, diagnosis and treatment of nonepileptic seizures. Curr Neurol Neurosci Rep 2001;1:381-9.

64. Buchanan N, Snars J. Pseudoseizures (non epileptic attack disorder)-clinical management and outcome in 50 patients. Seizure 1993;2:141-6.

65. Jawad SSM, Jamil N, Clarke EJ, Lewis A, Whitecross S, Richens A. Psychiatric morbidity and psychodynamics of patients with convulsive pseudoseizures. Seizure 1995;4:201-6.

66. Wilkus RJ, Dodrill, CB, Thompson PM. Intensive EEG monitoring and psychological studies of patients with pseudoepileptic seizures. Epilepsia 1984;25:100-7.

67. Arnold LM, Privitera MD. Psychopathology and trauma in epileptic and psychogenic seizure patients. Psychosom 1996;37(5):438-43.

68. Dericioglu N, Saygi S, Ciger A. The value of provocation methods in patients suspected of having nonepileptic seizures. Seizure 1999;8:152-6.

69. Alving J. Serum prolactin levels are elevated also after pseudo-epileptic seizures. Seizure 1998;7:85-9.

70. hukla G, Bhatia M, Vivekanandhan S, Gupta N, Tripathi M, Srivastava A, Pandey RM, Jain S. Serum prolactin levels for differentiation of nonepileptic versus true seizures: limited utility. Epilepsy Behav 2004;5:517-21.

71. Chen DK, So YT, Fisher RS. Therapeutics and technology assessment subcommittee of the American Academy of Neurology. Neurology 2005;65:668-75.

72. Bazil CW, Legros B, Kenny E. Sleep structure in patients with psychogenic non-epileptic seizures. Epilepsy Behav 2003;4:395-8.

73. Meierkord H, Will B, Fish D, Shorvon S. The clinical features and prognosis of pseudoseizures diagnosed using video-EEG telemetry. Neurology 1991;41(10):1643-6.

74. McDade G, Brown SW. Non-epileptic seizures: management and predictive factors of outcome. Seizure 1992;1:7-10.

75. Betts T, Boden S. Diagnosis, management and prognosis of a group of 128 correlates of intractable pseudoseizures. Part II. Previous childhood sexual abuse in the aetiology of these disorders. Seizure 1992;1:27-32.

76. Ramchandani D, Schindler B. Evaluation of pseudoseizures: a psychiatric perspective. Psychosom 1993;34(4):70-9.

77. Moore PM, Baker GA. Non-epileptic attack disorder: a psychological perspective. Seizure 1997;6: 429-34.

78. Gould R, Miller BL, Goldberg MA, Benson DF. The validity of hysterical signs and symptoms. J Nerv Ment Dis 1986;174:593-7.

79. Mace CJ, Trimble MR. 'Hysteria', 'functional' or 'psychogenic'? A survey of British neurologists' preferences. J R Soc Med 1991;84:471-5. 
34 Chapter 2

80. Kuyk J, Swinkels WAM, Spinhoven PH. Psychopathologies in patients with non-epileptic seizures with and without comorbid epilepsy: how different are they? Epilepsy Behav 2003;4:13-8.

81. Van Merode T, de Krom MCTFM, Knottnerus JA. Gender-related differences in non-epileptic attacks: a study of patients' cases in the literature. Seizure 1997;6:311-6.

82. Braun BG. The BASK model of dissociation. Dissociation 1988;1:4-22.

83. Bodde NMG, Brooks JL, Baker GA, Boon P, Hendriksen JGM, Mulder OG, Aldenkamp AP. Psychogenic non-epileptic seizures - Definition, etiology, treatment and prognostic issues: A critical review. Seizure 2009;18:543-53.

84. Reuber M, Howlett S, Khan A, Grünewald RA. Non-epileptic seizures and other functional neurological symptoms: predisposing, precipitating, and perpetuating factors. Psychosom 2007;48:230-8.

85. LaFrance W, Devinsky O. Treatment of nonepileptic seizures. Epilepsy Behav 2002;3:19-23.

86. Stone J, Sharpe M, Binzer M. Motor conversion symptoms and pseudoseizures: a comparison of clinical characteristics. Psychosom 2004;45:492-9. 


\section{Chapter 3}

Psychogenic non-epileptic seizures - Definition, etiology, treatment and prognostic issues:

A critical review

NMG Bodde, JL Brooks, GA Baker, PAJM Boon, JGM Hendriksen, OG Mulder, AP Aldenkamp

Seizure 2009;18:543-53 
36 Chapter 3

\section{Abstract}

In this review we systematically assess our currently available knowledge about psychogenic non-epileptic seizures (PNES) with an emphasis on the psychological mechanisms that underlie PNES, possibilities for psychological treatment as well as prognosis. Relevant studies were identified by searching the electronic databases. Case reports were not considered. 93 Papers were identified; 65 of which were studies. An open non-randomized design, comparing patients with PNES to patients with epilepsy is the dominant design. A working definition for PNES is proposed. With respect to psychological etiology, a heterogeneous set of factors have been identified. Not all factors have a similar impact, though. On the basis of this review we propose a model with several factors that may interact in both the development and prolongation of PNES. These factors involve psychological etiology, vulnerability, shaping, as well as triggering and prolongation factors. A necessary first step of intervention in patients with PNES seems to be explaining the diagnosis with care. Although the evidence for the efficacy of additional treatment strategies is limited, variants of cognitive (behavioural) therapy showed to be the preferred type of treatment for most patients. The exact choice of treatment should be based on individual differences in the underlying factors. Outcome can be measured in terms of seizure occurrence (frequency, severity), but other measures might be of greater importance for the patient. Prognosis is unclear but studies consistently report that $1 / 3$ rd to $1 / 4$ th of the patients become chronic. 


\section{Introduction}

Psychogenic non-epileptic seizures resemble epileptic seizures, have no electrophysiological correlate or clinical evidence for epilepsy, whereas there is positive evidence for psychogenic factors that may have caused the seizure ${ }^{1-3}$. With their somatic appearance and underlying psychological or psychiatric problems, these seizures appear on the boundaries of the medical and mental health services, although most patients seem to be seen in tertiary epilepsy centres. The incidence of PNES in the general population is relatively low, estimated at about $1.5 / 100,000$ persons per year; about $4 \%$ of the incidence of epilepsy ${ }^{4,5}$. However, data from epilepsy centres estimate a much higher incidence rate. In $25-30 \%$ of the patients referred to tertiary epilepsy centres for refractory epilepsy a diagnosis of PNES is obtained $^{6,7}$. A complicating factor is that between 5 and $40 \%$ of these patients with PNES has a concomitant diagnosis of epilepsy or has a past history with epileptic seizures ${ }^{8,9}$.

Although diagnosis can be difficult, the differential diagnosis between PNES and epilepsy has improved in the last thirty years, especially since the introduction of simultaneous video-EEG monitoring ${ }^{6,9,10}$. Diagnosing PNES is important because of the potential iatrogenic hazards such as potentially serious side effects of anti epileptic drugs and failure to recognize pseudo status-epilepticus with a potential hazard of intubation $^{5,11}$. The failure to recognize the psychological nature of these seizures also delays implementation of appropriate psychological treatment ${ }^{5}$. Social stigma attached to the diagnosis of epilepsy is considerable and patients that suffer such a stigma for a longer period can become hostile when the diagnosis changes from epilepsy to PNES ${ }^{12}$.

The differential diagnosis is thus a very important aspect and a first step in the treatment of PNES. However, when the medical diagnosis is only focused on excluding epilepsy, it can become a pure 'negative' process and consequently PNES becomes a non-disease ${ }^{13}$. A positive diagnosis is necessary in which the underlying psychological mechanisms are evaluated that can be used for treatment aspects. LaFrance and Devinsky $^{14}$ call this 'borderland diagnosis' referring to the fact that the diagnosis is best made by neurologists with expertise in clinical neurophysiology, especially longterm monitoring and V-EEG, whereas treatment is best initiated by psychologists whose experience affords them a familiarity with psychological constructs and conflicts. Theories regarding the psychological etiology of PNES are however very diverse. This probably reflects the heterogeneity of the psychogenic etiology of PNES that can be a symptom of various affective and psychiatric factors ${ }^{15,16}$. Literature is also hindered by variation and inconsistent use of terminology. As yet there is no accepted model to explain the psychogenic features leading to PNES, but there are indications that often more than one factor or psychogenic mechanism operates in $\mathrm{PNES}^{17}$. Also comparatively little research has been done on treatment and prognosis for patients with PNES. 
38 Chapter 3

In this review we therefore systematically assess the current knowledge about PNES with an emphasis on the psychological mechanisms that underlie PNES, psychological treatment, as well as prognosis. We not only aim at identifying relevant factors, which has been done excellently in some other reviews, but also attempt to organize such factors in an explanatory model. Such a model arranges factors in their relationships and can provide options for therapy and research. Although we can learn from other psychosomatic disorders and their theoretical background, such as conversion disorders, PNES are unique in their aspect, especially because of the paroxysmal nature. This implies that models for other psychosomatic disorders can not easily be transferred to PNES.

\section{Methods}

Relevant studies were identified by searching the electronic databases psycINFO, EMBASE, MEDLINE, PubMed and Online Contents. Articles included were identified by searching the terms: 'non-epileptic seizures'; 'non-epileptic attack disorder'; 'psychogenic non-epileptic seizures'; 'pseudo epileptic attack disorder'; 'psychogenic pseudoseizures'; 'psychogenic seizures'; 'dissociative episodes', 'hysterical seizures' with regard to etiology and treatment. In all cases 'seizures' were also replaced by 'fits' and 'attacks'.

Titles of articles and abstracts extracted during the search were reviewed for relevance, and if found to be applicable, the full-text article was retrieved. After selecting the articles, the search was expanded by using the PubMed function 'related articles'. In addition, reference lists of all articles that were identified in the electronic investigation were scanned. Further articles and conference papers were identified through hand searches in the library holdings of Kempenhaeghe and Maastricht University. Articles were included if they were published in English, Dutch or German. Case reports were not considered. Articles were included when published after 1980-2005 (26 years).

\section{Results}

A total of 93 papers were identified; 65 of these were studies and 28 reviews. Table 3.1 provides the main characteristics of the studies and Table 3.2 shows the reviews: 
Table 3.1 Overview of studies on definition, etiology, treatment and prognostic issues in patients with PNES.

\begin{tabular}{|c|c|}
\hline Reference & Study: design and number of patients \\
\hline Abubakr et al. ${ }^{12}$ & $\begin{array}{l}\text { Open cohort study; psychological factors in } 23 \text { patients with PNES; no } \\
\text { controls }\end{array}$ \\
\hline Aldenkamp and Mulder ${ }^{94}$ & $\begin{array}{l}\text { Open non-randomized comparative design; } 45 \text { PNES patients; three } \\
\text { treatment conditions }\end{array}$ \\
\hline Aldenkamp and Mulder ${ }^{51}$ & $\begin{array}{l}\text { Open non-randomized comparative design, comparing psychological } \\
\text { etiology in } 24 \text { PNES with } 24 \text { patients with epilepsy }\end{array}$ \\
\hline Alper et al. ${ }^{48}$ & $\begin{array}{l}\text { Open non-randomized comparative study in which a scale (DES) was } \\
\text { tested in } 132 \text { patients with conversion-type PNES versus } 169 \text { patients } \\
\text { with epilepsy (and complex partial seizures) }\end{array}$ \\
\hline Arnold and Privitera ${ }^{16}$ & $\begin{array}{l}\text { Double blind comparative design comparing psychological etiology in } \\
14 \text { patients with PNES and } 27 \text { with epilepsy }\end{array}$ \\
\hline Barry et al. ${ }^{75}$ & $\begin{array}{l}\text { Open and non-randomized non-controlled study in } 37 \text { patients with } \\
\text { PNES after head injury }\end{array}$ \\
\hline Benbadis $^{76}$ & $\begin{array}{l}\text { Retrospective study on patient files on the relationship between } \\
\text { chronic pain and PNES }\end{array}$ \\
\hline Benbadis et al. $^{8}$ & Evaluation of video-EEG in 32 patients with PNES \\
\hline Betts and Boden ${ }^{21}$ & $\begin{array}{l}\text { Retrospective open clinical follow-up study ( } 2 \text { years) in } 128 \text { patients } \\
\text { with PNES ( } 46 \text { combined with epilepsy). }\end{array}$ \\
\hline Betts and Boden ${ }^{41}$ & $\begin{array}{l}\text { Retrospective open non-randomized comparative design, with } 96 \\
\text { women with PNES, } 132 \text { women with epilepsy and } 87 \text { women with a } \\
\text { psychiatric diagnosis }\end{array}$ \\
\hline Bewley et al. ${ }^{50}$ & $\begin{array}{l}\text { Open non-randomized comparative study on measures of alexithymia } \\
\text { in } 21 \text { patients with PNES versus controls. }\end{array}$ \\
\hline Binder et al. ${ }^{27}$ & $\begin{array}{l}\text { Open non-randomized comparative design, comparing MMPI profiles } \\
\text { in } 12 \text { patients with PNES with } 31 \text { patients with epilepsy }\end{array}$ \\
\hline Bowman and Markand ${ }^{15}$ & $\begin{array}{l}\text { Open non-randomized non-controlled study in } 45 \text { patients with PNES; } \\
\text { outcome: DSM-III classifications }\end{array}$ \\
\hline Buchanan and Snars $^{70}$ & $\begin{array}{l}\text { Open non-randomized clinical retrospective study on clinical outcome } \\
\text { after individual treatment in } 50 \text { patients with PNES }\end{array}$ \\
\hline Carton et al. ${ }^{87}$ & $\begin{array}{l}\text { Open non-randomized postal questionnaire study on outcome in } 84 \\
\text { patients with PNES }\end{array}$ \\
\hline Cragar et al. ${ }^{10}$ & $\begin{array}{l}\text { Prospective open non-randomized comparative study on personality } \\
\text { traits in } 92 \text { patients with epilepsy, } 74 \text { patients with PNES and other } \\
\text { small groups. }\end{array}$ \\
\hline Drake et al. $^{46}$ & $\begin{array}{l}\text { Open non-randomized clinical retrospective study on psychiatric } \\
\text { symptoms in } 20 \text { patients with PNES }\end{array}$ \\
\hline Dworetzky et al. ${ }^{39}$ & $\begin{array}{l}\text { Comparison between } 34 \text { patients with epilepsy and } 22 \text { patients with } \\
\text { PNES, with a focus on seizure semiology }\end{array}$ \\
\hline Ettinger et al. ${ }^{82}$ & $\begin{array}{l}\text { Telephone based questionnaire on clinical psychological and } \\
\text { psychiatric characteristics in } 56 \text { patients with PNES }\end{array}$ \\
\hline Fargo et al. $^{73}$ & $\begin{array}{l}\text { Open non-randomized comparative study on neuropsychological and } \\
\text { quality of life outcomes in } 37 \text { patients with PNES and } 45 \text { patients with } \\
\text { epilepsy }\end{array}$ \\
\hline Farias et al. $^{79}$ & $\begin{array}{l}\text { Open non-randomized comparative study on seizure frequency after } \\
\text { presenting the diagnosis in } 22 \text { patients with PNES and } 10 \text { patients with } \\
\text { epilepsy }\end{array}$ \\
\hline Fleisher et al. ${ }^{24}$ & $\begin{array}{l}\text { Open non-randomized comparative study studying the effect of trauma } \\
\text { in } 30 \text { patients with PNES and } 32 \text { patients with epilepsy }\end{array}$ \\
\hline Galimberti et al. ${ }^{17}$ & $\begin{array}{l}\text { Open non-randomized comparative study on psychological profiles in } \\
31 \text { patients with PNES and } 38 \text { patients with PNES and epilepsy }\end{array}$ \\
\hline Goldstein et al. $^{83}$ & Evaluation of cognitive behavioural therapy \\
\hline
\end{tabular}


40

Chapter 3

\begin{tabular}{|c|c|}
\hline Reference & Study: design and number of patients \\
\hline Jawad et al. $^{65}$ & $\begin{array}{l}\text { Open and non-randomized comparative design in } 46 \text { female patients } \\
\text { with PNES compared to } 50 \text { female patients referred to a psychiatric } \\
\text { outpatient clinic }\end{array}$ \\
\hline Kuyk et al. ${ }^{36}$ & $\begin{array}{l}\text { Open and non-randomized comparative retrospective study on } \\
\text { dissociation in } 65 \text { patients with PNES and } 94 \text { patients with epilepsy }\end{array}$ \\
\hline Krumholz and Niedermeyer ${ }^{1}$ & $\begin{array}{l}\text { Retrospective follow-up study on the natural history and prognosis ( } 5 \\
\text { years) in } 34 \text { patients with PNES }\end{array}$ \\
\hline Lancman et al. ${ }^{64}$ & $\begin{array}{l}\text { Open non-randomized non-controlled study on psychological factors in } \\
93 \text { patients with PNES }\end{array}$ \\
\hline Leis et al. ${ }^{2}$ & $\begin{array}{l}\text { Retrospective study of EEG/video and medical records of } 47 \text { patients } \\
\text { with PNES }\end{array}$ \\
\hline Lempert and Schmidt $^{92}$ & $\begin{array}{l}\text { Open non-randomized non-controlled and retrospective follow-up } \\
\text { study on natural history and clinical outcome in } 50 \text { patients with PNES }\end{array}$ \\
\hline Lichter et al. ${ }^{28}$ & Clinical follow-up of 5 patients with postanasthetic PNES \\
\hline Lobello et al. $^{34}$ & $\begin{array}{l}\text { Open non-randomized comparative study of results of video evaluation } \\
\text { in } 91 \text { patients with PNES, } 37 \text { with epilepsy and } 13 \text { patients with } \\
\text { epilepsy and PNES }\end{array}$ \\
\hline Marquez et al. ${ }^{3}$ & $\begin{array}{l}\text { Retrospective open non-randomized comparative study looking at BMI } \\
\text { in } 46 \text { patients with PNES and } 46 \text { patients with epilepsy }\end{array}$ \\
\hline McDade and Brown ${ }^{90}$ & $\begin{array}{l}\text { Open non-controlled and non-randomized treatment study on } \\
\text { management and predictive factors of outcome in } 18 \text { patients with } \\
\text { PNES }\end{array}$ \\
\hline Meierkord et al. ${ }^{93}$ & $\begin{array}{l}\text { Open non-randomized non-controlled study on characteristics of } \\
\text { video-EEG in } 100 \text { patients with PNES }\end{array}$ \\
\hline Mökleby et al. ${ }^{55}$ & $\begin{array}{l}\text { Open non-randomized comparative study in } 23 \text { patients with PNES, } 23 \\
\text { patients with somatoform disorders and } 23 \text { normal controls }\end{array}$ \\
\hline Moore and Baker ${ }^{11}$ & $\begin{array}{l}\text { Retrospective study on psychological characteristics of patients files for } \\
185 \text { patients with PNES }\end{array}$ \\
\hline Müller et al. ${ }^{35}$ & $\begin{array}{l}\text { Epidemiological retrospective study of } 322 \text { medical records of patients } \\
\text { referred to an epilepsy centre. } 44(14 \%) \text { had PNES, some in } \\
\text { combination with epilepsy }\end{array}$ \\
\hline O'Sullivan et al. ${ }^{85}$ & Interview study on opinion of general practitioners in 23 patients \\
\hline Owczarek $^{61}$ & $\begin{array}{l}\text { Open non-randomized comparative study on MMPI profiles in } 66 \\
\text { patients with PNES, } 36 \text { patients with epilepsy and } 42 \text { patients with } \\
\text { combined PNES/epilepsy }\end{array}$ \\
\hline Owczarek $^{62}$ & $\begin{array}{l}\text { Open non-randomized comparative study on MMPI profiles in } 70 \\
\text { patients with PNES, } 42 \text { patients with epilepsy and } 40 \text { patients with } \\
\text { combined PNES/epilepsy }\end{array}$ \\
\hline Owczarek and Jedrzejczak ${ }^{47}$ & $\begin{array}{l}\text { Open non-randomized comparative study on MMPI profiles in } 38 \\
\text { patients with PNES, } 36 \text { patients with epilepsy and } 32 \text { patients with } \\
\text { combined PNES/epilepsy }\end{array}$ \\
\hline Prigatano et al. ${ }^{30}$ & Non-controlled open treatment study in 9 patients with PNES \\
\hline Prueter et al. ${ }^{54}$ & $\begin{array}{l}\text { Open non-randomized comparative study on dissociative features in } 19 \\
\text { patients with PNES, } 20 \text { patients with epilepsy and } 21 \text { patients with both } \\
\text { epilepsy and PNES }\end{array}$ \\
\hline Quigg et al. $^{56}$ & Open non-controlled study about quality of life and PNES in 30 patients \\
\hline Ramchandani and Schindler ${ }^{43}$ & $\begin{array}{l}\text { Open non-randomized non-controlled study on psychiatric factors in } 20 \\
\text { patients with PNES }\end{array}$ \\
\hline 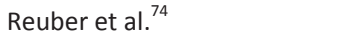 & Retrospective study on evidence of brain abnormality of patient files \\
\hline Reuber et al. ${ }^{49}$ & $\begin{array}{l}\text { Open postal questionnaire study on long-term outcome of a } \\
\text { retrospective sample of } 98 \text { patients with PNES and } 66 \text { patients with } \\
\text { PNES and epilepsy }\end{array}$ \\
\hline
\end{tabular}




\begin{tabular}{|c|c|}
\hline Reference & Study: design and number of patients \\
\hline Reuber et al. ${ }^{52}$ & $\begin{array}{l}\text { Study on psychological outcome in } 119 \text { patients with epilepsy and } 119 \\
\text { patients with PNES }\end{array}$ \\
\hline Reuber et al. ${ }^{53}$ & $\begin{array}{l}\text { Open postal questionnaire study in } 85 \text { patients with PNES and } 63 \text { with } \\
\text { epilepsy }\end{array}$ \\
\hline Reuber et al. ${ }^{88}$ & $\begin{array}{l}\text { Open postal questionnaire study on long-term outcome. Similar study } \\
\text { as Reuber et al. }{ }^{49,52} \text { with different outcomes measures }\end{array}$ \\
\hline Rusch et al. ${ }^{86}$ & $\begin{array}{l}\text { Open non-randomized non-controlled study on effects of psychological } \\
\text { treatment in } 26 \text { patients with PNES (including } 15 \text { patients with PNES } \\
\text { and epilepsy) }\end{array}$ \\
\hline Salmon et al. ${ }^{38}$ & $\begin{array}{l}\text { Psychological outcome and etiology in } 81 \text { patients with epilepsy and } 81 \\
\text { patients with PNES }\end{array}$ \\
\hline Sigurdardottir and Olafsson ${ }^{4}$ & Epidemiology of PNES (Icelandic study) \\
\hline Stewart et al. ${ }^{58}$ & $\begin{array}{l}\text { Open non-randomized comparative study in } 13 \text { patients with PNES } \\
\text { compared to patients with anxiety attacks }(n=11) \text { or combined PNES } \\
\text { and anxiety attacks }(n=13)\end{array}$ \\
\hline Szaflarski et al. ${ }^{32}$ & $\begin{array}{l}\text { Open non-randomized comparative study on quality of life aspects in } 45 \\
\text { patients with PNES and } 40 \text { patients with epilepsy }\end{array}$ \\
\hline Szaflarski et al. ${ }^{66}$ & $\begin{array}{l}\text { Open non-randomized comparative study on quality of life in } 53 \\
\text { patients with PNES and } 53 \text { patients with epilepsy }\end{array}$ \\
\hline Thompson et al. $^{60}$ & $\begin{array}{l}\text { Open non-randomized comparative study on psychological etiology in } \\
27 \text { patients with PNES and } 22 \text { patients with epilepsy }\end{array}$ \\
\hline Tojek et al. ${ }^{45}$ & $\begin{array}{l}\text { Open non-randomized comparative study on psychosocial risk factors in } \\
25 \text { patients with PNES and } 33 \text { patients with epilepsy }\end{array}$ \\
\hline Vanderzant et al. ${ }^{63}$ & Psychological outcome using the MMPI in 19 patients with PNES \\
\hline Vincentiis et al. ${ }^{67}$ & $\begin{array}{l}\text { Open non-randomized non-controlled comparative study on } \\
\text { psychological risk factors in } 21 \text { patients with PNES and epilepsy }\end{array}$ \\
\hline Walczak et al. ${ }^{89}$ & $\begin{array}{l}\text { Òpen non-randomized and non-controlled study on outcome after } \\
\text { diagnosis using telephonic interviews in } 51 \text { patients with PNES }\end{array}$ \\
\hline Witgert et al. ${ }^{7}$ & $\begin{array}{l}\text { Open non-randomized study on frequency of panic symptoms in } 39 \\
\text { patients with PNES }\end{array}$ \\
\hline Wyllie et al. ${ }^{68}$ & $\begin{array}{l}\text { Open non-randomized comparative study on video-EEG in } 18 \text { children } \\
\text { with PNES and } 20 \text { adults with PNES }\end{array}$ \\
\hline Zaroff et al. ${ }^{84}$ & Results of psychoeducation and psychotherapy in 10 patients with PNES \\
\hline
\end{tabular}

\section{Description of the studies}

Some comments on the results in Table 3.1 are in order. The dominant type of design is the open non-randomized comparative study. The studies are therefore not protected against the effects of bias, especially selection bias. Patients with epilepsy are mostly used as the comparator. This may seem obvious since the symptoms resemble epileptic seizures, but this is not logical when studying for example the underlying psychopathology or etiology which is presumed to be very different in epilepsy versus PNES. In many cases patients with PNES have been in the diagnostic process as 'epileptic patient' for many years. The effect on daily life may therefore not be different. Also, the sample size is mostly rather limited; the majority in the range of 20-30 patients. Given the high variability of the symptoms and underlying characteristics in these patients, it is doubtful whether any of the studies achieves sufficient power to allow formal conclusions. The larger studies are retrospective 
42 Chapter 3

studies and mostly studies on patient files. The only exceptions are postal questionnaire studies. In these studies such a high non-response rate was observed that bias cannot be excluded. The quality of the studies is even more limited when treatment issues are considered. In our Cochrane review, we identified only three studies with a quasi-randomized design ${ }^{18}$.

Table 3.2 Overview of reviews on definition, etiology, treatment and prognostic issues in patients with PNES.

\begin{tabular}{|c|c|}
\hline Reference & Review topic \\
\hline Alper $^{6}$ & General update \\
\hline Alsaadi and Marquez ${ }^{77}$ & PNES: diagnosis, etiology and treatment \\
\hline Baker et al. ${ }^{18}$ & Cochrane review on treatment of PNES \\
\hline Barry and Sanborn ${ }^{37}$ & Psychological factors \\
\hline Betts $^{78}$ & Management of PNES \\
\hline Bowman $^{59}$ & Indicators for prognosis \\
\hline Chabolla et al. ${ }^{23}$ & Classification \\
\hline Dekkers and van Domburg ${ }^{13}$ & Diagnosis with an emphasis on psychological diagnosis \\
\hline Fiszman et al. ${ }^{40}$ & Traumatic events and PTSD in patients with PNES \\
\hline Francis and Baker ${ }^{22}$ & $\begin{array}{l}\text { Description of PNES in an historic and societal context, } \\
\text { terminology, epidemiology, diagnosis and etiology }\end{array}$ \\
\hline Iriarte et al. ${ }^{9}$ & Diagnosis of PNES \\
\hline Kuyk et al. ${ }^{31}$ & Psychological diagnosis \\
\hline Krumholz 20 & Diagnosis and management \\
\hline LaFrance and Devinsky ${ }^{14}$ & Diagnosis and treatment \\
\hline LaFrance and Barry ${ }^{44}$ & Update on treatments of PNES \\
\hline LaFrance et al. ${ }^{42}$ & Results of an interdisciplinary workshop \\
\hline Lesser $^{33}$ & General update \\
\hline Massey and Riley ${ }^{25}$ & General update \\
\hline Ramani et al. ${ }^{57}$ & General update \\
\hline Reuber and Elger ${ }^{5}$ & Update on diagnosis and outcome of PNES \\
\hline Reuber and House ${ }^{71}$ & Treatment factors \\
\hline Riggio $^{26}$ & Seizure characteristics \\
\hline Rosenbaum $^{72}$ & Hypothesis why PNES occur mostly in women \\
\hline Scull ${ }^{19}$ & Terms for PNES \\
\hline Shen et al. ${ }^{81}$ & Protocol for presenting the diagnosis of PNES \\
\hline Sirven and Glosser ${ }^{69}$ & Epidemiology of PNES \\
\hline Trimble & General update \\
\hline Wyllie et al. ${ }^{80}$ & PNES in children \\
\hline
\end{tabular}

\section{Definition and terminology}

Several terms are used ${ }^{19}$, most frequently the term 'non-epileptic seizures' (NES) ${ }^{3,12,20}$, 'non-epileptic attack disorder' (NEAD) ${ }^{21,22}$, 'psychogenic non-epileptic seizures' $(\mathrm{PNES})^{10,17,23,24}$, 'pseudoepileptic attack disorder' (PEAD) ${ }^{13}$, 'pseudo-seizures' ${ }^{25}$, 'psychogenic pseudo-seizures' (PPS) ${ }^{9}$, 'psychogenic seizures',26,27 and 'dissociative episodes' ${ }^{28}$. In line with, e.g. Trimble ${ }^{29}$, Scull ${ }^{19}$ and Prigatano et al. $^{30}$, we prefer terminology that avoids the term 'pseudo', a term that tends to imply that the seizures are unreal and can have a pejorative meaning. Moreover, using the term 
'pseudo' may suggest 'malingering'. 'Non-epileptic seizure' (NES) is a term that is nonjudgmental, acceptable to patients and serving descriptive and neutral patterns at the same time. Adding the term 'psychogenic' can help to distinguish these seizures from other 'organic' based non-epileptic seizures, such as seizures due to cardiac disease. Thus, in our opinion the term 'psychogenic non-epileptic seizures' (PNES) $)^{10,17,31,32}$ is the preferred term.

Definitions vary widely, but the elements most common are:

a) an observable abrupt paroxysmal change in behaviour or consciousness ${ }^{12}$; sometimes also defined as episodes of altered movement, sensation, or experience $^{10}$ or the internal psychic state ${ }^{17}$

b) the absence of the characteristic electrophysiological changes in the brain, which accompany an epileptic seizure ${ }^{21}$; hence the absence of ictal or postictal EEG changes $^{12,14}$. The combined EEG and video recordings of seizure events (EEG-video recordings) therefore are considered the gold standard in the diagnosis of PNES $^{33,34}$

c) no evidence for other somatic causes for the seizures (such as cardiac disease) ${ }^{13,35}$

d) usually the seizure is time limited ${ }^{7}$

e) and resembles, or is mistaken for, epilepsy or at least mimics epileptic seizures ${ }^{17,32}$

f) there is no voluntary control ${ }^{3}$

g) the seizures are caused by 'a psychological process' ${ }^{5,10}$; 'a variety of psychogenic processes $^{\prime 9}$. This latter factor refers to the psychological etiology, the psychic causes of the seizures.

A working definition, based on the aforementioned elements could be: a psychogenic non-epileptic seizure is an observable abrupt paroxysmal change in behaviour or consciousness, that resembles an epileptic seizure, but that is not accompanied by the electrophysiological changes that accompany an epileptic seizure or clinical evidence for epilepsy, for which no other evidence is found for other somatic causes for the seizures, whereas there is positive evidence or a strong suspicion for psychogenic factors that may have caused the seizure.

\section{Psychological etiology}

Many psychosocial factors and psychological mechanisms have found to be associated with PNES, often in a non-systematic order. We firstly discuss each of these factors as they are presented in literature and subsequently order them in an attempt to develop a model that expresses the relationships between such factors. 
44 Chapter 3

\section{Trauma}

This factor is most commonly mentioned especially in early studies. A history of sexual or physical abuse or other significant traumas such as significant bereavement and post-traumatic stress disorder (PTSD) ${ }^{11,21,24,36-39}$. Fiszman et al. ${ }^{40}$ found very high rates (15-40\% exceeding the incidence in control) of general trauma (44-100\%) and physical or sexual abuse (23-77\%). PNES samples also showed a higher prevalence of PTSD than control groups, raising the possibility that PNES may arise as a clinical expression of a hypothetical PTSD subtype. According to Betts and Boden ${ }^{41}$ this factor is often underestimated as most patients will not easily disclose a history of abuse ('unspeakable dilemmas'). They see PNES either as a form of acting out of a 'flash back' experience, thus a kind of acting-out the memory of the abuse, or as a 'cut-off phenomenon', an automatic reaction to intrusion into consciousness of unpleasant memories. LaFrance et al. ${ }^{42}$ report that in children $9-18$ years old about $32 \%$ had a history of sexual abuse, $6 \%$ of physical abuse and $44 \%$ severe family stressors. Ramchandi and Schindler ${ }^{43}$ found 'guilt-laden bereavement' to be an important precursor of seizures.

\section{Dissociation}

This factor is often discussed in relation to traumatic experiences. Dissociation ${ }^{6,12,44}$ is not a true cause in the sense of an etiological factor, but merely a mechanism, i.e. a disruption of the usually integrated functions of identity, memory, consciousness or perceptions of the environment. Dissociation refers to a loss or altered integration of the continuity of the experience of the self. Its function is probably to spare the normally integrated conscious self from confronting the painful and unendurable by altering conscious experience ${ }^{6}$. Bowman and Markand ${ }^{15}$ conclude that PNES patients appeared to express dissociative distress about reported trauma, often sexual abuse $^{45}$. The 'conversion V' profile on the MMPI- ${ }^{46}$, collectively observed in the PNES patients is compatible with reports that dissociative reactions (dissociation between feelings and thoughts/memories) are common in these patients ${ }^{30,47}$. Dissociation and conversion are linked to such an extent that the ICD classifies conversion as a dissociative disorder ${ }^{6,48}$. In addition there are indications that PNES patients are characterized by a relatively high level of hypnotisability as measured with the Stanford Hypnotic Clinical Scale ${ }^{31,36}$.

\section{Somatisation disorder}

Somatisation disorder or high levels of somatisation, including Briquet's syndrome ${ }^{6,21,49}$, generally present as conversion disorder ${ }^{30}$. Reuber et al. ${ }^{49}$ found that as a group, PNES patients show a high tendency to express psychosocial distress by producing unexplained somatic symptoms which are brought to medical attention. Bewley et al. ${ }^{50}$ demonstrated a relationship between PNES and certain subscales of an 
instrument measuring alexithymia (Toronto Alexithymia Scale, TAS-20). Alexithymia is a concept expressing that patients experience emotions as physiological reactions as opposed to feelings.

\section{Personality factors or disorders ${ }^{15,51,52}$}

A problem in comparing studies on personality factors is that different diagnostic systems are used to describe personality disorders, such as the descriptive use of axis II DSM-IV personality disorders or the more dimensional (structural) categorisation on the basis of psychological tests such as the MMPI-2 or the DAPP Q. Some studies ${ }^{10,53}$ distinguish three types of personality disorders in patients with PNES: a) borderline personality disorder (assumed to be the most common type in patients with PNES); b) overly controlled personality; and c) avoidant personality disorder. According to Alper ${ }^{6}$, dependant personality traits are the dominant type of personality dysfunction in patients with PNES. Reuber et al. ${ }^{53}$ propose a kind of general characteristic of the personality structure of patients with PNES, described as 'emotional dysregulation'. This broad dimension of personality pathology reflects stable personality vulnerabilities, which put individuals at greater risk of anxiety and depressive symptoms. This has been termed 'general neurotic syndrome' in the past and is characterized by a combination of high trait anxiety/ high arousability combined with poor coping. Thompson et al. ${ }^{60}$ using personality assessments with the MMPI, report that patients with PNES have significantly higher scores on the scales 'hypochondriasis', 'hysteria', 'depression' and 'schizophrenia' than do patients with epilepsy. This was confirmed in the study by Owczarek ${ }^{61}$. Binder et al. ${ }^{27}$ report that PNES patients scored significantly higher on the somatoform MMPI profiles. Owczarek $^{62}$ used personality indices to interpret MMPI results and found that patients with PNES alone or in combination with epileptic seizures scored significantly higher than the epileptic group on anxiety measures. This suggests that the predisposition of PNES is reflected in the anxiety dimensions of the personality profile. Nonetheless, substantial disagreement exists about the sensitivity of the test, regardless of the interpretative algorithms used. Vanderzant et al. ${ }^{63}$, e.g. found no significant MMPI score differentiating between PNES and epilepsy.

\section{Coping}

A special element of personality is coping or the way difficult situations are handled. Some authors report a specific coping style in patients with PNES $^{3,10,55,64}$, often characterized by hostility (anger and mistrust in other people). It is possible that the hostile coping style may be related to relatively high incidence of physical and sexual abuse and that any subjective experience of 'not being understood' or rejected would increase the hostile behaviour ${ }^{55}$. Measuring defence mechanisms with the DMI (Defence Mechanisms Inventory) Jawad et al. ${ }^{65}$ found that patients with PNES were 
46 Chapter 3

characterized by higher scores on the 'reversal' scale and lower scores on the 'turning against self' scale. This indicates that these patients prefer to use denial and repression to perceived threats rather than to confront and solve problems. The authors state that therapists need to recognize the avoidant responses of the patient in dealing with negative life circumstances which have interfered with their ability to engage in deep intimate relationships and prevented them from acquiring effective coping skills. Noteworthy in this case is the study by Marquez et al. $^{3}$ in which a statistically significant association is found between PNES and high body-mass index. It is possible that the psychopathological processes underlying PNES also contribute to weight problems. PNES and weight deregulation may be two aspects of the PNES patients underlying coping pattern in situations with psychological distress.

\section{Psychiatric comorbidity}

Psychiatric disorders have been found, mostly depression ${ }^{12,29,58}$, panic disorder with or without agoraphobia and affective disorders such as chronic anxiety ${ }^{55,64,66}$. According to Abubakr et al. ${ }^{12}$ depression is the most common comorbid disorder in patients with PNES. In line with this observation, suicide attempts have been reported. Some studies $^{7}$ report that adolescents with PNES may experience a greater frequency of symptoms associated with panic attacks during their typical seizure events than adults. The results raise the possibility that the role of panic disorder in PNES may differ, depending on age of presentation. Psychiatric disorders, may however be the cause or the result of PNES, an epiphenomenon or a different diagnostic term to describe PNES. For example depression may be the result of having PNES for a longer period, it may be the etiological factor causing PNES and it may be a comorbid disorder (unrelated to PNES). Categorization of PNES patients into DSM-IV or ICD-10 diagnoses has been done where these seizures were diagnosed as either 'dissociative disorders' $(\text { ICD-10) })^{54}$ or on the DSM on either axis I, or axis II or both ${ }^{5,53}$. The most frequent DSM-IV diagnosis for PNES appears to be somatoform disorder (conversion disorder $)^{10,17,54}$. The second most common diagnosis was anxiety disorder ${ }^{17,55,56}$. For DSM-IV axis II PNES patients showed higher percentages of cluster B personality disorders, being indicative of possible 'acting out' behaviours ${ }^{17,57,58}$. Nonetheless, specificity of such classification has not been demonstrated ${ }^{59}$. PNES patients had multiple psychiatric diagnoses, including somatoform disorder (89\%), dissociative disorder (91\%), affective disorder (64\%), personality disorder (62\%), PTSD (49\%) and other anxiety disorders (47\%).

\section{Age factors}

Children with PNES appear to have a different psychological profile when compared to adults $^{37,51}$. In children the role of situational stress is more apparent ${ }^{67}$. Adolescence is recognized as a specific risk factor, being a potential time of turmoil and psychological 
distress, when self-esteem and important relationships are being developed and the person gains their own identity. These are highly vulnerable processes that in some cases may lead to somatoform reactions such as $\mathrm{PNES}^{68,69}$.

\section{Behavioural modification}

Behaviourally oriented concepts of primary and secondary gain and adaptation of the sick role are often the main factor behind the development of PNES in intellectually disabled persons ${ }^{30}$. Secondary gain may more generally play a role in the prolongation of seizures ${ }^{11,12}$. The primary gain is the reduction of subjective anxiety and related affects by expressing an underlying conflict or unmet need in the form of a physical symptom. This allows the patient to escape the unpleasant emotions evoked by conscious awareness of the conflict. This is not perceived or experienced consciously. Secondary gain involves clearly identifiable external incentives, i.e. meeting of dependency needs, monetary gain, escape from unpleasant circumstances or role demands, and so on. This gain may or may not be consciously perceived ${ }^{6}$.

Other behaviourally oriented concepts are symptom modelling and the influence of domestic stressors (relationship problems, family dysfunctioning) ${ }^{11,38}$. Symptom modelling is the process by which the patient may acquire a symptom on the basis of observing a physiologically genuine example of the symptom. This is particularly relevant to patients with both PNES and epilepsy, but also to patients with a relative with epilepsy, 61,64 .

Sometimes 'chronic PNES' are distinguished from 'acute' or situational PNES. The latter are generally short-lived, self-limiting and with good prognosis. Most commonly, domestic stressors precede the development of acute PNES ${ }^{70}$.

Malingering is sometimes seen in patients who expect financial compensation ${ }^{12,71}$; malingering is the only factor with conscious manipulation of the symptoms.

\section{Gender}

There is a dominance of the female gender ${ }^{12,26}$. Reasons for this preponderance are not entirely clear. No specific or consistent difference in the underlying psychopathology between men and women with PNES has been reported. However, some authors speculate that women and men differ in vulnerability to physical or emotional trauma and that at least in the affected women with PNES the attack is a reflection of 'rage, fear, and helplessness' against domination or abuse ${ }^{72}$.

\section{'Organicity'}

A specific vulnerability may play a role in the development of PNES, possibly as an extra factor. This factor is often labelled as 'organicity'. In some studies 
neuropsychological deficits have been found ${ }^{37,73}$. Other studies have reported subtle neurologic dysfunction ${ }^{74}$. Also histories of head injury may be a significant provocation factor in patients with PNES in as many as $20-30 \%{ }^{20,64,75}$ as well as chronic pain ${ }^{39}$. Benbadis $^{76}$ found a relationship between PNES and chronic pain or fibromyalgia.

Antiepileptic drug toxicity may increase the frequency or cause dramatic changes in the pattern of $\mathrm{PNES}^{1}$, which is a finding of particular importance in the light of the observed diagnostic delay in these patients. The effect of antiepileptics is in line with the observation that PNES sometimes occur after anaesthesia. A possible explanation for this relationship is that by inducing a state of altered awareness, an anaesthetic agent can initiate dissociative episodes in vulnerable personalities ${ }^{28}$.

The previously mentioned factors represent a heterogeneous group and each may have a differential impact in the causation, development and prolongation of PNES. Not all factors have a similar impact. Sexual abuse may be an example of a psychogenic factor, an underlying cause for PNES, whereas dissociation may be the actual psychological mechanism that shapes or modulates the seizures. Symptom modelling may simply be a factor that explains why the symptoms take the form of an epileptic seizure and not that of a tremor or movement disorder. Drug toxicity may not cause PNES but lower the threshold for PNES. In line with this, Galimberti et al. ${ }^{17}$ suggest that one factor is not always sufficient to develop PNES. In their opinion at least two aspects of a proposed three-factor process must be active to develop PNES, i.e. the presence of a psychopathological disorder and the influence of a 'general trigger mechanism' which leads to increased tendency towards somatisation ${ }^{8,51,63}$. Also Prigatano et al. ${ }^{30}$ postulate a two-factor model, based on the fact that many patients with PNES have neuropsychological deficits: one factor is an emotional mechanism such as a higher dissociation tendency in response to experiencing irresolvable situations that they cannot manage as adults; the second factor may be greater vulnerability of the brain for not tolerating conflictual situations. This interaction may well produce some underlying neurophysiological disturbance that disrupts sensorimotor function or consciousness, see also ${ }^{63,77}$. Reuber and Elger ${ }^{5}$ suggest a model with interacting predisposing, precipitating and perpetuating factors based on other models for psychosomatic disorders.

Based on the above factors we propose a model here, with 5 different layers or levels:

Level 1. Psychological etiology the factors that are involved in the causation of PNES, such as sexual abuse or other traumatic experiences.

Level 2. Vulnerability refers to factors that predispose a person to develop psychosomatic symptoms, such as PNES. Examples are personality factors, gender, neuropsychological impairments and age. Many authors have pointed to the specific vulnerability of patients with PNES both in terms of the emotional 'make-up' and their neuropsychological functioning. Also possible organic factors may play a role here. 
Level 3. Shaping factors can specifically shape the symptoms in the direction or form of 'seizures' (in contrast to for example movement disorders or 'headache-like symptoms'). A shaping factor may be a relative with epileptic seizures (symptom modelling) or having epilepsy in the past.

Level 4. Triggering factors create circumstances or situations that provoke PNES such as factors that refer to first gain. Also psychological mechanisms that transfer an emotional state into a seizure can be part of these triggering factors, such as dissociation and somatisation. Such factors explain why seizures occur on a specific day, or in a cluster or why there is a period of remission. This contrasts PNES from conversion states that more or less have a permanent presentation.

Level 5. Prolongation factors. The previous factors are specifically important in the development of PNES. Prolongation factors are important in explaining why the seizures persist and PNES may become a chronic disorder. These factors profile its frequency and its resistance against therapy. Such modulating factors are, e.g. the coping strategy of the patient and secondary gain aspects.

Levels
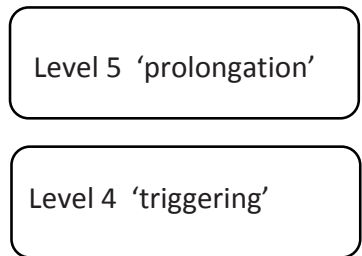

\section{Level 3 'shaping'}

Level 2 'vulnerability'

Level 1 'psychological etiology'

\section{Description}

Factors that explain why PNES persist such as coping factors

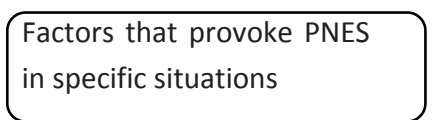

Factors that shape the symptoms into seizures

Emotional 'make-up'; organic \& neuropsychological impairments

Psychogenic causation such as traumatic experiences

\section{Processes}

Provocation of PNES

Development

of PNES

Figure 3.1 Model of psychological factors involved in PNES.

Figure 3.1. describes the assumed relationship between such factors. This model is not conclusive as some factors can interact at several levels of the model. Coping strategies may be involved in the causation of PNES and may have a role in the 
50 Chapter 3

vulnerability, whereas family factors may contribute to the prolongation of seizures and not only in the development. This model resembles other models used to explain somatoform disorders.

A comparable approach is seen in some studies that have attempted to distinguish subtypes of PNES, based on some of the previously mentioned factors. An interesting approach of the relationship between PNES and personality disorders is presented by Cragar et al. ${ }^{10}$. PNES subtypes have been described on dimensions of psychopathology as measured by the MMPI-2. Three personality clusters emerged. The authors offer tentative descriptions of the clusters: (1) 'depressed neurotics'; (2) 'somatic defenders'; (3) 'activated neurotics'. Clusters 1 and 3 also differ significantly on neurocognitive testing, with cluster 1 patients scoring lower than cluster 3 in memory functioning, while cluster 2 individuals show generally average cognition across domains. Reuber and House ${ }^{71}$ distinguish three groups, based on psychiatric comorbidity (present in $70 \%$ of the PNES patients in their study): (a) disorders of mooddepression, anxiety, panic and PTSD; (b) somatisation and abnormal illness behaviour; and (c) borderline personality.

\section{Treatment/intervention}

Several aspects of treatment and intervention are commonly reported.

\section{a) Explanation}

It is often emphasized that this is the necessary first step of intervention ${ }^{23,42,77-79}$. Important is that the diagnosis of PNES is communicated to the patient in a nonaccusative, open way ${ }^{80}$. Betts and Boden ${ }^{21}$ suggest using the term 'emotional attack' in the communication with the patient. A recent international workshop proposed to use the term 'functional seizure' ${ }^{42}$. Different authors mention different kinds of protocols for this phase ${ }^{21,81}$. Reuber and Elger ${ }^{5}$ report that PNES can stop with an explanation of the problem and no further therapy. This is also demonstrated in the study by Farias et al. ${ }^{79}$. While communicating with the patient, it is imperative to realize that PNES often result from a mismatch of traumatic experience and inability to cope, so simply telling patients that they do not have epilepsy may traumatize them further, especially when they are then abandoned to their fate ${ }^{5}$. In those cases, presenting the diagnosis and its nonorganic etiology may have led some patients to replace PNES with new confounding symptoms or symptom substitution ${ }^{82}$. Patients can understand the concept of emotions/stress causing involuntary physical reactions and that such reactions can be 'pathological' ${ }^{5}$. On the other hand, Alper ${ }^{6}$ warns for an early emphasis on psychogenic factors. In his experience, it is far better that the patient with PNES is being told they do not have epilepsy by the neurologist than to be informed of psychogenesis by the psychiatrist at this stage. Contrary to some reports it has been shown that outcome is better in patients with PNES who believe that they have PNES rather than epilepsy ${ }^{82}$. 


\section{b) Additional treatment}

Some patients will need a period of additional treatment that has to vary from patient to patient, based on the underlying psychological mechanisms that have triggered PNES $^{6,21,77}$. Only very few studies have examined the management of PNES. Inspiration has to come from studies looking at similar disorders ${ }^{5}$. Possibilities mentioned in literature are:

- Procedures of behaviour therapy or operant conditioning: the primary focus is attempting to prevent 'rewarding' of seizure activity by ignoring it and deliberately rewarding non-seizure activity by verbal praise and encouragement. The essential principle is to achieve extinction of the PNES as a conditioned response to secondary gain. Behavioural therapy uses progressive relaxation, systematic desensitization, exposure plus response prevention to modify anxiety and allow more adaptive responses ${ }^{44}$. A specific form of behaviour therapy is 'cognitive behaviour therapy' that is aimed at changing dysfunctional thought processes. Behaviour modification may be particularly useful in patients where the production of PNES has been reinforced inadvertently as a means of engaging the attention of others or to evade unwanted activities ${ }^{69}$. The techniques are particularly suited to the management of patients with neuropsychological impairment, psychotic levels of ego disorganization or severe personality disorders ${ }^{6,9,21,69}$. A recent open pilot study $^{83}$ of cognitive behavioural therapy for PNES found that participants had a significant reduction in PNES episode frequency and reported improved psychosocial functioning following 12 sessions of treatment.

Also special forms of (cognitive behavioural) therapy are mentioned in literature.

- Formal, intensive anxiety or anger management training, aimed at both reducing general tension and also specifically at helping patients to recognize seizure onset and immediately employing relaxation techniques to try to stop it. Prigatano et al. ${ }^{30}$ hypothesize that if PNES are precipitated by expressions of anger or other intolerable emotions, psychological treatment intended to enhance the awareness of unexpressed negative emotions and to confront ongoing stressors should decrease the frequency of PNES.

- Formal abreaction (mostly hypnotic abreaction) to try to discover how the patients feel during a seizure ${ }^{21}$.

- Formal individual psychotherapy ${ }^{26,65}$. There are different forms of psychotherapy, ranging from cognitive behavioural therapy to more supportive, practical forms to psychodynamic forms of psychotherapy, depending on the underlying problem and capacities of the patients ${ }^{14,21,70,82}$ (see also overview in ${ }^{77}$ ). LaFrance and Devinsky ${ }^{14}$ call this 'diagnosis-directed psychotherapy'.

Reuber and Elger ${ }^{5}$ claim that psychotherapy aims at modulating temperamental extremes, to help patients recognize early signs of crisis, or to disrupt secondary escalation. It may also be directed at the identification of stressors and the 
presentation of alternative ways of addressing problems in the social environment which are interacting with personal vulnerability. Also psychotherapy may focus on the original negative event or trauma believed to have precipitated the seizures ${ }^{11}$. Barry and Sanborn ${ }^{37}$ refer to the concept of language dysfunction allowing the patient to learn to express distress verbally and to eventually give up somatic preoccupations.

- Some patients benefit from group (psycho)therapy ${ }^{6,41,44,84}$. Prigatano et al. ${ }^{30}$ report that because many patients are emotionally or socially isolated many appreciated having a group experience simply because they wanted to know that they were not alone with their problems. Other advantages are summarized by LaFrance and Barry ${ }^{44}$, including explanation, possibly with the use of psychoeducation, support network building, decreasing social isolation, as well as allowing direct experiences witnessing NES and identifying possible causation.

- Family therapy (including couples therapy) ${ }^{6,21,44,82}$ : the family needs to cope with their anxiety about the seizures and learn not to reinforce them. Also in children family stressors are an important target for treatment ${ }^{37}$.

- Medication (tranquillizers), for a few patients who have PNES at night, medication can be used to prevent the patient waking up during the night for a few weeks ${ }^{21,71}$. Alper ${ }^{6}$ emphasizes that pharmacotherapy should be especially considered when there is a relation with panic disorder, major mood disorder, ADD or psychoses as these disorders have relatively specific pharmacotherapeutic approaches. LaFrance and Barry ${ }^{44}$ (see also ${ }^{14}$ ) suggest that pharmacotherapy for psychiatric comorbidities of PNES with a selective serotonin reuptake inhibitor (SSRI) or related compounds may be useful. As yet no acute pharmacological treatment has been developed except for stopping seizures with excessive sedation and paralytic agents used in 'pseudo status'. The pharmacotherapy of the dissociative disorders or of somatisation disorder is less well-established.

- For very chronic somatisers 'case-management' may be more appropriate ${ }^{71}$. The primary aim is then more limited, i.e. reducing emergency admissions, unnecessary investigations, and treatment ${ }^{5}$. Often the general practitioner has to be involved in such management ${ }^{85}$.

Although variants of cognitive (behavioural) therapy currently form the preferred type of treatment for most patients, the exact choice of treatment should be based on differences in e.g. coping style, anger control style, attitude style and defence style ${ }^{9,10}$. Ettinger et al. ${ }^{82}$ used for example an eclectic approach with elements of the above. Rusch et al. ${ }^{86}$ found that most of the patients benefited from exposure therapy, which is not surprising, given the considerable avoidance exhibited by these patients. Reuber and $E$ Elger ${ }^{5}$ emphasize that if the underlying etiology is an axis I disorder, such as depression, patients may respond to psychological or pharmacological treatments. If, on the other hand patients show evidence of maladaptive personality, chronic somatisation, or dissociation tendencies treatment may more realistically aim at 
behaviour modification rather than cure. Some patients may actually benefit from the treatment of their psychiatric comorbidity, such as depression. The experience is that at least 2 years of outpatient treatment is needed ${ }^{41}$. Reuber et al. ${ }^{53}$ emphasize that much of the vulnerability associated with personality pathology in patients with PNES have implications for psychotherapeutic treatment: efforts should focus on change of individual adaptation and coping processes rather than on basic tendencies in personality, which are less likely to change.

Betts and Boden ${ }^{21}$ report that for some patients (particularly post-traumatic or symbolic attacks) treatment in the community from the start is preferable and it may be important not to admit them to hospital. Buchanan and Snars ${ }^{70}$ confirm this approach: taking into account the frequency of domestic stresses in the etiology of PNES, it is not surprising that relapse should be frequent after hospital discharge. Moreover Müller et al. ${ }^{35}$, report that the observed tendency to refer patients with PNES to a centre of excellence too late (there is an average delay between the onset of PNES and diagnosis of 7 years) is an important obstacle for treatment; most of these patients will have had long periods in which they were treated with antiepileptic drugs for 'refractory epilepsy' which complicates their acceptance of the seizures as non-epileptic ${ }^{87}$.

It is also important to note that treatment can be focused on one level of the underlying psychogenic etiology, disregarding more fundamental problems when these can not be changed. For example, not all patients with trauma and abuse histories did require direct intervention for abuse or trauma memories to achieve cessation of their seizures ${ }^{38,86}$.

There is little literature on the efficacy of treatment strategies for PNES and no standardized treatment protocols for PNES exist ${ }^{9,10}$. Ettinger et al. ${ }^{82}$ summarise the methodological problems in most studies. Some of these studies were limited by small sample size, inclusion of patients with both PNES and epileptic seizures, reliance on methods other than video-EEG to make the PNES diagnosis and marked variability in the follow-up durations. Literature only mentions three studies with a randomized or quasi-randomized design which in fact do not allow definite conclusions ${ }^{18,44}$. In a noncontrolled study, Buchanan and Snars ${ }^{70}$, report successful outcomes in $50 \%$ of the patients, largely by confronting them with the diagnosis of PNES, $30 \%$ with formal psychotherapy and a similar number with ongoing support. Szaflarski et al. ${ }^{32}$ summarise the results of many studies and case reports and conclude that appropriate diagnosis and management of PNES can lead to remission of PNES in $19-52 \%{ }^{88,89}$, to improvement in $75-95 \%$ of the patients and decrease of health care utilization by $69-97 \%$. An important factor is mentioned by Sirven and Glosser ${ }^{69}$ : simply using the retrospectively estimated seizure frequency is not likely to produce useful data since the behaviour is plastic and might simply shift to another somatic complaint. Relevant outcome measures might include: health related quality of life indices, employment status, health care utilization rates, physical morbidity and mortality figures ${ }^{56}$. A relationship between seizure outcome and 'quality of life 
54 Chapter 3

measures' have been reported. The main finding is that a complete cessation of PNES is required to demonstrate a significantly higher QOL. Neither the rate nor the interval change in the rate of PNES following diagnosis was proportional to QOL indices. This suggests that the goal in treatment of NES should be full remission of PNES rather than a reduction in seizure frequency ${ }^{56}$.

A recent multidisciplinary, international workshop assessed the state of affairs on this field and laid the groundwork to fill the treatment void ${ }^{42}$. They recommend a PNES treatment study that would have 3 arms: a neurological follow-up control group, a cognitive-behavioural therapy (CBT) intervention group, and a psychopharmacological treatment group. Outcomes would include both measures of seizure occurrence (seizure frequency, but also seizure severity), measures assessing aspects of psychological etiology, but also practical measures for social outcome, such as employment.

In the case of coexistence of PNES and epileptic seizures in the same patient, it is particularly important to determine whether patients require adaptation of their AEDtreatment. In these patients, it is important that they learn to differentiate between the two types of seizures which make the self reports about seizure frequency more reliable.

\section{Prognosis}

Very few reviews have dealt with the prognosis of PNES once the diagnosis had been made. Therefore, our knowledge of prognosis remains sketchy ${ }^{21,71}$. Previous outcome studies described only small samples with 50 patients or less, had less than 2-year follow-up, focused on the persistence of PNES rather than wider psychosocial criteria or assessed no or few prognostic factors, although all investigators agree that outcome is variable ${ }^{52}$. Iriarte et al. ${ }^{9}$ report that in general $1 / 3 \mathrm{rd}$ of the patients will become seizure free after diagnosis and $50-70 \%$ will have improvement in seizure frequency. There are, however, no controlled studies of long-term outcome of PNES patients ${ }^{6}$. Reuber and House ${ }^{71}$ claim that a quarter of the patients become chronic. Ettinger et al. ${ }^{82}$ report a mean duration of PNES of 7.79 years with a range of 1-38 years. Betts and Boden ${ }^{21}$ report that although the immediate outcome of treatment measures will be reasonably good (see also ${ }^{90}$ ), at the 2-year follow-up many patients had seizure relapse. Especially with treatment in the clinic, this can be misleading. In the study by Krumholz and Niedermeyer ${ }^{1} 56 \%$ of the 34 patients were regarded as having poor outcome at 2-year follow-up, with very similar results for the 5-year follow-up period. In the studies of Farias et al. ${ }^{79}$ and $\mathrm{O}^{\prime}$ Sullivan et al. ${ }^{85}$ almost all patients had an initial good response to the diagnosis of PNES, but at follow up at 18 months about $80 \%$ of the patients had seizure relapse ${ }^{79,85}$.

Reuber et al. $^{52}$, report that patients admitted to epilepsy centres have a poor longterm prognosis. After a mean of 11 years after seizure onset and 4 years after diagnosis, two-thirds of the patients continued to have seizures and more than half 
were dependent on social security. On the contrary, Bodde et al. ${ }^{91}$ report a more favourable prognosis after diagnosis in an epilepsy centre both in terms of seizure frequency and psychological outcome. Such differences are probably caused by differences in study populations and type of diagnostic procedures. Buchanan and Snars ${ }^{70}$ distinguish an 'acute' from a 'chronic' group: $76 \%$ of the patients in their study showed improvement of seizure frequency and, on follow up, $80 \%$ of the acute group and $28 \%$ of the chronic group became seizure free. Wyllie et al. ${ }^{68}$ showed substantially better remission rates for children and adolescents of 73,75 and $81 \%$ after 1, 2 and 3 years follow-up.

Prognosis is different, dependent on the underlying psychological disorder. For some patients, an empathic confrontation with the fact that the seizures are non-epileptic may be enough to stop them ${ }^{91}$. Others only resolve with intensive cognitive, behavioural and anxiety management. Those which are probably replays of previous trauma require very intensive and prolonged therapy. In general it is observed that differences in psychopathology may have important implications for prognosis ${ }^{10}$. Iriarte et al. ${ }^{9}$ and Reuber and Elger ${ }^{5}$, summarise the characteristics of the patients with favourable prognoses: no or mildly severe psychiatric history ${ }^{10}$, short history of PNES/early diagnosis ${ }^{41,70,92}$, identifiable acute psychological trauma preceding the onset of PNES, living independently, absence of concomitant epilepsy ${ }^{93}$ (although this is debated ${ }^{52}$ ), a normal $I Q$, higher socio-economic class, less dramatic seizures (no positive motor features, no ictal incontinence or tongue biting, no PNES status or admission to intensive care), younger age ${ }^{51,68,94}$, the absence of a past history of violence $^{6}$, no ongoing use of $\mathrm{AED}^{\prime} \mathrm{s}^{1,87}$, and being female not male ${ }^{39,59,77}$. Outcome appeared to be associated with measures of personality traits. Better outcome is associated with lower scores of the higher order personality dimensions 'inhibitedness', 'emotional dysregulation' and 'compulsivity's2. Especially 'inhibitedness' is an important predictor for outcome and thus represents an important factor for prognosis. High scores exhibit reluctant self-disclosure and restricted affective expression of anger and of positive sentiments.

PNES often recur once the patient returns to the community, since he/she is often returning to the very stresses that led to PNES in the first place; relapse particularly of post- traumatic or symbolic PNES usually occurs ${ }^{52}$.

Outcome is nearly always discussed in terms of reduction of seizure frequency. Reuber and House ${ }^{71}$ emphasize that other outcomes (such as employment status) may be of greater importance for the patient. In that respect it is important that in some countries and under some conditions patients with PNES are not allowed to keep their driving license which may seriously restrict their occupational possibilities. Sirven and Glosser ${ }^{69}$ found that the longer the PNES continue, the lower the probability that psychosocial morbidity will improve even if the correct diagnosis is later made. Betts and Boden ${ }^{21}$ report that in a substantial number of patients, it seems difficult to completely remove the label of epilepsy. In many patients family pressure appears to lead to re-introduction of anticonvulsant medication. Sirven and 
56 Chapter 3

Glosser $^{69}$ demonstrated that if PNES even temporarily decline as a placebo response to AEDs, the belief in the diagnosis 'epilepsy' can be so strong that it can dissuade subsequent physicians from reconsidering the case or discontinuing therapy. Their conclusion is that it may take more courage to stop pharmacotherapy in such patients than to start it.

\section{Discussion}

In this systematic review we identified 93 papers through the period 1980 up till 2005 (26 years), of which 65 were actual studies. The quality of most research is limited, due to serious methodological limitations. Nonetheless, they represent some key data on treatment and etiology of PNES.

Although there are several terms used, in this review the non-judgemental term psychogenic non-epileptic seizures (PNES) is the preferred term. In a first phase PNES refer to not having epileptic seizures, but in a second phase it seems important to search for positive evidence for psychogenic factors that may have caused the seizures $^{95}$.

A wide range of psychogenic factors have been identified that may underlie the occurrence of PNES in individual patients ranging from a history of sexual abuse to personality disorders. Such factors do not have a similar impact; consequently some studies propose a 'multifactor approach': i.e. one factor is not always sufficient to develop PNES. In most patients several of such factors would interact to develop PNES in a patient. Examples are the presence of a psychopathological disorder and the influence of a "general trigger mechanism" or an emotional mechanism such as a higher dissociation tendency or a greater vulnerability of the brain for not tolerating conflictual situations. Based on the literature a model is proposed with five different layers: psychological etiology, vulnerability, shaping factors, trigger and prolongation factors. In this model the paroxysmal nature of the seizures is integrated, which is a specific aspect of PNES in comparison to other psychosomatic disorders. Possibly such a model can help in providing options for therapy, explaining therapy results, i.e. prognosis.

This model assumes that PNES is a unique symptom or disorder. Others such as Quigg et al. ${ }^{56}$ state that PNES should not be considered a disorder in itself, but a symptom of an underlying psychological or psychiatric disorder or recent trauma. Therefore PNES can also be considered a symptom very similar to somatoform disorders including somatisation and conversion.

In line with the heterogeneity of factors involved, a plethora of psychological treatment strategies is available ranging from family therapy to hypnosis. Till now, no accepted protocol for the treatment of PNES exists and no randomized clinical trials have been carried out. There is consensus that treatment should be focused on the psychogenic factors that have triggered the PNES in an individual patient, taking into 
account also the characteristics of the personality 'make-up', i.e. coping style, anger control style, attitude style and defence style. Also outcome can be measured in terms of seizure occurrence, but other measures might include quality of life, employment status and health care utilization. Both diagnosis and treatment seem to profit from a multidisciplinary approach, although not always simultaneously ${ }^{9,42,69}$.

Again, if PNES is not seen as a unique symptom but simply as one of the many possible symptoms of a somatoform disorder, then the question must be raised whether we should treat PNES as a separate symptom or only focus on the underlying psychogenic factors.

Prognosis is unclear but studies consistently report that $1 / 3^{\text {rd }}$ to $1 / 4^{\text {th }}$ of the patients become chronic. Characteristics of the patients with good outcome are: no or mildly severe psychiatric history, short history of PNES, identifiable acute psychological trauma preceding onset PNES, living independently and the absence of concomitant epilepsy. More attention is needed for other outcomes such as employment status that may be of greater importance for the patient. In a substantial number of patients it seems difficult to completely remove the label of epilepsy. In these cases it seems imperative that the patient can recognize the differences between PNES and epileptic seizures. In many patients family pressure appears to lead to re-introduction of anticonvulsant medication. Finally more systematic treatment -effect studies are needed and they probably benefit from a theoretical frame-work about the etiology of PNES. A possible first step might be testing validity of the proposed model for different PNES patients. 
58 Chapter 3

\section{References}

1. Krumholz A, Niedermeyer E. Psychogenic seizures: a clinical study with follow-up data. Neurology 1983;33:498-502.

2. Leis AA, Ross MA, Summers AK. Psychogenic seizures: Ictal characteristics and diagnostic pitfalls. Neurology 1992;42:95-9.

3. Marquez AV, Farias ST, Apperson M, Koopmans S, Jorgensen J, Shatzel A, Alsaadi TM. Psychogenic non-epileptic seizures are associated with an increased risk of obesity. Epilepsy Behav 2004;5:88-93.

4. Sigurdardottir KR, Olafsson E. Incidence of psychogenic seizures in adults: a population-based study in Iceland. Epilepsia 1998;39:749-52.

5. Reuber M, Elger CE. Psychogenic nonepileptic seizures: review and update. Epilepsy Behav 2003; 4: 205-16.

6. Alper K. Nonepileptic seizures. Neurologic Clinics (Epilepsy II: special issues) 1994 (12): 153-73.

7. Witgert ME, Wheless, JW, Breier JI Frequency of panic symptoms in psychogenic nonepileptic seizures. Epilepsy Behav 2005;6:174-8.

8. Benbadis SR, Agrawal V, Tatum WO. How many patients with psychogenic non-epileptic seizures also have epilepsy? Neurology 2001;57:915-7.

9. Iriarte J, Parra J, Urrestarazu E, Kuyk J. Controversies in the diagnosis and management of psychogenic pseudoseizures. Epilepsy Behav 2003;4:354-9.

10. Cragar DE, Berry DTR, Schmitt FA, Fakhoury TA. Cluster analysis of normal personality traits in patients with psychogenic nonepileptic seizures. Epilepsy Behav 2005;6:593-600.

11. Moore PM, Baker GA. Non-epileptic attack disorder: a psychological perspective. Seizure 1997; 6: 429-34.

12. Abubakr A, Kablinger A, Caldito G. Psychogenic seizures: clinical features and psychological analysis. Epilepsy Behav 2003;4:241-5.

13. Dekkers W, Van Domburg P. The role of doctor and patiënt in the construction of the pseudoepileptic attack disorder. Med Health Care Phil 2000;3:29-38.

14. LaFrance WC, Devinsky O. The treatment of nonepileptic seizures: historical perspectives and future directions. Epilepsia 2004;45:15-21.

15. Bowman ES, Markand ON. Psychodynamics and psychiatric diagnoses of pseudoseizure subjects. Am J Psychiatry 1996;153:57-63.

16. Arnold LM, Privitera MD. Psychopathology and trauma in epileptic and psychogenic seizure patients. Psychosomatics 1996;37(5):438-43.

17. Galimberti CA, Ratti MT, Murelli R, Marchioni E, Manni R, Tartara A. Patients with psychogenic nonepileptic seizures, alone or epilepsy-associated, share a psychological profile distinct from that of epilepsy patients. J Neurol 2003; 250: 338-46.

18. Baker GA, Brooks JL, Goodfellow L, Bodde N, Aldenkamp A. Treatments for non-epileptic attack disorder. Cochrane Database Syst Rev 2007; (January (1)):CD006370.

19. Scull DA. Pseudoseizures or non-epileptic seizures (NES); 15 synonyms. J. Neurol Neurosurg Psychiatry 1997;62:200

20. Krumholz A. Nonepileptic seizures: diagnosis and management. Neurology 1999;53(Suppl 2): S76-S83.

21. Betts T, Boden S. Diagnosis, management and prognosis of a group of 128 patients with non-epileptic attack disorder. Part I. Seizure 1992;1:19-26.

22. Francis P, Baker GA. Non-epileptic attack disorder (NEAD): a comprehensive review. Seizure 1999;8:53-61.

23. Chabolla DR, Krahn LE, So EL, Rummans TA. Psychogenic non-epileptic seizures; Mayo symposium on epilepsy part II. Mayo Found Med Educ Res 1996;71:493-500.

24. Fleisher W, Staley D, Krawetz P, Pillay N, Arnett JL, Maher J. Comparative study of trauma-related phenomena in subjects with pseudoseizures and subjects with epilepsy. Am J Psychiatry 2002;159:660-3.

25. Massey EW, Riley TL. Pseudoseizures: Recognition and treatment. Psychosomatics 1980;21:987-97.

26. Riggio, S. Psychogenic seizures. Emerg Med Clin N Am 1994;12:1001-12.

27. Binder LM, Salinsky MC, Smith SP. Psychological correlates of psychogenic seizures. J Clin Exp Neuropsychol 1994;16:524-30. 
28. Lichter I, Goldstein LH, Toone BK, Mellers JDC. Nonepileptic seizures following general anesthetics: a report of five cases. Epilepsy Behav 2004;5:1005-13.

29. Trimble M. Pseudo problems, pseudoseizures. Br J Hosp Med 1983; 326-33.

30. Prigatano GP, Stonnington CM, Fisher RS. Psychological factors in the genesis and management of nonepileptic seizures: clinical observations. Epilepsy Behav 2002;3:343-9.

31. Kuyk J, Leijten F, Meinardi H, Spinhoven Ph, Van Dyck R. The diagnosis of psychogenic non-epileptic seizures: a review. Seizure 1997;6:243-53.

32. Szaflarski JP, Hughes C, Szaflarski M, Ficker DM, Cahill WT, Li M, Privitera MD. Quality of life in psychogenic nonepileptic seizures. Epilepsia 2003;44:236-42.

33. Lesser, RP. Psychogenic seizures. Neurology 1996;46:1499-507.

34. Lobello K, Morgenlander JC, Radtke RA, Bushnell CD. Video/EEG monitoring in the evaluation of paroxysmal behavioral events: Duration, effectiveness, and limitations. Epilepsy Behav 2006;8:261-6.

35. Müller T, Merschhemke M, Dehnicke C, Sanders M, Meencke HJ. Improving diagnostic procedure and treatment in patients with non-epileptic seizures (NES). Seizure 2002;11:85-9.

36. Kuyk J, Spinhoven P, Van Emde Boas W, Van Dyck R. Dissociation in temporal lobe epilepsy and pseudo-epileptic seizure patients. J Nerv Ment Dis 1999;12:720-31.

37. Barry JJ, Sanborn K. Etiology, diagnosis and treatment of nonepileptic seizures. Curr Neurol Neurosci Rep 2001;1:381-9.

38. Salmon P, Al-Marzooqi SM, Baker G, Reilly J Childhood family dysfunction and associated abuse in patients with nonepileptic seizures: towards a causal model. Psychosom Med 2003;65:695-700.

39. Dworetzky BA, Strahonja-Packard A, Shanahan CW, Paz J, Schauble B, Bromfield EB. Characteristics of male veterans with psychogenic nonepileptic seizures. Epilepsia 2005;46:1418-22.

40. Fiszman A, Alves-Leon SV, Nunes RG, D'Andrea I, Figueira I. Traumatic events and posttraumatic stress disorder in patients with psychogenic nonepileptic seizures: a critical review. Epilepsy Behav 2004;5:818-25.

41. Betts T, Boden S. Diagnosis, management and prognosis of a group of 128 correlates of intractable pseudoseizures. Part II. Previous childhood sexual abuse in the aetiology of these disorders. Seizure 1992;1:27-32.

42. LaFrance WC, Alper K, Babcock D, Barry JJ, Benbadis S, Caplan R, Gates J, Jacobs M, Kanner A, Martin R, Rundhaugen L, Stewart R, Vert C. Nonepileptic seizures treatment workshop summary. Epilepsy Behavr 2006;8:451-61.

43. Ramchandani D, Schindler B. Evaluation of pseudoseizures: a psychiatric perspective. Psychosomatics 1993;34:70-9.

44. LaFrance WC, Barry JJ. Update on treatments of psychological nonepileptic seizures. Epilepsy Behav 2005;7:364-74.

45. Tojek TM, Lumley M, Barkley GB, Mahr G, Thomas A. Stress and other psychosocial characteristics of patients with psychogenic nonepileptic seizures. Psychosomatics 2000;41:221-6.

46. Drake ME, Pakalnis A, Phillips BB. Neuropsychological and psychiatric correlates of intractable pseudoseizures. Seizure 1992;1:11-3.

47. Owczarek K, Jedrzejczak J. Patients with coexistent psychogenic pseudoepileptic and epileptic seizures: a psychological profile. Seizure 2001;10:566-9.

48. Alper K, Devinsky O, Perrine, K, Luciano D, Vazquez B, Pacia S, Rhee E. Dissociation in epilepsy and conversion nonepileptic seizures. Epilepsia 1997;38(9):991-7.

49. Reuber M, House AO, Pukrop R, Bauer J, Elger CE. Somatization, dissociation and general psychopathology in patients with psychogenic non-epileptic seizures. Epilepsy Res 2003;57:159-67.

50. Bewley J, Murphy PN, Mallows J, Baker GA. Does alexithymia differentiate between patients with nonepileptic seizures, patients with epilepsy, and nonpatient controls? Epilepsy Behav 2005;7:430-37.

51. Aldenkamp AP, Mulder OG. Behavioural Mechanisms involved in Pseudo-epileptic Seizures: a comparison between patients with epileptic seizures and patients with pseudo-epileptic seizures. Seizure 1997;6:275-82.

52. Reuber M, Pukrop R, Bauer J, Helmstaedter C, Tessendorf N, Elger CE. Outcome in psychogenic nonepileptic seizures: 1 to 10-year follow-up in 164 patients. Ann of Neurol 2003;53:305-11.

53. Reuber M, Pukrop R, Bauer J, Derfuss R, Elger CE. Multidimensional assessment of personality in patients with psychogenic non-epileptic seizures. J Neurol Neurosurg Psychiatry 2004;75:743-8. 
60 Chapter 3

54. Prueter C, Schultz-Venrath U, Rimpau W. Dissociative and associated psychopathological symptoms in patients with epilepsy, pseudoseizures, and both seizure forms. Epilepsia 2002;43:188-92.

55. Mökleby K, Blomhoff S, Malt UF, Dahlström A, Tauböll E, Gjerstad L. Psychiatric comorbidity and hostility in patients with psychogenic nonepileptic seizures compared with somatoform disorders and healthy controls. Epilepsia 2002;43:193-8.

56. Quigg M, Armstrong RF, Farace E, Fountain NB. Quality of life outcome is associated with cessation rather than reduction of psychogenic nonepileptic seizures. Epilepsy Behav 2002;3:455-9.

57. Ramani SV, Quesney LF, Olson D, Gumnit RJ. Diagnosis of hysterical seizures in epileptic patients. Am J Psychiatry 1980;137:705-9.

58. Stewart RS, Lovitt R, Malcolm Stewart R. Are Hysterical Seizures More than Hysteria? A Research Diagnostic Criteria, DSM-III, and Psychometric Analysis. Am J Psychiatry 1982;139:926-9.

59. Bowman ES. Nonepileptic seizures: psychiatric framework, treatment and outcome. Neurology 1999;53 (Suppl 2):S84-S8

60. Thompson PM, Batzel LW, Wilkus RJ. Millon clinical multiaxial inventory assessments of patients manifesting either psychogenic or epileptic seizures. J Epilepsy 1992;5:226-30.

61. Owczarek, K. Somatisation indexes as differential factors in psychogenic pseudoepileptic and epileptic seizures. Seizure 2003;12:178-81.

62. Owczarek, K. Anxiety as a differential factor in epileptic versus psychogenic pseudoepileptic seizures. Epilepsy Res 2003;52:227-32.

63. Vanderzant CW, Giordano B, Berent S, Dreifuss FE, Sackellares JS. Personality of patients with pseudoseizures. Neurology 1986;36:644-8.

64. Lancman ME, Brotherton TA, Asconapé JJ, Penry JK. Psychogenic seizures in adults: a longitudinal analysis. Seizure 1993;2:281-6.

65. Jawad SSM, Jamil N, Clarke EJ, Lewis A, Whitecross S, Richens A. Psychiatric morbidity and psychodynamics of patients with convulsive pseudoseizures. Seizure 1995;4:201-6.

66. Szaflarski JP, Szaflarski M, Hughes C, Ficker DM, Cahill WT, Privitera MD. Psychopathology and quality of life: psychogenic non-epileptic seizures versus epilepsy. Med Sci Monit 2003;9:113-8.

67. Vincentiis S, Valente KD, Thomé-Souza S, Kuczinsky E, Fiore LA, Negrao, N. Risk factors for psychogenic nonepileptic seizures in children and adolescents with epilepsy. Epilepsy Behav 2006;8:294-8.

68. Wyllie E, Friedman D, Lüders H, Morris H, Rothner D, Turnbull J. Outcome of psychogenic seizures in children and adolescents compared with adults. Neurology 1991;41:742-4.

69. Sirven JI, Glosser DS. Psychogenic nonepileptic seizures: theoretic and clinical considerations. Neuropsychiatry Neuropsychol Behav Neurol 1998;11:225-35.

70. Buchanan N, Snars J. Pseudoseizures (non epileptic attack disorder)- clinical management and outcome in 50 patients. Seizure 1993;2:141-6.

71. Reuber M, House AO. Treating patients with psychogenic non-epileptic seizures. Curr Opin Neurol 2002;15:207-11.

72. Rosenbaum M. Psychogenic seizures-why women? Psychosomatics 2000;41:147-9.

73. Fargo JD, Schefft BK, Szaflarski JP, Dulay MF, Testa SM, Privitera MD, Yeh H-S. Accuracy of selfreported neuropsychological functioning in individuals with epileptic of psychogenic nonepileptic seizures. Epilepsy Behav 2004;5:143-50.

74. Reuber M, Fernandez G, Helmstaedter C, Qurishi A, Elger CE. Evidence of brain abnormality in patients with psychogenic nonepileptic seizures. Epilepsy Behav 2002;3:249-54.

75. Barry E, Krumholz A, Bergey GK, Chatha H, Alemayehu S, Grattan L. Nonepileptic posttraumatic seizures. Epilepsia 1998;39(4):427-31.

76. Benbadis SR. A spell in the epilepsy clinic and a history of 'chronic pain' or 'fibromyalgia' independently predict a diagnosis of psychogenic seizures. Epilepsy Behav 2005;6:264-5.

77. Alsaadi TM, Marquez AV. Psychogenic nonepileptic seizures. Am Fam Physician 2005;72:849-56.

78. Betts T. Management of psychogenic and pseudoepileptic seizures. In: Wolf P, editor. Epileptic seizures and syndromes. John Libbey and Company Ltd.;1994:643-50.

79. Farias ST, Thieman C, Alsaadi TM. Psychogenic nonepileptic seizures: acute change in event frequency after presentation of the diagnosis. Epilepsy Behav 2003;4:424-9.

80. Wyllie E, Benbadis SR, Kotagal P. Psychogenic seizures and other nonepileptic paroxysmal events in children. Epilepsy Behav 2002;3:46-50. 
81. Shen W, Bowman E, Markand O. Presenting the diagnosis of pseudoseizures. Neurology 1990;40: 756-9.

82. Ettinger AB, Devinsky O, Weisbrot DM, Ramakrishna RK, Goyal A. A comprehensive profile of clinical, psychiatric, and psychosocial characteristics of patients with psychogenic nonepileptic seizures. Epilepsia 1999;40(9):1292-8.

83. Goldstein LH, Deale AC, Mitchell-O'Malley AJ, Toone BK, Mellers JD. An evaluation of cognitive behavioral therapy as a treatment for dissociative seizures: a pilot study. Cogn Behav Neurol 2004;17:41-9.

84. Zaroff CM, Myers L, Barr WB, Luciano D, Devinsky O. Group psychoeducation as treatment for psychological nonepileptic seizures. Epilepsy Behav 2004;5:587-92.

85. O'Sullivan SS, Sweeney BJ, McNamara B. The opinion of the general practioner toward clinical management of patients with psychogenic nonepileptic seizures. Epilepsy Behav 2006;8:256-60.

86. Rusch MD, Morris GL, Allen L, Lathrop LA. Psychological treatment of nonepileptic events. Epilepsy Behav 2001;2:277-83.

87. Carton S, Thompson PJ, Duncan JS. Non-epileptic seizures: patients' understanding and reaction to the diagnosis and impact on outcome. Seizure 2003;12:287-94.

88. Reuber M, Mitchell AJ, Howlett S, Elger CE Measuring outcome in psychogenic nonepileptic seizures: how relevant is seizure remission? Epilepsia 2005;46:1788-95.

89. Walczak TS, Papacostas S, Williams DT, Scheuer ML, ,Lebowitz N, Notarfrancesco A. Outcome after diagnosis of psychogenic nonepileptic seizures. Epilepsia 1995;36:1131-7.

90. McDade G, Brown SW. Non-epileptic seizures: management and predictive factors of outcome. Seizure 1992;1:7-10.

91. Bodde NMG, Janssen AM, Theuns C, Vanhoutvin JF, Boon PA, Aldenkamp AP. Factors involved in the long-term prognosis of psychogenic nonepileptic seizures. J Psychosom Res 2007; 62:545-51.

92. Lempert T, Schmidt D. Natural history and outcome of psychogenic seizures: a clinical study in 50 patients. J. Neurol 1990;237:35-8.

93. Meierkord H, Will B, Fish D, Shorvon S. The clinical features and prognosis of pseudoseizures diagnosed using video-EEG telemetry. Neurology 1991;41:1643-6.

94. Aldenkamp AP, Mulder OG. Some considerations on diagnosis and treatment of pseudo-epileptic seizures in adolescents. Int J Adolesc Med Health 1989;4:81-90.

95. Bodde NMG, Brooks JL, Baker GA, Boon PAJM, Hendriksen JGM, Aldenkamp AP. Psychogenic nonepileptic seizures-diagnostic issues; a critical review. Clin Neurol Neurosurg 2009; 111:1-9. 
62 


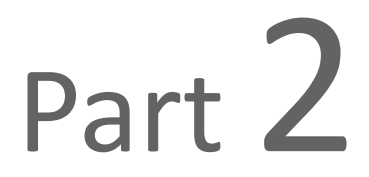

Lessons from current treatment

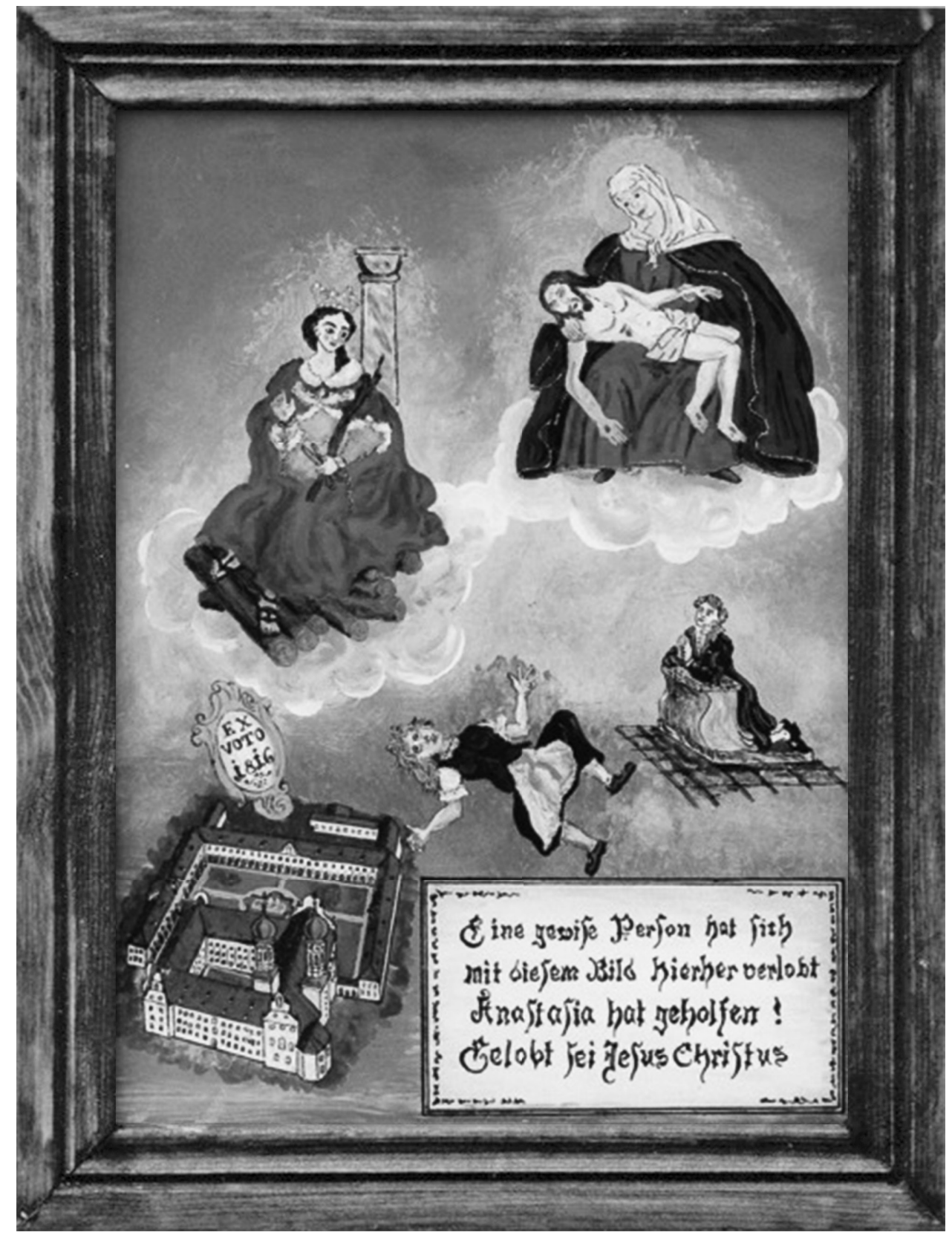


64 


\section{Chapter 4}

Factors involved in the long-term prognosis of psychogenic non-epileptic seizures

NMG Bodde, AMAJ Janssen, C Theuns, J Vanhoutvin, PAJM Boon, AP Aldenkamp

J Psychosom Res 2007;62:545-51 
66 $\mid$ Chapter 4

\section{Abstract}

\section{Introduction}

Information on the long-term effects of psychogenic non-epileptic seizures (PNES) is limited. We therefore reassessed 22 patients 4-6 years after the initial diagnosis of PNES in a tertiary referral epilepsy centre. The diagnosis was confirmed using clinical description and additional electroencephalogram (EEG) investigations in 1998, 1999 and 2000. Patients with epilepsy and PNES as comorbid symptoms were not included. Reassessments were aimed at seizure reduction and possible psychogenic factors.

\section{Methods}

Three psychological tests were used at baseline at the time of diagnosis and repeated at end point. These three tests assessed different "levels" of psychological function [i.e., complaints (The Symptoms Check List Revised), coping strategy (The Dissociation Questionnaire), and personality factors/psychopathology (The Dutch-language short version of the Minnesota Multiphasic Personality Inventory-2)].

\section{Results}

Twenty-two patients were included. Seizure frequency showed statistically significant reduction. At the time of diagnosis, none of the patients was seizure-free or had only yearly seizures, whereas at end point 7 , of 22 patients were completely in remission and 3 patients had only occasional seizures. The number of patients with daily seizures dropped from nine to two. It has not been fully clarified which factors caused this improvement, but the common denominators are that a definitive expert diagnosis in a tertiary centre was made and all possible efforts were made to inform the patient in a respectful manner about this diagnosis.

In addition to seizure reduction, there was improvement on different levels of psychological function, showing reduction in psychological distress, reduction in dissociative features such as amnesia, increase in self-control, reduction in feelings of dissatisfaction and passive avoidant behavior, and a more active attitude towards social contact.

\section{Conclusion}

In the long term, the patients with PNES who were included in our study have more self-control and approach social contact with a more self-confident attitude. This does not necessary reflect a causal relationship with the observed seizure reduction. Nonetheless, it is noteworthy that, post aut propter, the eradication of a symptom (i.e., seizures) with social consequences is followed by or is associated with a more confident social attitude. This opens possibilities for treatment strategies. 


\section{Introduction}

Psychogenic non-epileptic seizures (PNES) are a relatively frequently reported symptom. For example, $7-10 \%$ of patients referred to a specialized epilepsy center in The Netherlands have PNES ${ }^{1}$ and, internationally, estimates of up to $33 \%$ have been mentioned ${ }^{2}$. In theory, the distinction between epileptic seizures and PNES is evident ${ }^{3}$. Epileptic seizures are the clinical manifestation of a sudden abnormal change in brain function, accompanied by excessive electrical discharge of brain cells. PNES are defined as a sudden disruptive change in a person's behavior, which is usually timelimited and resembles or is mistaken for epilepsy but is not accompanied by abnormal paroxysmal discharges on electroencephalogram (EEG) and occurs as a symptom of emotional disturbances, personality factors, or present or historical social circumstances $^{4-6}$. Although diagnosis can be difficult, diagnostic features have been better characterized in recent years. Diagnosing PNES is important because of potential iatrogenic hazards. Patients may be diagnosed as suffering from intractable epilepsies and may be overtreated ${ }^{7}$. There are indications that prognosis in the long term may be worse in such cases ${ }^{8}$. In addition, long periods of uncertainty of the diagnosis may have a negative impact on social development and occupational opportunities $^{9}$, which again may have long-lasting effects. Comparatively little research has been done on long-term prognosis after the diagnosis ${ }^{10-12}$. Validated treatments and controlled trials are lacking ${ }^{13}$. Furthermore, follow-up period is mostly relatively short, varying from 3 months to a year after diagnosis ${ }^{14,15}$.

The definition of PNES is hindered by a diversity of conflicting terminologies, such as hysterical seizures, psychogenic seizures, non-epileptic seizures, and functional seizures $^{16,17}$. In the Diagnostic and Statistical Manual of Mental Disorders, Fourth Edition, PNES is classified as a "Conversion disorder with seizures or convulsions." This variation in terminology represents a variety of models proposed to explain PNES. In fact, theories regarding the causes of these seizures are probably as diverse as the phenomenology of this type of seizure. Using Diagnostic and Statistical Manual of Mental Disorders, Third Edition criteria, Stewart et al. ${ }^{18}$ were able to uncover several forms of psychopathology in patients with PNES, with a clear tendency for the combination of borderline and antisocial personality disorders. A remarkable finding was that hysteria was not a common diagnosis. The synonym "hysterical seizure" for PNES is, therefore, not correct. The variety of theoretical models explaining PNES probably reflects the heterogeneity of the psychogenic etiology of PNES, which can be a symptom of various affective and psychiatric factors ${ }^{19,20}$. As yet, there is no accepted model explaining the psychogenic factors leading to PNES. There are indications that, often, more than one factor or psychogenic mechanism operates in PNES ${ }^{15,21}$.

Some attempts have been made to classify patients with PNES into distinct groups requiring different types of interventions and with different prognosis ${ }^{22}$. For example, persisting seizures are expected to occur in patients with personality disorders ${ }^{8,23}$, whereas, patients who have PNES because of recently experienced extreme stressors 
68 Chapter 4

are considered relatively easy to treat and may, therefore, have PNES only as a temporary symptom ${ }^{24}$. The outcome may, therefore, help us to identify some psychogenic mechanisms. We lack, however, knowledge about the prognosis of PNES, as most studies are cohort studies that only report on the diagnosis but do not provide follow-up data. Long-term outcome may also help us to distinguish between "subtypes" of PNES, as patients with persistent seizures over time may have different psychogenic mechanisms in comparison to patients with full seizure remission.

With regard to outcome, there are different studies suggesting that seizure control alone is not a comprehensive measure of good medical or psychosocial outcome in PNES $^{11,25}$. Several studies have shown that other outcomes, such as employment status $^{26}$, may be of greater importance for patients. A consensus report on PNES treatment emphasized that if an intervention improved seizure control without changing the hypothesized etiology, the validity of the treatment could be called into question $^{13}$.

In this study, we will therefore reassess patients diagnosed with PNES 4-6 years after the initial diagnosis in a tertiary referral epilepsy center. Reassessments will be aimed at seizure frequency and possible psychogenic outcomes.

\section{Methods}

\section{Design}

Patients were consecutively included when:

1. They had a diagnosis of PNES. Patients with epilepsy and PNES as comorbid symptoms were not included.

2. The diagnosis had been confirmed in a tertiary referral epilepsy center using clinical description and additional EEG investigations (such as EEG video telemetry). The type of EEG investigation was based on clinical indications such as patient history and seizure semiology.

3. Diagnosis was made in the period 1998-2000.

4. Normal intelligence was assessed clinically.

5. Outcomes of neurological examination (including EEG data) and psychological assessments were present.

All patients were then reevaluated 4-6 years later. This time interval was chosen to focus on long-term outcomes - thus a period definitely outside the diagnostic phase but without coming into life-phase changes. 


\section{Patients}

In total, 28 patients were selected; 5 patients did not provide informed consent. Thus, in total, 23 patients were included in the study. One patient could not be scheduled for assessments, therefore, 22 patients participated in the study.

\section{Instruments}

Recordings for seizure frequency, using standardized seizure diaries, are based on selfreports and by-proxy reports. The same method was used at baseline and at end point. In our study, seizure remission was defined as full-year remission.

Three personality inventories were used at baseline at the time of diagnosis and repeated at end point. These tests assess different "levels" of psychological function:

1. Level of complaints: The Symptoms Check List Revised (SCL-90-R) is used to assess symptoms (levels) and psychological distress on the global severity index (indicates the overall level of psychological distress) ${ }^{27}$.

2. Level of coping strategy: The Dissociation Questionnaire (DIS-Q) is used. This is a scale based on the Dissociative Experiences Scale ${ }^{28}$, the Perceptual Alteration $\mathrm{Scale}^{29}$, and the Questionnaire of Experiences of Dissociation ${ }^{30}$ adapted from the Dutch language $\mathrm{e}^{31,32}$. This scale was used to analyze dissociative features and has four subscales:

(a) DIS-Q d1: identity confusion and depersonalization

(b) DIS-Q d2: self-control

(3) DIS-Q d3: amnestic and dissociation features

(4) DIS-Q d4: concentration "absorption" of environmental input.

3. Level of personality factors/psychopathology: The Dutch-language short version of the Minnesota Multiphasic Personality Inventory ([MMPI] is used ${ }^{33,34}$. The shortened Dutch version of the MMPI (NVM) contains 83 items, comprising five scales. Each item contains a statement for which the patient decides on appropriateness to one's case. The five NVM scales are as follows.

(a) Negativism (22 items): items referring to passive avoidant behavior, feelings of dissatisfaction and grudge regarding daily life events, and aggressive behavior. Individuals with a high score show a negative, dissatisfied, and hostile attitude toward other people, and tend to react with grumbling and complaining for feelings of discomfort. They often feel tense and behave self-defensively. In persons with a low score, this is not the case. This scale is related to the psychopathic deviate, hypomania, lie, depression, masculinity-feminity, and schizophrenia scales of the MMPI.

(b) Somatization (20 items): items connected with vague physical complaints. Persons with a high score tend to react to psychological stress with physical symptoms. Individuals with a low score do not. This scale is related to the hypochondriasis, hysteria, and depression scales of the MMPI. 
(c) Shyness (15 items): items reflecting feelings of shyness and difficulties in interpersonal contacts. People with a high score indicate that they feel shy often and regard this as a problem. They are reserved, introverted, silent, and less sociable. Persons with a low score do not feel shy and are jovial and talkative. This scale is related to the social introversion, hysteria, and psychopathic deviate scales of the MMPI.

(d) Psychopathology (13 items): items connected with delusional feelings, paranoid thoughts, and bizarre experiences. These are present in persons with a high score. Low and average scores should be considered normal. This scale is related to the paranoia, fake (F), and schizophrenia scales of the MMPI.

(e) Extraversion (13 items): items reflecting an active and energetic attitude toward various social contacts. Persons with a high score are extraverted, and persons with a low score are not. This scale provides no indication for introversion. It is related to the social introversion and depression scales of the MMPI.

\section{Statistical analysis}

Data were included in a data matrix through two independent inclusions. All data were analyzed with SPSS (Version 13). On the first step, frequencies and descriptions were calculated for all clinical and demographical variables. On the second step, a comparison was made (using $t$ test for dependent groups). Finally, linear regression was carried out to find personality characteristics that are predictors of seizure reduction in this group.

\section{Results}

Table 4.1 shows the most important clinical and demographic characteristics of the study sample. The average age of the patient sample is 30.4 years (S.D.=10.7; range, 15-49 years). Age had a normal distribution. The vast majority of patients in the sample were female (86.4\%). Personal situation varied considerably: $31.8 \%$ of patients were living with parents, whereas almost $40.9 \%$ of patients were married or were living together. A smaller part of the sample was divorced and single. Lower secondary school (40.9\%) and secondary school (40.9\%) were the highest educational levels for the majority of patients. The age of seizure onset was below 16 years for about a quarter of patients (23.8\%), and a group of similar size experienced onset during adolescence (16-20 years). Most patients, though (33.3\%) had their first seizure at the ages of $21-30$ years. The rest of the sample (19.1\%) had their first seizure above the age of 30 years. The age at which seizures were diagnosed as PNES was more equally spread and Table 4.1 shows that, in general, there was a $>7$-year delay between seizure onset and time of diagnosis ( 7.2 years). 
Table 4.1 Clinical and demographic characteristics of the study sample of 22 patients with PNES at diagnosis.

\begin{tabular}{|c|c|}
\hline Gender [ $(\%)]$ & \\
\hline Male & $3(13.6)$ \\
\hline Female & $19(86.4)$ \\
\hline Age in years [mean (S.D.)] & $30.4(10.7)$ \\
\hline Demographical characteristics $[n(\%)$ & \\
\hline Living with parents & $7(31.8)$ \\
\hline Single & $1(4.5)$ \\
\hline Married/living together & $9(40.9)$ \\
\hline Divorced and single & $4(18.3)$ \\
\hline Divorced and new partner & $1(4.5)$ \\
\hline Children [n (\%)] & \\
\hline 0 & $12(54.5)$ \\
\hline 1 & $3(13.6)$ \\
\hline 2 & $6(27.4)$ \\
\hline 3 & $1(4.5)$ \\
\hline Maximum educational level [ $n(\%)]$ & \\
\hline Primary school & $3(13.7)$ \\
\hline Lower secondary school & $9(40.9)$ \\
\hline Secondary school & $9(40.9)$ \\
\hline Higher education & $1(4.5)$ \\
\hline Age at seizure onset $[n(\%)]$ & \\
\hline$<16$ years & $5(23.8)$ \\
\hline $16-20$ years & $5(23.8)$ \\
\hline 21- 30 years) & $7(33.3)$ \\
\hline$>30$ years & 4 (19.1) \\
\hline Mean (S.D.) & $23.2(12.5)$ \\
\hline Age at diagnosis [n(\%)] & \\
\hline $15-20$ years & $5(22.7)$ \\
\hline $21-30$ years & $6(27.3)$ \\
\hline $31-40$ years & $6(27.3)$ \\
\hline $41-50$ years & $5(22.7)$ \\
\hline Mean (S.D.) & $30.4(10.7)$ \\
\hline Seizure type $[n(\%)]$ & \\
\hline Tonic-like & $1(4.5)$ \\
\hline Clonic-like & $2(9.1)$ \\
\hline Absence-like & $10(45.5)$ \\
\hline Periods of disorientation/fugues & $6(27.3)$ \\
\hline Atonic-like & $3(13.6)$ \\
\hline Seizure frequency at diagnosis $[n(\%$ & \\
\hline Seizure-free & $0(0)$ \\
\hline Yearly & $1(4.5)$ \\
\hline Monthly & $5(22.7)$ \\
\hline Weekly & $7(31.8)$ \\
\hline Daily & $9(41.0)$ \\
\hline Consciousness during seizure $[n(\%)]$ & \\
\hline Normal & $1(4.5)$ \\
\hline Disturbed or lower consciousness & $21(95.5)$ \\
\hline Preceding sensations of seizures (su & \\
\hline No & $13(59.1)$ \\
\hline Yes & $9(41.9)$ \\
\hline
\end{tabular}


Table 4.1 (continued)

\begin{tabular}{lr}
\hline Epilepsy in the family $[n(\%)]$ & \\
No epilepsy & $46(72.7)$ \\
First-degree relative & $2(18.2)$ \\
Second-degree relative & $9(40.9)$ \\
Preceding treatments/therapies [n (\%)] & $7(31.8)$ \\
$\quad$ None & $6(28.3)$ \\
Psychological and psychiatric treatments & \\
Other medical treatment & $19(87.5)$ \\
Antiepileptic medication [n (\%)] & $3(13.5)$ \\
No medication & $2(9.1)$ \\
AEDs & $20(81.9)$ \\
Type of assessment used to diagnose PNES [(n (\%)] & $3(13.5)$ \\
Reevaluation of EEGs plus routine EEG & \\
24-h EEG, sleep-deprivation EEG, or seizure recordings & 100 \\
MRI & \\
Comorbid medical disorders (\%) & \\
None &
\end{tabular}

Most of the PNES mimicked "absences" in their presentation (45.5\%). Periods of disorientation (fugue-like seizures) were also quite common (27.3\% of the patient group). Less common were atonic-like seizures (sudden drop attacks) (13.6\%), cloniclike (9.1\%) and tonic-like seizures (4.5\%). Seizure frequency was high. At the time of diagnosis, most patients had daily seizures (41.0\%), 31.8\% had weekly seizures, and $22.7 \%$ of the patient group reported monthly seizures. Only one patient reported a yearly frequency at time of diagnosis. None of the patients was seizure-free. All patients, except one, experienced disturbed or lower consciousness during seizure. A substantial group of patients $(41.9 \%)$ had preceding sensations, although the presentation varied considerably, ranging from visual sensations to nausea. The vast majority of patients $(72.7 \%$ ) did not have a familial history of epilepsy. Four patients had a first-degree relative with epilepsy, whereas two patients had a second-degree relative. One third of the patient group (31.8\%) had psychological or psychiatric treatment before seizures were diagnosed. Most patients were not on antiepileptic drug (AED) treatment at the time of diagnosis; three patients used AEDs at moderate doses. No complicating etiology predisposing to developing epilepsy was observed. Only one patient had no EEG (reevaluation of the EEG was made in another hospital); one patient had routine EEG; all other patients needed 24-h EEG, seizure recording, or sleep-deprivation EEG. In three patients, magnetic resonance imaging (MRI) was performed.

Figure 4.1 shows seizure frequency at baseline (at diagnosis) and at end point. The average time between diagnosis and end point was 4.7 years (S.D.=1.3). Seizure frequency was reduced statistically significant $(P \leq 0.001)$ : 10 patients were seizure-free or had only occasional seizures per year, whereas none of the patients fell into these categories at the time of diagnosis. 


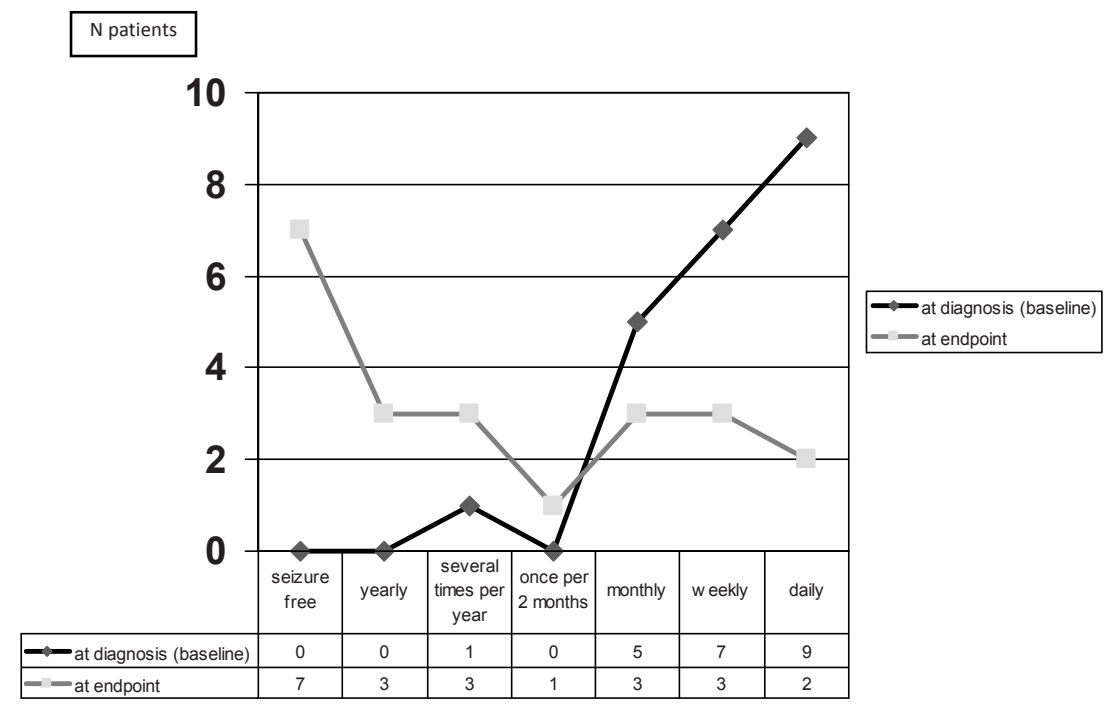

Figure 4.1 Seizure frequency of PNES at baseline (diagnosis) and at end point.

No relationship was found between reduction in seizure frequency and seizure type, age at onset, familial history of epilepsy, former treatment, use of AEDs, existence of preceding sensations, age, or gender. This was, however, at least partly due to the fact that the majority of the patients had a reduced seizure frequency; thus, variation was limited (all $P$ values $>0.05$ ).

A comparison of the personality inventories, assessed at baseline (diagnosis) and at end point, is presented in Table 4.2 and shows statistically significant changes for:

1. SCL-90: $(P=0.001)$ - indicates significant reduction in psychological distress at end point compared to that at baseline

2. DIS-Q $d 1$ : identity confusion $(P=0.01)$ - indicates that less complaints regarding identity confusion and depersonalization exist at end point

3. DIS-Q d2: loss of control $(P \leq 0.001)$ - indicates an increase in self-control at end point_compared to that at baseline

4. DIS-Q d3: amnesia ( $P=0.007)$ - indicates less amnestic/dissociation features at end point

5. NVM: negativeness $(P=0.036)$ - indicates reduction in passive avoidant behavior and feelings of dissatisfaction

6. NVM: extraversion $(P=0.005)$ - reflects a more active and energetic attitude toward social contacts. 
74 Chapter 4

Table 4.2 Changes in psychological inventories from baseline assessment (at the time of diagnosis) to end point assessments.

\begin{tabular}{lccc}
\hline & At diagnosis (baseline) & $\begin{array}{c}\text { At reevaluation } \\
\text { (end point) }\end{array}$ & $P$ \\
\hline $\begin{array}{l}\text { SCL-90 (psychoneurotic } \\
\text { complaints) }\end{array}$ & $169.25(43.8)$ & $134.50(47.8)$ & $\mathbf{0 . 0 0 1}$ \\
DIS-Q d1 & $1.6185(0.77)$ & $1.2462(0.40)$ & $\mathbf{0 . 0 1}$ \\
DIS-Q d2 & $2.2877(0.59)$ & $1.6092(0.56)$ & $\mathbf{0 . 0 0 0}$ \\
DIS-Q d3 & $2.1400(0.70)$ & $1.7169(0.83)$ & $\mathbf{0 . 0 0 7}$ \\
DIS-Q d4 & $1.8915(0.57)$ & $1.6023(0.61)$ & 0.098 \\
NVM negativeness & $4.60(1.30)$ & $3.87(1.25)$ & $\mathbf{0 . 0 3 6}$ \\
NVM somatization & $6.13(1.56)$ & $5.47(1.69)$ & 0.173 \\
NVM shyness & $4.93(1.87)$ & $4.73(1.83)$ & 0.595 \\
NVM psychopathology & $4.13(1.69)$ & $3.20(1.42)$ & 0.084 \\
NVM extraversion & $4.27(1.94)$ & $3.00(1.70)$ & $\mathbf{0 . 0 0 5}$ \\
\hline
\end{tabular}

Statistically significant values $(P \leq 0.05)$ are presented in bold.

In all comparisons, the scales at end point show less complaints/problems compared to baseline. Improvement on seizure frequency is thus associated with a larger improvement of function in these patients, specifically a reduction in psychological distress, and patients report a reduction in dissociative features such as amnesia, increase in self-control, reduction in feelings of dissatisfaction and passive avoidant behavior, and a more active attitude towards social contact.

Linear regression analysis was performed with seizure improvement as dependent variable. We used a digital variable for this analysis: "improvement or not" was rated as 1 (any reduction in seizure frequency from baseline to end point) or 0 (either no change from baseline to end point or worsening of seizure frequency). Scores on the personality inventories ( $\mathrm{SCL}, \mathrm{NVM}, \mathrm{DIS}-\mathrm{Q}$ ) at baseline were used as possible predictors. This analysis tests for possible psychogenic predictors for favorable or worse prognosis. The analysis shows a statistically significant relationship with two variables: psychopathology (NVM) on the first step $(P=0.04)$ and negativism (NVM) on the second step $(P=0.04)$, explaining $55.2 \%$ of the variance (hence, these are dominant factors explaining more than half of the variance of seizure improvement). The relationship can be interpreted as follows: with higher psychopathology, chances of seizure improvement are reduced; with lower negativism (self-avoidant behavior), chances of seizure improvement are increased.

In a second regression analysis, we evaluated which personality traits can be seen as predictors of seizure frequency at baseline. The results show that all scores on the personality inventories combined explain $87 \%$ of the variance, but that none of the separate scores is statistically significant. 


\section{Discussion}

Whereas none of the patients was seizure-free at diagnosis, a substantial portion of this group was in complete remission at end point. Although group size was limited, the results were convincing: at the time of diagnosis, none of the patients was seizurefree or had only yearly seizures, whereas at end point, 7 of 22 patients were completely in remission and 3 patients had only occasional seizures. The number of patients with daily seizures dropped from nine to two. It has not been fully clarified which factors caused this improvement as all patients had different procedures, but the common denominators were that a definitive and expert diagnosis was made in a tertiary center and that all possible efforts were made to inform the patient in a respectful manner about this diagnosis. Apparently, this is a sufficient procedure (although, in many patients, this is followed by a variety of treatment and counseling procedures) to reduce seizure frequency or to fully stop the seizures. Although many patients followed some form of treatment or counseling procedures, these types of intervention were individualized and showed a broad range. Maybe presenting the diagnosis is a kind of first phase for every patient. A second phase only follows when necessary and when the patient is open to the investigation of underlying psychological mechanisms. An important aspect of the presentation is focused on achieving the patients' acceptance of the diagnosis.

In a recent international interdisciplinary workshop that aimed to discuss the development of treatments for patients with non-epileptic seizures, it was stated that a major obstacle to treatment is the patients' refusal to accept the diagnosis. Therefore, the presentation of the diagnosis is considered pivotal in the acceptance of the diagnosis ${ }^{13}$.

Since these are patients with PNES only, part of the expert diagnosis was also to convince the patient to stop taking AEDs. Current taking of AEDs might, on a attribution level, be a sign for the patient that he or she does have an organic disease such as epilepsy. Reuber et al. ${ }^{12}$, in their long-term follow up study, found that $40.7 \%$ of patients with PNES only were taking anticonvulsants. They also found a relatively poor prognosis for this group.

In addition to seizure reduction, there is an improvement on different levels of psychological function. At the level of complaints, there is a reduction in psychological distress. At the level of coping strategy, there is a reduction in dissociative features such as amnesia and an increase in self-control. With regard to personality factors, there is a reduction in feelings of dissatisfaction and passive avoidant behavior, and a more active attitude towards social contact. The patients, therefore, seem to have more self-control and approach social contact with a more self-confident attitude. This does not necessarily reflect a causal relationship (i.e., these factors are not necessarily psychogenic mechanisms underlying PNES). Nonetheless, it is noteworthy that, post aut propter, the eradication of a symptom (i.e., seizures) with social consequences is followed by or is associated with a more confident social attitude. 
76 Chapter 4

Given the fact that only a minority of these patients had complex psychotherapeutic interventions, it is tempting to assume that, here, the psychological changes follow seizure reduction.

When the actual improvement of seizure frequency per patient was tested in linear regression analysis, the level of psychopathology and the tendency for passive avoidance behavior (NVM negativism) at the time of diagnosis were the strongest predictors. This indicates that the level of psychopathology is a negative predictor for prognosis and that a lower level of negativism (self-avoidant behavior) is a positive predictor for prognosis. The first finding may be helpful in clinical practice in identifying patients for treatment; the second finding may help us in finding adequate types of treatment for patients. We must still be careful in interpreting these data as the level of psychopathology and negativism explain improvement of seizure frequency, but not the actual seizure frequency at baseline, at the time of diagnosis. The second regression analysis shows that, at the time of diagnosis, many other psychological factors are involved, suggesting a multifactorial origin of the seizures. It is remarkable that the psychological factors combined account for almost $90 \%$ of seizure variance at baseline. Thus, other factors (or a more complex pattern of psychogenic influences) may be responsible for seizure onset rather than for seizure recurrence.

An additional finding that is worth mentioning is that there is still an average delay of 7.2 years between the reported seizure onset and the diagnosis of PNES. This has been reported in other studies in the past ${ }^{35}$, and this long delay still seems valid. In the light of the possible stigma of seizures, uncertainty about the diagnosis, and the impact of seizures on social functioning and occupational possibilities, this period must be shortened. In the light of this lengthy delay, the small number of patients on AED treatment is remarkable. In addition, the relatively limited number of patients (about one third of the sample) who had preceding psychological or psychiatric treatment is noteworthy. Possibly, there is a long "silent period" in which the patients do have PNES that occur infrequently or without serious impact on daily life, which may delay proper referral for diagnosis. Another reason for the observed diagnostic delay may be sampling bias. It is possible that patients with PNES who were referred to a tertiary referral epilepsy center have difficult-to-detect seizures or difficult- toclassify seizures. This may explain why the majority of the patients needed laborious EEG recordings, such as seizure recordings or sleep EEGs. This may also be an explanation for the fact that most of the patients had seizures mimicking "absences" or "periods of disorientation". Several authors, such as Meierkord et al. ${ }^{36}$, report that the majority of patients present with excessive motor manifestations and that unresponsiveness is a more seldom symptom. However, other authors, such as Leis et al. $^{37}$, caution against such conclusions, as unresponsiveness may go undetected more frequently. Possibly because of closer observations in a tertiary center, these symptoms dominate in this sample. 


\section{References}

1. Aldenkamp AP, Mulder OG. Behavioural Mechanisms involved in Pseudo-epileptic Seizures: a comparison between patients with epileptic seizures and patients with pseudo-epileptic seizures. Seizure 1997;6:275-82.

2. Cragar DE, Berry DTR, Schmitt FA, Fakhoury TA. Cluster analysis of normal personality traits in patients with psychogenic non-epileptic seizures. Epilepsy Behav 2005;6:593-600.

3. Krumholz A. Non-epileptic seizures: diagnosis and management. Neurology 1999;53:S76-S83.

4. Williams DT, Spiegel H, Mostofsky DI. Neurogenic and hysterical seizures in children and adolescents: differential diagnostic and therapeutic considerations. Am J Psychiatry 1978;135:82-6.

5. Betts T, Boden S. Diagnosis, management and prognosis of a group of 128 patients with non-epileptic attack disorder. Part I. Seizure 1992a;1:19-26.

6. Betts T, Boden S. Diagnosis, management and prognosis of a group of 128 correlates of intractable pseudoseizures. Part II. Previous childhood sexual abuse in the aetiology of these disorders. Seizure 1992b;1:27-32.

7. Ramani SV, Quesney LF, Olson D, Gumnit, RJ. Diagnosis of hysterical seizures in epileptic patients. Am Journ Psychiatry 1980;137:705-9.

8. Alper K. Non-epileptic seizures. Neurologic Clinics (Epilepsy II: special issues) 1994:12;153-73.

9. O'Sullivan SS, Sweeney BJ, McNamara B. The opinion of the general practitioner toward clinical management of patients with psychogenic non-epileptic seizures. Epilepsy Behav. 2006;8:256-60.

10. Sirven JI, Glosser DS. Psychogenic non-epileptic seizures: theoretic and clinical considerations. Neuropsychiatry, Neuropsychol, and Behav Neurol 1998;11:225-35.

11. Reuber M, House AO. Treating patients with psychogenic non-epileptic seizures. Curr Opin Neurol 2002;15:207-11.

12. Reuber M, Pukrop R, Bauer J, Helmstaedter C, Tessendorf N, Elger CE. Outcome in psychogenic nonepileptic seizures: 1 to 10-year follow-up in 164 patients. Ann Neurol 2003;53:305-11.

13. LaFrance WC, Alper K, Babcock D, Barry JJ, Benbadis S., Caplan R., Gates J, Jacobs M, Kanner A, Martin R, Rundhaugen L, Stewart R, Vert C. Non-epileptic seizures treatment workshop summary. Epilepsy Behav 2006;8:451-61.

14. Ettinger AB, Dhoon A, Weisbrot DM, Devinsky O. Predictive factors for outcome of non-epileptic seizures after diagnosis. J Neuropsychiatry Clinical Neurosci 1999;11:458-63.

15. Kanner AM, Parra J, Frey M, Stebbins G, Pierre-Louis S, Iriarte J. Psychiatric and neurologic predictors of psychogenic pseudoseizure outcome. Neurology 1999;53:933-8.

16. King DW, Gallagher BB, Murvin AJ, Smith DB, Marcus DJ, Hartlage LC, Charles Ward L. Pseudoseizures: diagnostic evaluation. Neurology 1982;32:18-23.

17. Scull DA. Pseudoseizures or non-epileptic seizures (NES); 15 synonyms. J. Neurol Neurosurg Psychiatry 1997;62:200.

18. Stewart RS, Lovitt R, Malcolm Stewart R. Are hysterical seizures more than hysteria? A research diagnostic criteria, DSM-III, and psychometric analysis. Am J Psychiatry 1982;139:926-9.

19. Bowman ES, Markand ON. Psychodynamics and psychiatric diagnoses of pseudoseizure subjects. Am J Psychiatry 1996;153:57-63.

20. Arnold LM, Privitera MD. Psychopathology and trauma in epileptic and psychogenic seizure patients. Psychosomatics 1996;37:438-43.

21. Galimberti, C.A., Ratti, M.T., Murelli, R., Marchioni, E., Manni, R. \& Tartara, A. Patients with psychogenic non-epileptic seizures, alone or epilepsy-associated, share a psychological profile distinct from that of epilepsy patients. J.Neurol. 2003;250:338-46.

22. Francis P, Baker GA. Non-epileptic attack disorder (NEAD): a comprehensive review. Seizure 1999;8:53-61.

23. Blumer D, Montouris G, Hermann B. Psychiatric morbidity in seizure patients on a neurodiagnostic monitoring unit. J Neuropsychiatry Clin Neurosci 1995;7:445-56.

24. Reuber M, Pukrop R, Bauer J, Derfuss R, Elger CE. Multidimensional assessment of personality in patients with psychogenic non-epileptic seizures. J Neurol Neurosurg Psychiatry 2004;75:743-8.

25. Barry E, Krumholz A, Bergey GK, Chatha H, Alemayehu S, Grattan L. Non-epileptic posttraumatic seizures. Epilepsia 1998;39:427-31. 
78 $\mid$ Chapter 4

26. Reuber M, Mitchell AJ, Howlett S, Elger CE. Measuring outcome in psychogenic non-epileptic seizures: how relevant is seizure remission? Epilepsia 2005;46:1788-95.

27. Derogatis LR. SCL-90: administration, scoring and procedures manual I for the r(evised) Version. Baltimore: Clinical Psychometrics Research Unit, Johns Hopkins University School of Medicine,1977.

28. Bernstein EM, Putman FW. Development, reliability, and validity of a dissociation scale. J Nerv and Ment Dis 1986;174:727-35.

29. Sanders S. The perceptual alteration scale: a scale measuring dissociation. Am J Clinl Hypn 1986;29:95-102.

30. Riley K.C. Measurement of dissociation. J Nerv Ment Dis 1988;176:449-50.

31. Vanderlinden J, Van Dyck R, Vandereycken W, Vertommen H. Dissociatieve ervaringen bij Vlamingen en Nederlanders; een studie met de Dissociation Questionnaire. Dth 1993;13:57-77.

32. Vanderlinden J, Van Dyck R, Vandereycken W, Vertommen H. Dissociative experiences in the general population in the Netherlands and Belgium: a study with the Dissociative Questionnaire (DIS-Q). Dissociation 1991;180-4.

33. Luteijn F, Kok AR. Handleiding Nederlandse Verkorte MMPI. Herziene uitgave. Lisse, (The Netherlands): Swets and Zeitlinger,1985.

34. Eurelings-Bontekoe EHM, Duijsens IJ, Snellen WM, Diekstra RFW, Ouwersloot G. DSM-III-R and ICD10 personality disorders and personality dimensions as assessed by the Dutch short form of the MMPI: preliminary results. Pers Individ Differ 1995;18:231-9.

35. Reuber M, Elger CE. Psychogenic non-epileptic seizures: review and update. Epilepsy Behav 2003;4:205-16.

36. Meierkord H, Will B, Shorvon S. The clinical features and prognosis of pseudoseizures diagnosed using video-EEG telemetry. Neurology 1991;41:1643-6.

37. Leis AA, Ross MA, Summers AK. Psychogenic seizures: ictal characteristics and diagnostic pitfalls. Neurology 1992;42:95-9. 


\section{Chapter 5}

Treatments for non-epileptic attack disorder: a Cochrane Review

GA Baker, JL Brooks, L Goodfellow, NMG Bodde, AP Aldenkamp Cochrane Database of Systematic Reviews 2007, Issue 1. Art. No.: CD006370 
80 $\mid$ Chapter 5

\section{Abstract}

\section{Background}

Psychogenic non-epileptic seizures (NES) have the outward appearance of epilepsy in the absence of physiological or electroencephalographic correlates. Non-epileptic seizures can occur in isolation or in combination with epileptic seizures. The development and maintenance of non-epileptic seizures has been well documented and there is a growing literature on the treatment of NES which includes nonpsychological (including anti-anxiety and antidepressant pharmacological treatment) and psychological therapies (including cognitive behavioural therapy (CBT), hypnotherapy and paradoxical therapy). Various treatment methodologies have been tried with variable success. The purpose of this Cochrane review was to establish the evidence base for treatment of NES.

\section{Objectives}

To assess whether treatments for NES result in a reduction in frequency of seizures and/or improvement in quality of life, and whether any treatment is significantly more effective than others.

\section{Search strategy}

We searched the Cochrane Epilepsy Group's Specialised Register (September 2005), the Cochrane Central Register of Controlled Trials (CENTRAL) (The Cochrane Library Issue 3, 2005), and PsycINFO (1806 to July 2005). No language restrictions were imposed. We checked the reference lists of retrieved studies for additional reports of relevant studies.

\section{Selection criteria}

Randomised or quasi-randomised studies were included that assessed one or more types of psychological or non-psychological interventions for the treatment of NES. Studies of childhood NES were excluded from our review.

\section{Data collection and analysis}

Three review authors independently assessed the trials for inclusion and extracted data. Outcomes included reduction in seizure frequency and improvements in quality of life.

\section{Main results}

Three small studies met our inclusion criteria and were of poor methodological quality. Two assessed hypnosis and the other paradoxical therapy. There were no detailed reports of improved seizure frequency or quality of life, and these trails provide no reliable evidence of a beneficial effect of these interventions.

\section{Authors' conclusions}

In view of the methodological limitations and the small number of studies, we have no reliable evidence to support the use of any treatment including hypnosis or paradoxical injunction therapy in the treatment of NES. Randomised studies of these and other interventions are needed. 


\section{Plain language summary}

There is no reliable evidence to support the use of any interventions for people with non-epileptic seizures.

There has been extensive investigation of the aetiology of non-epileptic seizures. However, the literature on the treatment of such seizures is less well defined. We conducted a review of randomised controlled trials of interventions for non-epileptic seizures. We found only three studies and from these no conclusive results can be drawn.

\section{Background}

Much research has been devoted to the aetiology of non-epileptic seizures. Significant links have been found between certain life events and the occurrence of non-epileptic seizures. In particular there have been consistent findings of co-occurrence of experiences of abuse in childhood or early adulthood and the development of nonepileptic events (Francis 1999a; Reilly 1999).

Psychological factors such as anxiety, stress, anger and other emotions as well as by mental tasks and thoughts (Francis 1999b) can trigger an attack, as can physiological states such as over-exertion and pain (Stone 2004). It is on the basis of such studies that much literature has evolved regarding potential treatments. Various psychological and non-psychological interventions such as Cognitive Behaviour Therapy (CBT), eye movement desensitization and reprocessing, and neurofeedback have been used alone or in combination in the treatment of non-epileptic seizures to reduce attack frequency and improve quality of life. Potential treatments include the following.

\section{Eye movement desensitization and reprocessing (EMDR)}

Chemali 2004 reported on the use of EMDR in the treatment of psychogenic seizures. This was a single case study involving a 48 year old female with post-traumatic stress disorder and psychogenic seizures that lasted for many hours. After 18 months of EMDR treatment (weekly sessions) the patient was described as "event-free". Follow up three months later confirmed she was still seizure free.

\section{Group psychoeducation}

An open-ended group psychotherapy program was given to 10 patients with NES by Zaroff 2004. This program included a "disorder-specific psychoeducation treatment 
$82 \mid$ Chapter 5

component". Only 7 of the 10 completed the majority of psychoeducational sessions. Seizure frequency was measured pre- and post-treatment. Four patients had no change in seizure frequency but three of these were seizure free at treatment initiation. Two patients had a reduction in seizure frequency and one an increase. The authors concluded that there was a non-significant trend towards improved quality of life (as measured by the QOLIE-31(Quality Of Life In Epilepsy) questionnaire). They also note that seizure remission following diagnosis supports the hypothesis that education about the disorder is effective in its treatment.

\section{Neurofeedback plus psychotherapy}

Swingle 1998 trained three patients presenting with non-epileptic events in the use of electroencephalographic (EEG) feedback between one and three times a week. Neurofeedback therapy is used in an effort to reduce general levels of arousal. The hypothesis is that high arousal levels are implicated in the development and or maintenance of attacks and reducing these levels may have an impact on attack frequency and/or severity. This neurofeedback therapy was used to reduce the EEG theta/sensorimotor rhythm (SMR) ratio. This treatment was used in conjunction with psychotherapy. The aim of the treatment protocol was to reduce the ratio of theta to sensorimotor rhythm (SMR). The author concluded that reductions in the theta/SMR ratio brought about by neurofeedback were associated with reductions in seizure behaviour. Swingle also added the use of EEG feedback training. He commented on the absence of a control group and the limitations this puts on the generalisability of his findings.

\section{Psychotherapy}

In their retrospective study Aboukasm 1998 divided 61 patients into four groups: (a) those receiving comprehensive epilepsy program (CEP) psychotherapy; (b) those only under CEP neurologist care; (c) those receiving non-CEP psychotherapy; and (d) those with no feedback or intervention. There were no details about the type of psychotherapy used. The authors reported that group D had significantly less desirable NES clinical outcomes than the other three groups and less improvement in QOL. They concluded that psychotherapy and feedback by CEP professionals experienced in epilepsy and NES was beneficial compared to other or no interventions.

\section{Cognitive behavioural psychotherapy}

In a paper by Rusch 2001 psychotherapeutic intervention focused on one of six symptom patterns: acute anxiety/panic; impaired affect regulation and interpersonal skills; somatization/conversion; depression; post-traumatic stress disorder; and reinforced behaviour pattern. Patients were treated according to the symptom 
pattern e.g. those in the acute anxiety/panic group received cognitive therapy with exposure; those in the reinforced behaviour pattern group received behavioural management strategies involving family or significant other participation to directly modify reinforcement patterns. Twenty-six of 33 patients completed treatment and of those, 21 were event-free by the end of treatment; the remaining five showing a significant reduction in frequency.

\section{Combined interventions}

\section{Psychotherapy, occupational therapy and minimal attention within in- patient setting}

McDade 1992 diagnosed 18 patients in an in-patient setting with NES; nine were solely experiencing NES and nine were experiencing a combination of NES and epilepsy. This group of clients poses a significant management problem as often the treating physician, the client and the family may have difficulty differentiating between seizures and non-epileptic events. Individual programmes were developed for each patient, but each programme included psychotherapy (orientation not specified), occupational therapy, and minimal attention being paid to the seizures. Sixteen of the patients completed the programme. Eight became seizure free, three had occasional NES and five were unchanged. At one year follow up, seizure patterns were reported to be similar and patients were also reporting an improvement in social functioning. The authors conclude that prognosis for NES is good when management takes place in a specialist unit with a multi-disciplinary approach and a team familiar with this patient group.

\section{Confrontation with diagnosis, psychotherapy and continuing clinical care}

In this study, the authors described outcome in 50 patients (including adults and children) with NES (Buchanan 1993). They divided their group into those with acute (18) and those with chronic NES (32). In the acute group direct communication of the diagnosis was the only intervention for $12 / 18$, six received formal psychotherapeutic support, one had barbiturates withdrawn, and one had family therapy. In terms of outcome, 15/18 (83\%) were seizure free at follow up and the remaining three had a marked improvement. The chronic group also had various psychiatric/psychological problems such as personality disorder, anxiety disorder, abnormal illness behaviour, major depression, somatisation disorder and Munchausen's syndrome. In this group various management approaches were used and some patients had more than one approach which included confrontation with the diagnosis, exploratory formal and/or supportive psychotherapy, continuing clinical care and firm management with limit 
84 $\mid$ Chapter 5

setting. With regard to outcome in the chronic group, 9/32 were seizure free, 11/32 were significantly improved and $8 / 32$ had no change at all.

\section{Operant conditioning}

Betts 1992a report on a group of 128 patients diagnosed with NES over a five year period (46 had the additional diagnosis of epilepsy, 82 had NES only). A variety of management strategies were offered; these included anxiety management, abreaction, psychotherapy/counselling, family therapy and medication (major tranquillizers). Most patients received more than one treatment and almost all were treated by operant conditioning. This was described by the authors as attempting to prevent rewarding of seizure activity by ignoring it and deliberately rewarding nonseizure activity by verbal praise and encouragement. At discharge it was reported that $63 \%$ (76) of patients no longer had NES and $24 \%$ (29) had a partial resolution the remainder had either no change or were worse. At two year follow up, seizures had returned in $34 \%$ (41) or partially returned $14 \%$ (17) while $31 \%$ (37 were still seizure free. In $8 \%(10)$ the diagnosis of NES was found to be incorrect. The authors comment that inpatient treatment results may be misleading. Once the patient returns to the community and the stresses that may have led to the attack disorder, NES may return.

\section{Retrospective follow-up studies}

An exploration of reaction to diagnosis and treatment subsequently offered was undertaken by Riaz 1998. They retrospectively collected data regarding 91 patients admitted to an inpatient facility. Of those 25 were diagnosed with NEAD and 15 of these were included in the final analysis. The authors also collected follow-up data by semi-structured interviews. They reported that a comparison of seizure frequency from admission to follow up (one to two years) indicated $27 \%$ of the sample were still seizure free, $40 \%$ had a greater than $50 \%$ reduction, and $13 \%$ had experienced an increase in seizure frequency. With regard to treatment, $20 \%$ had been seen by a psychiatrist, $40 \%$ had been followed up in epilepsy clinics and $40 \%$ had received no contact with specialist services. Unfortunately, this paper does not indicate whether those who became seizure free were mainly those who had received some form of intervention.

\section{Objectives}

To assess whether treatments for NES result in a reduction in frequency of seizures and/or improvement in quality of life, and whether any treatment is significantly more effective than others. 


\section{Criteria for considering studies for this review}

\section{Types of studies}

Randomised controlled trials (RCTs) or quasi-randomised studies (e.g. where randomisation is according to the day of the week or date of birth). The studies may be single or double blind or unblinded.

\section{Types of participants}

Adult male or female with any type of non-organic non-epileptic seizures, with or without learning disabilities.

\section{Types of interventions}

Any psychological or behaviour modification therapies such as use of cognitive behaviour therapy, relaxation therapy, bio-feedback, counselling, hypnotherapy, conditioning, physical therapies, massage, aromatherapy.

\section{Exclusion criteria}

Studies restricted to children.

\section{Types of outcome measures}

\section{Primary outcome measures}

\section{Seizure reduction}

(a) Fifty per cent or greater reduction in seizure frequency.

(b) Seizure free.

(c) Percentage change in seizure frequency.

\section{Secondary outcome measures}

(a) Quality of life (QOL).

(b) Seizure severity - provided a standardized and validated scale is used.

\section{Search methods for identification of studies}

See: Cochrane Epilepsy Group methods used in reviews.

We searched the Cochrane Epilepsy Group's Specialised Register (12 September 2005). This register contains reports of trials identified from regular searches of the Cochrane Central Register of Controlled Trials (CENTRAL) and of MEDLINE. Relevant 
86 Chapter 5

reports are also identified by handsearching selected journals and conference proceedings. A more detailed description of this activity can be seen by clicking on the link above and selecting 'Specialised Register'.

In addition, we carried out searching as follows:

\section{Electronic databases}

We searched the following databases using the strategies described. There were no language restrictions.

\section{(1) The Cochrane Central Register of Controlled Trials}

(CENTRAL) (The Cochrane Library Issue 3, 2005) was searched using similar terms to those outlined in (2) below.

\section{(2) MEDLINE (Ovid) (1966 to July 2005)}

1. exp SEIZURES/ or Seizure\$.mp. [mp=title, original title, abstract, name of substance word, subject heading word]

2. epilep\$.ab,ti.

3. non-epileptic attack\$.mp.]

4. non-epileptic seizure $\$ . m p$.

5. (psychogenic and attack\$).mp.

6. (psychogenic and seizure\$).mp.

7. pseudoseizure\$.mp.

8. functional seizure\$.mp.

9. NEAD.mp.

10. non-epileptic attack disorder.mp.

11. hysterical seizure\$.mp.

12. somatoform disorder\$.mp. or exp somatoform disorders/

13. psychophysiologic\$disorder\$/ or exp psychophysiologic disorders/

14. exp dissociative disorders/ or dissociative disorder\$.mp.

15. exp conversion disorder/ or conversion disorder\$.mp.

16. (somatisation or somatization).mp.

17. or/1-16

18. psychotherapy.mp. or exp PSYCHOTHERAPY, MULTIPLE/ or exp PSYCHOTHERAPY/ or exp PSYCHOTHERAPY, GROUP/ or exp "IMAGERY (PSYCHOTHERAPY)"/ or exp PSYCHOTHERAPY, BRIEF/ or exp PSYCHOTHERAPY, RATIONAL-EMOTIVE/

19. assertive therapy.mp.

20. aromatherapy.mp. or exp AROMATHERAPY/

21. art therapy.mp. or exp Art Therapy/

22. autogenic training.mp. or exp Autogenic Training/ 
23. abreaction.mp. or exp ABREACTION/

24. aversive therapy.mp. or exp Aversive Therapy/

25. acceptance commitment therapy.mp.

26. exp Behavior Therapy/ or behav\$ therapy.mp.

27. Behav\$ modification.mp.

28. biofeedback.mp. or exp "Biofeedback (Psychology)"/

29. bibliotherapy.mp. or exp BIBLIOTHERAPY/

30. cognitive therapy.mp. or exp Cognitive Therapy/

31. cognitive behav\$ therapy.mp.

32. cognitive analytical therapy.mp.

33. counsel\$̧ing.mp or exp COUNSELING/

34. catharsis.mp. or exp CATHARSIS/

35. colo\$r therapy.mp. or exp Color Therapy/

36. crisis intervention.mp. or exp Crisis Intervention/

37. couples therapy.mp. or exp Couples Therapy/

38. conditioning.mp. or exp "Conditioning (Psychology)"/

39. classical conditioning.mp. or exp Conditioning, Classical/

40. operant conditioning.mp. or exp Conditioning, Operant/

41. exp DESENSITIZATION, PSYCHOLOGIC/ or desensitization.mp.

42. dance therapy.mp. or exp Dance Therapy/

43. family therapy.mp. or exp Family Therapy/

44. free association.mp. or exp Free Association/

45. hypnosis.mp. or exp HYPNOSIS/

46. gestalt therapy.mp. or exp Gestalt Therapy/

47. humanistic therapy.mp.

48. flooding.mp. or exp Implosive Therapy/

49. implosive therapy.tw

50. autosuggestion therapy.mp.

51. music therapy.mp. or exp Music Therapy/

52. marital therapy.mp. or exp Marital Therapy/

53. nondirective therapy.mp. or exp Nondirective Therapy/

54. directive therapy.mp.

55. milieu therapy.mp. or exp Milieu Therapy/

56. meditation.mp. or exp MEDITATION/

57. play therapy.mp. or exp Play Therapy/

58. psychotherapeutic processes.mp. or exp Psychotherapeutic Processes/

59. psychodrama.mp. or exp PSYCHODRAMA/

60. exercise therapy.mp. or exp Exercise Therapy/

61. exp psychotherapy, rational-emotive/ or rational emotive therapy.mp.

62. residential treatment.mp. or exp Residential Treatment/

63. reality therapy.mp. or exp Reality Therapy/

64. exp Suggestion/ or suggestion therapy.mp. 
$88 \mid$ Chapter 5

65. socioenvironmental therapy.mp. or exp Socioenvironmental Therapy/

66. systemic therapy.mp.

67. exp Systems Theory/ or systems therapy.mp.

68. stress management.mp. or exp Adaptation, Psychological/

69. psychoanalytic therapy.mp. or exp Psychoanalytic Therapy/

70. transactional analysis.mp. or exp Transactional Analysis/

71. therapeutic community therapy.mp.

72. patient centred therapy.mp.

73. client centred therapy.mp.

74. exp "EARLY INTERVENTION (EDUCATION)"/ or exp CRISIS INTERVENTION/ or exp INTERVENTION STUDIES/

75. therapy.mp.

76. treatment outcome.mp. or exp Treatment Outcome/

77. outcome.mp.

78. or/18-77

79. randomized controlled trial.pt.

80. controlled clinical trial.pt.

81. exp Randomized Controlled Trials/

82. exp Random Allocation/

83. exp Double-Blind Method/

84. exp Single-Blind Method/

85. clinical trial.pt.

86. exp Clinical Trials/

87. (clin\$ adj trial\$).ab,ti.

88. ((singl\$ or doubl\$ or trebl\$ or tripl\$) adj (blind\$ or mask\$)).ab,ti.

89. $\exp$ PLACEBOS/

90. placebo\$.ab,ti.

91. random\$.ab,ti.

92. $\exp$ Research Design/

93. or/79-92

94. (animals not human).sh.

95. 93 not 94

96. 17 and 78 and 95

(3)PsycINFO (Ovid)

(1806 to July 2005) was searched using similar terms to those outlined in (2) above.

\section{References from published studies}

We reviewed the reference lists of retrieved studies to search for additional reports of relevant studies. 


\section{Methods of the review}

Trials were independently assessed for inclusion by five review authors (JB, GB, AA, $N B, L G$ ) with disagreements resolved by mutual discussion.

The same five review authors independently extracted the following data and again any differences of opinion were resolved by mutual discussion:

(1) Study methods:

(a) design (e.g. parallel or crossover design);

(b) randomisation method (allocation concealment and list generation);

(c) blinding method;

(d) quality of allocation concealment (A, adequate; B, unclear; C, inadequate).

(2) Participants:

(a) number (total/per group);

(b) age and sex distribution;

(c) exclusions withdrawal;

(d) type of seizures;

(e) duration of attack disorder;

(f) aetiology of attack disorder;

(g) presence or absence of learning disability.

(3) Type of intervention and control.

(4) Duration of follow up.

(5) Outcome data (as described earlier).

We intended to assess the results of each intervention separately. As only three randomised controlled clinical trials were found that used differing methodologies, no meta-analysis was undertaken but results for individual studies are given in tables.

\section{Description of studies}

\section{Hypnosis and non-epileptic seizures}

One study investigated the effects of hypnosis on non-epileptic seizures (Moene 2002). This study included 45 adult in-patients with conversion disorder. Seven experienced paroxysmal myoclonic outbursts and eight had seizures or convulsions. Twenty four were allocated randomly to the experimental group and 21 to the control group. The average duration of conversion disorder was 3.9 years (range two months to 22 years; standard deviation [SD] 4.5 months). Forty per cent (18) of the 45 had acute onset (within three days). Sixty two per cent (28) (an undisclosed proportion of whom had acute onset) developed conversion symptoms in connection with a previous physical complaint or affliction in the relevant part of the body. Thirty-two $(72.7 \%)$ of the patients used medication (benzodiazepines (43.2\%), medication for somatic complaints (45.5\%) and painkillers (44.4\%) most frequently). No discussion of withdrawal of medication or otherwise was included. 
90 Chapter 5

Patients in both treatment and control groups followed a group therapy programme with the aim of increasing problem-solving skills. This programme consisted of group psychotherapy, social skills training, formulating and evaluating treatment goals, creative therapy and sports. In addition, conversion patients also had physiotherapy, individual exercise sessions and bed rest. The experimental group had the addition of hypnotic treatment. This involved one preparatory session followed by eight weekly sessions lasting one hour. Part of this treatment involved the patients learning selfhypnosis and they were instructed to practice each day for 30 minutes. In the control group, instead of hypnosis, a treatment aimed at optimising non-specific or common therapy factors was implemented. This involved a preparatory session followed by eight weekly session lasting one hour.

The primary outcome measure used was the Video Rating Scale for Motor Conversion Symptoms (VRMC). Follow up in this study was eight months after pre-treatment assessment.

A further study by Moene 2003 included 44 adult outpatients with conversion disorder (motor type) or somatisation disorder (with motor conversion symptoms). Of the 44, six experienced paroxysmal myoclonic outbursts and two had seizures or convulsions. Twenty were randomly allocated to the treatment group and 24 to the waiting list control group. The treatment group received one preparatory session followed by 10 weekly sessions. Two hypnotic strategies were used: (1) direct symptom alleviation used suggestions designed to alter conditioned cues to motor symptoms; (2) emotional expression/insight involved age regression to explore factors implicated in the development of the symptoms. Self hypnosis was also taught and patients were asked to practice the symptom alleviation strategies for 30 minutes a day. A waiting list control group was used.

Average duration of conversion disorder was 3.7 years (range two months to 16.7 years; SD 4.7 months). In terms of onset, 37.2\% (16) patients had acute onset (within three days) and $47.8 \%$ (21) developed conversion symptoms in connection with a previous physical complaint or affliction in the relevant part of the body. Twenty-one $(48.8 \%)$ of the patients used medication (benzodiazepines (14\%), medication for somatic complaints (30.2\%) and painkillers (34.8\%) most frequently). No discussion of withdrawal of medication or otherwise was included.

Primary outcome measure used was the VRMC. Follow up for the treatment group was at six months after their tenth session. No follow up was arranged for the waiting list control group. 
It is noted that preliminary data on eight adults with motor conversion symptoms (one described as having pseudo-epileptic seizures) was published by Moene in 1998 (Moene 1998).

\section{Paradoxical intention and non-epileptic seizures}

We found one randomised controlled clinical trial investigating the effects of paradoxical intention on non-epileptic seizures (Ataoglu 2003). This study included 30 adults with conversion disorder, specifically pseudoseizures. Fifteen were randomly allocated to the experimental group and 15 to the control group after exclusions for abnormal EEG, organic disease, previous psychiatric treatment etc. In the experimental group, patients were hospitalised and given two paradoxical intention treatment sessions per day. During sessions, patients were encouraged to imagine anxiety provoking situations and/or experiences. The aim was to help the patients to re-experience their traumas and experience their conversion attacks. After three weeks, patients were discharged. Three weeks post discharge, a re-assessment took place and comparisons of anxiety and conversion scores were made. In the control group, patients were prescribed diazepam as outpatients (5-15mgs) they were given appointments at 10, 20,30, and 45 days to review their progress and also were reviewed at the end of treatment for anxiety and conversion symptoms.

The overall mean duration of conversion disorder for the whole sample was 42 days (experimental group 34 days; control group 48 days). There was no discussion of medication use in these groups. The aetiology was not detailed; however anxiety provoking situations and experiences, and traumatic events were mentioned. The primary outcome measure was anxiety score as measured by the Hamilton Rating Scale for Anxiety (HRSA). Follow up in this study was three weeks after the study finished. The study duration was six weeks therefore follow up was approximately two months after the start of the study.

It is noted that an earlier account of this research was published by Ataoglu, in 1998 (Ataoglu 1998).

\section{Methodological quality of included studies}

\section{Hypnosis and non-epileptic seizures}

Moene 2002 used block randomisation (block sizes: $3 \times 4,2 \times 6,2 \times 8,2 \times 4$ and $2 \times 2$ ) to allocate patients to treatment conditions. This was concealed from the therapist and assessors. The assessors rating the outcomes were blinded to treatment allocation. Further details of randomisation or blinding method are not provided. In terms of methodological weaknesses, of the 45 patients with conversion symptoms, eight were reported to have seizures or convulsions and seven were reported to have 
92 Chapter 5

paroxysmal myoclonic outbursts, however patients could have more than one symptom so the exact number is unclear. There was no detail regarding seizure frequency or change in seizure frequency, nor were there measures of quality of life or seizure severity.

Moene 2003 used block randomisation (unspecified) to assign patients to experimental (hypnosis) or control (waiting list) conditions. The assessors rating the outcomes were blinded to treatment allocation. No further details of randomisation or blinding method were provided. In terms of methodological weaknesses, only two of the patients with conversion symptoms were documented as having seizures or convulsions, although six were reported to have paroxysmal myoclonic outbursts (patients may have more than one symptom so the exact number is unclear). There was no detail regarding seizure frequency or change in seizure frequency, nor were there measures of quality of life or seizure severity.

\section{Paradoxical intention and non-epileptic seizures}

In this study (Ataoglu 2003), random allocation was effected by a computerised system; no further information is provided. All patients were assessed by a psychiatrist who was blinded as to the patients' group throughout the study. There were some methodological weaknesses in the study design: absence of a placebo control group and the two groups received their interventions in different settings inpatient and outpatient.

\section{Results}

\section{Hypnosis and non-epileptic seizures}

Moene 2002 provided no results specific to non-epileptic seizures. It is stated that frequency and duration of seizures was noted by staff and patients throughout the study. From this they calculated the mean percentage change in frequency and duration which was converted to a representative score on the VRMC rating scale. However, none of these scores were provided in the paper.

The authors analyses were time and condition by time interactions. Their outcome measures were the VRMC, SCL-90 (Symptom Checklist-90; Dutch version) a self report measure of psychoneuroticism, the ICIDH (International Classification of Impairments, Disabilities and Handicaps) subscale for physical activities), and the ICIDHP (the perceived problems subscale). The authors reported significant symptom reduction in patients with a conversion disorder of the motor-type; however this was independent of the treatment condition. They reported no significant condition effects and no significant condition-by-time interactions for any of the outcome measures. However, 
a significant main effect for time was reported on all of the outcome measures (VRMC, $F(2,82)=28.07, P=0.001 ; \quad S C L-90, F(3,126)=3.37, P=0.05 ; \quad I C I D H, F(3$, 123)=12.76, $P=0.000 ; \operatorname{ICIDHP}, F(3,123)=8.97, P=0.000)$. The authors concluded that the addition of hypnosis to the treatment programme did not affect outcome.

Moene 2003 provided no results specific to NES. As with their 2002 study, the outcome measures were VRMC, SCL-90 and ICIDH. The authors reported significant treatment results for a hypnosis-based treatment in patients with a conversion disorder, motor type. There was a statistically significant difference between the mean VRMC scores (treatment group 5.9, SD 1.3; control group 3.8, SD 1.4; $t=5.065$, $P=0.001$ ). The analysis of the ICIDH results indicated that the treatment group improved more than controls on this interview measure of general motor impairment (treatment group $\mathrm{t}=3.63, P<0.01$; control group $\mathrm{t}=1.074, P=0.29$ ). The authors found no significant effect of treatment on the SCL-90 (main effects: group $F(1,41)=0.385$, $P=0.54$; time $F(3,126)=3.636, P=0.064$. interaction: $F(1,41=0.345, P=0.56)$. At sixmonth follow up the authors reported that improvement was maintained.

\section{Paradoxical intention and non-epileptic seizures}

No specific non-epileptic attack frequency or severity results were provided by Ataoglu 2003 as the primary outcome measure in this study was anxiety score. However, the authors noted percentage of the sample in each group who showed no conversions symptoms in the last two weeks at follow up: Experimental group 14 (93.3\%); Control group 9 (60\%). There was a significant improvement in recovery rate in the PI group when compared than the diazepam-treated group ( $t=2.27, P=0.034)$.

The authors analysed anxiety scores on the HRSA before and after treatment. There was no significant difference between pre-treatment anxiety scores. Both groups recorded significantly decreased anxiety scores by the end of treatment (diazepamtreated group $z=3.24, P=0.0012 ; \mathrm{PI}$ group $(z=3.41, P=0.0007)$. A greater degree of significance was found in the PI group when comparing the difference between preand post-treatment anxiety scores $(z=2.43, P=0.015)$.

\section{Discussion}

Patients with non-epileptic seizures represent a heterogeneous group with diverse psychological problems against a background of longstanding physical, psychological or sexual abuse, inadequate social skills and chronic adjustment problems (Devinsky 1998; Francis 1999a; Reilly 1999; Rusch 2001). Consequently, non-epileptic seizures represent a serious problem for the patient, the family and the treating clinician. The costs to society can be significant with reported costs in the US of US\$100,000 per 
94 Chapter 5

year per patient (Martin 2003). The challenge for the treating clinician relates to providing an accurate diagnosis and an effective treatment. The evidence for how best to manage and treat patients with this condition however is scarce. The available evidence relies on clinical case studies or studies that lack scientific rigour. A number of authors have recognised the benefits of CBT, including Betts 1993; Lesser 2003; and Ramani 1993. There is a clear recognition that patients with non-epileptic seizures would benefit from cognitive behavioural treatment and this should be in the context of a multidisciplinary team (Betts 1993; Lesser 2003; Ramani 1993).

This review, like previous reviews (Rusch 2001) clearly highlights that there is a lack of well-designed trials to inform treating physicians as to what therapeutic treatments exist and how effective they may be with this condition. According to Reuber and colleagues (Reuber 2005) lessons however can be drawn from the treatment of similar types of psychopathology (somatoform disorder, post-traumatic stress disorder and hypochondria), where cognitive behavioural treatment is considered the psychological treatment of choice. Finally it is difficult to disagree with the view of Devinsky who comments that while "our ability to diagnose NES has advanced significantly in the past two decades, our understanding of its pathophysiology and our ability to provide effective treatment has progressed in small tentative steps in the past century" (Devinsky 1998). It would seem that the status quo remains.

\section{Authors' conclusions}

\section{Implications for practice}

There is currently no sound evidence base on which to base treatment decisions for people with non-epileptic attacks.

\section{Implications for research}

Consensus is required regarding appropriate outcome measures, including measures of NES frequency and quality of life measures.

Pragmatic randomised clinical trials are required to assess the effectiveness of potential interventions. 


\section{Tables}

Characteristics of included studies

\begin{tabular}{|c|c|}
\hline Study & Ataoglu 2003 \\
\hline Methods & $\begin{array}{l}\text { Method of randomisation: computerised } \\
\text { Blinding: psychiatrist blinded to treatment group } \\
\text { Treatment duration: } 6 \text { weeks. }\end{array}$ \\
\hline Participants & $\begin{array}{l}\text { Diagnosis: Pseudoseizures / Conversion Disorder using DSM IV criteria } \\
\text { N=30. } \\
\text { Participants: } 29 \text { female, mean age } 27 \text { (range 18-35). } \\
\text { History: no information provided regarding previous seizures or comorbid conditions. } \\
\text { Setting: Department of psychiatry, Turkey. }\end{array}$ \\
\hline Interventions & $\begin{array}{l}\text { Paradoxical Intention group }(\mathrm{N}=15) \text { : Inpatient treatment in psychiatric ward, } 2 \text { sessions a } \\
\text { day for } 3 \text { weeks. } \\
\text { Diazepam group }(\mathrm{N}=15) \text { : Outpatient treatment }(5-15 \mathrm{mg} / \text { day). Appointments at } 10,20,30 \\
\& 45 \text { days. }\end{array}$ \\
\hline Outcomes & $\begin{array}{l}\text { Hamilton Rating Scale for Anxiety before and after treatment. } \\
\text { Frequency of conversion attacks in past week noted for each patient with changes in these } \\
\text { scores converted to percentages. } \\
\text { Leaving the study early. }\end{array}$ \\
\hline Notes & \\
\hline $\begin{array}{l}\text { Allocation } \\
\text { concealment }\end{array}$ & B - Unclear \\
\hline Study & Moene 2002 \\
\hline Methods & $\begin{array}{l}\text { Method of randomisation: block. } \\
\text { Blinding: therapists and assessors blind. } \\
\text { Treatment duration: } 8 \text { months. }\end{array}$ \\
\hline Participants & $\begin{array}{l}\text { Diagnosis: Conversion Disorder (motor type) or Somatisation Disorder (with motor } \\
\text { conversion symptoms) using DSM IIIR criteria } \\
\mathrm{N}=45 \text {. } \\
\text { Participants: } 34 \text { female, mean age } 36.8 \text { years (sd } 11.31 \text {, range } 18-56 \text { years). } \\
\text { History: mean age of onset = } 32.6 \text { years (sd } 10.9 \text { years, range } 16-54 \text { years). Mean symptom } \\
\text { duration = } 3.9 \text { years (sd } 4.5 \text { months, range } 2 \text { months- } 22 \text { years). Acute onset, 18. Previous } \\
\text { outpatient treatment, } 33 \text {. Previous inpatient treatment, } 18.32 \text { used medication. } 37 \text { used } \\
\text { technical aids. } \\
\text { Setting: outpatient psychiatric departments in The Netherlands. }\end{array}$ \\
\hline Interventions & $\begin{array}{l}\text { Both groups consisted of inpatient treatment programme (group work, individual } \\
\text { physiotherapy, exercise and bed rest). } \\
\text { Treatment group }(\mathrm{N}=26 \text { ) included an introductory session followed by } 1 \text { hour per week for } \\
8 \text { weeks of hypnosis. Also encouraged to practice self hypnosis for } 1 / 2 \text { hour per day with } \\
\text { audiotape. } \\
\text { Control group }(\mathrm{N}=23 \text { ) included } 8 \text { weeks of } 1 \text { hour sessions encouraging patients to talk } \\
\text { about their experience and homework to write about sessions. }\end{array}$ \\
\hline Outcomes & $\begin{array}{l}\text { Video Rating Scale for Motor Conversion Symptoms. } \\
\mathrm{D} \text { (isabilities) code items from the International Classification of Impairments, Disabilities } \\
\text { and Handicaps. } \\
\text { Symptom CheckList-90. } \\
\text { Stanford Hypnotic Clinical Scale for Adults. } \\
\text { Patient expectations of treatment outcome. } \\
\text { Leaving the study early. }\end{array}$ \\
\hline \multicolumn{2}{|l|}{ Notes } \\
\hline $\begin{array}{l}\text { Allocation } \\
\text { concealment }\end{array}$ & B - Unclear \\
\hline
\end{tabular}


96 Chapter 5

Characteristics of included studies

\begin{tabular}{|c|c|}
\hline Study & Moene 2003 \\
\hline Methods & $\begin{array}{l}\text { Method of randomisation: block. } \\
\text { Blinding: assessors blind. } \\
\text { Treatment duration: } 3 \text { months (follow up at } 6 \text { months for treatment group). }\end{array}$ \\
\hline Participants & $\begin{array}{l}\text { Diagnosis: Conversion Disorder (motor type) or Somatisation Disorder (with motor } \\
\text { conversion symptoms) using DSM IIIR criteria } \\
\mathrm{N}=44 \text {. } \\
\text { Participants: } 75 \% \text { female, mean age } 36.6 \text { years (sd } 11 \text { years, range } 18-61 \text { years). } \\
\text { History: Mean age of onset, } 33.8 \text { years (sd } 11.3 \text { years, range } 15-59 \text { years). Mean symptom } \\
\text { duration, } 3.7 \text { years (sd } 4.7 \text { months, range } 2 \text { months }-16.7 \text { years). Previous history of same } \\
\text { or other conversion symptoms, 18. Sudden onset, } 16 \text {. Identifiable stressor reported, } 12 . \\
\text { Previous psychiatric care, } 32 \text { ( } 9 \text { as inpatient). } 21 \text { used medication. } 16 \text { used technical aids. } \\
\text { Setting: Outpatient psychiatric departments in The Netherlands. }\end{array}$ \\
\hline Interventions & $\begin{array}{l}\text { Treatment group ( } \mathrm{N}=24) 1 \text { hour introductory session explaining rationale for using } \\
\text { hypnosis followed by hypnosis sessions } 1 \text { hour per week for } 10 \text { weeks. Also encouraged to } \\
\text { practice self hypnosis for } 1 / 2 \text { hour per day with audiotape. } \\
\text { Control group }(\mathrm{N}=25 \text { ) waiting list for hypnosis. }\end{array}$ \\
\hline Outcomes & $\begin{array}{l}\text { Video Rating Scale for Motor Conversion Symptoms. } \\
\text { D(isabilities) code items from the International Classification of Impairments, Disabilities } \\
\text { and Handicaps. } \\
\text { Symptom CheckList- } 90 \text {. } \\
\text { Stanford Hypnotic Clinical Scale for Adults. } \\
\text { Patient expectations of treatment outcome. } \\
\text { Leaving the study early. }\end{array}$ \\
\hline \multicolumn{2}{|l|}{ Notes } \\
\hline $\begin{array}{l}\text { Allocation } \\
\text { concealment }\end{array}$ & B - unclear \\
\hline
\end{tabular}

Characteristics of excluded studies

\begin{tabular}{|c|c|}
\hline Study & Reason for exclusion \\
\hline Aboukasm 1998 & Not RCT: retrospective, non-randomised. \\
\hline Betts 1992a & Not RCT: retrospective, non-randomised. \\
\hline Betts 1992b & Not RCT: retrospective, non-randomised. \\
\hline Bhattacharyya 1971 & Not RCT: no control group. \\
\hline Bleichhardt 2004 & $\begin{array}{l}\text { RCT for CBT of multiple somatoform symptoms but no indication of the symptoms of } \\
\text { the sample; therefore no indication that people with non-epileptic attacks were } \\
\text { included in the sample. }\end{array}$ \\
\hline Buchanan 1993 & Not RCT: retrospective, non-randomised. \\
\hline Chemali 2004 & Not RCT: case report. \\
\hline Couprie 1995 & Not RCT: case report. \\
\hline Dickes 1974 & Not RCT: allocation, no control group. \\
\hline Dickinson 2003 & $\begin{array}{l}\text { RCT for care recommendation letter intervention for somatization in primary care but } \\
\text { no indication of the symptoms of the sample; therefore no indication that people with } \\
\text { non-epileptic attacks were included in the sample. }\end{array}$ \\
\hline Farias 2003 & Not RCT: no control group for people with non-epileptic attacks. \\
\hline Ford 1977 & No indication that people with non-epileptic attacks were included in the sample. \\
\hline Goldstein 2004 & Not RCT: open trial of the effectiveness of CBT on treatment of non-epileptic attacks. \\
\hline Hellman 1990 & $\begin{array}{l}\text { RCT for behavioural medicine interventions for people with psychosomatic } \\
\text { complaints. No indication that people with non-epileptic attacks were included in the } \\
\text { sample. }\end{array}$ \\
\hline Hiller 2003 & Neurological symptoms indicated but non-epileptic attacks not specified. \\
\hline
\end{tabular}


Characteristics of excluded studies

\begin{tabular}{|c|c|}
\hline Study & Reason for exclusion \\
\hline Jongsma 1999 & Not RCT: follow-up study. \\
\hline Kolk 2004 & RCT: no indication that people with non-epileptic attacks were included in the sample \\
\hline Krull 1990 & Not RCT: no control group. \\
\hline Larisch 2004 & $\begin{array}{l}\text { RCT: no indication that people with non-epileptic attacks were included in the } \\
\text { sample. }\end{array}$ \\
\hline Lehmann 1984 & $\begin{array}{l}\text { RCT: no indication that people with non-epileptic attacks were included in the } \\
\text { sample. }\end{array}$ \\
\hline Lempert 1990 & Not RCT: retrospective data collection. \\
\hline Lidbeck 1997 & $\begin{array}{l}\text { RCT: no indication that people with non-epileptic attacks were included in the } \\
\text { sample. }\end{array}$ \\
\hline Lyles 2003 & $\begin{array}{l}\text { RCT: no indication that people with non-epileptic attacks were included in the } \\
\text { sample. }\end{array}$ \\
\hline McDade 1992 & Not RCT: no control group. \\
\hline Menza 2001 & $\begin{array}{l}\text { Not RCT: not randomised, no control group, no indication that people with non- } \\
\text { epileptic attacks were included in the study. }\end{array}$ \\
\hline Muller 2001 & RCT: no indication that people with non-epileptic attacks were included in the study. \\
\hline Noyes 1998 & $\begin{array}{l}\text { Not RCT: not randomised and no control group. No indication that people with non- } \\
\text { epileptic attacks were included in the study. }\end{array}$ \\
\hline Peters 2002 & RCT: No indication that people with non-epileptic attacks were included in the study. \\
\hline Prigatano 2002 & Not RCT: no control group. \\
\hline Pu 1986 & Not RCT: no control group. \\
\hline Ramani 1982 & Not RCT: no control group. \\
\hline Riaz 1998 & Not RCT: retrospective study. \\
\hline Rost 1994 & RCT: no indication that people with non-epileptic attacks were included in the study. \\
\hline Rusch 2001 & Not RCT: no control group and no randomisation. \\
\hline Shapiro 1997 & Not RCT: no control group. \\
\hline Shapiro 2004 & $\begin{array}{l}\text { Not RCT: no indication that people with non-epileptic attacks were included in the } \\
\text { study. }\end{array}$ \\
\hline Sheehan 1980 & RCT: no indication that people with non-epileptic attacks were included in the study. \\
\hline Skupin 1975 & $\begin{array}{l}\text { Not RCT: no indication that people with non-epileptic attacks were included in the } \\
\text { study. }\end{array}$ \\
\hline Smith 1986 & RCT: no indication that people with non-epileptic attacks were included in the study. \\
\hline Speckens 1995 & RCT: no indication that people with non-epileptic attacks were included in the study. \\
\hline Speed 1996 & $\begin{array}{l}\text { Not RCT: no control group and no indication that people with non-epileptic attacks } \\
\text { were included in the study. }\end{array}$ \\
\hline Sumathipala 2000 & RCT: no indication that people with non-epileptic attacks were included in the study. \\
\hline Swingle 1998 & Not RCT: no control group and no randomisation. \\
\hline Volz 2000 & RCT: no indication that people with non-epileptic attacks were included in the sample. \\
\hline Volz 2003 & RCT: no indication that people with non-epileptic attacks were included in the sample. \\
\hline Wilkinson 1994 & $\begin{array}{l}\text { Not RCT: no control group, no randomisation and no indication that people with non- } \\
\text { epileptic attacks were included in the sample. }\end{array}$ \\
\hline Williams 1979 & Not RCT: no control group and no randomisation. \\
\hline Zaroff 2004 & Not RCT: no control group. \\
\hline
\end{tabular}


98 Chapter 5

Cover sheet

Title Treatments for non-epileptic attack disorder

Author(s) Baker GA, Brooks JL, Goodfellow L, Bodde N, Aldenkamp A

Contribution Baker, G.A (guarantor of the review) was involved in the following:

of author(s) conceiving the review, designing the review, coordinating the review, data collection for the review, screening search results, screening retrieved papers against inclusion criteria, appraising quality of papers, interpretation of data, performing previous work that was the foundation of current study, providing general advice on the review, writing the review, providing a methodological perspective, providing a clinical perspective, providing a policy perspective, providing a consumer perspective.

Brooks, J was involved in the following: designing the review, coordinating the review, data collection for the review, screening search results, organizing retrieval of papers, screening retrieved papers against inclusion criteria, appraising quality of papers, abstracting data from papers, writing to authors of papers for additional information, providing additional data about papers, obtaining and screening data on unpublished studies, data management for the review, interpretation of data, providing a methodological perspective, providing a clinical perspective, providing a policy perspective, providing a consumer perspective, writing the review.

Goodfellow, L. was involved in: data collection for the review, screening search results, organising retrieval of papers, screening retrieved papers against inclusion criteria, appraising quality of papers, abstracting data from papers, data management for the review.

Bodde, N. was involved in: conceiving the review, designing the review, appraising quality of papers, abstracting data from papers, providing a methodological perspective, providing a clinical perspective, providing general advice on the review.

Aldenkamp, A.P. was involved in: conceiving the review, designing the review, appraising quality of papers, abstracting data from papers, providing a methodological perspective, providing a clinical perspective, providing general advice on the review, performing previous work that was the foundation of current study. 


\section{References}

\section{References to studies included in this review}

Ataoglu 2003 \{published data only\}

Ataoglu A, Ozcetin A, Icmeli C, Ozbulut O. Paradoxical therapy in conversion reaction. Journal of Korean Medicine 2003;18:581-4.

Moene 2002 \{published data only\}

Moene FC, Spinhoven P, Hoogduin KA., van Dyck R. A randomised controlled clinical trial on the additional effect of hypnosis in a comprehensive treatment programme for in-patients with conversion disorder of the motor type. Psychotherapy and Psychosomatics 2002;71:66-76.

Moene 2003 \{published data only\}

Moene FC, Spinhoven P, Hoogduin KA, van Dyck R. A randomized controlled clinical trial of a hypnosis-based treatment for patients with conversion disorder, motor type. International Journal of Clinical and Experimental Hypnosis 2003;51:29-80.

\section{References to studies excluded from this review}

Aboukasm 1998

Aboukasm A, Mahr G, Gahry BR, Thomas A, Barkley GL. Retrospective analysis of the effects of psychotherapeutic interventions on outcomes of psychogenic nonepileptic seizures. Epilepsia 1998;39:470-3.

Betts 1992

Betts T, Boden S. Diagnosis, management and prognosis of a group of 128 patients with non-epileptic attack disorder. Seizure 1992;1(Part I):19-26.

Betts 1992b

Betts T, Boden S. Diagnosis, management and prognosis of a group of 128 patients with non-epileptic attack disorder. Previous childhood sexual abuse in the aetiology of these disorders. Seizure 1992;1(Part II):27-32.

Bhattacharyya 1971

Bhattacharyya DD, Singh R. Behavior therapy of hysterical fits. American Journal of Psychiatry 1971;128:602-6.

Bleichhardt 2004

Bleichhardt G, Timmer B, Rief W. Cognitive-behavioural therapy for patients with multiple somatoform symptoms--a randomised controlled trial in tertiary care. Journal of Psychosomatic Research 2004;56:449-54.

Buchanan 1993

Buchanan N, Snars J. Pseudoseizures (non-epileptic attack disorder) - clinical management and outcome in 50 patients. Seizure 1993;2:141-6.

Chemali 2004

Chemali Z, Meadows M. The use of eye movement desensitization and reprocessing in the treatment of psychogenic seizures. Epilepsy and Behavior 2004;5:784-7.

Couprie 1995

Couprie W, Wijkicks EFM, Rooijmans HGM, van Gijn J. Outcome in conversion disorder: a follow up study. Journal of Neurology, Neurosurgery and Psychiatry 1995;58:750-2.

Dickes 1974

Dickes RA. Brief therapy of conversion reactions: an in-hospital technique. American Journal of Psychiatry 1974;131:584-6.

Dickinson 2003

Dickinson WP, Dickinson LM, deGruy FV, Main DS, Candib LM, Rost K. A randomized clinical trial of a care recommendation letter intervention for somatization in primary care. Annals of Family Medicine 2003;1:228-35. 
$100 \mid$ Chapter 5

Farias 2003

Farias ST, Thieman C, Alsaadi TM. Psychogenic nonepileptic seizures: acute change in event frequency after presentation of the diagnosis. Epilepsy and Behavior 2003;4:424-9.

Ford 1977

Ford CV, Long KD. Group psychotherapy of somatizing patients. Psychotherapy and Psychosomatics 1977;28:294-304.

Goldstein 2004

Goldstein LH, Deale AC, Mitchell-O'Malley SJ, Toone BK, Mellers JD. An evaluation of cognitive behavioral therapy as a treatment for dissociative seizures: a pilot study. Cognitive and Behavioral Neurology 2004;17:41-9.

Hellman 1990

Hellman CJ, Budd M, Borysenko J, McClelland DC, Benson H. A study of the effectiveness of two group behavioral medicine interventions for patients with psychosomatic complaints.Behavioral Medicine 1990;16:165-73.

Hiller 2003

Hiller W, Fichter MM, Rief W. A controlled treatment study of somatoform disorders including analysis of healthcare utilization and cost-effectiveness. Journal of Psychosomatic Research 2003;54:369-80.

Jongsma 1999

Jongsma MJ, Mommers JM, Renier WO, Meinardi H. Follow-up of psychogenic, non-epileptic seizures: a pilot study-experience in a Dutch special centre for epilepsy. Seizure 1999;8:146-8.

Kolk 2004

Kolk AM, Schagen S, Hanewald GJ. Multiple medically unexplained physical symptoms and health care utilization: outcome of psychological intervention and patient-related predictors of change. Journal of Psychosomatic Research 2004;57:379-89.

Krull 1990

Krull F, Schifferdecker M. Inpatient treatment of conversion disorder: a clinical investigation of outcome. Psychotherapy and Psychosomatics 1990;53:161-8.

Larisch 2004

Larisch A, Schweickhardt A, Wirsching M, Fritzsche K. Psychosocial interventions for somatizing patients by the general practitioner: a randomized controlled trial. Journal of Psychosomatic Research 2004;57:507-14.

Lehmann 1984

Lehmann E, Hassel P, Thorner GW, Karrass W. [Alternative therapy concept for the treatment of psychosomatic disorders. Controlled double-blind evaluation of fluspirilene versus bromazepam]. Fortschritte der Medizin 1984;102:1033-6.

Lempert 1990

Lempert T, Schmidt D. Natural history and outcome of psychogenic seizures: a clinical study in 50 patients. Journal of Neurology 1990;237:35-8.

Lidbeck 1997

Lidbeck J. Group therapy for somatization disorders in general practice: effectiveness of a short cognitive-behavioural treatment model. Acta Psychiatrica Scandinavica 1997;96:14-24.

Lyles 2003

Lyles JS, Hodges A, Collins C, Lein C, Given CW, Given B, et al. Using nurse practitioners to implement an intervention in primary care for high-utilizing patients with medically unexplained symptoms. General Hospital Psychiatry 2003;25:63-73.

McDade 1992

McDade G, Brown SW. Non-epileptic seizures: management and predictive factors of outcome. Seizure 1992;1:7-10.

Menza 2001

Menza M, Lauritano M, Allen L., Warman M, Ostella F, Hamer RM, et al. Treatment of somatization disorder with nefazodone: a prospective, open-label study. Annals of Clinical Psychiatry 2001;13(3):153-8. 
Muller 2001

Muller T, Mannel M, Murck H, Rahlfs VW. Treatment of somatoform disorders with St. John's wort: a randomized, double-blind and placebo-controlled trial. Psychosomatic Medicine 2004;66:538-47.

Noyes 1998

Noyes R Jr, Happel RL, Muller BA, Holt CS, Kathol RG, Sieren LR et al. Fluvoxamine for somatoform disorders: an open trial. General Hospital Psychiatry 1998;20:339-44.

Peters 2002

Peters S, Stanley I, Rose M, Kaney S, Salmon P. A randomized controlled trial of group aerobic exercise in primary care patients with persistent, unexplained physical symptoms. Family Practice 2002;19:665-74.

Prigatano 2002

Prigatano GP, Stonnington CM, Fisher RS. Psychological factors in the genesis and management of nonepileptic seizures: clinical observations. Epilepsy and Behavior 2002;3:343-9. Pu 1986

Pu T, Mohamed E, Iman K, El-Roey A. One hundred cases of hysteria in Eastern Libya: A sociodemographic study. British Journal of Psychiatry 1986;148:606-9.

Ramani 1982

Ramani V, Gumnit RJ. Management of hysterial seizures in epileptic patients. Archives of Neurology 1982;39:78-81.

Riaz 1998

Riaz H, Comish S, Lawton L, Scheepers B. Non-epileptic attack disorder and clinical outcome: a pilot study. Seizure 1998;7:365-8.

Rost 1994

Rost K, Kashner TM, Smith RG Jr. Effectiveness of psychiatric intervention with somatization disorder patients: improved outcomes at reduced costs. General Hospital Psychiatry 1994;16(6):381-9.

Rusch 2001

Rusch MD, Morris GL, Allen L, Lathrop L. Psychological treatment of nonepileptic events. Epilepsy and Behavior 2001;2:277-83.

Shapiro 1997

Shapiro AP, Teasell RW. Strategic-behavioural intervention in the inpatient rehabilitation of nonorganic (factitious/conversion) motor disorders. Neurorehabilitation 1997;8:183-92.

Shapiro 2004

Shapiro AP, Teasell W. Behavioural interventions in the rehabilitation of acute $v$ chronic non-organic (conversion/ factitious) motor disorders. British Journal of Psychiatry 2004;185:140-6.

Sheehan 1980

Sheehan DV, Ballenger J, Jacobsen G. Treatment of endogenous anxiety with phobic, hysterical, and hypochondriacal symptoms. Archives of General Psychiatry 1980;37:51-9. Skupin 1975

Skupin G, Franzke HG. [The role of chlorazepate dipotassium (Tranxilium) in the therapy of psychosomatic syndromes (author's translation)]. Medizinische Klinik 1975;70:1279-83.

Smith 1986

Smith G R Jr, Monson RA, Ray DC. Psychiatric consultation in somatization disorder. A randomized controlled study. New England Journal of Medicine 1986;314:1407-13.

Speckens 1995

Speckens AE, van Hemert AM, Spinhoven P, Hawton KE, Bolk JH, Rooijmans HG. Cognitive behavioural therapy for medically unexplained physical symptoms: a randomised controlled trial. British Medical Journal 1995;7016:1328-32.

Speed 1996

Speed J. Behavioral management of conversion disorder: retrospective study. Archives of Physical Medicine and Rehabilitation 1996;77:147-54.

Sumathipala 2000

Sumathipala A, Hewege S, Hanwella R, Mann AH. Randomized controlled trial of cognitive behaviour therapy for repeated consultations for medically unexplained complaints: a feasibility study in Sri Lanka. Psychological Medicine 2000;30:747-57. 
102 Chapter 5

Swingle 1998

Swingle PG. Neurofeedback treatment of pseudoseizure disorder. Biological psychiatry 1998;44:11969.

Volz 2000

Volz HP, Moller H.J, Reimann I, Stoll K D. Opipramol for the treatment of somatoform disorders results from a placebo-controlled trial. European Neuropsychopharmacology 2000;10:211-7. Volz 2003

Volz HP, Murck H, Kasper S, Moller HJ. St John's wort extract (LI 160) in somatoform disorders: results of a placebo-controlled trial.[erratum appears in Psychopharmacology (Berl). 2003;167(3):333]. Psychopharmacology 2002;164:294-300.

Wilkinson 1994

Wilkinson P, Mynors-Wallis L. Problem-solving therapy in the treatment of unexplained physical symptoms in primary care: a preliminary study. Journal of Psychosomatic Research 1994;38(6):591-8. Williams 1979

Williams DT, Gold AP, Shrout P, Shaffer D, Adams D. The impact of psychiatric intervention on patients with uncontrolled seizures. Journal of Nervous and Mental Disease 1979;167:626-31. Zaroff 2004

Zaroff CM, Myers L, Barr WB, Luciano D, Devinsky O. Group psychoeducation as treatment for psychological nonepileptic seizures. Epilepsy and Behavior 2004;5:587-92.

\section{Additional references}

Allen 2002

Allen LA, Escobar JI, Lehrer PM, Gara MA, Woolfolk RL. Psychosocial treatments for multiple unexplained physical symptoms: a review of the literature. Psychosomatic Medicine 2002;64:939-50. Ataoglu 1998

Ataoglu A, Sir A, Ozkan, M. Paradoxical therapy in conversion disorder. Turkish Journal of Medical Sciences 1998;28:419-21. Betts 1993

Betts T, Duffy N. Non-epileptic attack disorder (pseudoseizures) and sexual abuse: a review. In: Gram L, Johannessen SI, Osterman PO, Sillanpää M, editors(s). Pseudo Epileptic Seizures. Petersfield: Wrightson Biomedical, 1993:55-65.

Devinsky 1998

Devinsky O. Nonepileptic psychogenic seizures: Quagmires of pathophysiology, diagnosis and treatment. Epilepsia 39;5:458-62.

Francis 1999a

Francis P, Baker GA. Non-epileptic attack disorder (NEAD): a comprehensive review. Seizure 1999;8:53-61.

Francis $1999 b$

Francis PL, Baker GA, Appleton PL. Stress and avoidance in pseudoseizures: testing the assumptions. Epilepsy Research 1999;34:241-9.

Heminghyt 1993

Heminghyt E, Areng S, Slinning R. An eclectic approach to the treatment of pseudo-epileptic seizures. In: Gram L, Johannessen SI, Osterman PO, Sillanpää M, editors(s). Pseudo Epileptic Seizures. Petersfield: Wrightson Biomedical, 1993:55-65.

Kroenke 2000

Kroenke K, Swindle R. Cognitive-behavioral therapy for somatization and symptom syndromes: a critical review of controlled clinical trials. Psychotherapy and Psychosomatics 2000;69:205-15.

LaFrance 2004

LaFrance WC Jr., Devinsky O. The treatment of nonepileptic seizures: historical perspectives and future directions. Epilepsia 2004;45(Suppl 2):15-21.

Lesser 2003

Lesser RP. Treatment and outcome of psychogenic nonepileptic seizures. Epilepsy Currents 2003;3:198-200. 
Martin 2003

Martin R, Bell B, Hermann B, Mennemeyer S. Non epileptic seizures and their costs: the role neuropsychology. In: Pritigano GP, Pliskin NH, editors(s). Clinical Neuropsychology and Cost outcome Research: A beginning. NY USA: Psychology Press, 2003:235-58.

Moene 1998

Moene FC, Hoogduin K AL, van Dyck R. The inpatient treatment of patients suffering from (motor) conversion symptoms: a description of eight cases. International Journal of Clinical and Experimental Hypnosis 1998;46:171-90.

Ramani 1993

Ramani V. Review of psychiatric treatment strategies in non-epileptic seizures. In: Rowan AJ, Gates JR, editors(s). Non-epileptic seizures. MA, USA: Butterworth-Heinemann, 1993:259-67.

Reilly 1999

Reilly J, Baker GA, Rhodes J, Salmon P. The association of sexual and physical abuse with somatization: characteristics of patients presenting with irritable bowel syndrome and non-epileptic attack disorder. Psychological Medicine 1999;29:399-406.

Reuber 2002

Reuber M, House AO. Treating patients with psychogenic non-epileptic seizures. Current Opinion in Neurology 2002;15:207-11.

Reuber 2005

Reuber M, Howlett S, Kemp S. Psychologic treatment of patients with psychogenic nonepileptic seizures. Expert Review in Neurotherapeutics 2005;5:737-52.

Rusch 2001

Rusch MD, Morris GL, Allen L, Lathrop L. Psychological treatment of nonepileptic events. Epilepsy and behaviour 2001;2:277-83.

Stone 2004

Stone J, Sharpe M, Binzer M. Motor conversion symptoms and pseudoseizures: a comparison of clinical characteristics. Psychosomatics 2004;45:492-99. 
104 । 


\section{Chapter 6}

Nondrug treatments for psychogenic non-epileptic seizures: what's the evidence?

JL Brooks, L Goodfellow, NMG Bodde, AP Aldenkamp, GA Baker Epilepsy Behav 2007;11:367-77 
106 Chapter 6

\section{Abstract}

\section{Objective}

The purpose of this Cochrane review was to establish the evidence base for treatment of psychogenic nonepileptic seizures.

\section{Methods}

Six hundred eight references were identified using a search strategy designed with the support of the Cochrane Review Epilepsy Group library. The search employed Medline and Psychlnfo, and included hand searches of relevant journals (Seizure, Epilepsia, Epilepsy \& Behavior, Epilepsy Research).

\section{Results}

Three studies were found that met the inclusion criteria; two used hypnosis and one used paradoxical therapy. None included detailed reports of improved seizure frequency or quality of life, although reduction in seizure frequency was mentioned. All three studies concluded that the intervention used was beneficial in the treatment of psychogenic non-epileptic seizures.

\section{Conclusions}

The limited number of studies and poor methodology preclude these results from being generalizable. There is a need for well- designed clinical trials to identify the most suitable treatments for this population. 


\section{Introduction}

Although much research has been devoted to the etiology of psychogenic nonepileptic seizures ${ }^{1,2}$, little attention has been given to the systematic evaluation of treatment programs, although there have been various reviews of the research literature over the years ${ }^{3-7}$. Patients with psychogenic non-epileptic seizures represent a heterogeneous group with diverse psychological problems against a background of long-standing physical, psychological, or sexual abuse, inadequate social skills and chronic adjustment problems ${ }^{1,2,8}$. Consequently, psychogenic non-epileptic seizures (PNES) represent a serious problem for the patient, the family, and the treating clinician. The costs to society can be significant, with reported costs in the United States of US\$100,000 per year per patient ${ }^{9}$. The challenge for the treating clinician relates to providing an accurate diagnosis and an effective treatment. The evidence for how best to manage and treat patients with this condition, however, is scarce. The available evidence relies on clinical case studies or studies that lack scientific rigor. In addition, there is no overall theoretical framework for the understanding of PNES on which to base the development of treatment strategies and research protocols. Various psychological and nonpsychological interventions, such as cognitive behavior therapy $(\mathrm{CBT})^{4,10,11}$, eye movement desensitization and reprocessing ${ }^{13}$, and neurofeedback ${ }^{14}$, have been used alone or in combination in the treatment of PNES to reduce attack frequency and improve quality of life.

In the studies, there was variable detail provided regarding how the diagnosis of PNES was given, although diagnosis is usually through exclusion of epilepsy and other paroxysmal conditions. Expert analysis of video-telemetry recordings can result in identification of PNES as the result of seizure-like physical activity in the absence of any EEG correlates. More details regarding how these diagnoses are made are given in Reuber's 2005 article $^{15}$. In some cases, because the diagnosis of conversion disorder was the focus, rather than the more specific PNES, DSM-IV criteria were used ${ }^{16}$.

Several studies have attempted to document the treatment outcomes of various types of intervention. McDade and Brown reported on the outcomes of treatment using psychotherapy, occupational therapy, and minimal attention within an in patient setting. The authors concluded that prognosis for PNES is good when management takes place in a specialist unit with a multidisciplinary approach and a team familiar with this patient group ${ }^{17}$. In the same year, Betts and Boden reported on a group of 128 patients diagnosed with PNES over a 5 - year period ${ }^{18}$. A variety of management strategies were offered; these included anxiety management, abreaction, psychotherapy/counseling, family therapy, and medication (major tranquillizers). At discharge it was reported that $63 \%$ (76) of patients no longer had PNES and 24\% (29) had a partial resolution; the remainder had either no change or were worse. At 2- year follow up, seizures had returned in 34\% (41) and partially returned $14 \%$ (17) while $31 \%$ (37) were still seizure free. In $8 \%(10)$ the diagnosis of PNES was found to be incorrect. The authors commented that inpatient treatment 
results may be misleading. Once the patient returns to the community and the stresses that may have led to the attack disorder, PNES may return ${ }^{18}$.

Confrontation with diagnosis, psychotherapy and continuing clinical care were the main components of a study by Buchanan and Snars, who reported that 9 of 32 became seizure free, 11 of 32 significantly improved, and 8 of 32 exhibited no change at all $^{19}$. A later study involved combining neurofeedback with psychotherapy ${ }^{14}$. The author concluded that reductions in the theta/SMR ratio brought about by neurofeedback were associated with reductions in seizure behavior. Swingle also added the use of EEG feedback training. He commented on the absence of a control group and the limitations this puts on the generalizability of his findings.

In their retrospective study, Aboukasm et al. divided 61 patients into four groups: (A) those receiving comprehensive epilepsy program (CEP) psychotherapy; (B) those only under a CEP neurologist's care; (C) those receiving non-CEP psychotherapy; and (D) those with no feedback or intervention. There were no details about the type of psychotherapy used. The authors reported that Group D had significantly less desirable PNES clinical outcomes than the other three groups and less improvement in quality of life (QOL). They concluded that psychotherapy and feedback by CEP professionals experienced in epilepsy and PNES were beneficial compared with other or no interventions ${ }^{20}$. Rusch et al. described how the psychotherapeutic interventions focused on one of six symptom patterns: acute anxiety/panic; impaired affect regulation and interpersonal skills; somatization/conversion; depression; posttraumatic stress disorder; and reinforced behavior pattern. Patients were treated according to the symptom pattern; for example, those in the acute anxiety/panic group received cognitive therapy with exposure; those in the reinforced behavior pattern group received behavioral management strategies involving family or significant other participation to directly modify reinforcement patterns. Twenty-six of thirty-three patients completed treatment, and of those, 21 were event free by the end of treatment, the remaining 5 showing a significant reduction in frequency ${ }^{3}$.

An open-ended group psychotherapy program was published by Zaroff et al. This treatment was given to 10 patients with PNES and included a "disorder-specific psychoeducation treatment component". Only 7 of the 10 completed the majority of psychoeducational sessions. Seizure frequency was measured pre- and posttreatment. Four patients had no change in seizure frequency, but three of these were seizure free at treatment initiation. Two patients had a reduction in seizure frequency, and one, an increase. The authors concluded that there was a nonsignificant trend toward improved QOL (as measured by the Quality of Life in Epilepsy-31 Inventory [QOLIE-31]). They also note that seizure remission following diagnosis supports the hypothesis that education about the disorder is effective in its treatment ${ }^{22}$.

Many of these studies, however, were plagued by methodological difficulties, and none were randomized controlled clinical trials. Randomized controlled clinical trials (RCTs) represent the gold standard for evaluating the clinical effectiveness of treatment. The aim of this article is to systematically review RCTs that have evaluated 
the outcomes of treatment for patients with PNES. The excluded studies are summarized in Table 6.1.

The main objectives of the review were to assess whether RCTs of treatments for PNES result in a reduction in frequency of seizures and/or improvement in QOL and to assess if any treatment is significantly more effective than others. Treatments included CBT, hypnotherapy, and paradoxical therapy. Medication trials were not included specifically in this review as our focus was noninvasive, nondrug treatments for PNES. Primary outcome measures were seizure frequency and percentage change in seizure frequency. Secondary outcome measures were QOL and seizure severity measures.

A formal systematic review has been completed as part of The Cochrane Library series.

Table 6.1 Characteristics of excluded studies.

\begin{tabular}{|c|c|}
\hline Study & Reason for exclusion \\
\hline Aboukasm et al., $1998^{35}$ & Not RCT: retrospective, nonrandomized \\
\hline Betts and Boden , $1992^{36}$ & Not RCT: retrospective, nonrandomized \\
\hline Betts and Boden, $1992^{37}$ & Not RCT: retrospective, nonrandomized \\
\hline Bhattacharyya and Singh, $1971^{38}$ & Not RCT: no control group \\
\hline Bleichhardt et al., $2004^{39}$ & $\begin{array}{l}\text { RCT for CBT of multiple somatoform symptoms, but no indication of } \\
\text { the symptoms of the sample; therefore, no indication that people with } \\
\text { non-epileptic attacks were included in the sample }\end{array}$ \\
\hline Buchanan and Snars, $1993^{40}$ & Not RCT: retrospective, nonrandomised \\
\hline Chemali et al., $2004^{13}$ & Not RCT: case report \\
\hline Couprie et al., $1995^{41}$ & Not RCT: case report \\
\hline Dickes, $1974^{42}$ & Not RCT: allocation, no control group \\
\hline Dickinson et al., $2003^{43}$ & $\begin{array}{l}\text { RCT assessing the impact of a care recommendation letter intervention } \\
\text { for somatization in primary care, but no indication of the symptoms of } \\
\text { the sample; therefore, no indication that people with non-epileptic } \\
\text { attacks were included in the sample }\end{array}$ \\
\hline Farias et al., $2003^{44}$ & Not RCT: no control group for people with non-epileptic attacks \\
\hline Ford and Long, $1977^{45}$ & $\begin{array}{l}\text { No indication that people with non-epileptic attacks were included in } \\
\text { the sample }\end{array}$ \\
\hline Goldstein et al., $2004^{46}$ & $\begin{array}{l}\text { Not RCT: open trial of the effectiveness of CBT in treatment of non- } \\
\text { epileptic attacks }\end{array}$ \\
\hline Hellman et al., $1990^{47}$ & $\begin{array}{l}\text { RCT for behavioral medicine interventions for people with } \\
\text { psychosomatic complaints; no indication that people with non- } \\
\text { epileptic attacks were included in the sample }\end{array}$ \\
\hline Hiller et al., $2003^{48}$ & $\begin{array}{l}\text { Neurological symptoms indicated, but non-epileptic attacks not } \\
\text { specified }\end{array}$ \\
\hline Jongsma et al., $1999^{49}$ & Not RCT: follow-up study \\
\hline Kolk et al., $2004^{50}$ & $\begin{array}{l}\text { RCT: no indication that people with non-epileptic attacks were included } \\
\text { in the sample }\end{array}$ \\
\hline Krull and Schifferdecker, $1990^{51}$ & Not RCT: no control group \\
\hline Larisch et al., $2004^{52}$ & $\begin{array}{l}\text { RCT: no indication that people with non-epileptic attacks were included } \\
\text { in the sample }\end{array}$ \\
\hline
\end{tabular}


Table 6.1 (Continued)

\begin{tabular}{|c|c|}
\hline Study & Reason for exclusion \\
\hline Lehmann et al., $1984^{53}$ & $\begin{array}{l}\text { RCT: no indication that people with non-epileptic attacks were } \\
\text { included in the sample }\end{array}$ \\
\hline Lempert and Schmidt, $1990^{54}$ & Not RCT: retrospective data collection \\
\hline Lidbeck, $1997^{55}$ & $\begin{array}{l}\text { RCT: no indication that people with non-epileptic attacks were } \\
\text { included in the sample }\end{array}$ \\
\hline Lyles et al., $2003^{56}$ & $\begin{array}{l}\text { RCT: no indication that people with non-epileptic attacks were } \\
\text { included in the sample }\end{array}$ \\
\hline McDade and Brown, $1992^{57}$ & Not RCT: no control group \\
\hline Menza et al., $2001^{58}$ & $\begin{array}{l}\text { Not RCT: not randomized, no control group, no indication that } \\
\text { people with non-epileptic attacks were included in the study }\end{array}$ \\
\hline Muller et al., $2001^{59}$ & $\begin{array}{l}\text { RCT: no indication that people with non-epileptic attacks were } \\
\text { included in the study }\end{array}$ \\
\hline Noyes et al., $1998^{60}$ & $\begin{array}{l}\text { Not RCT: not randomized and no control group; no indication that } \\
\text { people with non-epileptic attacks were included in the study }\end{array}$ \\
\hline Peters et al., $2002^{61}$ & $\begin{array}{l}\text { RCT: no indication that people with non-epileptic attacks were } \\
\text { included in the study }\end{array}$ \\
\hline Prigatano et al., $2002^{62}$ & Not RCT: no control group \\
\hline Pu et al., $1986^{63}$ & Not RCT: no control group \\
\hline Ramani and Gumnit, $1982^{64}$ & Not RCT: no control group \\
\hline Riaz et al., $1998^{65}$ & Not RCT: retrospective study \\
\hline Rost et al., $1994^{66}$ & $\begin{array}{l}\text { RCT: no indication that people with non-epileptic attacks were } \\
\text { included in the study }\end{array}$ \\
\hline Rusch et al., $2001^{3}$ & Not RCT: no control group and no randomization \\
\hline Shapiro Teasell, $1997^{67}$ & Not RCT: no control group \\
\hline Shapiro and Teasell, $2004^{68}$ & $\begin{array}{l}\text { Not RCT: no indication that people with non-epileptic attacks were } \\
\text { included in the study }\end{array}$ \\
\hline Sheehan et al., $1980^{69}$ & $\begin{array}{l}\text { RCT: no indication that people with non-epileptic attacks were } \\
\text { included in the study }\end{array}$ \\
\hline Skupin and Franzke, $1975^{70}$ & $\begin{array}{l}\text { Not RCT: no indication that people with non-epileptic attacks were } \\
\text { included in the study }\end{array}$ \\
\hline Smith et al., $1986^{71}$ & $\begin{array}{l}\text { RCT: no indication that people with non-epileptic attacks were } \\
\text { included in the study }\end{array}$ \\
\hline Speckens et al., $1995^{72}$ & $\begin{array}{l}\text { RCT: no indication that people with non-epileptic attacks were } \\
\text { included in the study }\end{array}$ \\
\hline Speed, $1996^{73}$ & $\begin{array}{l}\text { Not RCT: no control group and no indication that people with non- } \\
\text { epileptic attacks were included in the study }\end{array}$ \\
\hline Sumathipala et al., $2000^{74}$ & $\begin{array}{l}\text { RCT: no indication that people with non-epileptic attacks were } \\
\text { included in the study }\end{array}$ \\
\hline Swingle, $1998^{75}$ & Not RCT: no control group and no randomization \\
\hline Wilkinson and Mynors-Willis, $1994^{76}$ & $\begin{array}{l}\text { Not RCT: no control group, no randomization, and no indication } \\
\text { that people with non-epileptic attacks were included in the sample }\end{array}$ \\
\hline Williams et al., $1979^{77}$ & Not RCT: no control group and no randomization \\
\hline Volz et al., $2000^{78}$ & $\begin{array}{l}\text { RCT: no indication that people with non-epileptic attacks were } \\
\text { included in the sample }\end{array}$ \\
\hline Volz et al., $2003^{79}$ & $\begin{array}{l}\text { RCT: no indication that people with non-epileptic attacks were } \\
\text { included in the sample }\end{array}$ \\
\hline Zaroff et al., $2004^{80}$ & Not RCT: no control group \\
\hline
\end{tabular}




\section{Methods}

Studies were included in the review if they were RCTs or quasi-randomized studies (e.g., where randomization is according to the day of the week or date of birth). The studies may be single or double blind or unblinded. Participants were described as adult male or female with any type of non-organic PNES, with or without learning disabilities. With respect to interventions, any psychological or behavior modification therapies, such as CBT, relaxation therapy, biofeedback, counseling, hypnotherapy, conditioning, physical therapies, massage, and aromatherapy, were included.

Studies were excluded if they did not follow RCT methodology and/or used children in the study.

\section{Search strategy}

The search strategy was designed with support from the Cochrane Review librarian. The search used Medline and PsychInfo (searches conducted on 12 September 2005 using the search strategy detailed in Table 6.2) and included hand searches of relevant journals (Seizure, Epilepsia, Epilepsy \& Behavior, Epilepsy Research). We searched the Cochrane Epilepsy Group's Specialized Register (7 September 2005), the Cochrane Central Register of Controlled Trials (CENTRAL) (The Cochrane Library 2005, issue 3), and cross-references from identified publications. We checked the reference lists of retrieved studies for additional reports of relevant studies.

We identified any cross- references from relevant articles and contacted colleagues to ask if they were aware of any studies that we had missed. Of the 608 references identified, most had to be excluded as they did not refer to the treatment outcomes and did not include people with psychogenic non-epileptic attacks. Of the remaining studies relating specifically to treatment outcomes, an additional 48 were excluded from this review. The identified abstracts were independently checked by five review authors (J.B., G.B., A.A., N.B., and L.G.) to assess the relevance for inclusion in the review.

Trials were independently assessed for inclusion by five review authors (J.B., G.B., A.A., N.B., L.G.), with disagreements resolved by mutual discussion. The same authors independently extracted the following data, and again, any differences of opinion were resolved by mutual discussion:

1. Study methods
a. Design (e.g. parallel or crossover design)
b. Randomization method (allocation concealment and list generation)
c. Blinding method
d. Quality of allocation concealment (A, adequate; B, unclear; C, inadequate) 
2. Participants
a. Number (total/per group)
b. Age and sex distribution
c. Exclusions withdrawal
d. Type of seizures
e. Duration of attack disorder
f. Etiology of attack disorder
g. Presence or absence of learning disability

3. Type of intervention and control

4. Duration of follow up

5. Outcome data (as described earlier)

Table 6.2 Database search strategy

Database: Ovid MEDLINE (R) <1966 to July Week 4 2005>

Search Strategy

exp SEIZURES/ or Seizures.mp. (61960)

non-epileptic attacks.mp.(48)

non-epileptic seizures.mp. (89)

(psychogenic and attack) \$. mp. [mp=title, original title, abstract, name of substance word, subject heading word] (129)

5 (psychogenic and seizure) \$. mp. [mp=title, original title, abstract, name of substance word, subject heading word] (348)

6 pseudoseizures.mp. (329)

7 functional seizure\$.mp.(5)

8 NEAD.mp.(14)

9 non-epileptic attack disorder.mp. (19)

10 hysterical seizure\$.mp. (38)

11 somatoform disorder\$.mp. or exp Somatoform Disorders/ (8769)

12 psychophysiologic\$ disorder\$.mp. or exp Psychophysiologic Disorders/ (15269)

13 dissociative disorders\$.mp. or exp Dissociative Disorder/ (2185)

14 conversion disorder\$.mp. or exp Conversion disorder/ (1528)

15 somatisation.mp. (216)

16 somatization.mp. (1829)

17 psychotherapy.mp. or exp PSYCHOTHERAPY, MULTIPLE/ or exp PSYCHOTHERAPY/ or exp PSYCHOTHERAPY, GROUP/ or exp "IMAGERY (PSYCHOTHERAPY)"/ or exp PSYCHOTHERAPY, BRIEF/ (98665)

18 psychotherapy.mp. or exp PSYCHOTHERAPY, MULTIPLE/ or exp PSYCHOTHERAPY/ or exp PSYCHOTHERAPY, GROUP/ or exp "IMAGERY (PSYCHOTHERAPY)"/ or exp PSYCHOTHERAPY, BRIEF/ or exp PSYCHOTHERAPY, RATIONAL-EMOTIVE/ (98665)

19 assertive therapy.mp. (0)

20 aromatherapy.mp. or exp AROMATHERAPY/ (362)

21 art therapy.mp. or exp Art Therapy/(804)

22 autogenic training.mp. or exp Autogenic Training/(960)

23 abreaction.mp. or exp ABREACTION/ (349)

24 aversive therapy.mp. or exp Aversive Therapy/(778)

25 acceptance commitment therapy.mp. (6)

26 exp Behavior Therapy/ or behavior therapy.mp. (31538)

27 Behavior therapy.mp. (737)

28 Behavior modification.mp. (2014) 
Table 6.2 Database search strategy (continued)

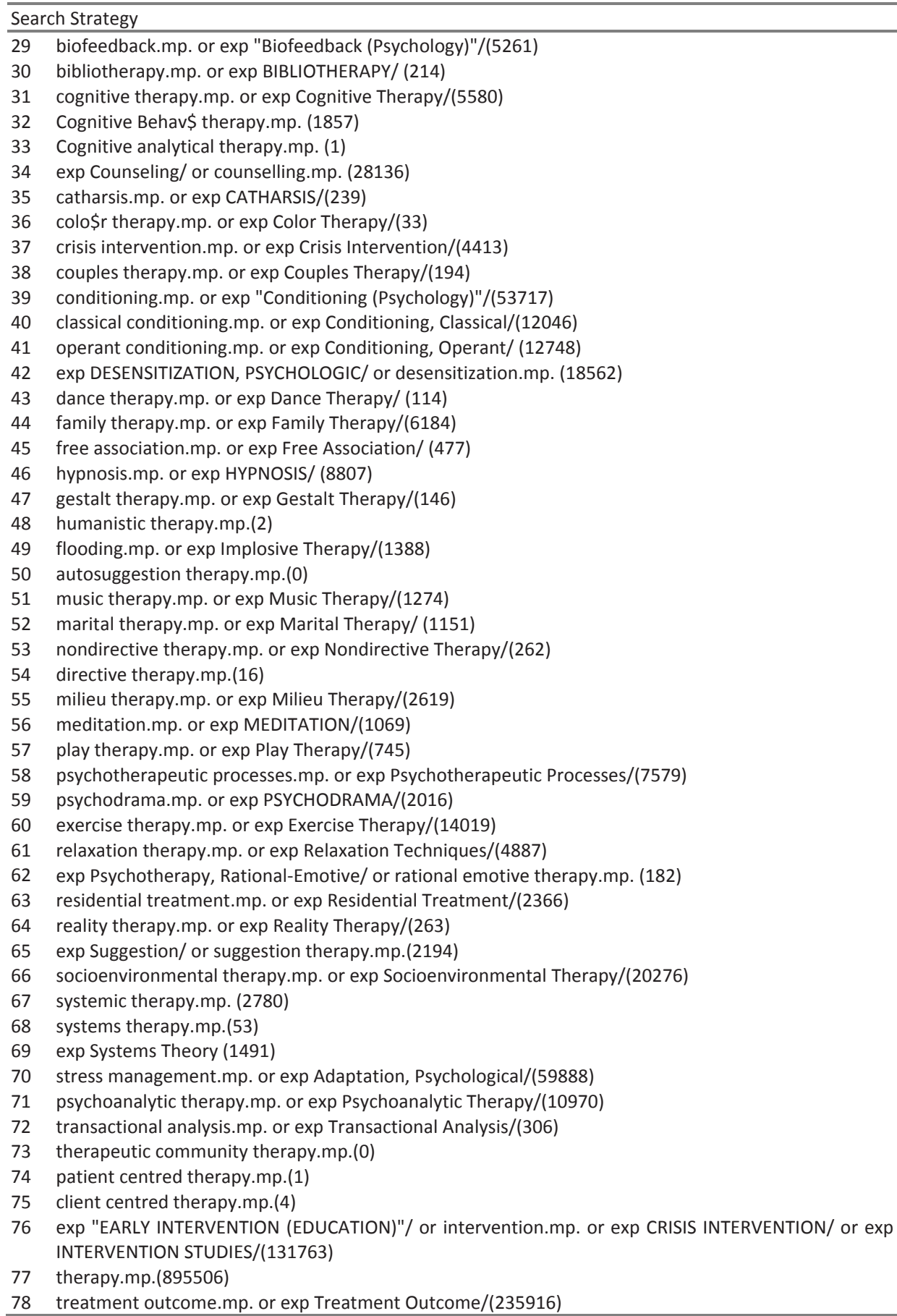


114 Chapter 6

Table 6.2 Database search strategy (continued)

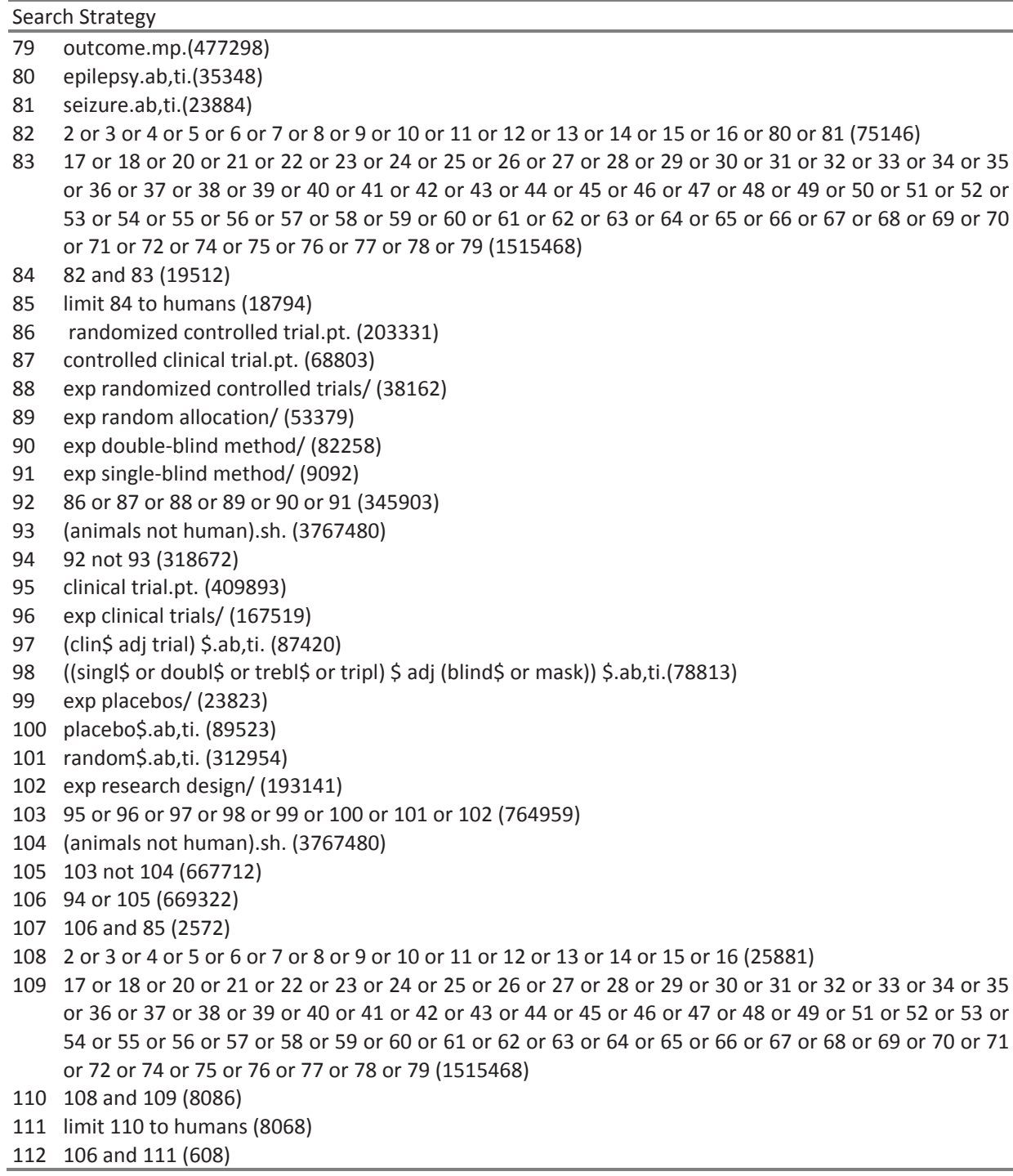

\section{Results}

We reported the results of each intervention separately. As only three RCTs were found, no meta-analysis was undertaken, but results for individual studies are given. Results have been tabulated rather than combined in a meta-analysis. 


\section{Hypnosis and psychogenic non-epileptic seizures}

Moene and colleagues ${ }^{23}$ investigated the effects of hypnosis on PNES. This study included 45 adult inpatients with conversion disorder. Seven experienced paroxysmal myoclonic outbursts and eight had seizures or convulsions. Twenty- four were allocated randomly to the experimental group and 21 to the control group. The average duration of conversion disorder was 3.9 years (range, 2 months- 22 years; SD, 4.5 months). In 18 of 45 (40\%), the onset was acute (within 3 days). Twenty-eight (62\%) (an undisclosed proportion of whom had acute onset) developed conversion symptoms in connection with a previous physical complaint or affliction in the relevant part of the body. Thirty-two (72.7\%) patients used medication (benzodiazepines, 43.2\%; medication for somatic complaints, 45.5\%; and painkillers, $44.4 \%$ most frequently). No discussion of withdrawal of medication or otherwise was included.

Patients in both treatment and control groups followed a group therapy program with the aim of increasing problem-solving skills. This program consisted of group psychotherapy, social skills training, formulation and evaluation of treatment goals, creative therapy, and sports. In addition, patients with conversion disorder had physiotherapy, individual exercise sessions, and bed rest and, in the experimental group, hypnotic treatment also. The hypnotic treatment involved one preparatory session followed by eight weekly 1-hour sessions, each. As part of this treatment, the patients learned self-hypnosis and were instructed to practise each day for 30 minutes. In the control group, instead of hypnosis, a treatment aimed at optimizing non-specific or common therapy factors was implemented. This involved a preparatory session followed by eight weekly 1-hour sessions.

The primary outcome measure used was the Video Rating Scale for Motor Conversion Symptoms (VRMC). Follow-up in this study occurred 8 months after pretreatment assessment.

Another study by the same authors ${ }^{24}$ included 44 adult outpatients with conversion disorder (motor type) or somatization disorder (with motor conversion symptoms). Of the 44, six experienced paroxysmal myoclonic outbursts and two had seizures or convulsions. Twenty were randomly allocated to the treatment group and 24 to the waiting list control group. The treatment group received one preparatory session followed by 10 weekly sessions. Two hypnotic strategies were used: (1) In direct symptom alleviation, suggestions were designed to alter conditioned cues to motor symptoms. (2) Emotional expression/insight involved age regression to explore factors implicated in the development of the symptoms. Self- hypnosis was also taught and patients were asked to practice the symptom alleviation strategies for 30 minutes a day. A waiting list control group was used.

Average duration of conversion disorder was 3.7 years (range, 2 months-16.7 years; SD, 4.7 months). In terms of onset, 16, (37.2\%) patients had acute onset (within 3 days) and 21 (47.8\%) developed conversion symptoms in connection with a previous 
$116 \mid$ Chapter 6

physical complaint or affliction in the relevant part of the body. Twenty-one $(48.8 \%)$ patients used medication (benzodiazepines, $14 \%$; medication for somatic complaints, $30.2 \%$; and painkillers. $34.8 \%$, most frequently). No discussion of withdrawal of medication or otherwise was included.

The primary outcome measure used was the VRMC. Follow-up for the treatment group occurred 6 months after their tenth session. No follow-up was arranged for the waiting list control group.

Preliminary data on eight adults with motor conversion symptoms (one described as having pseudo-epileptic seizures) were published by Moene et al. ${ }^{25}$.

\section{Paradoxical intention and psychogenic non-epileptic seizures}

We found one RCT investigating the effects of paradoxical intention on PNES by Ataoglu et al. ${ }^{16}$. This study included 30 adults with conversion disorder, specifically pseudo-seizures. Fifteen were randomly allocated to the experimental group and 15 to the control group after exclusions for abnormal EEG, organic disease, previous psychiatric treatment, and so on. In the experimental group, patients were hospitalized and given two paradoxical intention treatment sessions per day. During sessions, patients were encouraged to imagine anxiety- provoking situations and/or experiences. The aim was to help the patients to reexperience their traumas and experience their conversion attacks. After 3 weeks, patients were discharged. Three weeks postdischarge, a reassessment took place, and anxiety and conversion scores were compared. In the control group, patients were prescribed diazepam as outpatients (5-15 mg); they were given appointments at 10, 20,30, and 45 days to review their progress and also were reviewed at the end of treatment for anxiety and conversion symptoms.

The overall mean duration of conversion disorder for the whole sample was 42 days (experimental group, 34 days; control group, 48 days). Medication use in these groups was not discussed. Etiology was not detailed; however, anxiety- provoking situations and experiences and traumatic events were mentioned. The primary outcome measure was anxiety score as measured by the Hamilton Rating Scale for Anxiety (HRSA). Follow-up in this study occurred 3 weeks after completion of the study. As the study lasted 6 weeks; follow-up was approximately 2 months after the start of the study. An earlier account of this research was published by Ataoglu et al. in $1998^{26}$.

\section{Methodological quality of included studies}

\section{Hypnosis and psychogenic non-epileptic seizures}

Moene et al. ${ }^{23}$ used block randomization (block sizes: $3 \times 4,2 \times 6,2 \times 8,2 \times 4$ and $2 \times 2$ ) to allocate patients to treatment conditions. This was concealed from the therapist and assessors. The assessors rating the outcomes were blinded to treatment allocation. Further details on randomization or blinding method were not provided. In 
terms of methodological weaknesses, of the 45 patients with conversion symptoms, 8 were reported to have seizures or convulsions and 7 were reported to have paroxysmal myoclonic outbursts; however, as patients could have more than one symptom, the exact number is unclear. There were no details on seizure frequency or change in seizure frequency, nor were there measures of QOL or seizure severity.

Moene et al. ${ }^{24}$ used block randomization (unspecified) to assign patients to the experimental (hypnosis) or control (waiting list) condition. The assessors rating the outcomes were blinded to treatment allocation. No further details of randomization or blinding method were provided. In terms of methodological weaknesses, only two of the patients with conversion symptoms were documented as having seizures or convulsions, although six were reported to have paroxysmal myoclonic outbursts (patients may have more than one symptom so the exact number is unclear). There were no details on seizure frequency or change in seizure frequency, nor were there measures of quality of life or seizure severity.

\section{Paradoxical intention and psychogenic non-epileptic seizures}

In this study by Ataoglu et al. ${ }^{16}$, random allocation was effected by a computerized system; no further information was provided. All patients were assessed by a psychiatrist who was blinded as to the patients' groups throughout the study. There were some methodological weaknesses in the study design: there was no placebo control group, and the two groups received their interventions in different settings inpatient and outpatient.

\section{Results of included studies}

\section{Hypnosis and psychogenic non-epileptic seizures}

Moene et al. ${ }^{23}$ provided no results specific to PNES. They stated that the frequency and duration of seizures were noted by staff and patients throughout the study. From this they calculated the mean percentage change in frequency and duration, which was converted to a representative score on the VRMC rating scale. However, none of these scores were provided in the article.

Moene and colleagues' compared outcome measures across the experimental and control groups. They also looked at comparisons of outcome measures from pretreatment assessment, mid-treatment, post-treatment and follow-up assessments. Their outcome measures were the VRMC, Symptom Checklist-90 (SCL-90, Dutch version), a self- report measure of psychoneuroticism; the International Classification of Impairments, Disabilities and Handicaps (ICIDH, subscale for physical activities); and the ICIDHP (perceived problems subscale). The authors reported significant symptom reduction in patients with a conversion disorder of the motor-type; however, this was independent of the treatment condition. They reported no significant condition effects and no significant condition $x$ time interactions for any of the outcome 
measures. However, a significant main effect for time was reported on all of the outcome measures (VRMC, $F(2,82)=28.07, P=0.001$; SCL-90, $F(3,126)=3.37, P=0.05$; $\operatorname{ICIDH}, F(3,123)=12.76, P=0.000 ; \operatorname{ICIDHP}, F(3,123)=8.97, P=0.000)$. The authors concluded that the addition of hypnosis to the treatment program did not affect outcome.

Moene et al. $^{24}$ provided no results specific to PNES. As with their 2002 study, the outcome measures were the VRMC, SCL-90, and ICIDH. The authors reported significant treatment results for a hypnosis-based treatment in patients with a conversion disorder, motor type. There was a statistically significant difference between the mean VRMC scores (treatment group: 5.9, SD 1.3; control group: 3.8, SD $1.4 ; \mathrm{t}=5.065, P=0.001$ ). Analysis of the ICIDH results indicated that the treatment group improved more than controls on this interview measure of general motor impairment (treatment group $\mathrm{t}=3.63, P<0.01$; control group $\mathrm{t}=1.074, P=0.29$ ). The authors found no significant effect of treatment on the SCL-90 (main effects: group $F(1,41)=0.385, P=0.54$; time $F(3,126)=3.636, P=0.064$. interaction: $F(1,41)=0.345$, $P=0.56)$. At 6-month follow-up the authors reported that improvement was maintained.

\section{Paradoxical intention and psychogenic non-epileptic seizures}

No specific psychogenic non-epileptic attack frequency or severity results were provided by the authors ${ }^{16}$, as the primary outcome measure in this study was anxiety score. However, the authors noted percentage of the sample in each group who manifested no conversions symptoms in the last 2 weeks at follow-up: experimental group, 14 (93.3\%); control group, 9 (60\%). There was a significant improvement in recovery rate in the paradoxical intention group when compared with the diazepamtreated group ( $t=2.27, P=0.034$ ).

The authors analyzed anxiety scores on the HRSA before and after treatment. There was no significant difference between pretreatment anxiety scores. Both groups recorded significantly decreased anxiety scores by the end of treatment (diazepamtreated group: $z=3.24, P=0.0012$; paradoxical intention group: $z=3.41, P=0.0007)$ ) A greater degree of significance was found in the PI group when comparing the difference between pre- and post-treatment anxiety scores $(z=2.43, P=0.015)$. The included studies are summarized in Table 6.3. 
Nondrug treatments for psychogenic non-epileptic seizures: what's the evidence? 119

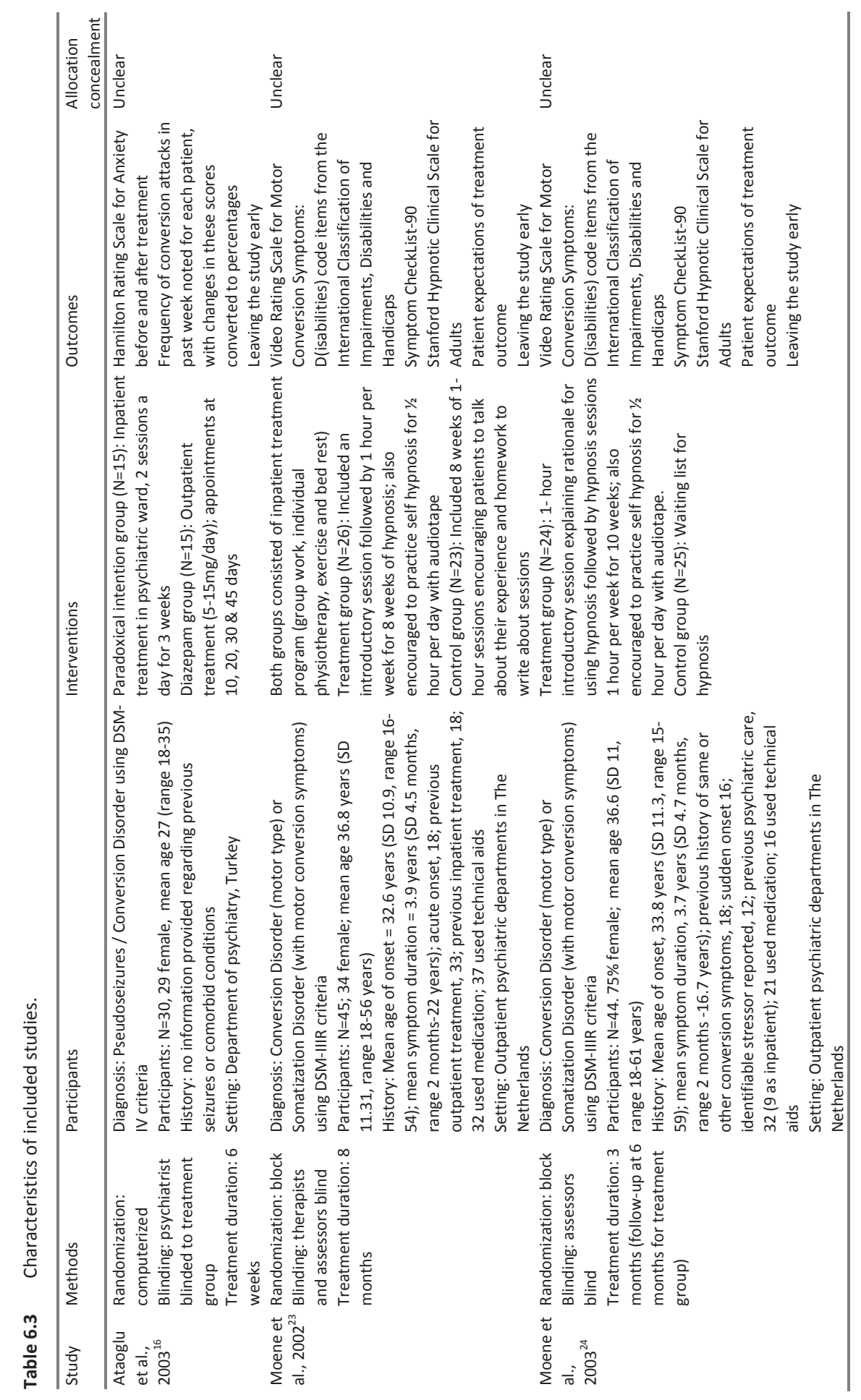




\section{Discussion}

This review, in line with previous reviews ${ }^{3}$, clearly highlights that there is a lack of well-designed trials to inform treating physicians as to what therapeutic treatments exist and how effective they may be for this condition. An overall theoretical framework for understanding the development of PNES would provide a foundation on which to develop treatment strategies and research protocols. Various frameworks have been proposed in an effort to elucidate the development of PNES. They include models based on biopsychosocial ${ }^{27,28}$, psychodynamic ${ }^{29}$, $\operatorname{cognitive}^{30,31}$, and learning theory $^{32}$ approaches. Although such theoretical models have been discussed ${ }^{33,34}$, no dominant theoretical framework has thus far emerged. According to Reuber and colleagues $^{7}$, lessons can be drawn from the treatment of similar types of psychopathology (somatoform disorder, posttraumatic stress, and hypochondria), for which the frameworks are, on the whole, better developed and CBT is considered the psychological treatment of choice.

The area would benefit from much clearer outcomes including measurement of the number of events, the improvement in the QOL associated with treatment, and the improvement in psychological and social skills. There is a need for pragmatic RCTs to demonstrate the efficacy of the different treatment options for this group of patients. The absence of well-designed clinical trials represents a failure to provide evidence of what treatment of choice should be offered to patients with PNES. More scientifically rigorous research is warranted

Finally, it is difficult to disagree with Devinsky ${ }^{8}$, who comments that although "our ability to diagnose PNES has advanced significantly in the past two decades, our understanding of its pathophysiology and our ability to provide effective treatment has progressed in small tentative steps in the past century". It would seem that the status quo remains. 


\section{References}

1. Francis P, Baker GA. Non-epileptic attack disorder (NEAD): a comprehensive review. Seizure 1999;8:53-61.

2. Reilly J, Baker GA, Rhodes J, Salmon P. The association of sexual and physical abuse with somatization: characteristics of patients presenting with irritable bowel syndrome and non-epileptic attack disorder. Psychol Med 1999;29:399-406.

3. Rusch MD, Morris GL, Allen L, Lathrop L. Psychological treatment of non-epileptic events. Epilepsy Behav 2001;2:277-83.

4. Ramani V. Review of psychiatric treatment strategies in non-epileptic seizures. In: Rowan AJ, Gates JR, editors. Non-epileptic seizures. Boston: Butterworth-Heinemann; 1993:259-67.

5. Reuber M, House AO. Treating patients with psychogenic non-epileptic seizures. Curr Opin Neurol 2002;15:207-11.

6. Lesser RP. Treatment and outcome of psychogenic non-epileptic seizures. Epilepsy Curr 2003;3: 198-200.

7. Reuber M, Howlett $\mathrm{S}$, Kemp S. Psychologic treatment of patients with psychogenic non-epileptic seizures. Expert Rev Neurotherapeutics 2005;5:737-52.

8. Devinsky O. Nonepileptic psychogenic seizures: quagmires of pathophysiology, diagnosis and treatment. Epilepsia 1998;39:458-62.

9. Martin R, Bell B, Hermann B, Mennemeyer S. Non epileptic seizures and their costs: the role neuropsychology. In: Prigitano GP, Pliskin NH, editors. Clinical neuropsychology and cost outcome research: a beginning. New York: Psychology Press; 2003:235-58.

10. Betts T, Duffy N. Non-epileptic attack disorder (pseudoseizures) and sexual abuse: a review. In: Gram L, Johannessen SI, Osterman PO, Sillanpää M, editors. Pseudo epileptics seizures. Wrightson Biomedical: Petersfield;1993:55-65.

11. Lesser RP. Treatment and outcome of psychogenic non-epileptic seizures. Epilepsy Currents 2003;3:198-200.

13. Chemali Z, Meadows M. The use of eye movement desensitization and reprocessing in the treatment of psychogenic seizures. Epilepsy Behav 2004; 5:784-7.

14. Swingle PG. Neurofeedback treatment of pseudoseizure disorder. Biol Psychiatry 1998; 44:1196-9.

15. Reuber M. Psychogenic non-epileptic seizures: diagnosis, aetiology, treatment, prognosis. Swiss Arch Neurol Psychiatry 2005;156:47-57.

16. Ataoglu A, Ozcetin A, Icmeli C, Ozbulut O. Paradoxical therapy in conversion reaction. J Kor Med 2003;18:581-4.

17. McDade G, Brown SW. Non-epileptic seizures: management and predictive factors of outcome. Seizure 1992;1:7-10.

18. Betts T, Boden S. Diagnosis, management and prognosis of a group of 128 patients with non-epileptic attack disorder. Seizure 1992;1(Pt. I):19-26.

19. Buchanan N, Snars J. Pseudoseizures (non-epileptic attack disorder): clinical management and outcome in 50 patients. Seizure 1993;2:141-6.

20. Aboukasm A, Mahr G, Gahry BR, Thomas A, Barkley GL. Retrospective analysis of the effects of psychotherapeutic interventions on outcomes of psychogenic non-epileptic seizures. Epilepsia 1998;39:470-3.

22. Zaroff CM, Myers L, Barr WB, Luciano D, Devinsky O. Group psychoeducation as treatment for psychological nonepileptic seizures. Epilepsy Behav 2004;5:587-92.

23. Moene FC, Spinhoven P, Hoogduin KA., van Dyck R. A randomised controlled clinical trial on the additional effect of hypnosis in a comprehensive treatment programme for in-patients with conversion disorder of the motor type. Psychother Psychosom 2002;71(2):66-76.

24. Moene FC, Spinhoven P, Hoogduin KA, van Dyck R. A randomized controlled clinical trial of a hypnosis-based treatment for patients with conversion disorder, motor type. Int J Clin Exp Hypnosis 2003;51:29-80.

25. Moene FC, Hoogduin KAL, van Dyck R. The inpatient treatment of patients suffering from (motor) conversion symptoms: a description of eight cases. Int J Clin Exp Hypnosis 1998;46:171-90. 
26. Ataoglu A, Sir A, Ozkan, M. Paradoxical therapy in conversion disorder. Turk J Med Sci 1998;28: 419-21.

27. Katon W, Kleinman A, Rosen G. Depression and somatization: a review. Part I. Am J Med 1982;72: 127-35.

28. Katon W, Kleinman A, Rosen G. Depression and somatization: a review. Part II. Am J Med 1982; 72:241-7.

29. Gabbard O. Psychodynamic psychiatry in clinical practice. $4^{\text {th }}$ ed. Washington, DC: American Psychiatric Association; 2005. p. 283-312.

30. Trimble MR. Historical overview. In: Somatoform disorders: a medicolegal guide. Cambridge, UK/New York: Cambridge University Press; 2004. p. 1-20.

31. Brown RJ. The cognitive psychology of dissociative states. Cogn Neuropsychiatry 2002;7:221-35.

32. Gumnit RJ, Gates JR. Psychogenic seizures. Epilepsia 1986;27(Suppl. 2):S124-9.

33. Bjørnaes $\mathrm{H}$. Aetiological models as a basis for individualized treatment of pseudo-epileptic seizures. In: Gram L, Johannessen SI, Ostersman PO, Sillanpaa M, editors. Pseudo-epileptic seizures. Bristol, PA: Wrightson Biomedical; 1993.

34. LaFrance Jr WC, Barry JJ. Update on treatments of psychological nonepileptic seizures. Epilepsy Behav 2005;7:363-74.

35. Aboukasm A, Mahr G, Gahry BR, Thomas A, Barkley GL. Retrospective analysis of the effects of psychotherapeutic interventions on outcomes of psychogenic nonepileptic seizures. Epilepsia 1998;39:470-3.

36. Betts T, Boden S. Diagnosis, management and prognosis of a group of 128 patients with non-epileptic attack disorder. Seizure 1992;1(Part I):19-26.

37. Betts T, Boden S. Diagnosis, management and prognosis of a group of 128 patients with non-epileptic attack disorder: previous childhood sexual abuse in the aetiology of these disorders. Seizure 1992;1(Part II):27-32.

38. Bhattacharyya DD, Singh R. Behavior therapy of hysterical fits. Am J Psychiatry 1971;128:602-6.

39. Bleichhardt G, Timmer B, Rief W. Cognitive-behavioural therapy for patients with multiple somatoform symptoms--a randomised controlled trial in tertiary care. J Psychosom Res 2004;56: 449-54.

40. Buchanan N, Snars J. Pseudoseizures (non-epileptic attack disorder): clinical management and outcome in 50 patients. Seizure 1993;2:141-6.

41. Couprie W, Wijkicks EFM, Rooijmans HGM, van Gijn J. Outcome in conversion disorder: a follow up study. J Neurol Neurosurg Psychiatry 1995;58:750-2.

42. Dickes RA. Brief therapy of conversion reactions: an in-hospital technique. Am J Psychiatry 1974;131:584-6.

43. Dickinson WP, Dickinson LM, deGruy FV, Main DS, Candib LM, Rost K. A randomized clinical trial of a care recommendation letter intervention for somatization in primary care. Ann Fam Med 2003;1: 228-35.

44. Farias ST, Thieman C, Alsaadi TM. Psychogenic non-epileptic seizures: acute change in event frequency after presentation of the diagnosis. Epilepsy Behav 2003;4:424-9.

45. Ford CV, Long KD. Group psychotherapy of somatizing patients. Psychother Psychosom 1977;28: 294-304.

46. Goldstein LH, Deale AC, Mitchell-O'Malley SJ, Toone BK, Mellers JD. An evaluation of cognitive behavioral therapy as a treatment for dissociative seizures: a pilot study. Cogn Behav Neurol 2004;17:41-9.

47. Hellman CJ, Budd M, Borysenko J, McClelland DC, Benson H. A study of the effectiveness of two group behavioral medicine interventions for patients with psychosomatic complaints. Behav Med 1990;16:165-73.

48. Hiller W, Fichter MM, Rief W. A controlled treatment study of somatoform disorders including analysis of healthcare utilization and cost-effectiveness. J Psychosom Res 2003;54:369-80.

49. Jongsma MJ, Mommers JM, Renier WO, Meinardi H. Follow-up of psychogenic, non-epileptic seizures: a pilot study-experience in a Dutch special centre for epilepsy. Seizure 1999;8:146-8

50. Kolk AM, Schagen S, Hanewald GJ. Multiple medically unexplained physical symptoms and health care utilization: outcome of psychological intervention and patient-related predictors of change. J Psychosom Res 2004;57:379-89. 
51. Krull F, Schifferdecker M. Inpatient treatment of conversion disorder: a clinical investigation of outcome. Psychother Psychosom 1990;53:161-8.

52. Larisch A, Schweickhardt A, Wirsching $M$, Fritzsche K. Psychosocial interventions for somatizing patients by the general practitioner: a randomized controlled trial. J Psychosom Res 2004; 57:507-14.

53. Lehmann E, Hassel P, Thorner GW, Karrass W. [Alternative therapy concept for the treatment of psychosomatic disorders: controlled double-blind evaluation of fluspirilene versus bromazepam]. Fortschr Med 1984;102:1033-6.

54. Lempert T, Schmidt D. Natural history and outcome of psychogenic seizures: a clinical study in 50 patients. J Neurol 1990;237:35-8.

55. Lidbeck J. Group therapy for somatization disorders in general practice: effectiveness of a short cognitive-behavioural treatment model. Acta Psychiatr Scand 1997;96:14-24.

56. Lyles JS, Hodges A, Collins C, Lein C, Given CW, Given B, et al. Using nurse practitioners to implement an intervention in primary care for high-utilizing patients with medically unexplained symptoms. Gen Hosp Psychiatry 2003;25:63-73.

57. McDade G, Brown SW. Non-epileptic seizures: management and predictive factors of outcome. Seizure 1992;1:7-10.

58. Menza M, Lauritano M, Allen L, Warman M, Ostella F, Hamer RM, et al. Treatment of somatization disorder with nefazodone: a prospective, open-label study. Ann Clin Psychiatry 2001;13:153-8.

59. Muller T, Mannel M, Murck H, Rahlfs VW. Treatment of somatoform disorders with St. John's wort: a randomized, double-blind and placebo-controlled trial. Psychosom Med 2004;66:538-47.

60. Noyes R Jr, Happel RL, Muller BA, Holt CS, Kathol RG, Sieren LR et al. Fluvoxamine for somatoform disorders: an open trial. Genl Hosp Psychiatry 1998;20:339-44.

61. Peters S, Stanley I, Rose M, Kaney S, Salmon P. A randomized controlled trial of group aerobic exercise in primary care patients with persistent, unexplained physical symptoms. Fam Pract 2002;19:665-74.

62. Prigatano GP, Stonnington CM, Fisher RS. Psychological factors in the genesis and management of nonepileptic seizures: clinical observations. Epilepsy Behav 2002;3:343-9.

63. Pu T, Mohamed E, Iman K, El-Roey A. One hundred cases of hysteria in Eastern Libya: a sociodemographic study. Br J Psychiatry 1986;148:606-9.

64. Ramani V, Gumnit RJ. Management of hysterical seizures in epileptic patients. Arch Neurol 1982; 39:78-81.

65. Riaz H, Comish S, Lawton L, Scheepers B. Non-epileptic attack disorder and clinical outcome: a pilot study. Seizure 1998;7:365-8.

66. Rost K, Kashner TM, Smith Jr RG. Effectiveness of psychiatric intervention with somatization disorder patients: improved outcomes at reduced costs. Gen Hosp Psychiatry 1994;16:381-9.

67. Shapiro AP, Teasell RW. Strategic-behavioural intervention in the inpatient rehabilitation of nonorganic (factitious/conversion) motor disorders. Neurorehabilitation 1997;8:183-92.

68. Shapiro AP, Teasell W. Behavioural interventions in the rehabilitation of acute $v$ chronic non-organic (conversion/ factitious) motor disorders. Br J Psychiatry 2004;185:140-6.

69. Sheehan DV, Ballenger J, Jacobsen G. Treatment of endogenous anxiety with phobic, hysterical, and hypochondriacal symptoms. Arch Gen Psychiatry 1980;37:51-9.

70. Skupin G, Franzke HG. [The role of chlorazepate dipotassium (Tranxilium) in the therapy of psychosomatic syndromes (author's translation)]. Med Klin 1975;70:1279-83.

71. Smith Jr GR, Monson RA, Ray DC. Psychiatric consultation in somatization disorder: a randomized controlled study. N Engl J Med 1986; 314:1407-13.

72. Speckens AE, van Hemert AM, Spinhoven P, Hawton KE, Bolk JH, Rooijmans HG. Cognitive behavioural therapy for medically unexplained physical symptoms: a randomised controlled trial. $\mathrm{Br} \mathrm{Med} J$ 1995;7016:1328-32.

73. Speed J. Behavioral management of conversion disorder: retrospective study. Arch Phys Med Rehabil 1996; 77:147-54.

74. Sumathipala A, Hewege S, Hanwella R, Mann AH. Randomized controlled trial of cognitive behaviour therapy for repeated consultations for medically unexplained complaints: a feasibility study in Sri Lanka. Psychol Med 2000;30:747-57.

75. Swingle PG. Neurofeedback treatment of pseudoseizure disorder. Biol Psychiatry 1998; 44:1196-9.

76. Wilkinson P, Mynors-Wallis L. Problem-solving therapy in the treatment of unexplained physical symptoms in primary care: a preliminary study. J Psychosom Res 1994;38:591-8. 
124 Chapter 6

77. Williams DT, Gold AP, Shrout P, Shaffer D, Adams D. The impact of psychiatric intervention on patients with uncontrolled seizures. J Nerv Ment Dis 1979;167:626-31.

78. Volz HP, Moller H.J, Reimann I, Stoll K D. Opipramol for the treatment of somatoform disorders results from a placebo-controlled trial. Eur Neuropsychopharmacol 2000;10:211-7.

79. Volz HP, Murck H, Kasper S, Moller HJ. St John's wort extract (LI 160) in somatoform disorders: results of a placebo-controlled trial [erratum appears in Psychopharmacology (Berl) 2003;167:333]. Psychopharmacology (Berl) 2002;164:294-300.

80. Zaroff CM, Myers L, Barr WB, Luciano D, Devinsky O. Group psychoeducation as treatment for psychological non-epileptic seizures. Epilepsy Behav 2004;5:587-92. 


\section{Part 3}

Patient characteristics and psychogenic aetiology

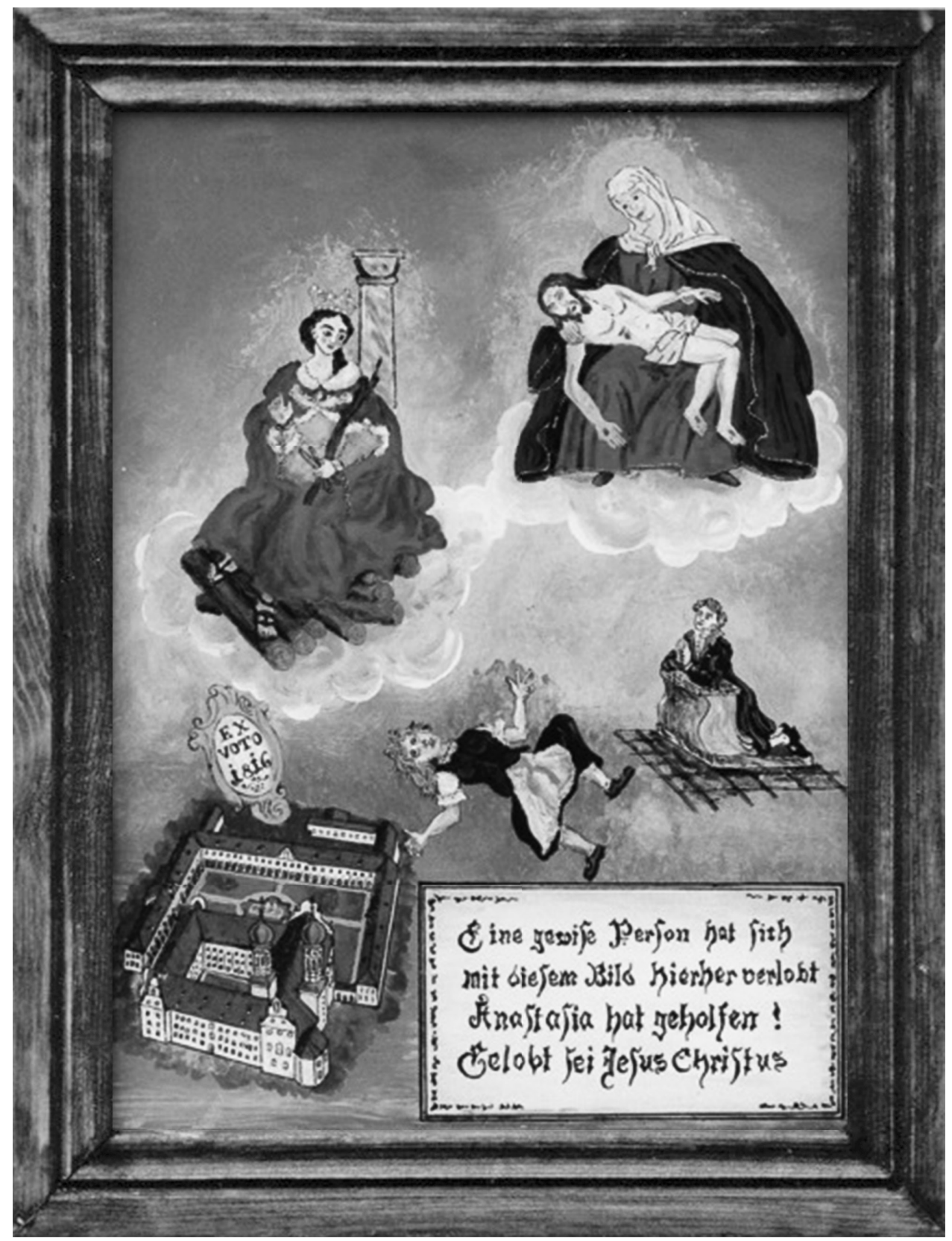




\section{Chapter 7}

MMPI-2 personality profiles of patients with psychogenic non-epileptic seizures

NMG Bodde, DCJ Bartelet, M Ploegmakers, RHC Lazeron, AP Aldenkamp, PAJM Boon

Epilepsy Behav 2011;20:674-80 
128 Chapter 7

\section{Abstract}

This comparative study explored whether psychogenic non-epileptic seizures (PNES) are a unique disorder with distinctive personality characteristics or (seen from the personality profile) PNES are allied with the domain of a general functional somatic symptom and syndrome (FSSS). We compared the Minnesota Multiphasic Personality Inventory 2 (MMPI-2) results for 41 patients with newly diagnosed PNES and 43 patients with newly diagnosed insomnia. There were no statistically significant quantitative scoring differences on the main clinical scales, indicating that there is no substantial difference in "personality make-up" between the two groups with a FSSS. Additional subscale analysis indicated that patients with PNES reported significantly more somatic complaints (Hysteria 4) and bizarre sensory experiences (Schizophrenia 6). Further profile analysis revealed that the personality pattern of patients with PNES was characterized by a strong tendency toward "conversion $\mathrm{V}$, a lack of control pattern and less excessive worries" as compared with patients with insomnia. Patients with PNES are characterized by a stronger tendency toward somatization and externalization, which has treatment implications. 


\section{Introduction}

Psychogenic non-epileptic seizures (PNES) resemble epileptic seizures, but have no electrophysiological correlate or clinical evidence for epilepsy, whereas there is positive evidence that psychogenic factors may have caused the seizures ${ }^{1-3}$. With their somatic appearance and underlying psychological or psychiatric problems, the patients with these seizures present on the boundaries of the medical and mental health services. The incidence of PNES in the general population is relatively low, estimated at about $1.5 / 100,000$ persons per year ${ }^{4-6}$. Tertiary referral centers estimate a much higher incidence rate ${ }^{7}$. Twenty-five to thirty percent of the patients referred to tertiary epilepsy centers for refractory epilepsy are diagnosed with PNES ${ }^{8,9}$.

In the diagnostic process two phases can be identified. First, the medical diagnosis requires excluding epilepsy and other somatic causes ("negative" diagnosis). Second is the "positive" diagnosis, for which the underlying psychological mechanisms are evaluated that can be used in treatment ${ }^{10,11}$. Over the years many psychological mechanisms have been suggested ${ }^{12-17}$. Also, attempts have been made to classify possible subgroups of PNES based on different psychogenic etiological factors ${ }^{18,19}$. Recent studies have shown that PNES are caused by the interaction of multiple factors, not all of which have a similar impact in different patients. Elsewhere we proposed a theoretical model comprising the different etiological factors that may be involved in the causation, development, and provocation of $\mathrm{PNES}^{11,20}$. Although this model resembles other models ${ }^{6,21}$, mostly derived from other psychosomatic symptoms, there are also specific factors, especially because of the paroxysmal nature of the seizures. An example is the distinction of triggering factors that create circumstances or situations that provoke PNES. These factors differentiate PNES from other conversion disorders, such as conversion paralyses, that more or less are permanent. Therefore, in this model PNES are considered a unique disorder ${ }^{11,20}$.

Others, however, such as Quigg et al. ${ }^{22}$, state that PNES should not be considered a disorder in itself, but a symptom of an underlying psychological or psychiatric disorder or recent trauma. In this approach PNES are considered a symptom very similar to other functional somatic symptoms and syndromes (FSSS) ${ }^{23,24}$. Studies increasingly show the high tendency of patients with PNES to somatize ${ }^{25}$ and to have other somatoform disorders in their patient history. For example, Mökleby et al. ${ }^{26}$ showed that $43 \%$ of the patients with PNES in their study had somatoform pain disorders and $30 \%$ had an undifferentiated somatoform disorder. O' Sullivan et al. ${ }^{16}$ reported that $34 \%$ of their patients with PNES in a tertiary referral centre exhibited more than one other potential somatoform symptom.

Although, as yet, there is no accepted model to explain PNES, all studies agree that personality factors are an important "modulating" factor in the development of PNES $^{27}$. Personality traits characterize a person's typical manner of thinking, feeling, perceiving, and relating to others across a wide range of situations ${ }^{28}$. In some cases 
personality traits or personality patterns can be so maladaptive that they constitute a personality disorder ${ }^{29}$. It is suggested that although only a minority of the general population is diagnosed with a personality disorder, many individuals have a personality pattern that is referred to as a "personality dysfunction" or "difficult personality". The latter increases their vulnerability to develop a serious mental disorder or psychosomatic symptoms ${ }^{20,30}$. Personality factors may explain why one patient is able to restore psychological balance after a trauma, whereas other patients develop severe psychosomatic symptoms. Specific personality factors may contribute to different psychosomatic symptoms ${ }^{20}$.

The Minnesota Multiphasic Personality Inventory 2 (MMPI-2) is one of the most frequently used assessment tools for psychopathology. The MMPI-2 has previously been used in studies in of patients with PNES. However, most of those studies used the MMPI-2 in the first phase of diagnosis, as an extra tool to try to differentiate PNES from epilepsy ${ }^{31-34}$. The results of the majority of these studies confirmed the clinical utility of the MMPI-2 as a diagnostic aid in the differentiation of PNES ${ }^{35-38}$. Most studies that used the MMPI-2 to assess underlying psychopathology in the second phase, after the non-epileptic diagnosis was confirmed, used patients with epilepsy as a control group ${ }^{19,39}$. Few studies have attempted to find differences between the personality profiles of patients with PNES and patients with other functional somatic symptoms with a psychogenic origin. The comparison of patients with PNES and patients with epilepsy can be criticized on two grounds. First, epilepsy is not a mental disorder. Second, many patients with PNES have been through the diagnostic process as an "epileptic patient" for many years. The effect may therefore not be different and patients with epilepsy may not be the ideal population to study the role of personality factors in the psychogenicity of PNES.

Our research question is whether we must consider PNES as a unique disorder with distinctive personality characteristics or as (seen from the personality profile) allied to the domain of a general FSSS, in line with other symptoms such as tension headache, irritable bowel syndrome, chronique fatigue and insomnia ${ }^{23,24}$. Functional somatic symptoms are defined as physical symptoms that may suggest a general medical condition, but for which after extensive medical assessment no organic cause and bodily mechanisms are identified. Psychogenic factors are supposed to play a role in the etiology $y^{23,40-42}$. We therefore did not use patients with epilepsy as the control group, but instead included patients with insomnia. Insomnia is a broad concept that can be divided into several subdiagnoses, several of which have no organic causes and hence are a somatoform symptom or FSSS $^{23,43}$. A crucial etiological factor in such disorders is dysfunction of personality ${ }^{44 ; 45}$. Some of the patients have a "symptomatic" insomnia based on comorbid psychiatric disorders, such as a mood disorder. Our study included only those patients with insomnia for which no organic cause for the sleeping problems was found and the insomnia was not exclusively related to another mental disorder ${ }^{40}$. The MMPI- 2 was used in these patients for additional assessment of the psychogenic cause and subsequent psychological treatment. 
In this study we analyzed whether the MMPI-2 profile of patients with PNES is specific to PNES or is a more general characteristic of FSSS. The clinical relevance is obviously whether specific treatment or referral to general institutions for mental health is sufficient for people with PNES.

\section{Methods}

\section{Participants}

Consecutive patients diagnosed with PNES or insomnia in a tertiary referral epilepsy and sleep medicine center during 2006 and 2007 were included in this study. All patients were referred by the neurologist or sleep physician for additional assessment of the psychogenic cause and subsequent psychological treatment. The assessment involved extensive history taking, DSM-IV diagnosis, and personality inventories. This type of selection method precluded a count of the number of patients excluded based on the study criteria. Furthermore, patients were excluded if they could not adequately complete the personality inventory because they had low intelligence or were illiterate. The study was approved by the local medical ethics committee. All participants gave informed consent.

For the diagnosis of PNES, clinical descriptions and additional EEG investigations (such as EEG video telemetry) were used. The type of EEG investigation was based on clinical indications such as patient history and seizure semiology. Patients with PNES were excluded from the study if they showed evidence of comorbid epilepsy. The insomnia group included only those patients with sleep disorders for which no organic cause had been found and for which psychological factors were dominant. Also, sleep disorders resulting exclusively from a diagnosable DSM-IV mental disorder ${ }^{40}$, that is, a "symptomatic" insomnia, were excluded. Thus, the patients with insomnia could have other complaints, such as depressive symptoms, as long as the sleeping problems were not based exclusively on a depressive disorder.

Eventually, 43 referred patients were included in the psychogenic insomnia group and 41 patients in the PNES group. All MMPI-2 profiles were screened on validity and reliability using the information of the validity scales, described under Results. The profiles of all patients were shown to be reliable and valid ${ }^{46,47}$.

\section{Measures and procedure}

In this comparative cohort study, all patients completed the MMPI-2. This objective self-report personality inventory contains 567 items, distributed among four scales: Validity, Clinical, Content, and Supplementary scales. Internal consistency reliability coefficients (Cronbach's $\alpha$ ) of the clinical scales ranged from 0.37 to $0.86^{48}$. 
This study focused on the main clinical scales (370 items), in addition to the 31 subscales, which consist of the 28 Harris-Lingoes subscales and the 3 Social Introversion subscales. The main clinical scales measure the following constructs: (1) Hypochondriasis (Hs), (2) Depression (D), (3) Hysteria (Hy), (4) Psychopathic Deviate (Pd), (5) Masculinity/Femininity (Mf), (6) Paranoia (Pa), (7) Psychasthenia (Pt), (8) Schizophrenia (Sc), (9) Hypomania (Ma) and (10) Social Introversion (Si). Patients were asked to identify whether a given statement applied to them or was not (true/false items).

The MMPI-2 is widely used for personality assessment and has been employed in many previous studies to assess pathological personality features ${ }^{47}$. The MMPI- 2 has also been used in studies of patients with PNES ${ }^{35,49-51}$. In general, the MMPI-2 is considered to be robust for changes over time ${ }^{48}$. Because of this the MMPI- 2 was conceptualized to be a measure of stable traits ${ }^{39}$. The interpretation of the MMPI-2 is based on clinical experience rather then on one or more underlying theories ${ }^{52}$. In addition to analysis of the absolute scores on the main clinical scales, the relative contribution of the specific subscales to the total score is interpreted by using the Harris-Lingoes subscales and the Social Introversion subscales. The clinical scales represent a relatively heterogeneous content. Systematic analysis of the subgroups of items within these scales may supplement and enhance the interpretation of the MMPI- $2^{48,53}$

The differences and relationships between scores are compared using profile analysis $^{52,54}$. Since the development of the initial MMPI, researchers have emphazised the need to interpret the configurations of scores on the clinical scales in addition to absolute scores ${ }^{46}$. There is a vast amount of previous research that aimed to describe or differentiate patient groups based on their MMPI profiles ${ }^{37,55,56}$. Specifically, this study focuses on possible differences in patterns that might be observed.

\section{Statistical analysis}

All data were analyzed with SPSS Version 13 (SPSS, Inc, Chigaco, IL, USA). First, frequencies and descriptives were calculated for the main clinical and demographic variables for each group separately. Chi-square testing was used to evaluate whether the patient groups differed significantly on the clinical and demographic variables. Subsequently, the two patient groups were compared using the independent-sample $T$ test. The purpose was to find any differences on the MMPI-2 clinical and subscales that might indicate a difference in underlying personality structure. To correct for multiple testing, only $P$ values $<0.01$ were considered to represent statistically significant differences. 


\section{Results}

The main demographic characteristics of the two groups are summarized in Table 7.1, separately for patients with PNES $(n=41)$ and patients with insomnia $(n=43)$. Eightyfour patients participated in this study. Mean age was 35 years $(S D=12)$, and the majority of the participants were females (72.6\%). The two groups appeared to be comparable with respect to most characteristics, except employment status $\left(X^{2}[3,84]=14.40, P=0.002\right)$. Fewer patients with PNES were employed compared with patients with insomnia, because of the larger number of patients with PNES unemployed with disability status.

Table 7.1 Demographic characteristics of the patients with PNES $(\mathrm{N}=41)$ and patients with insomnia $(\mathrm{N}=43)$.

\begin{tabular}{lcc}
\hline Variable & Patients with PNES & Patients with insomnia \\
\hline Gender (\%) & & \\
Male & $17.1 \%$ & $37.2 \%$ \\
Female & $82.9 \%$ & $62.8 \%$ \\
Age in years, mean (SD) & $33.41(12.52)$ & $38.30(11.15)$ \\
Marital status & & \\
Single & $41.5 \%$ & $30.2 \%$ \\
Married/cohabiting & $53.7 \%$ & $67.4 \%$ \\
Divorced/single & $4.9 \%$ & $2.3 \%$ \\
Maximum educational level & & \\
Primary school & $14.6 \%$ & $2.3 \%$ \\
Secondary school & $63.4 \%$ & $62.8 \%$ \\
Higher education & $22.0 \%$ & $34.9 \%$ \\
Employment status & & \\
Unemployed & $24.4 \%$ & $23.3 \%$ \\
Unemployed after disability & $36.6 \%$ & $16.3 \%$ \\
Employed & $17.1 \%$ & $53.5 \%$ \\
Attending school & $22.0 \%$ & $7.0 \%$ \\
\hline
\end{tabular}

\section{Validity scales}

A cutoff score of 10 (69T) was used on the L and $\mathrm{K}$ scales as well as the VRIN (Variable Response Inconsistency) and TRIN (True Response Inconsistency) scales ${ }^{46,47}$. All profiles included were reliable and valid and no patients had to be excluded because of this. There were no significant differences on the validity scales between patients with PNES and those with insomnia. Both patient groups are characterized by relatively mild elevations on the so-called infrequency scales ( $F$ and F-back), with overall mean F-scale scores of 64.44 (20.5) for patients with PNES and 57.66 (13.8) for patients with insomnia, and F-back-scale scores of 64.66 (22.1) for patients with PNES and 59.48 (19.1) for those with insomnia. This indicates that both patient groups did not have a tendency to exaggerate their responses (no "cry for help"). 


\section{Comparison of the MMPI main clinical scales}

None of the scores on the main clinical scales differed statistically significantly between the two groups. Two clinical subscales showed statistically significant differences. Patients with PNES reported more somatic complaints such as headaches, dizziness, and balance problems on subscale Hy4 $(M=70.12, S D=13.34)$ than patients with insomnia $(M=58.65, S D=13.35)(t=3.939, P=<0.001)$. Moreover, patients with PNES reported more bizarre sensory experiences, such as absence-like states, hallucinations, and unusual thoughts. They also more often reported abnormal physical sensations $(S c 6)(M=74.20, S D=17.83)$ than the patients with insomnia $(M=61.42, \mathrm{SD}=14.68)(t=3.592, P=0.001)$.

\section{Profile analysis}

\section{Main clinical scales}

Two observations could be made based on the profile derived from the scores on the main scales (see Figure 7.1). The first observation concerns the so-called "conversion valley pattern", or conversion V, a "neurotic triad configuration" that was found in the PNES profile and not the insomnia profile. According to Wilkus et al. ${ }^{12}$, "conversion V" is a profile characterized by elevated scores on scales 1 and 3 (both $>59$ ) and a score on scale 2 that is at least 10 points lower. For the patients with PNES, the 10-point criterion was reached for the scale 3 versus 2 comparison and was almost reached for the scale 1 versus 2 comparison. We therefore do not have a true conversion $V$, but a tendency toward such a pattern. This pattern represents the tendency for patients with PNES not only to report psychosomatic complaints, but also to pursue a medical explanation for their symptoms as well as to be reluctant to accept that psychological factors may underlie their symptoms. This is characteristic of "classic conversion symptoms" and of a somatoform disorder diagnosis ${ }^{48}$. In this configuration, the relative elevations of scales 1 and 3 are also important. In the PNES group, scale 3 scores are relatively higher than scale 1 scores.

In contrast, in the insomnia group scale 2 was elevated compared with scales 1 and 3 , indicating that these patients, in general, tend to be more open to a psychological explanation for their symptoms and tend to suffer more.

A second observation was based on the comparison between the last two main clinical scales: scale 9 (Ma) and scale 0 (Si). A pattern characterized by substantially higher scores on scale 9 than scale 0 was observed for the patients with PNES. This represents a "lack of control" pattern. 


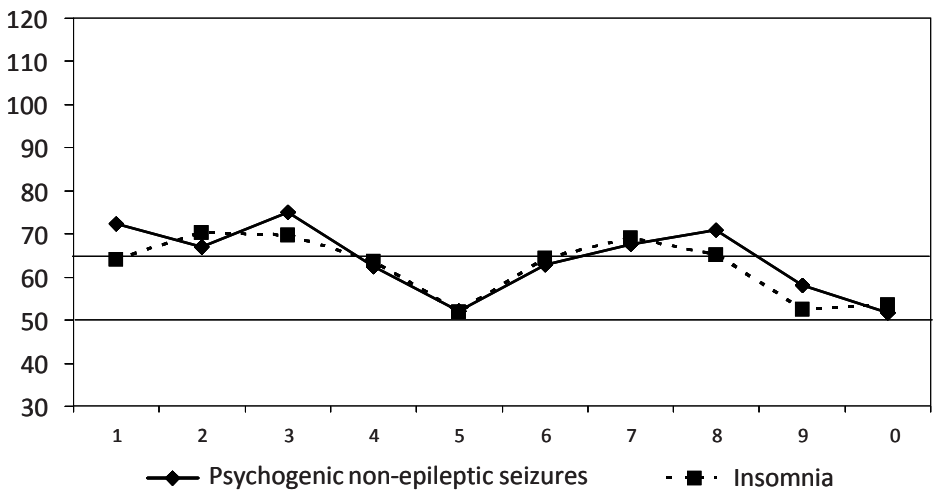

Figure 7.1 Mean scores on the Main Clinical Scales:

(1) Hs, Hypochondriasis; (2) D, Depression; (3) Hy, Hysteria; (4) Pd, Psychopathic Deviate; (5 ) Mf, Masculinity-Femininity; (6) Pa, Paranoia; (7) Pt, Psychastenia; (8) Sc, Schizophrenia; (9) Ma, Hypomania; (0) Si, Social Introversion.

\section{Subscales}

Patients with insomnia scored higher on scale 2 (Depression) subscales than patients with PNES, with the exception of the third subscale (D3) which measured physical malfunctioning. The patients with insomnia more often reported feelings such as being sad, depressed, unhappy, and pessimistic about the future. Although very high scores on scale 2 (exceeding a $T$ score of 70 ) indicate clinical depression, more moderate high scores tend to be indicative of a personality style ${ }^{48}$. This is the case for the patients with insomnia.

On the scale $3(\mathrm{Hy})$ subscales, both patient groups reported similar average scores. They differed only on the Somatic Complaints subscale (Hy4), and this difference was significant (see Figure 7.2). A difference was also observed for the Self-Alienation subscale ( $\mathrm{Pd} 5$ ), on which subjects diagnosed with insomnia scored considerably higher than individuals with PNES (see Figure 7.3). Patients with insomnia more often reported feeling unhappy, having problems with concentration, and having a bleak perspective on life in general. A statistically significant difference was also found on the Bizarre Sensory Experiences subscale (Sc6), on which patients with PNES scored significantly higher than those with insomnia (see Figure 7.4).

Other large differences between the two groups could be noted on the Lack of Ego Mastery (Cognitive) (Sc3) and Lack of Ego Mastery (Defective Inhibition) (Sc5) subscales. Although patients with insomnia scored higher on Sc3, patients with PNES had higher scores on Sc5. Patients with insomnia more often reported having concentration and attention problems and the fear of losing their mind. Patients with PNES more often reported that they did not feel in emotional control, felt restless, and felt irritable. On the scale 9 (Ma) subscales, two differences between the groups could be observed. Patients with PNES scored higher on the Amorality (Ma1) and 
Imperturbality (Ma3) subscales (see Figure 7.5). Patients with PNES tended to see others as unfair and denied having social fears. They more often reported being impatient and short-tempered toward others. However, on the Psychomotor Acceleration (Ma2) subscale, patients with PNES scored lower. They did not report overactive thought processes or excessive motor activity. In contrast, the patients with insomnia tended not to see others as selfish and unfair, but reported feeling tense and restless and having problems with overactive thought processes and excessive motor activity. A last difference could be observed on the Social Avoidance scale (Si2) (see Figure 7.6). Although individuals with PNES scored lower on all three Social Introversion subscales than patients with insomnia, the contrast was most obvious on the second subscale measuring Avoidance (Si2). The patients with insomnia tended to withdraw more from social groups and to avoid the cooperation with others.

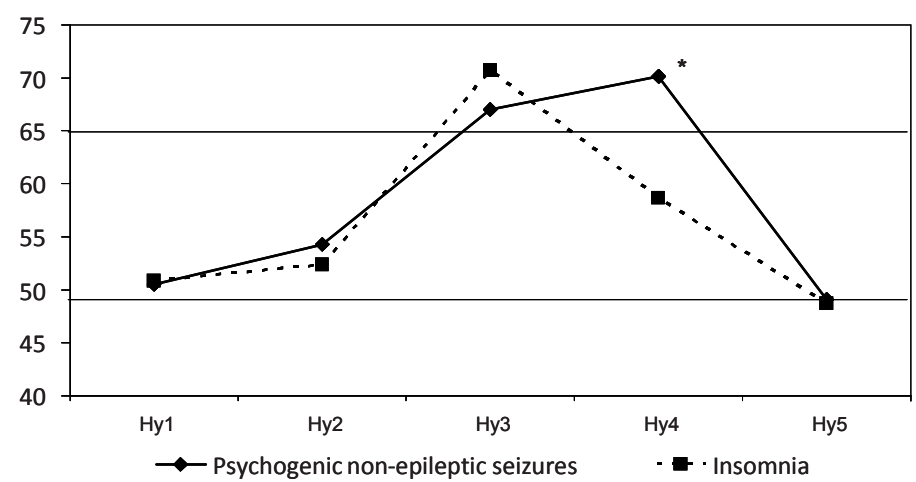

Figure 7.2 Mean score on the clinical subscales of scale 3, Hy (Hysteria):

Hy1, Denial of Social Anxiety; Hy2, Need for Affection; Hy3, Lassitude-Malaise; Hy4, Somatic Complaints; Hy5, Inhibition of Aggression.

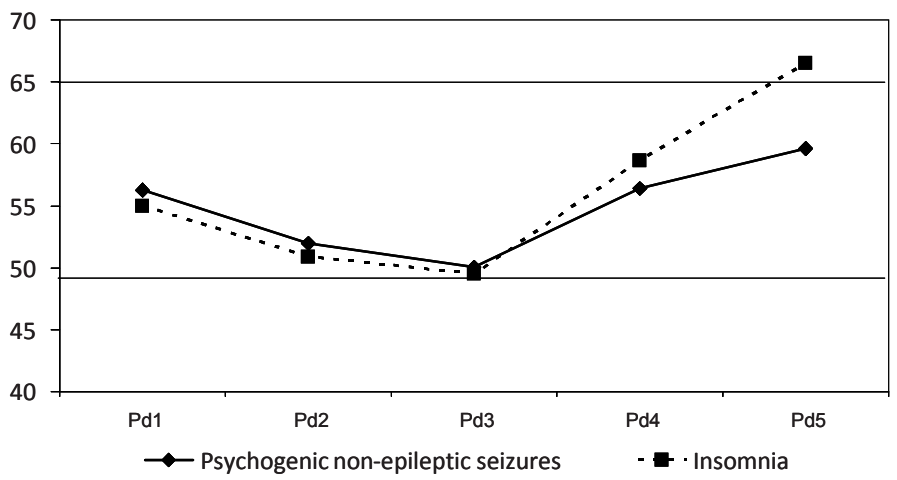

Figure 7.3 Mean scores on the clinical subscales of scale 4, Pd (Psychopathic Deviate)

Pd1, Familial Discord; Pd2, Authority Problems; Pd3, Social Imperturbability; Pd4, Social Alienation; Pd5, Self-alienation. 


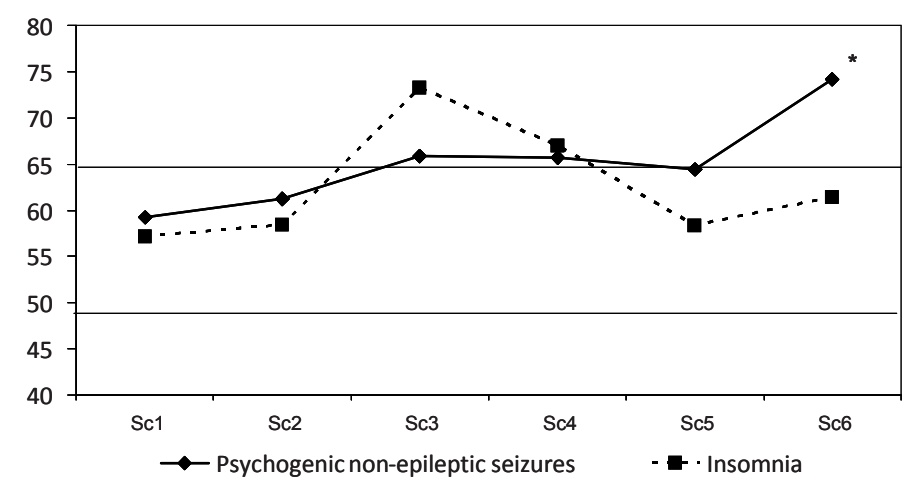

Figure 7.4 Mean scores on the clinical subscales of scale 8, Sc (Schizophrenia):

Sc1, Social Alienation; Sc2, Emotional Alienation; Sc3, Lack of Ego Mastery (Cognitive); Sc4, Lack of Ego Mastery (Conative); Sc5, Lack of Ego Mastery (Defective Inhibition); Sc6, Bizarre Sensory Experiences.

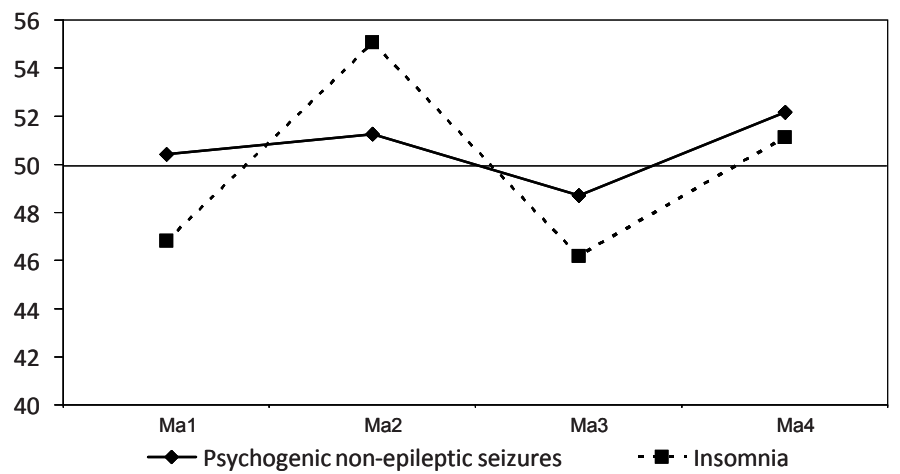

Figure 7.5 Mean scores on the clinical subscales of scale 9, (Ma (Hypomania):

Ma1, Amorality; Ma2, Psychomotor Acceleration; Ma3, Imperturbability; Ma4, Ego Inflation.

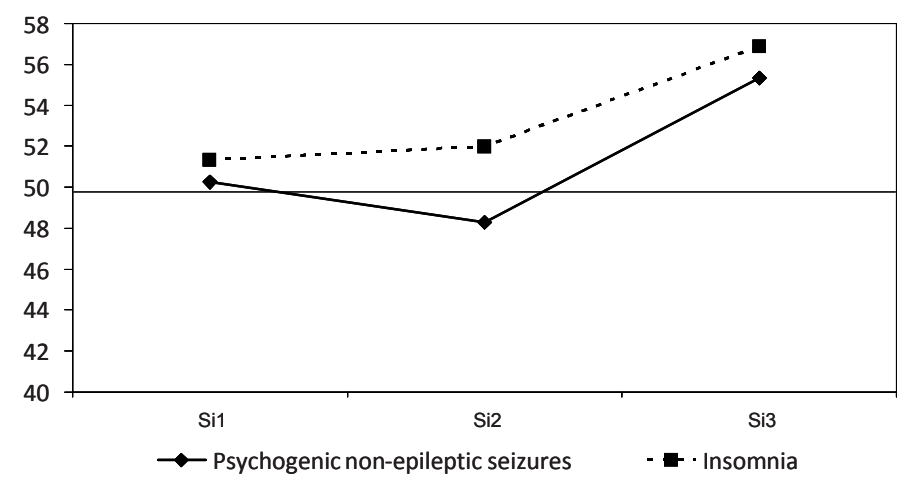

Figure 7.6 Mean scores on the clinical subscales of scale 0 , SI (Social Introversion):

Si1, Shyness/Self-consciousness; Si2, Social Avoidance; Si3, Self/Other Alienation. 


\section{Discussion}

The MMPI-2 showed no statistically significant quantitative scoring differences on the clinical main scales between the patients with PNES and the patients with insomnia included in this study. The first conclusion, therefore, is that in terms of the main personality characteristics, there is no substantial difference in "personality make-up" between the two groups with a FSSS. This indicates that, as seen from the personality profile, PNES do not constitute a specific, unique syndrome, but are part of "the family" of FSSS. In this interpretation, it is rather arbitrary which symptom is presented. This is in line with Quigg et al. ${ }^{22}$, who reported that PNES are not a disorder in themselves, but a symptom of an underlying psychological or psychiatric disorder or recent trauma.

When the results were analyzed on a more detailed level, that is, on the level of subscale and profile analysis, differences between the two groups emerged. These differences do not change the overall conclusion, but may have important implications for treatment.

1. The patients with PNES manifested higher variability in somatic complaints than the patients with insomnia. This indicates a tendency to react with a variation of somatoform symptoms and a tendency to shift more easily from symptom to symptom. In contrast, patients with insomnia tended to report more dejected feelings such as "being sad", "being unhappy", "feeling depressed", and "being pessimistic about their life and future". Thus, the patients with insomnia expressed more feelings indicating that they suffer from the symptoms.

2. The patients with PNES reported significantly more unusual sensory experiences, probably reflecting the manner in which they experienced their psychogenic seizures.

3. The patients with PNES more often reported feeling of irritable, restless, and out of emotional control. These feelings are projected toward the social environment ("acting out"). In contrast, the patients with insomnia tended to report more cognitive symptoms such as attention and concentration problems.

Overall, these findings indicate that patients with insomnia are more acutely aware of their symptoms and are more likely to acknowledge the presence of distress. Patients with PNES may suffer as much or more from their symptoms, but they seem to lack the psychological awareness of the causes and consequences of their psychological dysfunction.

4. Looking further into interaction patterns with their environment there is, again on a subscale level, a tendency for patients with PNES to see others as "selfish and unfair" and to experience themselves as having an open, but impatient attitude toward others with no social fears. On the contrary, the patients with insomnia 
showed a tendency to experience themselves as tense and ignored and they tended to withdraw from social groups.

5. Finally, looking at the profile analysis, the two groups had different profiles. The patients with PNES showed a tendency toward the so-called "conversion V" pattern, which represents the tendency to report psychosomatic complaints with a strong preference for a medical explanation. In contrast, the insomnia group did not show this pattern; in general, they were more open to a psychological explanation for their disorder.

In summarizing the profiles it is clear that there are relative differences regarding the extent of somatization and externalization between the patient groups. The patients with PNES had a greater tendency to manifest psychosomatic symptoms and also to shift more easily between symptoms. Although patients with PNES suffered from their symptoms, they more frequently projected the burden of their symptoms to the environment. They tended to have great difficulty in acknowledging the presence of psychological distress and had a strong preference for a medical explanation for their symptoms.

The aforementioned stronger somatization tendency has been reported in other studies of patients with PNES ${ }^{19,25,57-59}$. Somatization seems to play a central role in the PNES population, although the causality of somatization as an etiological factor is difficult to establish ${ }^{6,57}$. Somatization is probably an important mechanism by which emotional problems are externalized. The function is mostly the avoidance of full awareness of the emotional burden and the escape from full responsibility for the emotional problems ${ }^{11,18}$. Also, there may be a lack of coping strategies to resolve psychological problems in another way ${ }^{6}$. Attribution of the symptoms to a medical cause has also been reported in other PNES studies. A number of studies found that the difficulty in accepting a psychogenic diagnosis also results from an inability of patients with PNES to link the experienced symptoms to specific causes ("I never feel stressed when I have the seizures" $)^{60-62}$. The resulting confusion seems to enhance the critical view of patients with PNES towards an underlying psychogenic explanation.

Although the sleeping problems of the patients with insomnia we assessed were also related to psychological factors, somatization and externalization seemed to play a less important role. The finding that patients with insomnia show more intrinsic distress about their symptoms has been reported in other studies as well; patients with insomnia obviously suffer from their symptoms ${ }^{56,63}$. In particular, the cognitive worrying we observed is characteristic of many patients referred to mental health institutions ${ }^{64}$.

These results also have prognostic and treatment implications. The combination of somatization and externalization might explain the difficulty that patients with PNES have in accepting their diagnosis and being motivated for nonmedical treatment. In addition, difficulty in creating a positive patient relationship after the diagnosis of PNES is explained is often described ${ }^{30,65}$. This is problematic, as studies consistently 
report that one-third to one-fourth of the patients become chronic ${ }^{20,66}$. It has been illustrated that a good therapeutic relationship is crucial for a favorable long-term outcome of PNES ${ }^{67,68}$. Patients with PNES often find the idea that psychogenic factors are responsible for their physical symptoms unacceptable and counterintuitive ${ }^{60-62,69}$. They thus persist in viewing their seizures as having an organic origin. Consequently they go to the physician with the expectation that some tests will be performed, a diagnosis will be made, and a medical treatment will be prescribed as with any other medical illness ${ }^{44,70}$. "Are you sure all necessary investigations have been performed and none of them showed any signs of epilepsy'" is one of the most frequently asked questions by patients in our clinical practice.

Moreover, as was pointed out by Green et al. ${ }^{61}$, society still seems to hold views that organic illnesses are genuine and legitimate whereas psychological conditions are not. Therefore, people who are told that their illness has a psychological origin are more likely to feel rejected by doctors and believe that they are viewed as being malingerers or attention-seekers ${ }^{61,65}$. This reinforces their tendency to seek medical responsibility for these symptoms. This pattern, in combination with the previous interaction factors (feeling they are viewed as attention seekers, etc.) may explain why "hostile coping" is a frequently reported coping style among patients with PNES $^{20,26}$

What all this means is that treatment decisions require a cautious approach in patients with PNES. The fundamental factor in a good therapeutic relationship is trust $^{30,67,71}$. Given the tendency of patients with PNES toward somatization and attribution of their symptoms to a medical cause, trust in a psychological treatment will improve when treatment starts within a medical center, instead of direct referral to a mental health institution. Some studies support this conclusion, postulating that strongly somatizing patients are not willing to accept referral for treatment to a psychological institution that has no contact with the institution that currently provides their medical care ${ }^{14,65,66,69}$. Aboukasm et al. ${ }^{69}$ compared four treatment programs and found that the best outcome occurred after the so-called "comprehensive" treatment program given in a specialized tertiary epilepsy center. This is in line with the suggestion that patients with PNES should preferably be treated in or in alliance with a medical center also treating epilepsy ${ }^{65}$.

Finally, there are limitations to this study that are worth mentioning. One reason for the lack of differences on the main clinical scales is that multiple factors are involved and that structural personality factors alone are not sufficient to generate a specific somatoform disorder ${ }^{11,20,27}$. In other words, by restricting ourselves to personality profiles alone, no real differences could have been found. Second, generalization of the results may be restricted by selection bias. Both the patients with PNES and those with insomnia were referred to a tertiary referral center and therefore probably represent the more complicated cases. Furthermore, we included only patients who were referred by the neurologist or sleep physician for further psychological 
assessment and treatment. This selection method precluded a count of the number of patients excluded on the basis of the study criteria. Future research should include this information to better estimate base rate information in relation to selection ratio for both groups. Furthermore, we did not use a control group without symptoms. Also, it is not expected that patients with insomnia represent all patients with different somatoform symptoms. So, ideally, two other control groups would have been needed to improve generalizability. Finally, future research comparing patients with PNES with other FSSS is recommended. 


\section{References}

1. Krumholz A, Niedermeyer E. Psychogenic seizures: a clinical study with follow-up data. Neurology 1983;33:498-502.

2. Leis AA, Ross MA, Summers AK. Psychogenic seizures: Ictal characteristics and diagnostic pitfalls. Neurology 1992;42:95-9.

3. Marquez AV, Farias ST, Apperson M, Koopmans S, Jorgensen J, Shatzel A, Alsaadi TM. Psychogenic nonepileptic seizures are associated with an increased risk of obesity. Epilepsy Behav 2004;5:88-93.

4. Sigurdardottir KR, Olafsson E. Incidence of Psychogenic Seizures in Adults: A population-based study in Iceland. Epilepsia 1998;39:749-52.

5. Szaflarski JP, Ficker DM, Cahill WT, Privitera MD. Four-year incidence of psychogenic nonepileptic seizures in adults in Hamilton Country, OH. Neurology 2000;55:1561-63.

6. Reuber M, Elger CE. Psychogenic nonepileptic seizures: review and update. Epilepsy Behav 2003; 4:205-16.

7. Benbadis SR, Hauser AW. An estimate of the prevalence of psychogenic non-epileptic seizures. Seizure 2000;9:280-1.

8. Alper K. Nonepileptic seizures. Neurol Clin (Epilepsy II: special issues) 1994;12:153-73.

9. Witgert ME, Wheless, JW, Breier JI. Frequency of panic symptoms in psychogenic nonepileptic seizures. Epilepsy Behav. 2005;6:174-8.

10. Kuyk J, Leijten F, Meinardi H, Spinhoven Ph, Dyck R van. The diagnosis of psychogenic non-epileptic seizures: a review. Seizure 1997;6(4):243-53.

11. Bodde NMG, Brooks JL, Baker GA, Boon PAJM, Hendriksen JGM, Aldenkamp AP. Psychogenic nonepileptic seizures-Diagnostic issues: a critical review. Clin Neurol Neurosurg 2009;111:1-9.

12. Wilkus RJ, Dodrill CB, Thompson PM. Intensive EEG Monitoring and psychological studies of patients with pseudoepileptic seizures. Epilepsia 1984;25:100-7.

13. Vanderzant CW, Giordani B, Berent S, Dreifuss FE, Sackellares JC. Personality of patients with pseudoseizures. Neurology 1986;36:664-8.

14. Sirven JI, Glosser DS. Psychogenic Nonepileptic Seizures: Theoretic and Clinical Considerations. Neuropsychiatry Neuropsychol Behav Neurol 1998;11:225-35.

15. LaFrance WC, Devinsky O. The Treatment of Nonepileptic Seizures: Historical Perspectives and Future Directions. Epilepsia 2004;45(Suppl. 2):15-21.

16. O'Sullivan SS, Spillane JE, McMahon EM, Sweeney BJ, Galvin RJ, McNamara B, Cassidy EM. Clinical characteristics and outcome of patients diagnosed with psychogenic nonepileptic seizures: a 5-year review. Epilepsy Behav 2007;11:77-84.

17. LaFrance WC, Rusch MD, Machan JT. What is "treatment as usual" for non-epileptic seizures? Epilepsy Behav. 2008;12:388-94.

18. Drake ME, Pakalnis A, Phillips BB. Neuropsychological and psychiatric correlates of intractable pseudoseizures. Seizure 1992;1:11-3.

19. Cragar DE, Berry DTR, Schmitt FA, Fakhoury T.A. Cluster analysis of normal personality traits in patients with psychogenic non-epileptic seizures. Epilepsy Behav 2005; 6:593-600.

20. Bodde NMG, Brooks JL, Baker GA, Boon PAJM, Hendriksen JGM, Mulder OG, Aldenkamp AP. Psychogenic non-epileptic seizures - definition, etiology, treatment and prognostic issues; a critical review. Seizure 2009;18:543-53.

21. Reuber M, Howlett S, Khan A, Grünewald RA. Non-epileptic seizures and other functional neurological symptoms: predisposing, precipitating and perpetuating factors. Psychosomatics 2007;48 (3): $230-8$.

22. Quigg M, Armstrong RF, Farace E, Fountain NB. Quality of life outcome is associated with cessation rather than reduction of psychogenic nonepileptic seizures. Epilepsy Behav 2002;3:455-9.

23. Mayou R and Farmer A. ABC of psychological medicine: Functional somatic symptoms and syndromes. Br Med J 2002;325:265-8.

24. Kroenke K, Sharpe M, Sykes R. Revising the classification of somatoform disorders: key questions and preliminary recommendations. Psychosomatics 2007;48:277-85.

25. Reuber M, House AO, Pukrop R, Bauer J, Elger CE. Somatization, dissociation and general psychopathology in patients with psychogenic non-epileptic seizures. Epilepsy Res 2003;57:159-67. 
26. Mökleby K, Blomhoff S, Malt UFr, Dahlström A, Tauböll E, Gjerstad L. Psychiatric comorbidity and hostility in patients with psychogenic nonepileptic seizures compared with somatoform disorders and healthy controls. Epilepsia 2002;43:193-8.

27. Reuber M, Pukrop R, Bauer J, Derfuss R, Elger CE. Multidimensional assessment of personality in patients with psychogenic non-epileptic seizures. J Neurol Neurosurg Psychiatry 2004;75:743-8.

28. Reuber M, Pukrop R, Bauer J, Helmstaedter C, Tessendorf N, Elger CE. Outcome in psychogenic nonepileptic seizures: 1 to 10-Year follow-up in 164 patients. Ann Neurol 2003; 53:305-11.

29. Millon T, Grossman S, Millon C, Meagher S, Ramnath R. Personality disorders in modern life, 2 nd ed. New York: Wiley; 2004

30. Lacey C, Cook M, Salzberg M. The neurologist, psychogenic non-epileptic seizures, and borderline personality disorder. Epilepsy Behav. 2007;11:492-8.

31. Binder LM, Salinsky MC, Smith SP. Psychological correlates of psychogenic seizures. J Clin Exp Neuropsychol. 1994;16:524-30.

32. Binder LM, Kindermann SS, Heaton RK, Salinsky MC. Neuropsychologic impairment in patients with non-epileptic seizures. Arch Clin Neuropsychol 1998;13:513-22.

33. Storzbach D, Binder LM, Salinsky MC, Campbell BR, Mueller RM. Improved prediction of nonepileptic seizures with combined MMPI and EEG measures. Epilepsia 2000;41:332-7.

34. Cragar DE, Schmitt FA, Berry DT, Cibula JE, Dearth CM, Fakhoury TA. A comparison of MMPI-2 decision rules in the diagnosis of nonepileptic seizures. J Clin Exp Neuropsychol 2003;25:793-804.

35. Wilkus RJ, Dodrill CB. Factors affecting the outcome of MMPI and neuropsychological assessments of psychogenic and epileptic seizure patients. Epilepsia 1989;30:339-47.

36. Dodrill CB, Wilkus RJ, Batzel LW. The MMPI as a diagnostic tool in nonepileptic seizures. In: Rowan AJ, Gates JP, editors. Non-epileptic seizures. Boston: Butterworth-Heinemann; 1993.p.211-9.

37. Derry PA, McLachlan RS. The MMPI-2 as an adjunct to the diagnosis of pseudoseizures. Seizure 1996;5:35-40.

38. Fargo JD, Schefft BK, Kent GP, Szaflarski JP, Privitera MD, Yeh HS. The prevalence of seizure types among individuals referred for phase I neuropsychological assessment: demographic and neuropsychological characteristics. Clin Neuropsychol 2007;21:442-55.

39. Testa SM, Schefft BK, Szaflarski JP, Yeh H-S, Privitera MD. Mood, personality, and health-related quality of life in epileptic and psychogenic seizure disorders. Epilepsia 2007;48:973-82.

40. Diagnostic and statistical manual of mental disorders. (DSM-IV-TR) Washington, DC: American Psychiatric Assoc; 2000.

41. Reuber M, Mitchell AJ, Howlett SJ, Crimlisk HL, Grünewald RA. Functional symptoms in neurology: questions and answers. J Neurol Neurosurg Psychiatry 2005;76:307-14.

42. Woolfolk RL, Allen LA, Tiu JE. New directions in the treatment of somatization. Psychiatr Clin North Am 2007;30:621-44

43. Schneider-Helmert D. Twenty-four-hour sleep-wake function and personality patterns in chronic insomniacs and healthy controls. Sleep 1987;10:452-62.

44. Bass C, Murphy M. Somatoform and personality disorders: syndromal comorbidity and overlapping developmental pathways. J Psychosom Res.1995; 39:403-27.

45. Van de Laar M, Verbeek I, Pevernagie D, Aldenkamp AP, Overeem S. The role of personality traits in insomnia. Sleep Med Rev 2010;14:61-8.

46. Butcher JN, Graham JR, Ben-Porath YS. Methodological problems and issues in MMPI, MMPI-2, and MMPI-A research. Psychol Assess 1995; 7:320-9.

47. Greene RL, Gwin R, Staal M. Current status of MMPI-2 Research: a methodologic overview. J Person Assess 1997;68:20-36.

48. Graham JR. MMPI-2: assessing personality and psychopathology. 4th ed.New York: Oxford Univ. Press; 2006.

49. Butcher JN. Personality assessment without borders: adaptation of the MMPI-2 across cultures. J Person Assess 2004;83:90-104.

50. Schramke CJ, Valeri A, Valeriano JP, Kelly KM. Using the Minnesota Multiphasic Inventory 2, EEGs, and clinical data to predict non-epileptic events. Epilepsy Behav 2007;11:343-6.

51. Russell H. Coady L, Chaytor N. The impact of seizure-related items and comorbid medical conditions on the MMPI-2 profiles of patients with epilepsy and psychogenic nonepileptic seizures. Epilepsy Behav 2009;15:325-9. 
52. Helmes E, Reddon JR. A Perspective on developments in assessing psychopathology: a critical review of the MMPI and MMPI-2. Psychol Bull 1993;113:453-71.

53. Griffith NM, Szaflarski JP, Schefft BK, Isaradisaikul D, Meckler JM, McNally KA, Privitera MD. Relationship between semiology of psychogenic non-epileptic seizures and Minnesota Multiphasic Personality Inventory Profile. Epilepsy Behav 2007;11:105-11.

54. Butcher JN, Williams CL. Essentials of MMPI-2 and MMPI-A interpretation. Minneapolis: Univ Minnesota Press; 1992.

55. Riley JL, Robinson ME. Validity of MMPI-2 profiles in chronic back pain patients: differences in path models of coping and somatization. Clin J Pain 1998;14:324-35.

56. Kalogjera-Sackellares D, Cartwright RD. Comparison of MMPI profiles in medically and psychologically based insomnias. Psychiatry Res 1997;70:49-56.

57. Owczarek K. Somatization indexes as differential factors in psychogenic pseudoepileptic and epileptic seizures. Seizure 2003;12:178-81.

58. Hixson JD, Balcer LJ, Glosser G, French JA. Fear sensitivity and the psychological profile of patients with psychogenic nonepileptic seizures. Epilepsy Behav 2006;9:587-92.

59. LaFrance WC, Alper K, Babcock D, Barry JJ, Benbadis S, Caplan R, Gates J, Jacobs M, Kanner A, Martin R, Rundhaugen L, Stewart R, Vert C. Non-epileptic seizures treatment workshop summary. Epilepsy Behav 2006;8:451-61.

60. Carton S, Thompson PJ, Duncan JS. Non-epileptic seizures: patients' understanding and reaction to the diagnosis and impact on outcome. Seizure 2003;12:287-94.

61. Green A, Payne S, Barnitt R. Illness representations among people with non-epileptic seizures attending a neuropsychiatry clinic: a qualitative study based on the self-regulation model. Seizure 2004;13:331-9.

62. Thompson R, Isaac CL, Rowse G, Tooth CL, Reuber M. What is it like to receive a diagnosis of nonepileptic seizures? Epilepsy Behav 2009;14:508-15.

63. Tsushima WT, Ingolfsdottir E. MMPI-2 scores of patients with insomnia. Psychol Rep 2004;94:267-72.

64. Greene RL. The MMPI-2/MMPI: an interpretive manual. Boston: Allyn \& Bacon; 1991.

65. Kanner AM. Is the neurologist's role over once the diagnosis of psychogenic nonepileptic seizures is made? No! Epilepsy Behav 2008;12:1-2.

66. Reuber M, House AO. Treating patients with psychogenic non-epileptic seizures. Curr Opin Neurol 2002;15:207-11.

67. Stonnington CM, Barry JJ, Fisher RS. Conversion disorder. Am J Psychiatry 2006;163:1510-7.

68. Marchetti RL, Kurcgant D, Neto JG, von Bismark MA, Marchetti LB, Fiore LA. Psychiatric diagnoses of patients with psychogenic non-epileptic seizures. Seizure 2008;17:247-53.

69. Aboukasm A, Mahr G, Rader Gahry B, Thomas A, Barkley GL. Retrospective analysis of the effects of psychotherapeutic interventions on outcomes of psychogenic nonepileptic seizures. Epilepsia 1998;39:470-3.

70. Reuber M. Psychogenic nonepileptic seizures: Answers and questions. Epilepsy Behav 2008;12: 622-35.

71. Gates JR. Nonepileptic seizures: classification, coexistence with epilepsy, diagnosis, therapeutic approaches, and consensus. Epilepsy Behav 2002;3:28-33. 


\section{Chapter 8}

\section{Patients with psychogenic non-epileptic seizures referred to a tertiary epilepsy centre: Patient characteristics in relation to diagnostic delay}


146 Chapter 8

\section{Abstract}

\section{Objective}

This clinical study examines patient and seizure characteristics of patients with psychogenic non-epileptic seizures (PNES) in a tertiary epilepsy centre. The main focus was whether a new subgroup of PNES patients emerged with a relatively short referral time and possible specific characteristics.

\section{Methods}

All PNES patients referred to a specialist program in our centre between mid 2007 and mid 2009 were consecutively included. This yielded a study cohort of 90 patients.

Results

The majority of the patients have a patient history with many medical symptoms and they were or had been in treatment by a medical specialist. Furthermore diffuse psychological/psychiatric symptoms and subsequent treatments are also remarkably common, in general without a clear psychological diagnosis. The average time between seizure onset and referral to an epilepsy centre is remarkably low (4.29 years). About $50 \%$ of the patients were referred within 2 years of seizure onset. This 'active high speed referral group' had significantly more previous psychological complaints, significantly more previous psychological/psychiatric treatments and a trend towards more previous medical investigations.

\section{Conclusion}

There seems to be a new subgroup of PNES patients with a short referral time, characterized by a more active attitude towards examination of the symptoms in combination with an active attitude to apply for treatment. However, the PNES cohort as a whole is characterized by having somatoform symptoms based on a process of somatization. 


\section{Introduction}

Psychogenic non-epileptic seizures (PNES) are sudden paroxysmal changes in behaviour or consciousness, that resemble epileptic seizures, but are not accompanied by the electrophysiological changes that characterize an epileptic seizure. Also, there is no clinical evidence of other organic disease that may explain the seizures, whereas there is positive evidence for psychogenic factors that may have caused the seizures $^{1-3}$. The incidence of PNES in the general population is about $1.5 / 100,000$ persons per year. This is equivalent to about $4 \%$ of the incidence of epilepsy ${ }^{2,4,5}$. However, the prevalence of PNES in patients referred to epilepsy centres is estimated to be about $15-30 \% \%^{2,6,7}$. Apparently a group of these patients have such severe or difficult-to-diagnose symptoms that referral to a tertiary epilepsy centre is needed $^{8}$. A complicating observation, especially for the patients referred to specialized epilepsy centres, is that between $5-40 \%$ of the patients with PNES have a concomitant diagnosis of epilepsy or have a past history with epileptic seizures ${ }^{9,10}$.

In diagnosing PNES two consecutive phases can be identified ${ }^{3,11}$. Initially, organic factors must be excluded. This is a necessary first step, since the presence of clear psychogenic factors does not exclude the possibility of epilepsy ${ }^{12}$. The diagnosis of PNES is based on history taking, seizure observations and EEG recordings ${ }^{2,5,13}$. The differential diagnosis can be challenging ${ }^{14-16}$. Also, various studies demonstrated that many signs that have been considered typical for PNES, appeared not to be specific and can also be found in epileptic seizures, especially in those seizures that originate from the frontal lobe ${ }^{2,14,17}$.

The second phase aims at obtaining a 'positive diagnosis' in which the underlying psychological mechanisms are evaluated that can be used for treatment ${ }^{3,18}$. Theories regarding the psychological etiology of PNES are diverse. This probably reflects the heterogeneity of the psychogenic etiology of PNES ${ }^{19,20}$. Recent studies showed that PNES are caused by an interaction of multiple factors in which not all factors may have a similar impact in an individual patient ${ }^{3,21,22}$. Attempts are made to organize different etiological factors in a descriptive model. Also several studies have tried to classify possible subgroups of PNES based on different etiological factors ${ }^{23-25}$.

Over the years several patient and seizure characteristics about PNES have been consistently reported ${ }^{2,3}$. In general, there is a predominance of the female gender (of about $75-99 \%)^{6,26}$. Age at onset is at about $20-30$ years ${ }^{5,7,27}$. A higher incidence of PNES has been found in patients with a lower educational level ${ }^{22}$. At time of diagnosis a majority of the patients report a relatively high seizure frequency (daily or weekly seizures) ${ }^{28,29}$. Meierkord et al. ${ }^{30}$ revealed that the majority of patients (66\%) had seizures with major motor manifestation (resembling tonic-clonic seizures). Seizures in the category "unresponsiveness" ('absence-type seizures') are a less frequent reported symptom. However, Leis et al. ${ }^{1}$ have demonstrated that unresponsiveness may often remain undetected so they warn against such conclusions. 
Although PNES patients constitute a heterogeneous group, psychiatric co-morbidity or even multiple psychiatric diagnoses, have also consistently been reported $^{19,22,31}$. Especially mood disorders (mostly depression) ${ }^{32,33}$, anxiety disorders ${ }^{31,34}$; and personality disorders ${ }^{35}$ are frequently mentioned ${ }^{5,7,11,29,36-38}$. Often the exact definition of the psychiatric disorder is however lacking or nonconclusive, due to differences in methodology, the selection criteria or missing information ${ }^{2}$.

An additional consistent finding is the long delay of approximately 7 years between seizure onset and the (final) diagnosis of PNES, at least in those patients that have been referred to tertiary centres. This finding has been reconfirmed and still seems valid over the years ${ }^{2,5,7,19,28,39-41}$. Reuber and Elger ${ }^{5}$ argue that a potential reason for this diagnostic delay could be that patients often present their seizures to generalists, physicians in emergency care departments a.o. instead of experts in the assessment and treatment of seizures. Non-expert physicians may act 'better safe than sorry' when they are faced with seizures and treat these seizures as organic although they are uncertain about the diagnosis. Several studies showed that a large number of patients who were referred to tertiary epilepsy centres with 'intractable epilepsy' or with an uncertain diagnosis, were later diagnosed as having PNES $^{15,18,41,43}$. Also, it is possible that patients with PNES referred to a tertiary epilepsy centre are exactly those patients in whom the seizures are difficult to detect or difficult to classify, 28 . The diagnostic delay is seen as worrisome since diagnosing PNES is essential for adequate therapy and can prevent unnecessary drug treatment ${ }^{3,42,44}$.

Although this delay is consistently reported and seems stable around 7 years, our recent experience in clinical practice suggests that for some patients the time between onset of seizure symptoms and referral to a tertiary centre seems to be much shorter. There is no change in referral guidelines in our country so our assumption is that this is related to patient characteristics. As this has not yet been reported, we analyzed the patient characteristics of a non-selective group of PNES patients referred to our tertiary epilepsy centre. Our main focus is on assessing patient characteristics of a possible 'new' subgroup of PNES patients with a relative short referral time.

\section{Methods}

\section{Participants}

All patients aged $>12$ years referred to the epilepsy centre between mid 2007 and mid 2009 were consecutively included in the study after a final diagnosis of PNES was made. Epilepsy as concomitant disorder was not an exclusion criterion. The study was approved by the local Medical Ethics Committee. 


\section{Procedure}

This study is an open non-controlled clinical cohort study. Patients were included after the diagnostic phase was completed and the patients were referred to an expert team. The PNES diagnosis had to be confirmed in the tertiary epilepsy centre by an experienced neurologist/epileptologist, using clinical description and additional EEG investigations (also EEG video telemetry). The type of EEG investigation was based on clinical indication such as patient history and seizure semiology.

\section{Statistical analyses}

Statistical analyses were performed using SPSS 16.0. (SPSS, Inc, Chicago, IL). For relevant variables parametric $t$-tests or non-parametric statistics were used (MannWhitney $U$ tests). The significance level was set at $5 \%$. In addition a non-parametric correlation analysis was performed.

\section{Results}

Table 8.1 shows the main demographical and clinical characteristics of the 90 patients included. There is a dominance of the female gender and mean age at referral was 31.71 years. Most patients have a lower educational level, such as special education, primary school or lower vocational education. Most patients solely have PNES, although about one third of the patients had PNES in combination with epilepsy. Only in one patient there was doubt about comorbidity with epilepsy, but no doubt about PNES.

A large part of the patients does not live independent, but with their parents (35.6\%). The mean age of this home living group is 20 years, but $30 \%$ is older than 21 years. Furthermore, about half of the patients reports having a complicated family background, such as divorced parents or a family breakdown due to external circumstances such as a deceased parent. In $20 \%$ of the patients epilepsy or other types of seizures occurred in the first line (parents or siblings) or second line (grandparents and friends). The mean age of onset of the seizures is 26.5 years, with a standard deviation of 12.9 years. The youngest patient was 5 years at seizure onset and the oldest patient was 63 years old. At time of referral to the epilepsy centre almost half of the patients (46\%) used AED medication. AED polytherapy was used in $26 \%$ of the patients; $20 \%$ of the patients used AED monotherapy. Furthermore, psychotropic medication is used in $20 \%$ of the patients and $7 \%$ used sleep medication. $27 \%$ Of the patient group used other medication such as medication for the heart. Only $36 \%$ of the patients did not use any medication at the time of referral. 
150 Chapter 8

Table 8.1 Patient characteristics.

\begin{tabular}{lcc}
\hline & Number & Percentage \\
\hline Number of patients & 90 & 100 \\
Gender & & 24.4 \\
Male & 22 & 75.6 \\
Female & 68 & \\
Age at time of diagnosis & & \\
Minimum age & 13.92 & \\
Maximum age & 63.33 & \\
Mean & (SD & \\
Median & 29.17 & 12 \\
Education & & 14 \\
Special education & 11 & 27.5 \\
Primary school & 13 & 27.5 \\
Lower secondary school & 25 & 12 \\
Middle level secondary school & 25 & 7 \\
Higher education & 10 & \\
Unknown & 6 & 71 \\
Also epilepsy? & & 28 \\
No & 64 & 1 \\
Yes & 25 & \\
Doubt & 1 & \\
\hline
\end{tabular}

Table 8.2 summarizes seizure frequency and seizure type at time of diagnosis in the epilepsy centre. Most of the patients had daily or weekly seizures. Seizures types were divided into different categories, based on the classification proposed by Betts and Boden $^{33}$. Most of the patients had 'twilight state' symptoms, which are characterised by sudden episodes of loss of consciousness and psychic symptoms. A second common seizure type is 'the tonic-clonic like seizure', that resembles epileptic seizures with a tonic phase and clonic movements. Other frequent seizure types were 'cloniclike' or 'atonic-like' (drop attacks). 'Absence-like' seizures were uncommon in this cohort.

These different seizures types can also be divided into two different broad categories $^{2,30}$, i.e. 'major motor manifestation' and 'unresponsiveness, flaccidity'. This classification is based on either seizures that involve movements and jerks or falling (major motor manifestation) or without any movement (unresponsiveness). The categories are equally common in our cohort (39\% major motor manifestations versus $46 \%$ unresponsiveness). Some patients (14\%) have more than one seizure type. 
Table 8.2 PNES frequency and seizure type at time of diagnosis.

\begin{tabular}{lccc}
\hline Seizure frequency & \% of the study group & Seizure Type & \% of the study group* \\
\hline Daily & 21 & 'Twilight state' & 34 \\
Weekly & 44 & 'Tonic-clonic like' & 24 \\
Monthly & 13 & 'Clonic-like' & 11 \\
Yearly & 10 & 'Atonic-like' & 10 \\
Seizure free & 2 & 'Clonic and twilight state' & 5 \\
Unclear & 10 & 'Tonic-like' & 2 \\
& 'Clonic and Stupor-like' & 2 \\
& 'Absence-like' & 2 \\
& Unknown & 1 \\
\hline
\end{tabular}

* Some patients have more than one seizure type.

Table 8.3a shows that only a minority of this cohort has no general medical complaints in the patient history before referral. The vast majority of the patients reports frequent medical and physical complaints.

In line with this finding, Table $8.3 \mathrm{~b}$ shows that only a minority of $21 \%$ of the patient group had no previous history of medical treatments before referral to our tertiary epilepsy centre. The majority of the patients had been in treatment for one or more medical diseases or problems. These were treatments by a medical specialist, such as a neurologist or medical specialist for internal medicine.

Table 8.3 History of medical symptoms and medical treatment before referral.

\begin{tabular}{|c|c|c|c|}
\hline a. Medical symptoms & $\begin{array}{l}\text { Percentage of the study } \\
\text { group }\end{array}$ & $\begin{array}{l}\text { b. Previous medical } \\
\text { treatment for }\end{array}$ & $\begin{array}{l}\text { Percentage of the study } \\
\text { group }\end{array}$ \\
\hline No medical complaints & 28 & Suggested head injury & 34 \\
\hline Chronic headache & 16 & $\begin{array}{l}\text { Chronic diseases } \\
\text { (a.o. diabetes mellitus, } \\
\text { asthmatic bronchitis, } \\
\text { tumour and pulmonary } \\
\text { embolism) }\end{array}$ & 22 \\
\hline Sleeping problems & 12 & Neurological disorders & 21 \\
\hline Chronic fatigue & 11 & $\begin{array}{l}\text { General medical } \\
\text { problems }\end{array}$ & 21 \\
\hline Chronic pain & 10 & Seizure-like symptoms & 18 \\
\hline Addiction problems & 4 & Epilepsy & 8 \\
\hline Hyperventilation & 4 & No medical treatments & 21 \\
\hline Hypertension & 4 & & \\
\hline Menstrual complaints & 3 & & \\
\hline Memory complaints & 2 & & \\
\hline Heart complaints & 2 & & \\
\hline $\begin{array}{l}\text { Physical disability/ } \\
\text { wheelchair bound }\end{array}$ & 2 & & \\
\hline ADHD & 1 & & \\
\hline Obesity & 1 & & \\
\hline
\end{tabular}


Table 8.4a shows that most of the patients have no confirmed previous psychological or psychiatric disorder or clearly defined and diagnosed symptoms. Despite this lack of confirmed psychological or psychiatric diagnosis, Table $8.4 \mathrm{~b}$ shows that about two third of the patient group had previous psychological or psychiatric treatments before they were referred to the epilepsy centre.

Table 8.4 History of psychological/psychiatric symptoms and subsequent treatments before referral.

\begin{tabular}{|c|c|c|c|}
\hline $\begin{array}{l}\text { a. Previously confirmed } \\
\text { psychological/psychiatric } \\
\text { symptoms or disorders }\end{array}$ & $\begin{array}{l}\text { Percentage of } \\
\text { study group }\end{array}$ & $\begin{array}{l}\text { b. Previous psychological and/or } \\
\text { psychiatric treatments }\end{array}$ & $\begin{array}{l}\text { Percentage of } \\
\text { study group* }\end{array}$ \\
\hline $\begin{array}{l}\text { No confirmed } \\
\text { psychological/psychiatric disorder }\end{array}$ & 72.5 & $\begin{array}{l}\text { Psychological treatment of longer } \\
\text { duration }\end{array}$ & 47 \\
\hline Depression & 11 & $\begin{array}{c}\text { Psychiatric treatment of longer } \\
\text { duration }\end{array}$ & 24 \\
\hline Suicide attempt(s) & 5.5 & Counseling by a social worker & 8 \\
\hline Borderline personality disorder & 3 & $\begin{array}{l}\text { Acute admission for psychiatric } \\
\text { treatment }\end{array}$ & 6 \\
\hline Eating disorder & 2 & $\begin{array}{l}\text { Single psychological or psychiatric } \\
\text { consultation }\end{array}$ & 8 \\
\hline Anxiety attacks & 2 & Family counselling & 7 \\
\hline Self mutilation & 2 & $\begin{array}{c}\text { No psychological/psychiatric } \\
\text { interventions }\end{array}$ & 37 \\
\hline Asperger syndrome & 2 & & \\
\hline Mood swings & 1 & & \\
\hline
\end{tabular}

* Some patients have more than one symptom or treatment.

Figue 8.1 shows on the horizontal axis the patients and on the vertical axis the number of years between seizure onset and referral to the epilepsy centre. This shows that the average time between seizure onset and referral to the tertiary centre is 4.29 years ( $S D=6.44$ years). However, the relatively high standard deviation illustrates that there is a large range. The minimum time between the first seizure and a referral was 1 month and the maximum time was 25 years and 4 months. The blue line in Figure 8.1 shows the time for each individual patient between seizure onset and referral to the tertiary epilepsy centre. The red line represents the average time of this study group. Globally about $50 \%$ of the patients were referred within two years of the seizure onset. The other $50 \%$ of the patient group is referred around the average period $(30 \%)$ or were referred after a very long period from seizure onset. About $20 \%$ of the patients were referred after 9 years or longer from seizure onset.

We compared these groups for differences. In general, differences were limited. Naturally, the first group has a much shorter referral delay. Furthermore, this group had significantly more previous psychological complaints (Mann-Whitney $U$ 793,000, $P=0.034$ ), more previous psychological or psychiatric treatments (Mann-Whitney $U$ 
23,000, $P=0.03$ ) and a trend towards more previous medical investigations (Mann Whitney $U$ 19,500, $P=0.06$ ).

Further analyses of the referral patterns of all patients showed that most patients $(41 \%)$ were referred for 'diagnostic uncertainty' or for a second opinion (13\%). Other referral questions were unsatisfactory seizure control and/or side-effects of the antiepileptic drugs (15\%) or 'recurrent seizures' (10\%). In a mere $4 \%$ of the patients a clear suspicion of PNES was the actual referral reason. Furthermore 53\% of the patients were referred by a neurologist from a general hospital or by a family doctor (40\%). Only $1 \%$ of the patients was referred by an psychiatrist.

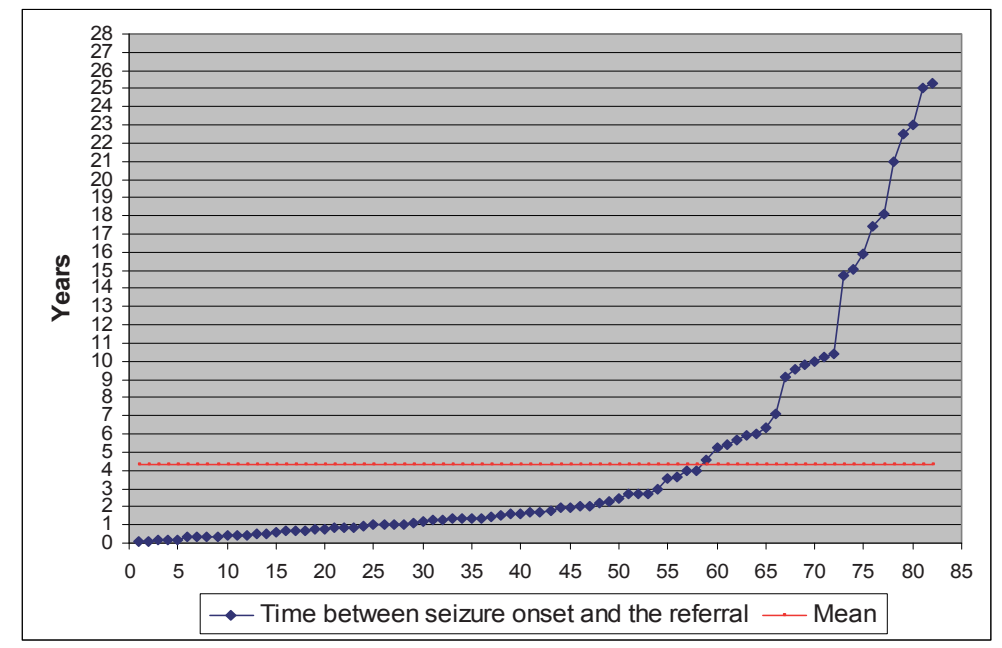

Figure 8.1 Time between seizure onset and referral to the tertiary epilepsy centre.

* $n=8$ missing values for diagnostic delay because of no record in the patient file

\section{Discussion}

This clinical study was aiming at exploring characteristics of patients with PNES, referred between mid 2007 and mid 2009 to and diagnosed in a tertiary epilepsy centre. We were particularly interested in the patient characteristics of a possible new subgroup of PNES patients with a relative short referral time.

Some of the consistently reported characteristics of PNES patients ${ }^{2,3,5,6,22}$ were also found in our cohort: a predominance for the female gender (75.6\%) and a lower educational level. Approximately one third of the patients does not live independent, but with their parents. $30 \%$ of this 'home living' group is older than 21 years, which 
could represent a higher tendency towards dependency. Also about half of the cohort report complications in the family of origin, such as divorced parents or problematic relationship(s) within the family. About $20 \%$ of the patients had relatives in first or second line with seizures. This is lower than expected as we have suggested ${ }^{2,3}$ that patients with PNES must have had models for seizures in their direct environment.

As reported in other studies ${ }^{28,29}$, seizure frequency at time of diagnosis is high: $65 \%$ of the patients had weekly or daily seizures. A broad distinction of the seizures into 'major motor manifestation' and 'unresponsiveness, flaccidity ${ }^{30}$ reveals that both types are equally common in occurrence (39\% versus $46 \%$ ). The relatively high percentage of unresponsiveness is in line with Leis et al. ${ }^{1}$ demonstrating that unresponsiveness may often remain undetected by the referring institute. It may be these patients that are referred to and diagnosed in a tertiary centre ${ }^{28}$. In accordance with a study by Bodde et al. ${ }^{3}$, most patients had only PNES, although about one third of the patients had PNES and epilepsy as comorbid disorder. Only $4 \%$ of the patients were referred with a clear suspicion of PNES. Diagnostic uncertainty or unsatisfactory seizure control were the main referral reasons. This corresponds with the observation that apparently a group of PNES patients have such frequent or difficult-to-diagnose symptoms that referral to a tertiary epilepsy centre is needed. Almost half of the patients (46\%) used antiepileptic drugs at time of referral. This is in accordance with other studies ${ }^{29,45}$, although the high percentage of patients on polytherapy in our cohort (26\%) is remarkable. Only one third of the patients did not use any medication at time of referral.

The majority of the patients (about 70\%) report other medical symptoms in their patient history prior to referral to the epilepsy centre. Especially chronic headache, sleeping disorders, chronic fatigue and chronic pain are frequently mentioned. These are symptoms that are difficult to confirm objectively. In line with these medical symptoms, the vast majority of the patients were or had been in treatment for one or more medical diseases by a medical specialist. Only a minority (18\%) had no previous history of medical treatments at time of diagnosis in our centre. If compared with the general population about $30 \%$ will consult a specialist (source: Statistics Netherlands ${ }^{46}$ ). Especially head injury was reported by about one third of the patients. Kuyk $^{47}$ and Benbadis ${ }^{48}$ also found that some of the PNES patients had a history of head injury. Similar results have also been reported for other conversion patients ${ }^{49}$. The relationship between this finding and the development of PNES or other conversion symptoms is unknown.

In addition to the large amount of former medical symptoms and treatment, more or less elusive psychological/psychiatric symptoms and subsequent treatments are also remarkably common. Patients reported for example stress at work, performance anxiety and mood swings in their patient history. These types of psychological symptoms seem to be difficult to verify since only $19 \%$ of these patients had a diagnosed and confirmed psychological or psychiatric disorder such as a depressive disorder. This implies that in the vast majority of the patients (81\%) previous 
psychological and psychiatric treatments were initiated without a clear diagnosis, but based on indistinct, equivocal complaints or symptoms.

Summarizing these findings, our cohort is characterized by having a patient history with many medical and psychological/psychiatric symptoms and an active drive towards seeking subsequent treatment for them. In general there is a lack of clear diagnoses. These findings seem to indicate the presence of somatoform symptoms and a process of somatization in PNES patients. In somatization, physical symptoms occur in the absence of any identifiable bodily mechanism. Patients experience and communicate somatic distress, have a somatic explanation for their symptoms and look for medical treatment ${ }^{50,51}$. Patients with somatoform symptoms mostly do not have clear psychological /psychiatric disorders, but they have vague, indistinct and difficult to verify complaints, generally somatically defined such as chronic headache etc. In line with this somatic definition, they are not referred by psychiatrists but by neurologists and family practitioners ${ }^{52}$.We also found this reference pattern in our patient cohort.

The most striking finding in this study is the relatively low average time between seizure onset and referral to a tertiary epilepsy centre of 4.29 years. This is different from most of the reports that have demonstrated an average of approximately 7 years $2,3,5,7,15,19,28,40,41$. Furthermore, the standard deviation was high (6.44 years). Almost $50 \%$ of the patients were referred within 2 years after seizure onset.

According to our hypothesis we analyzed this so-called 'active high speed referral group' on specific characteristics. In contrast with the findings of O'Sullivan et al. ${ }^{53}$, who found a shorter diagnostic delay for patients with PNES alone, we did not find delay differences between PNES patients only and PNES patients with comorbid epilepsy. We did find that our active high speed referral group had significantly more previous psychological/psychiatric complaints and more previous psychological/ psychiatric treatments in their patient history. Furthermore, there is a strong trend towards more previous medical investigations. So this active group is characterised by a stronger drive for medical examinations and treatment of mostly indistinct, equivocal symptoms.

Nonetheless, this does not indicate a specific subgroup with specific distinctive features. Our cohort as a whole is characterized by having many diffuse psychological/ psychiatric and/or medical symptoms. This is in line with the consistent finding of psychiatric comorbidity and the tendency to somatize in PNES patients ${ }^{13,20,31,39,54,55}$. For example O' Sullivan et al. ${ }^{53}$ report that $34 \%$ of their PNES patients in a tertiary referral centre (Cork University Hospital) exhibited multiple potential somatoform symptoms. They also state that they feel this is an underestimation of the cooccurrence of other potential somatoform disorders. It therefore seems more likely that there is a continuum of somatization in the PNES patients referred to an epilepsy centre, in which a group of patients has a more active attitude towards medical investigations and treatment of these symptoms. 
Currently, it is not possible to clarify whether this continuum of somatization might differentiate PNES patients based on the DSM-IV classification system of somatoform disorders. The DSM-IV distinguishes seven different types of somatoform disorders: somatization disorder, undifferentiated somatoform disorder, conversion disorder, pain disorder, hypochondriasis, body dysmorphic disorder and somatoform disorder not otherwise specified. In most cases, PNES is classified as a conversion disorder, since the seizures present as a 'pseudo neurological symptom', affecting voluntary or sensory function and suggesting dysfunction of the nervous system (DSM-IV) ${ }^{56}$. However, given the elusive symptoms in the patient history, other classifications types may also be considered, especially a somatization disorder (SD). A SD is characterized by having symptoms affecting different medical area's; so pain symptoms, gastrointestinal symptoms and sexual symptoms have to be reported as well. In order to confirm such a diagnosis often additional physical examinations and diagnostic tests are required to exclude organic disorders. Such investigations are costly and often not available in the patient history ${ }^{51}$. Furthermore, autobiographic memory of past medical or psychiatric symptoms is often unreliable. Patients seem to forget or fail to report previously reported symptoms that are no longer troublesome ${ }^{57,58}$. Also, clinicians need to systematically discuss former symptoms ${ }^{51}$. For these reasons, the actual prevalence of a SD may be substantially higher than literature suggests ${ }^{51}$. Remarkably, even in the 'high speed referral group', which is characterized by more medical investigations and treatments, a SD according to DSM criteria was not significantly more confirmed than in patients who were referred much later. A potential explanation might be that physicians are 'better safe than sorry' in diagnosing a SD. Furthermore, in the Dutch system patients are referred to different specialists for different symptoms, so a specialist may lose track on the whole patient history.

Our study does not provide reasons for this high speed referral pattern in a subgroup of the PNES patients. It may be the changed position of the epilepsy centres, which are now widely known to have specific expertise in diagnosing and treating PNES. Also the topic of 'somatically unexplained symptoms' seems to get more attention in hospitals ${ }^{59,60}$. However, there are no strong indications that these changes have led to a different referral pattern. It may also be failure of institutions for psychological and psychiatric treatment to cope with these strongly somatizing patients. In general, the shorter the diagnostic delay, the better. However, if these 'active high speed referral' patients are constantly referred for (medical) investigation of changing symptoms, this will also prevent appropriate treatment. Only cooperation between hospitals or tertiary referral centres and institutions for mental health might prevent this kind of 'medical shopping'. Furthermore Ettinger et al. ${ }^{39}$ suggested that future investigations should determine what effect revealing a PNES diagnosis has on the frequency and severity of other symptoms, such as headache and other pain symptoms. In some patients the resolution of the PNES may be followed by the development of substitute symptoms. Also PNES may not be the most serious manifestation of a SD. 
Finally, in our study we analysed descriptive characteristics of patients with PNES. Our focus was not on assessing personality traits. It is possible that using psychological tests could differentiate patients from the 'high speed referral group' at a different level. Especially at the level of coping mechanisms changes can be hypothesized. Coping styles refer to the way people act upon a setback, such as having symptoms, in their lives. Changes might be found between more active or passive coping styles $^{3,61,62}$. The search for possible subgroups for PNES remains important to improve tailored treatment for this heterogeneous group of patients. 


\section{References}

1. Leis AA, Ross MA, Summers AK. Psychogenic seizures: Ictal characteristics and diagnostic pitfalls. Neurology 1992;42:95-9.

2. Bodde NMG, Brooks JL, Baker GA, Boon PAJM, Hendriksen JGM, Aldenkamp AP. Psychogenic nonepileptic seizures - diagnostic issues: a critical review. Clin Neurol and Neurosurg 2009;111:1-9.

3. Bodde NMG, Brooks JL, Baker GA, Boon PAJM, Hendriksen JGM, Mulder OG, Aldenkamp AP. Psychogenic non-epileptic seizures - definition, etiology, treatment and prognostic issues: a critical review. Seizure 2009;18:543-53.

4. Sigurdardottir KR, Olafsson E. Incidence of psychogenic seizures in adults: a population-based study in Iceland. Epilepsia 1998;39:749-52.

5. Reuber M, Elger CE. Psychogenic non-epileptic seizures: review and update. Epilepsy Behav 2003;4:205-16.

6 Abubakr A, Kablinger A, Caldito G. Psychogenic seizures: clinical features and psychological analysis. Epilepsy Behav 2003;4:241-5.

7. Baillès E, Pintor L, Torres X, Fernández-Egea E, De Pablo J, Arroyo S. Psychiatric disease in patients with psychogenic non-epileptic seizures referred from an epilepsy unit in a general hospital. Actas Esp Pisquiatr 2004;32:76-81.

8. Alper K. Nonepileptic seizures. Neurol Clin (Epilepsy II: special issues) 1994(12):153-73.

9. Iriarte J, Parra J, Urrestarazu E, Kuyk J. Controversies in the diagnosis and management of psychogenic pseudoseizures. Epilepsy Behav 2003;4:354-9.

10. Benbadis SR, Agrawal V, Tatum WO. How many patients with psychogenic non-epileptic seizures also have epilepsy? Neurology 2001;57:915-7.

11. LaFrance WC, Devinsky O. The treatment of non-epileptic seizures: historical perspectives and future directions. Epilepsia 2004;45:15-21.

12. Berkhoff M, Briellmann RS, Radanov BP, Donati F, Hess CW. Developmental background and outcome in patients with non-epileptic versus epileptic seizures: a controlled study. Epilepsia 1998;39:463-9.

13. Marchetti RL, Kurcgant D, Neto JG, Von Bismark MA, Marchetti LB, Fiore LA. Psychiatric diagnoses of patients with psychogenic non-epileptic seizures. Seizure 2008;17:247-53.

14. Saygi S, Katz A, Marks DA, Spencer SS. Frontal lobe partial seizures and psychogenic seizures: comparison of clinical and ictal characteristics. Neurology 1992;42:1274-7.

15. Alsaadi TM, Thieman C, Shatzel A, Farias S. Video-EEG telemetry can be a crucial tool for neurologists experienced in epilepsy when diagnosing seizure disorders. Seizure 2004;13:32-4.

16. Fejerman N. Non-epileptic disorders imitating generalized idiopathic epilepsies. Epilepsia 2005;46: 80-3.

17. Marquez AV, Farias ST, Apperson M, Koopmans S, Jorgensen J, Shatzel A, Alsaadi TM. Psychogenic non-epileptic seizures are associated with an increased risk of obesity. Epilepsy Behav 2004;5:88-93.

18. Kuyk J, Leijten F, Meinardi H, Spinhoven Ph, Dyck R van. The diagnosis of psychogenic non-epileptic seizures: a review. Seizure 1997;6:243-53.

19. Bowman ES, Markand ON. Psychodynamics and psychiatric diagnoses of pseudoseizure subjects. Am J Psychiatry 1996;153:57-63.

20. Baslet G, Roiko A, Prensky E. Heterogeneity in psychogenic non-epileptic seizures: understanding the role of psychiatric and neurologic factors. Epilepsy Behav 2010;17: 236-41.

21. Prigatano GP, Stonnington CM, Fisher RS. Psychological factors in the genesis and management of nonepileptic seizures: clinical observations. Epilepsy Behav 2002;3:343-9.

22. Galimberti CA, Ratti MT, Murelli R, Marchioni E, Manni R, Tartara A. Patients with psychogenic nonepileptic seizures, alone or epilepsy-associated, share a psychological profile distinct from that of epilepsy patients. J Neurol 2003;250:338-46.

23. Drake ME, Pakalnis A, Phillips BB. Neuropsychological and psychiatric correlates of intractable pseudoseizures. Seizure 1992;1:11-3.

24. Cragar DE, Berry DTR, Schmitt FA, Fakhoury T.A. Cluster analysis of normal personality traits in patients with psychogenic nonepileptic seizures. Epilepsy Behav 2005;6:593-600.

25. Reuber M, Pukrop R, Bauer J, Derfuss R, Elger CE. Multidimensional assessment of personality in patients with psychogenic non-epileptic seizures. J Neurol Neurosurg Psychiatry 2004;75:743-8. 
26. Riggio, S. Psychogenic seizures. Emergency Medicine Clinics of North America 1994;12: 1001-1012.

27. Wyllie E, Friedman D, Lüders H, Morris H, Rothner D, Turnbull J. Outcome of psychogenic seizures in children and adolescents compared with adults. Neurology 1991;41:742-4.

28. Bodde NMG, Janssen AM, Theuns C, Vanhoutvin JF, Boon PA, Aldenkamp AP. Factors involved in the long-term prognosis of psychogenic non-epileptic seizures. J Psychosom Res 2007;62:545-51.

29. Lempert T, Schmidt D. Natural history and outcome of psychogenic seizures: a clinical study in 50 patients. J Neurol 1990;237:35-8.

30. Meierkord H, Will B, Fish D, Shorvon S. The clinical features and prognosis of pseudoseizures diagnosed using video-EEG telemetry. Neurology 1991;41:1643-6.

31. Mökleby K, Blomhoff S, Malt UF, Dahlstrom A, Tauboll E, Gjerstad L. Psychiatric comorbidity and hostility in patients with psychogenic non-epileptic seizures compared with somatoform disorders and healthy controls. Epilepsia 2002;43:193-8.

32. Stewart RS, Lovitt R, Malcolm Stewart R. Are hysterical seizures more than hysteria? A research diagnostic criteria, DSM-III, and psychometric analysis. Am J Psychiatry 1982;139:926-9.

33. Betts T, Boden S. Diagnosis, management and prognosis of a group of 128 patients with non-epileptic attack disorder. Part I. Seizure 1992;1:19-26.

34. Szaflarski JP, Szaflarski M, Hughes C, Ficker DM, Cahill WT, Privitera MD. Psychopathology and quality of life: psychogenic non-epileptic seizures versus epilepsy. Med Sci Monit 2003;9:113-8.

35. Ramani SV, Quesney LF, Olson D, Gumnit RJ. Diagnosis of hysterical seizures in epileptic patients. Am J Psychiatry 1980;137:705-9.

36. Reuber M, House AO. Treating patients with psychogenic non-epileptic seizures. Curr Opin Neurol 2002;15:207-11.

37. D'Alessio L, Giagante B, Oddo S, Silva WW, Solis P, Consalvo D, Kochen S. Psychiatric disorders in patients with psychogenic non-epileptic seizures, with and without comorbid epilepsy. Seizure 2006;15:333-9.

38. Baslet G, Roiko A, Prensky E. Heterogeneity in psychogenic non-epileptic seizures: understanding the role of psychiatric and neurological factors. Epilepsy Behav 2010;17:236-41.

39. Ettinger AB, Devinsky O, Weisbrot DM, Ramakrishna RK, Goyal A. A comprehensive profile of clinical, psychiatric, and psychosocial characteristics of patients with psychogenic non-epileptic seizures. Epilepsia 1999;40:1292-8.

40. Reuber M, Fernández G, Bauer J, Helmstaedter C, Elger CE. Diagnostic delay in psychogenic nonepileptic seizures. Neurology 2002;58:493-5.

41. Carton S, Thompson PJ, Duncan JS. Non-epileptic seizures: patient's understanding and reaction to the diagnosis and impact on outcome. Seizure 2003;12:287-94.

42. Jongsma MJ, Mommers JM, Renier WO, Meinardi H. Follow-up of psychogenic, non-epileptic seizures: a pilot study - experience in a Dutch special centre for epilepsy. Seizure 1999;8:146-8.

43. Kuyk J, Dunki Jacobs L, Aldenkamp AP, Meinardi H, Spinhoven Ph, Van Dyck R. Pseudo-epileptic seizures: hypnosis as a diagnostic tool. Seizure 1995;4:123-8.

44. Müller T, Merschhemke M, Dehnicke C, Sanders M, Meencke HJ. Improving diagnostic procedure and treatment in patients with non-epileptic seizures (NES). Seizure 2002;11: 85-9.

45. Jones SG, O' Brien TJ, Adams SJ, Mocellin R, Kilpatrick CJ, Yerra R, Lloyd JH, Velakoulis D. Clinical characteristics and outcome in patients with psychogenic non-epileptic seizures. Psychosom Med 2010;72:487-97.

46. Wingen A, Otten F. Trends in consultaties huisarts, specialist en fysiotherapeut door ouderen. Centraal Bureau voor de Statistiek / Statistics Netherlands 2006:84-91.

47. Kuyk J. Pseudo-epileptic seizures: Differential diagnosis and psychological characteristics. Doctoral dissertation. The Netherlands: VU University Amsterdam; 1999. Retrieved from: paper version.

48. Benbadis SR. Psychogenic non-epileptic seizures. EMedicine from WebMD; 2010. Retrieved from: http://emedicine.medscape.com/article/1184694-treatment.

49. Moene F. Hypnosis and conversion disorder. Doctoral dissertation. The Netherlands: KUN Nijmegen; 2001.Retrieved from: paper version.

50. Lipowski ZJ. Somatization: the concept and its clinical application. Am J Psychiatry 1988;145:1358-68

51. Woolfolk RL, Allen LA \& Tiu JE. New directions in the treatment of somatization. Psychiatr Clin North Am 2007;2:621-44. 
52. Gregory ES, Oye G. Stability of somatization disorder and somatization symptoms among primary care patients. Arch Gen Psychiatry 1999;56:90-5.

53. O'Sullivan SS, Spillane JE, McMahon EM, Sweeney BJ, Galvin RJ, McNamara B, Cassidy EM. Clinical characteristics and outcome of patients diagnosed with psychogenic non-epileptic seizures: a 5-year review. Epilepsy Behav 2007;11:77-84.

54. Alper K, Devinsky O, Perrine K, Vazquez B, Luciano D. Psychiatric classification of nonconversion nonepileptic seizures. Arch Neurol 1995;52:199-201.

55. Reuber M, House A, Pukrop R, Bauer J, Elger EC. Somatization, dissociation and general psychopathology in patients with psychogenic non-epileptic seizures. Epilepsy Res 2003;57:159-67.

56. DSM-IV, Diagnostic and statistical manual of mental disorders. Fourth edition Washington, DC: American Psychiatric Association: 1994.

57. Simon GE, Von Korff M. Recall of psychiatric history in cross-sectional surveys: implications for epidemiologic research. Epidemiol.Rev 1995;17:221-7.

58. Simon GE, Gureje O. Stability of somatisation disorder and somatisation symptoms among primary care patients. Arch Gen Psychiatry 1999;56:90-5.

59. Brown RJ. Medically unexplained symptoms: a new model. Psychiatry 2006;5:43-7.

60. De Gucht V, Maes S. Explaining medically unexplained symptoms: towards a multidimensional, theory based approach to somatisation. J Psychosom Res 2006;60:349-52.

61. Goldstein LH, Drew C, Mellers J, Mitchell-O'Malley S, Oakly DA. Dissociation, hypnotizability, coping styles and health locus of control: characteristics of pseudoseizure patients. Seizure 2000;9:314-22.

62. Reuber M, Mitchell AJ, Howlett SJ, Crimlisk HL, Grünewald RA. Functional symptoms in neurology: questions and answers. J Neurol Neurosurg Psychiatry 2005;76:307-14. 


\section{Chapter 9}

\section{Subgroup classification in patients with psychogenic non-epileptic seizures}

NMG Bodde, SJM Van der Kruijs, Ijff DM, RHC Lazeron, KEJ Vonck, PAJM Boon, AP Aldenkamp 


\section{Abstract}

\section{Introduction}

In this open non-controlled clinical cohort study, the applicability of a theoretical model for the diagnosis of psychogenic non-epileptic seizures (PNES) was studied in order to define a general psychological profile and to specify possible subgroups.

\section{Methods}

Forty PNES patients were assessed with a PNES "test battery" consisting of eleven psychological instruments, e.g., a trauma checklist, the global cognitive level, mental flexibility, speed of information processing, personality factors, dissociation, daily hassles and stress and coping factors.

\section{Results}

The total PNES group was characterized by multiple trauma, personality vulnerability (in a lesser extent, neuropsychological vulnerabilities), no increased dissociation, many complaints about daily hassles that may trigger seizures and negative coping strategies that may contribute to prolongation of the seizures. Using factor analysis, specific subgroups were revealed: a 'psychotrauma subgroup', a 'high vulnerability somatizing subgroup' (with high and low cognitive level) and a 'high vulnerability sensitive personality problem subgroup'.

\section{Conclusion}

Using a theoretical model in PNES diagnosis, PNES seem to be a symptom of distinct underlying etiological factors with different accents in the model. Hence, describing a general profile seems to conceal specific subgroups with subsequent treatment implications. This study identified three factors, representing two dimensions of the model, that are essential for subgroup classification: psychological etiology (psychotrauma or not), vulnerability, e.g., the somatization tendency, and sensitive personality problems/characteristics ('novelty seeking'). For treatment, this means interventions could be tailored to the main underlying etiological problem. Also, further research could focus on differentiating subgroups with subsequent treatment indications and possible different prognoses. 


\section{Introduction}

About $25-30 \%$ of the patients referred to tertiary epilepsy centers or specialized hospitals have psychogenic non-epileptic seizures (PNES) $)^{1-4}$. A psychogenic nonepileptic seizure is defined as a clinically observable paroxysmal change in behavior or consciousness that resembles an epileptic seizure but is not accompanied by the typical electrophysiological and behavioral changes that accompany an epileptic seizure. There is also an absence of any known organic etiology for the seizures, whereas there is positive evidence or a strong suspicion for the existence of psychogenic factors ${ }^{3,5-7}$.

Earlier research in the field of PNES has mainly focused on the differential diagnosis with epileptic seizures. The correct medical diagnosis of PNES remains a challenge, but since the introduction of simultaneous video EEG-monitoring, the differential diagnosis of PNES-epilepsy has greatly improved ${ }^{1,8-11}$. The true challenge in the diagnostic process of PNES, however, is not only to exclude epilepsy and other organic factors but also to avoid that PNES becomes a 'nondisease' ${ }^{12}$. A subsequent positive diagnosis is required involving the underlying psychological mechanisms ${ }^{7,9,13,14}$. There is consensus that in most patients, multiple underlying psychogenic factors or mechanisms are involved in different combinations and with variable effects on $\operatorname{prognosis}^{15,16}$.

In a small group of PNES patients, the communication of the PNES diagnosis in a clear, empathic way will result in seizure reduction ${ }^{7,17-19}$. However, patients with PNES comprise a very heterogeneous patient group ${ }^{20-24}$. Several studies report that for many PNES patients, the long-term prognosis is not good. In about $1 / 3^{\text {rd }}$ to $1 / 4^{\text {th }}$ of the patients, PNES become chronic ${ }^{7,25}$. Patients often show 'medical shopping' in a search for second opinions. Also, symptom characteristics may shift from seizures to other psychosomatic symptoms mimicking e.g. movement disorders ${ }^{26,27}$. As a result, the patients remain in a purely medical environment and are not referred to appropriate psychological therapy ${ }^{28,29}$.

To achieve optimal therapeutic outcome, the choice of treatment should be adjusted to the individual patient's combination of underlying etiological factors ${ }^{7,9,15,29,30}$. Recently, we have proposed a theoretical model distinguishing five different levels

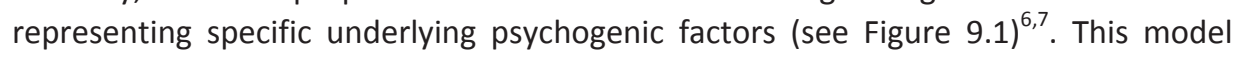
was derived from a literature search on psychological etiology and PNES. The model resembles other models with predisposing, precipitating en perpetuating factors to explain somatoform disorders ${ }^{16,31-33}$, but more specific factors have been added in relation to PNES. Level 1, psychological etiology, refers to factors involved in the causation of PNES, such as sexual abuse or other traumatic experiences ${ }^{34,-37}$. However, not all people who have had traumatic experiences develop PNES ${ }^{38,39}$. Many authors have pointed to the specific vulnerability of PNES patients both in terms of their emotional profile and their neuropsychological functioning. Examples are personality factors, gender and age $e^{9,26,29,40-44}$. Also, possible organic factors such as head trauma, 
may induce higher vulnerability ${ }^{45-47}$. Level 2, vulnerability, therefore, refers to characteristics that predispose a person to develop psychosomatic symptoms, such as PNES. Level 3, shaping factors, refers to factors that explain why the symptoms are 'seizures' and not for example functional movement disorders, sleep disorders or 'headache-like symptoms'. A shaping factor may be a close friend or relative with epileptic seizures (symptom modeling) (see ${ }^{20,48}$ ) or having had epilepsy in the past. Level 4, triggering factors, refers to factors that create circumstances or specific situations that provoke a seizure at a specific moment, such as PNES during school break or after a marital quarrel ${ }^{49,50}$. Also, psychological mechanisms that transfer an emotional state into a seizure can be part of these triggering factors, such as dissociation and somatization ${ }^{1,14,21,51,52}$. Such factors explain why seizures occur on a specific day, or in a cluster or why there is a period of remission. This distinguishes PNES from conversion states that generally have a more permanent presentation. Level 5, prolongation, refers to factors that are important in explaining why the seizures persist over time and PNES may become a chronic disorder. These factors determine its frequency and its resistance against therapy. Such modulating factors are, e.g., the coping style of the patient and secondary gain aspects ${ }^{9,49,53}$.

levels
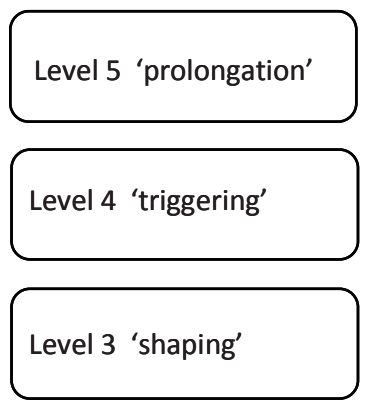

\section{Level 2 'vulnerability'}

Level 1 'psychological description

\section{Factors that explain why PNES persist such as coping factors}

Factors that provoke PNES

in specific situations

\section{Factors that shape the} symptoms into seizures

Emotional 'make-up'; organic \& neuropsychological impairments

Psychogenic causation such as traumatic experiences

Figure 9.1 Diagnostic model of psychogenic factors involved in psychogenic non-epileptic seizures ${ }^{6,7}$. 
Figure 9.1 describes the assumed relationship between the factors. The model is not conclusive as some factors can interact at different levels. Coping strategies may be involved in the causation of PNES and may have a role in the vulnerability, whereas family factors may contribute to the prolongation of seizures and not only in the development ${ }^{54}$.

The current study focuses on the applicability of this model in the diagnosis of PNES. Relevant and available tests covering the different factors of the model were used to identify dominant factors for the total group and for specific subgroups. There was a focus on subgroups since many factors have been related to PNES but seldom account for the patient group as a whole $e^{7,23,24,52,55,56}$. Recent studies increasingly focus on finding criteria to differentiate subgroups in PNES, using PNES phenomenology ${ }^{57}$, descriptive patient characteristics ${ }^{58}$, personality factors and/or cognitive functioning ${ }^{9,24}$. As yet, these criteria were not investigated using a diagnostic model. In this study, tests used in clinical practice were integrated in the diagnostic model in order to systematically assess relevant factors and subgroups.

\section{Methods}

\section{Participants}

Patients were consecutively included when:

1. The PNES diagnosis had been confirmed in the tertiary referral epilepsy centre using clinical description and additional EEG investigations (such as video-EEG monitoring). The type of EEG investigation was based on clinical indications, such as patient history and seizure semiology.

2. The diagnosis was confirmed in the period 2009-2010.

3. They were $>15$ years old.

4. They had a normal intelligence. Mental retardation was an exclusion criterion.

5. They did not have major psychiatric comorbidity, such as major clinical depression.

In total, 40 patients were selected that met the inclusion criteria.

\section{Procedure}

This study was an open non-controlled clinical cohort study. All patients were psychologically assessed by trained clinical psychologists. The history of all patients was taken, and a DSM-IV classification was made. The different levels of the theoretical model were assessed using a psychological PNES "test battery". In this battery, eleven psychological tests/instruments were selected that met the criteria for validity and reliability and had norm scores. For level 1, no norm scores were 
available, but we could use a trauma checklist. Also, level 3, shaping, mostly refers to symptom modeling for which no normed psychological test is available. Since dissociation is supposed to modulate between level 3 and 4 , we used the dissociation questionnaires for this level.

The following tests were selected:

Level 1 'psychological etiology': Trauma: TEC (Traumatic Experiences Checklist)

Level 2 'vulnerability': $\quad$ A) Neuropsychological factors

- Global Cognitive level: Raven

(Raven Progressive Matrices)

- Mental flexibility: TMT

(Trail Making Test)

- Speed of information processing: CVST

(Computerized Visual Searching Task)

B) Personality factors

- Short TCI (Dutch language short version of the Temperament and Character Inventory)

- Short MMPI (Dutch language short version of the Minnesota Multiphasic Personality Inventory)

Level 3 'shaping': Dissociation

- DIS Q (Dissociation Questionnaire)

- SDQ-20 (Somatoform Dissociation Questionnaire)

Level 4 'triggering': Daily hassles and stress: EPCL

(Everyday Problem Checklist)

Level 5 'prolongation':

Coping

- UCS (Utrecht Coping Scale)

- CERQ (Cognitive Emotion Regulation Questionnaire)

An extensive description of the instruments is attached in Appendix A.

\section{Statistical analysis}

Statistical analyses were performed using SPSS 16.0. (SPSS, Inc, Chigaco, IL). The individual results were converted to z-scores to allow comparability among the tests. In a first step of the analyses, we explored whether the scores on the profile of the total group differed significantly from the 'norm z-value' of 0 that represents no difference with the norm population. Secondly, we performed subgroup analysis. In a univariate approach, relevant factors were inspected separately. However, this 
approach ignores the intercorrelations between the different tests and levels of the model. Subsequently, we, therefore, used a multivariate correlational approach with factor analysis. The significance level was set at $5 \%$.

\section{Results}

Table 9.1 shows the main demographical and clinical characteristics of the 40 patients. There was a dominance of the female gender, and mean age during assessment was 30 years. Most patients had only PNES, although about one-third of the patients had PNES in combination with epilepsy. Most patients had at least monthly seizures, and four patients were seizure free in the past three months. Thirteen patients reported no or only a mild impact of the seizures on their daily functioning, whereas eighteen patients reported frequent to severe impact on their daily living. Most patients lived with their parents or with a partner, and only two patients lived alone. Sixteen patients were unemployed or disabled to go to school or work.

Table 9.1 Demographical and clinical characteristics of the study group.

\begin{tabular}{|c|c|}
\hline $\mathrm{N}$ & 40 \\
\hline Gender (male:female) & $8: 32$ \\
\hline Mean age (years) & 30 \\
\hline Age range (years) & $15.7-63$ \\
\hline Additional epilepsy (no:yes) & $30: 10$ \\
\hline \multicolumn{2}{|l|}{ PNES frequency } \\
\hline - Currently seizure free & 4 \\
\hline - Less than monthly & 2 \\
\hline - Monthly & 3 \\
\hline - Weekly & 15 \\
\hline - Daily & 10 \\
\hline \multicolumn{2}{|l|}{ Impact of PNES on daily functioning } \\
\hline - No impact & 3 \\
\hline - Occasionally & 10 \\
\hline - Frequently & 9 \\
\hline - Seriously & 6 \\
\hline - Completely & 3 \\
\hline \multicolumn{2}{|l|}{ Social status } \\
\hline - Living with parents & 18 \\
\hline - Living alone & 2 \\
\hline - Married/living with partner & 19 \\
\hline \multicolumn{2}{|l|}{ Education/work } \\
\hline - School & 11 \\
\hline - Unemployed & 6 \\
\hline - Disabled & 10 \\
\hline - Employed & 9 \\
\hline - School and employment & 3 \\
\hline
\end{tabular}




\section{A. Profile analysis of the total PNES group}

Figure 9.2 shows the profile of the total group in z-scores for the different levels in the model: 0 is the average report in the general population; based on reference values, scores of -1 and -2 show deviation of respectively 1 standard deviation and 2 standard deviations from the reference. Vice versa scores of +1 and +2 show scores higher than reference value. Statistically significant differences with the norm scores are provided in the figure.

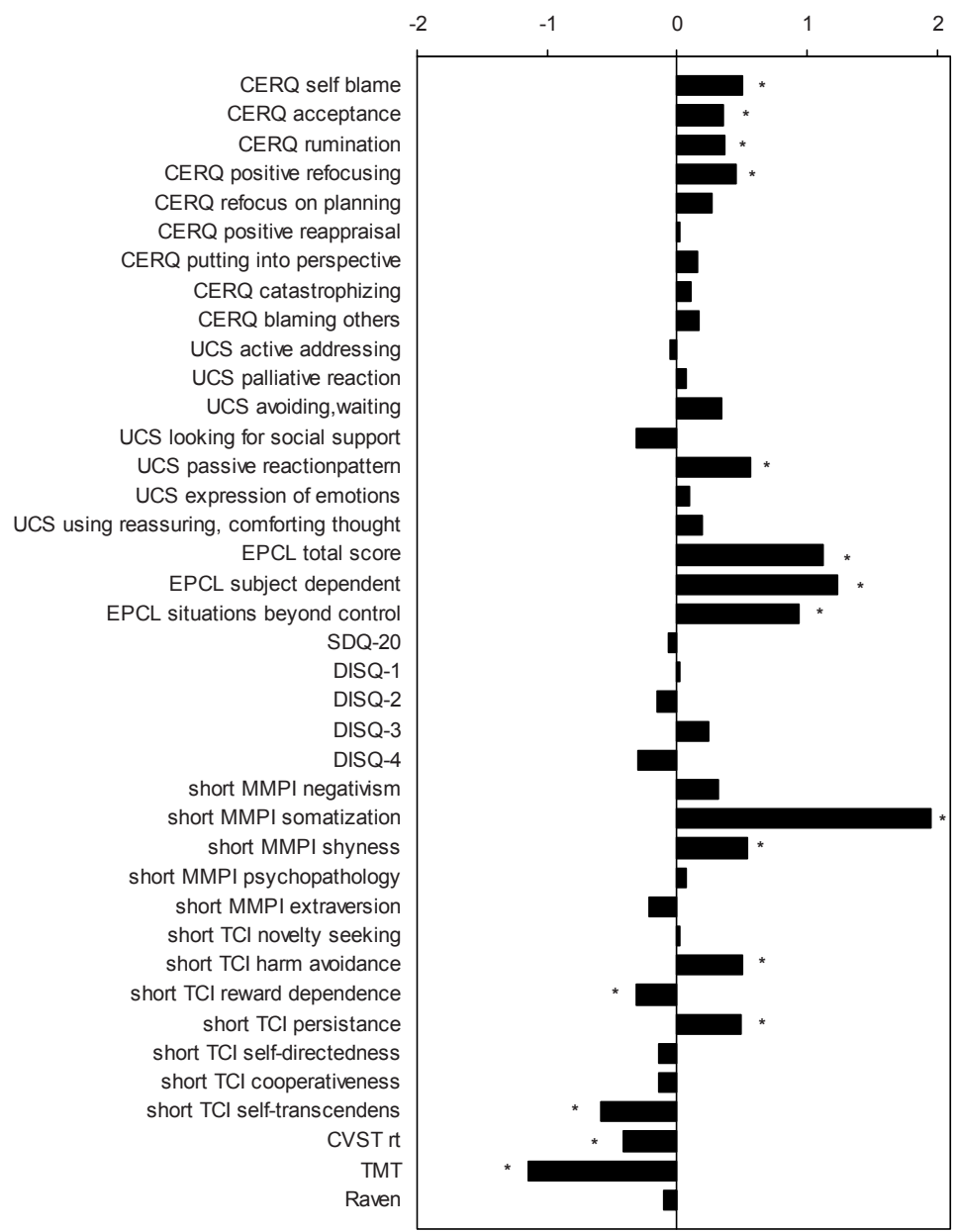

Figure 9.2 Profile of scores of the total PNES group normalized by using z-scores.

$*$ = Statistically significant differences with norm scores. 


\section{Level 1: 'psychological etiology'}

For the TEC (Traumatic Experiences Checklist), no norm scores are defined; therefore, z-values cannot be reported. The TEC was, therefore, not included in the profile. One can argue that any trauma may have an effect and is not 'normal'. Seventy percent of our patients did report a traumatic event, and $52 \%$ reported multiple traumas. These percentages seem to deviate from 'the normal situation'. However, the TEC allows reports over a whole range of situations, some of which actually are more common in the general population, such as 'emotional neglect'. If we only inspect the variables in the TEC 'threat of body/life', 'sexual harassment' and 'sexual abuse' than $42.5 \%$ of our patients reported such traumas. Breslau et al. ${ }^{100}$ reported that traumas that result in a Post Traumatic Stress Disorder (PTSD), generally associated with severe trauma, occurred in only $8 \%$ of the population.

Level 2: 'vulnerability'

a. Neuropsychological function. Global cognitive level (Raven) was not significantly different from normal, but PNES patients showed greater rigidity and lacked planning skills (TMT; $\mathrm{t}=2.063 ; P=0.046$ ). Moreover, they were characterized by slowing of central information processing speed (CVST; $t=4.329 ; P \leq 0.001$ ).

b. Emotional profile/personality factors. Significant differences on the short TCl (short version of the Temperament and Character Inventory) with the reference values were found on three 'temperament dimensions', e.g., higher 'harm avoidance' ( $t=0.837$; $P=0.001)$, lower 'reward dependence' $(\mathrm{t}=2.057 ; P=0.046)$ and higher 'persistence' ( $\mathrm{t}=3.140 ; P=0.003)$ and on one 'dimension of character': lower 'self transcendence' $(\mathrm{t}=4.265 ; P \leq 0.001)$. These results characterized the PNES patients as having a careful, anxious attitude, being vigilant for potential danger (high harm avoidance) in combination with a practical approach of situations and being insensitive for social signals (low reward dependence). The total PNES group were shown to be diligent and perfectionistic despite setbacks (high persistence). They had difficulty tolerating ambiguity and uncertainty and a strong need to control (low self-transcendence).

On the short MMPI (short version of the Minnesota Multiphasic Personality Inventory), PNES patients scored relatively high in 'somatization' ( $\mathrm{t}=8.416 ; P=0.001)$ and 'shyness' ( $\mathrm{t}=2.558 ; P=0.015)$. This indicated a strong tendency to react with (psycho)somatic complaints on psychological distress and also a tendency to be introverted, to be less sociable and to attempt to internally control emotions.

\section{Level 3 'shaping'}

No statistically significant differences were found with the reference values for the SDQ-20 (Somatoform Dissociation Questionnaire) and the DIS-Q (Dissociation Questionnaire). The PNES group as a whole did not show increased scores for both forms of dissociation. 
170 Chapter 9

Level 4 'triggering'

The EPCL (Everyday Problem Checklist) showed a statistically significant higher number of 'total complaints' ( $\mathrm{t}=4.497 ; P \leq 0.001)$, 'subject dependent complaints' ( $\mathrm{t}=5.516 ; P=<0.001$ ) and 'situations beyond control of the subjects' ( $\mathrm{t}=3.066 ; P=0.004)$. The PNES group as a whole reported having many daily hassles and chronic stressors during the past two months within several life domains.

\section{Level 5 'prolongation'}

The UCS (Utrecht Coping Scale) showed a higher tendency towards a passive, 'wait and see' attitude ( $\mathrm{t}=3.129 ; P=0.003)$ when confronted with problems or events requiring adjustment. Furthermore, on a behavioral coping level, the patients tended to avoid problems and tended to avoid looking for social support.

The CERQ (Cognitive Emotion Regulation Questionnaire) showed statistically significant higher scores for 4 areas: 'acceptance' ( $t=2.510 ; P=0.016)$, 'positive refocusing' ( $\mathrm{t}=2.689 ; P=0.010)$, 'self blame' ( $\mathrm{t}=2.665 ; P=0.011)$ and 'rumination' $(\mathrm{t}=2.423 ; P=0.020)$.

\section{B. Subgroup analysis: univariate approach and factor analysis}

Some of the total group results were remarkable, such as the lack of dissociation. We, therefore, investigated whether the overall results merely represented an average concealing specific subgroups. The subgroups were inspected by dividing the total group into subgroups based on a) psychological etiology, b) the tendency to dissociate, c) the tendency to report daily hassles, d) the cognitive level and e) psychopathology.

\section{a) Subgroups based on psychological etiology}

The profile was inspected separately for patients who reported a psychotrauma on the TEC total score and patients who did not report a trauma, which is presented in Figure 9.3. Patients with a reported trauma $(n=28)$ differed from patients without reported trauma $(n=12)$ on level 2 with more mental slowing on the CVST ( $t=-2.690$; $P=0.011$ ). The short MMPI showed more 'negativism', indicating more suffering from their problems ( $\mathrm{t}=2.030 ; P=0.049)$, and more 'shyness', indicating attempting to internally control emotions ( $\mathrm{t}=-2.891 ; P=0.006)$. The short $\mathrm{TCl}$ showed more 'harm avoidance' ( $\mathrm{t}=-2.304 ; P=0.027$ ) and less 'self-directedness' ( $\mathrm{t}=2.343 \quad P=0.024)$ for the patients with reported trauma. This showed this subgroup to be more anxious and being vigilant for potential danger (high harm avoidance) in combination with being fragile/immature and having difficulties pursuing meaningful personal goals and values in their lives (low self-directedness). On level 3, patients with trauma showed increased psychoform dissociation, e.g., scale d1: 'identity confusion and 
depersonalization', than did patients without trauma ( $\mathrm{t}=-2.166 ; P=0.037)$. On level 4, no differences were found. On level 5 , there was an increased score on the coping subscale 'blaming others' ( $\mathrm{t}=-2.490 ; P=0.018$ ), referring to having a cognitive coping strategy of holding other people responsible.

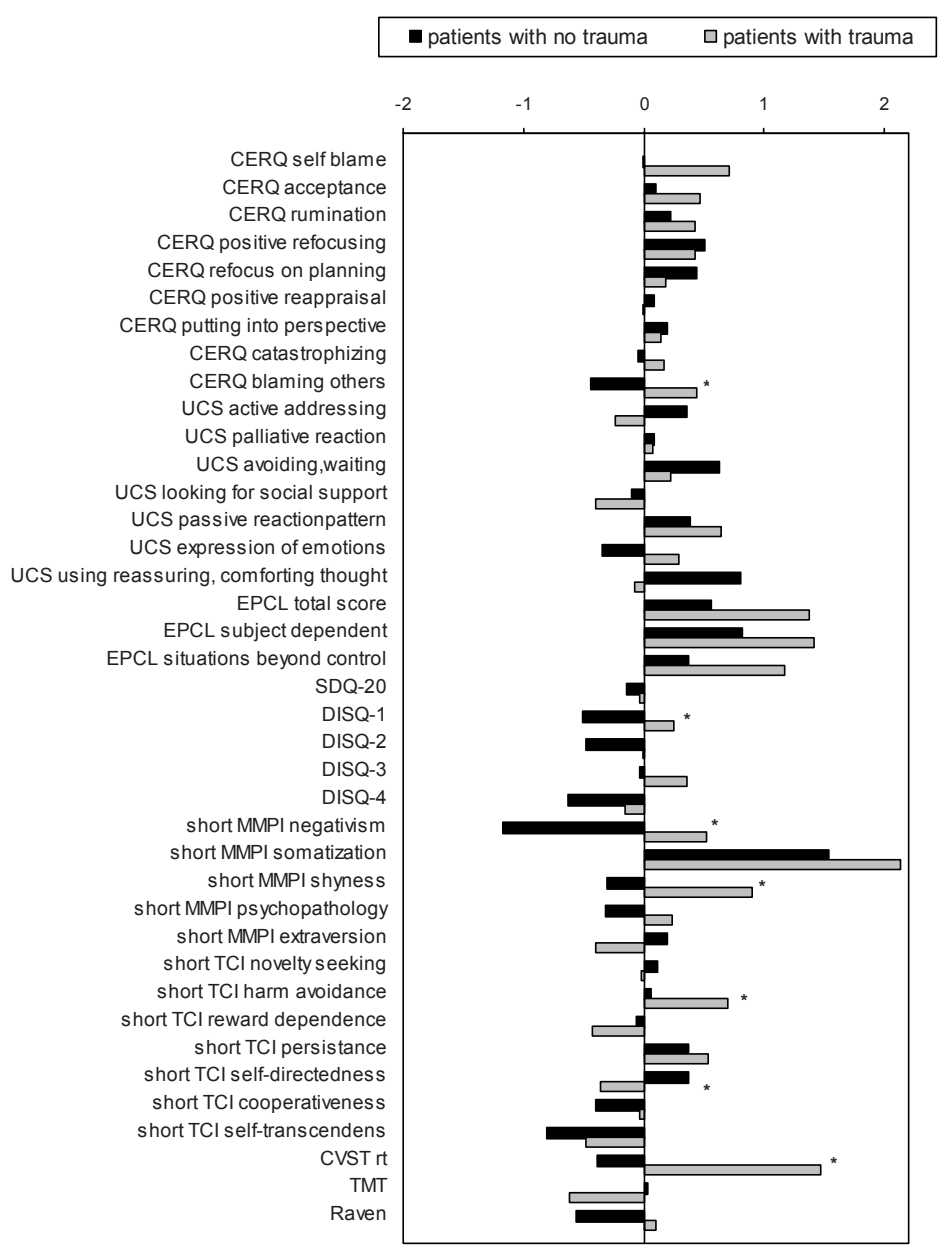

Figure 9.3 Profile comparison of patients with a reported trauma versus patients without a reported trauma.

* Statistically significant differences between the two groups.

When the group was divided into two subgroups, a) patients with no or one trauma and b) patients with multiple traumas, a similar pattern was found, though less pronounced. Patients with multiple traumas $(n=21)$ differed from patients with no or a 
$172 \mid$ Chapter 9

single trauma $(\mathrm{n}=19)$ on level 2 with more 'shyness' $(\mathrm{t}=-2.153 ; P=0.038)$ on the short MMPI. On level 3, increased dissociation was found for scale d1:' identity confusion and depersonalization' ( $\mathrm{t}=-2.487 ; P=0.019$ ). On level 4 , no differences were found, and on level 5 , there was again an increased score on the subscale 'blaming others' $(\mathrm{t}=-2.632 ; P=0.012)$.

\section{b) Subgroups based on dissociation}

As the average profile did not show increased scores on the dissociation scales, it was explored whether two subgroups would exist. The patients were consequently divided into scores (based on the cut-off score provided by the SDQ-20 manual) that represent higher dissociation tendency (scores $>25$; $n=17$ ) and lower dissociation tendency $(n=23)$. Patients with higher dissociation showed on level 2 increased somatization ( $\mathrm{t}=-2.293 ; P=0.027$ ) on the short MMPI. On level 3, obviously, the dissociation subscales 'loss of control' ( $\mathrm{t}=-2.980 ; P=0.005)$ and 'amnesia' ( $\mathrm{t}=-2.485$; $P=0.023$ ) of the DIS-Q were increased. On level 4, 'total complaints' ( $t=-2.743$; $P=0.012$ ) and 'subject dependent complaints' ( $t=-2.694 ; P=0.012)$ on the EPCL were increased in patients with higher dissociation tendency. On level 5, patients with higher dissociation tendency showed increased scores on the subscale 'blaming others' ( $\mathrm{t}=-2.128 ; P=0.042)$.

\section{c) Subgroups based on the tendency to report daily hassles and stressors}

As increased levels of daily hassles and complaints on the EPCL were dominant in the average profile, we distinguished patients that reported an extremely high number of complaints over the past two months (scores on the EPCL>z-score $1(n=14)$ from the remaining patients. This revealed that patients with a high level of complaints showed on level 2 a higher tendency on the short MMPI towards 'negativism' ( $t=2.661$; $P=0.11)$ and on the short TCl increased 'harm avoidance' ( $t=1.997 ; P=0.04)$, less 'persistence' ( $\mathrm{t}=-2.917 ; P=0.006)$ and less 'self-directedness' ( $\mathrm{t}=-6.692 ; P \leq 0.001)$. On level 3, all dissociation scales were increased in the patients with a high level of complaints (SDQ-20 $\mathrm{t}=3.440 ; \quad P=0.001$; Dis-Q $\mathrm{d} 1$ : 'identity confusion and depersonalization' $\mathrm{t}=3.701 ; \quad P=0.001 ; \quad$ Dis- $\mathrm{Q} d 2$ : 'self-control' $\mathrm{t}=3.921 ; \quad P \leq 0.001$; Dis-Q d3: 'amnestic and dissociation features' $t=2.910 ; \quad P=0.006 ; \quad$ Dis- $Q$ d4: 'concentration 'absorption' of environmental input' $\mathrm{t}=2.212$; $P=0.033$ ).

\section{d) Subgroups based on global cognitive level}

The patients were also divided by those scoring average or higher on the Raven and patients scoring below average. Patients scoring below average showed decreased 'persistence' on the short $\mathrm{TCl}(\mathrm{t}=2.299 ; P=0.03)$ on level 2 and increased 'positive refocusing' (t=2.175; $P=0.043$ ) on level 5. 


\section{e) Subgroups based on psychopathology}

A division based on psychopathology ( $>$ or < than the z-score 0 on the subscale psychopathology of the short MMPI) did not reveal any significant differences, which may be caused by the fact that only 10 patients had scores higher than z-score 0 .

The former step suggests that the total group of PNES patients consisted of subgroups with differential patterns with regard to the factors presented in the model (Figure 9.1). In a second step of the subgroup analysis, we used a multivariate correlational approach with factor analysis. Seven variables were entered in the factor analysis. The choice for these variables was based on the highest correlating variables as well as a representation of each level. Therefore we entered the following:

Level 1: TEC total score (1)

Level 2: Neuropsychological: CVST (2)

Personality: short TCI novelty seeking (3) and short MMPI somatization (4)

Level 3: SDQ-20 norm score (5)

Level 4: EPCL total complaints (6)

Level 5: CERQ self blame (7).

Factor analysis was used, based on principal component analysis. In four steps, the cut-off score of eigenvalue $<1$ was reached. At that point, a satisfactory $80 \%$ of the variance was explained. This implicates that the seven variables have sufficient (80\%) explaining power for the variation in the investigated sample. A four-factor solution was achieved (presented in Table 9.2).

Table 9.2 Results of the factor analysis.

\begin{tabular}{|c|c|c|c|c|c|}
\hline & & \multicolumn{4}{|c|}{ Component } \\
\hline & & Factor 1 & Factor 2 & Factor 3 & Factor 4 \\
\hline Level 1 & TEC & .586 & $\underline{-.650}$ & -.017 & .096 \\
\hline \multirow[t]{3}{*}{ Level 2} & short MMPI somatization & $\overline{.041}$ & .663 & -.111 & .654 \\
\hline & Short $\mathrm{TCl}$ novelty seeking & -.356 & .342 & .746 & -.182 \\
\hline & CVST & -.388 & $\underline{-.417}$ & .401 & .639 \\
\hline Level 3 & SDQ-20 norm score & .800 & -.018 & .043 & .237 \\
\hline Level 4 & EPCL total complaints & .661 & .569 & .071 & -.078 \\
\hline Level 5 & CERQ self blame & .511 & -.094 & .693 & -.073 \\
\hline
\end{tabular}

High loadings on a factor $(>.40)$ are underlined and in bold.

Factor 1 shows a subgroup characterized by a psychotraumatic origin of PNES without any involvement of level 2 vulnerability. These patients were not necessarily predisposed to develop somatization symptoms based on increased vulnerability; the reported trauma is essential. There was a high level of somatoform dissociation, complaints in daily life and cognitive coping problems (self blame), which is in line 
with the results of the former profile analysis. This subgroup may be characterized as the 'psychotrauma subgroup'. This factor alone is valid for $28 \%$ of the study population, so it may represent between $1 / 4$ and $1 / 3$ of the population.

Factor 2 has a high negative loading for the TEC indicating that psychotrauma had no essential role in the psychogenic origin of PNES in these patients. There was, however, on level 2 a high vulnerability with respect to personality factors: a high tendency for somatization. The CVST indicated an undisturbed level of cognitive function. On level 4, there was a high level of complaints in daily life. This factor can be characterized as 'high vulnerability somatization subgroup' representing patients with a strong tendency to react with (psycho)somatic complaints on psychological distress (without a clear psychotraumatic origin) because of a personality vulnerability. This factor is valid for $21 \%$ of the population.

Factor 3 also shows no loading on psychotrauma. There was again on level 2 a high vulnerability on personality factors, however not focusing on somatization. This factor shows a high loading for 'novelty seeking' on the short $\mathrm{TCl}$, indicating a strong tendency to react impulsively and to have quick tempers. They also loaded on 'self blame' on the CERQ and had mental slowing/rigidity as cognitive style on the CVST. This factor can be characterized as the 'high vulnerability sensitive personality problem subgroup' and represents $17 \%$ of this population.

Factor 4 shows a combination of a high somatization tendency with a rigid and slow cognitive style on level 2 and no stress in daily life. This factor (representing 14\% of this population) seems to be a low cognitive level variant of factor 2 with patients that easily develop somatization symptoms, however, without the burden of daily hassles; the ' $h i g h$ vulnerability somatization subgroup with a low cognitive level'.

In fact, factor analysis shows two dimensions that are essential: the psychological etiology (psychotrauma or not) and the vulnerability e.g., the somatization tendency and the sensitive personality problems ('novelty seeking'), resulting in three subgroups. Subgroups 2 and 4 are similar, except for their cognitive level and for the burden they experience in daily life.

\section{Discussion}

\section{A. Profile analysis of the total PNES group}

The diagnostic profile of the total group showed some remarkable findings. On level 1 ('psychological etiology'), 70\% of the patients did report one or more traumatic experiences before the age of 18 . Although this percentage was relatively high, it seemed comparable with other studies on $\mathrm{PNES}^{21,37}$. The psychological instrument we used, the TEC, allowed reports over a whole range of traumatic experiences. When we specifically focused on physical and sexual abuse, than $42.5 \%$ of the patients reported such traumas. To compare, Breslau et al. ${ }^{100}$ reported that traumas resulting in a 
posttraumatic stress disorder occurred in $8 \%$ of the general population. Hence, physical and sexual abuse during childhood is an important etiological factor in PNES. Level 2 effects ('vulnerability') showed that the neuropsychological impairments were mostly related to a defensive 'avoidance type' of cognitive style (slow, rigid). These effects may be seen as a consequence of personality characteristics and the burden of the seizures rather than as a causal factor. This is line with the fact that similar neuropsychological impairments in epilepsy and PNES have been reported for many years ${ }^{101-103}$. Drane et al. ${ }^{104}$ also pointed to 'cognitive style characteristics' when they raised the possibility that PNES patients may often make an inadequate effort in taking the tests so their findings may not be trustworthy. Also, Hill and Gale ${ }^{56}$ mentioned that abnormal neuropsychological functioning in PNES patients has been attributed to psychological and motivational factors. Hence, neuropsychological impairments do not seem to contribute to an increased vulnerability for PNES.

The assessment of personality factors on level 2 showed an increased tendency of somatization, referring to reacting with (psycho)somatic symptoms on psychological distress, a finding that is often reported in recent PNES studies ${ }^{14,26,51}$. The personality profile showed, in a lesser degree, also increased shyness on the short MMPI, referring to being less sociable and to attempt to internally control emotions. The short $\mathrm{TCl}$ showed a personality profile of having an anxious, practical and perfectionistic attitude with difficulties tolerating ambiguity and a strong need to control.

Remarkable was the absence of increased scores on tests for level 3 ('shaping'), indicating that dissociation was not increased in the average profile. This is in line with other studies (e.g., ${ }^{51,81,105,106}$ ) showing that although dissociation scores were higher in PNES patients, these scores did not indicate severe significant dissociative tendencies for the group as a whole.

On level 4 ('triggering'), the total PNES group reported many complaints about possible burdens in daily life in the past two months that may trigger seizures.

Level 5 ('prolongation') showed coping problems that may contribute to prolongation, such as a passive and/or avoidant attitude when confronted with problems. These coping problems have been found in other studies as well ${ }^{105,107,108}$.

Although these findings are useful in describing PNES patients as a group, the results might simply represent a 'grand average' concealing specific subgroups. Lally et al. ${ }^{39}$ formulated this different, e.g. there may be no "one fits all" in terms of theory application (see also Mazza ${ }^{52}$ ) and subgroup analysis might reveal more specific characteristics.

\section{B. Subgroup analysis}

Univariate analysis, using dichotomization in low and high scores, showed that subgroups indeed exist. The subgroup of patients with severe (physical and sexual) trauma was characterized by more mental slowing and significantly more 'negativism', 
more 'shyness', more 'harm avoidance' and less 'self-directedness'. This subgroup, who suffered more from their problems, was more introverted and was trying hard to internally control emotions. These patients had an anxious attitude and were being vigilant for potential danger. The low 'self-directedness' referred to being immature, fragile and sensitive for external pressure, which can make it difficult to pursue meaningful personal goals and values. Also, in this subgroup, we found a higher tendency for psychoform dissociation on the level of identity confusion. The absence of increased dissociation was, therefore, an average characteristic of the total group but was not true for patients with a reported trauma. Other studies found subgroups in PNES exhibiting more dissociative tendencies related to trauma as well ${ }^{109}$ even in non-clinical samples ${ }^{110}$. It is remarkable though that somatoform dissociation was not increased in this subgroup, especially since the PNES represent a psychosomatic symptom. The crucial factor is whether there was a reported trauma or not. When the variable 'multiple trauma' was included, the observed pattern did not change. The psychological profile seemed directly linked to the traumatic experiences, and the patients suffered from the consequences. The combination of a high level of distress and an identifiable link to an etiological factor may help these patients to benefit from psychological therapy and to accept the diagnosis since it can be integrated into their personal history $^{111}$.

Subgroup division based on dissociation did not provide new information. This was possibly a result of the high relationship between dissociation and other factors in the model $^{81}$. Similarly, a division based on cognitive level did not show new information. The cognitive results primarily reflected a slow and rigid cognitive style and were, therefore, closely related to other factors in the model. This may conceal its effect on subgroup division. Also, psychopathology was not an essential factor. This was probably an effect of sampling bias and test selection, combined with a statistical effect. Severe and/or acute psychiatric comorbidity was an exclusion criterion. Moreover and as a consequence of the previous factor, only 10 patients had a z-score higher than 0 ('normal'), which did not allow sufficient power to detect differences.

One other factor showed new information: reporting daily hassles and complaints, a level 4 ('triggering') factor. Patients with an extreme high level of complaints revealed more 'passive type' of personality characteristics (e.g., increased 'harm avoidance', less 'persistence' and less 'self directedness') on the short $\mathrm{TCl}$ and an increased tendency to dissociate on both somatoform and psychological forms of dissociation.

Taken as a whole, these univariate analyses suggested that the investigated patients with PNES had some characteristics in common but that a subgroup approach provides more information. Especially, the importance of an underlying traumatic psychological etiology was shown. The effect of other factors was possibly concealed by high intercorrelations between the factors. We, therefore, used a multivariate correlational approach with factor analysis. This generated 4 factors that characterized subgroups of patients: 
a) A psychotrauma subgroup; about $1 / 4$ and $1 / 3$ of the investigated patients.

b) A high vulnerability somatization subgroup; about $1 / 5$ of the patients.

c) A high vulnerability sensitive personality problem subgroup; less than $1 / 5$ of the patients.

d) A high vulnerability somatization, low cognitive level subgroup with no stress in daily life.

This group is a variation of group b with low cognitive level; a small group of $14 \%$ of the investigated patients.

We concluded that in our study, two dimensions are essential: the psychological etiology (psychotrauma or not) and the vulnerability e.g., the somatization tendency and the sensitive personality problems ('novelty seeking'), resulting in three subgroups. The fact that the first two factors in our model (Figure 9.1) were dominant is in line with the model in which the etiology starts at levels one and two, and subsequent factors are secondary factors.

The concept of subgroups is in line with recent other PNES studies ${ }^{7,24,25,56}$ in which the chosen classification was based on seizure characteristics and/or psychological criteria. Unfortunately, the distinguished subgroups were not easy to compare since different criteria and psychological tests were used. However, more studies found traumatic experiences and dissociation, cognitive functioning and personality factors, especially somatization, to be discriminatory variables in defining subgroups (see ${ }^{44,112}$ ). An interesting approach was to define subgroups based on the relationship between PNES and personality disorders, previously presented by Cragar et al. ${ }^{9}$. Psychogenic non-epileptic seizure subtypes had been described on dimensions of psychopathology as measured by the MMPI-2. Three personality clusters emerged. The authors offered tentative descriptions of the clusters: (1) 'depressed neurotics'; (2) 'somatic defenders'; and (3) 'activated neurotics'. Clusters 1 and 3 also differed significantly on neurocognitive testing, with cluster 1 patients scoring lower than cluster 3 in memory functioning, while cluster 2 individuals showed generally average cognition across domains. Reuber and House ${ }^{25}$ distinguished three groups, based on psychiatric comorbidity (present in $70 \%$ of the PNES patients in their study): (a) disorders of mood-depression, anxiety, panic and PTSD; (b) somatization and abnormal illness behavior; and (c) borderline personality. Furthermore, Hill and Gale ${ }^{56}$ recently found two PNES subgroups based on differences in cognitive functioning and seizure semiology. The PNES two-subgroup model (nonmotor and motor), in comparison to patients with temporal lobe epilepsy (TLE), showed a trend towards superior performance across nearly all cognitive measures for the nonmotor NES subgroup. Conversely, the subgroup with motor PNES symptoms showed performance generally comparable to TLE patients. Finally, a very recent study of Magaudda et al. ${ }^{112}$ specifically focused on patients with a combination of both epilepsy and PNES. They showed that this so called "mixed PNES group" could be divided in three subgroups based on epilepsy type, mental level, comorbid psychiatric 
disorders, and history of traumatic experiences. In line with our results in their 'group $3^{\prime}$, the PNES etiology was not related to epilepsy but to the psychic trauma.

Our study showed that two dimensions are essential and constitute three subgroups. This is important in clinical practice. In the psychotrauma group, there is the overwhelming impact of psychotrauma, possibly followed by psychological aftermath 'gone wrong', leading to functional somatic symptoms. In this case, there is no specific vulnerability, and the emotions caused by the psychotrauma might be simply too distressing to find another than a somatic channel, leading partially to dissociation. Treatment should focus on the psychotrauma, and in fact these patients seem to be highly comparable with patients with Posttraumatic Stress Disorder. So, although in most patients PTSD cannot be diagnosed (see Bailles et $a{ }^{55}$ ), the role of trauma in this subgroup may be as important. Fiszman et al. ${ }^{37}$ already suggested that PNES may arise as a clinical expression of a hypothetical PTSD subtype, the core symptoms of which are dissociative. For further research, it would be interesting to compare this trauma PNES group (without PTSD) with PTSD patients. Selkirk et al. ${ }^{113}$ also differentiated PNES patients reporting sexual abuse from PNES patients not reporting a sexual abuse history. Bakvis et al. ${ }^{114}$ also found also differences on biological level; basal hypercortisolism was more pronounced in traumatized patients with PNES as compared to nontraumatized PNES patients.

The second and fourth groups are patients with a specific personality vulnerability. They are prone to react with somatic symptoms to emotional overload. Here, treatment should not only focus on symptom control but also on providing patients more effective coping strategies to handle critical emotional situations. This is of course more challenging in the fourth subgroup. Finally, the third subgroup has PNES as part of their personality problems, which has been extensively discussed in previously published work $^{26}$. 


\section{Appendix A. Description of instruments}

\section{Level 1: 'Psychological etiology'}

\section{* The Traumatic Experiences Checklist (TEC) $)^{59}$}

The TEC is a 29-item self-report questionnaire retrospectively assessing potential childhood traumatic experiences in the period of 0 to 18 years of life. The TEC was developed as self-report scale as some patients may be less inhibited to report traumatic experiences on self-report measures than in the context of face-to-face trauma interviews ${ }^{60}$. The TEC includes a wide range of potentially traumatic experiences that are not necessarily traumatizing to every individual. However, experiences that are not traumatic to most individuals can be quite traumatic to others $^{59}$. The TEC has a total score and distinguishes 5 subscales: emotional neglect; emotional abuse; threat of body/life; sexual harassment and sexual abuse. Psychometric analysis shows satisfactory reliability ${ }^{61}$ and validity ${ }^{59}$.

\section{Level 2 'Vulnerability'}

\section{a. Cognitive functions (neuropsychological testing)}

* Global cognitive level. The Raven Progressive Matrices (Raven) was used. This nonverbal instrument includes multiple choice tests of abstract reasoning. An assessment with the Raven yields a total and a percentile score ${ }^{62}$. Reliability studies, covering a very wide age range, many cultural groups, and clinical as well as healthy populations, show a good reliability, internal consistency and retest reliability ${ }^{62,63}$.

* Trail Making Test (adult version). This test consists of two parts, A and B, and is a test for mental flexibility and planning. In fact, this test measures executive function, which is a key cognitive function ${ }^{64}$. Especially, trail $B$ is a good predictor of brain impairment. Although there is a practice effect when the test is administered repeatedly in the same subject, alternate forms of trails $A$ and $B$ have been developed and shown to be reliable ${ }^{65}$. In this study, the test was only administered once to the same patient. Furthermore, normative data used nowadays take into account factors such as age and level of education, which makes interpreting the scores very reliable over different patient groups ${ }^{66-68}$.

* Central (mental) information processing speed: The Computerized Visual Searching Task (CVST): The CVST is an adaption of Goldstein's Visual Searching Task and gives an indication of the speed of information processing. The test score is the total average searching time of correct answers in seconds ${ }^{69}$. 
180 Chapter 9

\section{b. Emotional profile (Personality factors)}

* The Dutch language short version of the Temperament and Character Inventory TCI (short TCTI, Dutch: VTCI). The short and Dutch version of the TCl was used, including only the main scales ${ }^{70-72}$. The short $\mathrm{TCl}$ is based on the psychobiological theory of personality of Cloninger ${ }^{73-75}$ in which both normal and deviant variations in personality are described. The short $\mathrm{TCl}$ has 4 dimensions of temperament: 'novelty seeking'; 'harm avoidance'; 'reward dependence' and 'persistence' and three dimensions of character: 'self-directedness', 'cooperativeness' and 'self-transcendence'. Reliability and validity are acceptable ${ }^{76,77}$.

* The Dutch language short version of the Minnesota Multiphasic Personality Inventory ( short MMPI, Dutch: NVM) ${ }^{78,79}$. The five short MMPI scales are as follows:

- Negativism (22 items): items referring to passive avoidant behavior, feelings of dissatisfaction and grudge regarding daily life events, and aggressive behavior. This scale is related to the psychopathic deviate, hypomania, lie, depression, masculinity-feminity, and schizophrenia scales of the MMPI.

- Somatization (20 items): items connected with vague physical complaints. This scale is related to the hypochondriasis, hysteria, and depression scales of the MMPI.

- Shyness (15 items): items reflecting feelings of shyness and difficulties in interpersonal contacts. This scale is related to the social introversion, hysteria, and psychopathic deviate scales of the MMPI.

- Psychopathology (13 items): items connected with delusional feelings, paranoid thoughts, and bizarre experiences. This scale is related to the paranoia, fake (F), and schizophrenia scales of the MMPI.

- Extraversion (13 items): items reflecting an active and energetic attitude towards various social contacts. This scale is related to the social introversion and depression scales of the MMPI.

\section{Level 3 'Shaping'}

\section{Dissociation}

Dissociation is a broad concept that involves both psychological manifestations, such as disturbances of consciousness and/or identity or an altered perception of the environment, as somatoform manifestations, specifically referring to a lack of the normal integration of sensorimotor components of experience, e.g., hearing, speaking and moving ${ }^{80}$. Not all types seem to be related to PNES ${ }^{81,82}$. Therefore, two types of 
dissociation scales were included: the DIS-Q measuring more psychological forms of dissociation, and the SDQ-20 specifically measuring somatoform types of dissociation.

* The Dissociation Questionnaire (DIS-Q). This scale is based on the Dissociative Experiences Scale $(D E S)^{83}$, the Perceptual Alteration Scale $(P A S)^{84}$ and the Questionnaire of Experiences of Dissociation (QED) ${ }^{85}$, and it has been adapted for the Dutch language $^{86,87}$. The scale has four subscales: Dis-Q d1: identity confusion and depersonalization; Dis-Q d2: self-control; Dis-Q d3: amnestic and dissociation features; Dis-Q d4: concentration 'absorption' of environmental input. The DIS-Q is extensively assessed psychometrically. All psychometric studies suggest that the DIS-Q is reliable and is able to differentiate persons with dissociative disorders from other groups $^{87}$.

* Somatoform Dissociation Questionnaire $(S D Q-20)^{88,89}$. This self-report questionnaire evaluates the severity of somatoform dissociation. The items pertain to negative (e.g., analgesia) and positive (e.g., site-specific pain) dissociative phenomena ${ }^{39}$. Several studies showed that the psychometric characteristics of the scale to be very satisfactory ${ }^{88,90-93}$.

\section{Level 4 'Triggering'}

* The Everyday Problem Checklist (EPCL, dutch: APL) [94]. This self-report questionnaire measures the frequency and the intensity of daily hassles and chronic stressors experienced during the past two months within several life domains ${ }^{94,95}$. Two subscales can be distinguished: 1) EPCL-DEP (Dutch: APL-AFH) consisting of items representing events and conditions that are caused by the subjects themselves (subject dependent); and 2) EPCL-IND (Dutch: APL-ONA) containing items referring to situations beyond control of the subject. There is also a total score (TOT-score) indicating the subjective experience of psychosocial stress in the past two months. Test-retest reliability is qualified as satisfactory [94].

\section{Level 5 'Prolongation'}

* The Utrecht Coping Scale (UCS); coping with problems and events (Dutch: UCL) ${ }^{96}$. This scale aims at defining characteristic coping behavior confronted with problems or events requiring adjustment. The UCS scales seem to take an intermediate position between "trait" and "state", conforming to the theoretical view on coping as a personality style ${ }^{97}$. There are six subscales: 'actively addressing'; 'palliative reaction'; 'avoiding/ waiting'; 'looking for social support'; 'passive reaction pattern'; 'expression of emotions'; and 'using reassuring and comforting thoughts'. Reliability of the UCS is studied in different subject groups and shows sufficient results ${ }^{96,97}$. 
182 Chapter 9

* Cognitive Emotion Regulation Questionnaire (CERQ). The CERQ is a multidimensional questionnaire constructed to identify the cognitive coping strategies someone uses after having experienced negative events or situations. The questionnaire refers exclusively to thoughts (a cognitive level) after having experienced a negative event ${ }^{98}$. The nine conceptually separate emotion regulation strategies described are 'selfblame'; 'acceptance'; 'rumination'; 'positive refocusing'; 'refocus on planning'; 'positive reappraisal'; 'putting into perspective'; 'catastrophizing' and 'blaming others' Garnefski et al. ${ }^{98}$ showed that the subscales can be grouped into adaptive and less adaptive regulation strategies. Reliability of the scales for divers populations and validity of the CERQ are mentioned as good up to very good ${ }^{98,99}$. 


\section{References}

1. Alper K. Nonepileptic seizures. Neurol Clin 1994;12:153-73.

2. Sigurdardottir KR, Olafsson E. Incidence of psychogenic seizures in adults: a population-based study in Iceland. Epilepsia 1998;39:749-52.

3. Reuber M, Elger CE. Psychogenic non-epileptic seizures: review and update. Epilepsy Behav 2003; 4:205-16.

4. Witgert ME, Wheless, JW, Breier JI. Frequency of panic symptoms in psychogenic nonepileptic seizures. Epilepsy Behav 2005;6:174-8.

5. Leis AA, Ross MA, Summers AK. Psychogenic seizures: ictal characteristics and diagnostic pitfalls. Neurology 1992;42:95-9.

6. Bodde NMG, Brooks JL, Baker GA, Boon PAJM, Hendriksen JGM, Aldenkamp AP. Psychogenic nonepileptic seizures-diagnostic issues: a critical review. Clin Neurol Neurosurg 2009;111:1-9.

7. Bodde NMG, Brooks JL, Baker GA, Boon PAJM, Hendriksen JGM, Mulder OG, Aldenkamp AP. Psychogenic non-epileptic seizures - definition, etiology, treatment and prognostic issues; a critical review. Seizure 2009;18:543-53.

8. Alsaadi TM, Thieman C, Shatzel A, Farias S. Video-EEG telemetry can be a crucial tool for neurologists experienced in epilepsy when diagnosing seizure disorders. Seizure 2004;13:32-4.

9. Cragar DE, Berry DTR, Schmitt FA, Fakhoury TA. Cluster analysis of normal personality traits in patients with psychogenic nonepileptic seizures. Epilepsy Behav 2005;6:593-600.

10. Ali S, Jabeen S, Arain A, Wassef T, Ibrahim A. How to use your clinical judgment to screen for and diagnose psychogenic non-epileptic seizures without video electroencephalogram. Innov Clin Neurosci 2011;8:36-42.

11. Syed TU, LaFrance WC, Kahriman ES et al. Can semiology predict psychogenic nonepileptic seizures? A prospective study. Ann Neurol 2011;69:997-1004.

12. Dekkers W, Van Domburg P. The role of doctor and patiënt in the construction of the pseudoepileptic attack disorder. Med Health Care and Philos 2000;3:29-38.

13. LaFrance WC, Devinsky O. The treatment of nonepileptic seizures: historical perspectives and future directions. Epilepsia 2004;45:15-21.

14. LaFrance WC, Barry JJ. Update on treatments of psychological nonepileptic seizures. Epilepsy Behav 2005;7:364-74.

15. Prigatano GP, Stonnington CM, Fisher RS. Psychological factors in the genesis and management of nonepileptic seizures: clinical observations. Epilepsy Behav 2002;3:343-9.

16. Reuber M. The etiology of psychogenic non-epileptic seizures: towards a biopsychosocial model. Neurol Clin 2009;27:909-24.

17. Bodde NMG, Janssen AMAJ, Theuns C, Vanhoutvin JFG, Boon PAJM, Aldenkamp AP. Factors involved in the long-term prognosis of psychogenic nonepileptic seizures. J Psychosom Res 2007;6:545-51.

18. McKenzie P, Oto M, Russell A, Pelosi A, Duncan R. Early outcome and predictors in 260 patients with psychogenic nonepileptic attacks. Neurology 2010;74:64-9.

19. Hall-Patch LH, Brown R, House A, Howlett s, Kemp S, Lawton G, Mayor R, Smith P, Reuber M. Acceptability and effectiveness of a strategy for the communication of the diagnosis of psychogenic nonepileptic seizures. Epilepsia 2010;51:70-8.

20. Brown MC, Levin BE, Ramsay E, Katz DA, Duchowny MS. Characteristics of patients with nonepileptic seizures. J Epilepsy 1991,4:225-9.

21. Bowman ES, Markand ON. Psychodynamics and psychiatric diagnoses of pseudoseizure subjects. Am J Psychiatry 1996;153:57-63.

22. Arnold LM, Privitera MD. Psychopathology and trauma in epileptic and psychogenic seizure patients. Psychosomatics 1996;37:438-43.

23. Duncan R, Otto M. Predictors of antecedent factors in psychogenic nonepileptic attacks: multivariate analysis. Neurology 2008;71:1000-5.

24. Baslet G, Roiko A, Prensky E. Heterogeneity in psychogenic nonepileptic seizures: understanding the role of psychiatric and neurologic factors. Epilepsy Behav 2010;17:236-41.

25. Reuber M, House AO. Treating patients with psychogenic non-epileptic seizures. Curr Opin Neurol 2002;15:207-11. 
184 Chapter 9

26. Bodde NMG, Bartelet DCJ, Ploegmakers M, Lazeron RHC, Aldenkamp AP, Boon PAJM. MMPI-II personality profiles of patients with psychogenic nonepileptic seizures. Epilepsy Behav 2011;20: 674-80.

27. McKenzie PS, Oto M, Graham CD, Duncan R. Do patients whose psychogenic non-epileptic seizures resolve, 'replace' them with other medically unexplained symptoms? Medically unexplained symptoms arising after a diagnosis of psychogenic non-epileptic seizures. J Neurol Neurosurg Psychiatry 2011;18:1-3.

28. Ettinger AB, Devinsky O, Weisbrot DM, Ramakrishna RK, Goyal A. A comprehensive profile of clinical, psychiatric, and psychosocial characteristics of patients with psychogenic nonepileptic seizures. Epilepsia 1999;40:1292-8.

29. Reuber M, Pukrop R, Bauer J, Derfuss R, Elger CE. Multidimensional assessment of personality in patients with psychogenic non-epileptic seizures. J Neurol Neurosurg Psychiatry 2004;75:743-8.

30. Galimberti CA, Ratti MT, Murelli R, Marchioni E, Manni R, Tartara A. Patients with psychogenic nonepileptic seizures, alone or epilepsy-associated, share a psychological profile distinct from that of epilepsy patients. J Neurol 2003;250:338-46.

31. LaFranceW, Devinsky O. Treatment of nonepileptic seizures. Epilepsy Behav 2002;3:19-23.

32. Stone J, Sharpe M, Binzer M. Motor conversion symptoms and pseudoseizures: a comparison of clinical characteristics. Psychosomatics 2004;45:492-9.

33. Reuber M, Howlett S, Khan A, Grünewald RA. Non-epileptic seizures and other functional neurological symptoms: predisposing, precipitating, and perpetuating factors. Psychosomatics 2007;48:230-8.

34. Barry JJ, Sanborn K. Etiology, diagnosis and treatment of nonepileptic seizures. Curr Neurol Neurosci Rep 2001;1:381-9

35. Fleisher W, Staley D, Krawetz P, Pillay N, Arnett JL, Maher J. Comparative study of trauma-related phenomena in subjects with pseudoseizures and subjects with epilepsy. Am J Psychiatry 2002;159:660-3.

36. Salmon P, Al-Marzooqi SM, Baker G, Reilly J. Childhood family dysfunction and associated abuse in patients with nonepileptic seizures: towards a causal model. Psychosom Med 2003;65:695-700.

37. Fiszman A, Alves-Leon SV, Nunes RG, D'Andrea I, Figueira I. Traumatic events and posttraumatic stress disorder in patients with psychogenic nonepileptic seizures: a critical review. Epilepsy Behav 2004;5:818-25.

38. Mueser KT, Rosenberg SD, Goodman LA, Trumbetta SL. Trauma, PTSD and the course of severe illness: an interactive model. Schizophr Res 2002;53:123-43.

39. Lally N, Spence W, McCusker C, Craig J, Morrow J. Psychological processes and histories associated with nonepileptic versus epileptic seizure presentations. Epilepsy Behav 2010;17:360-5.

40. Wyllie E, Friedman D, Lüders H, Morris H, Rothner D, Turnbull J. Outcome of psychogenic seizures in children and adolescents compared with adults. Neurology 1991;41:742-4.

41. Thompson PM, Batzel LW, Wilkus RJ. Millon clinical multiaxial inventory assessments of patients manifesting either psychogenic or epileptic seizures. J Epilepsy 1992;5:226-30.

42. Sirven JI, Glosser DS. Psychogenic nonepileptic seizures: theoretic and clinical considerations. Neuropsychiatry Neuropsychol Behav Neurol 1998;11:225-35.

43. Rosenbaum M. Psychogenic seizures-why women? Psychosomatics 2000;41:147-9.

44. Harden CL, Jovine L, Burgut FT, Carey BT, Nikolov BG, Ferrando SJ. A comparison of personality disorder characteristics of patients with nonepileptic psychogenic pseudoseizures with those of patients with epilepsy. Epilepsy Behav 2009;14:481-3.

45. Reuber M, Fernandez G, Helmstaedter C, Qurishi A, Elger CE. Evidence of brain abnormality in patients with psychogenic nonepileptic seizures. Epilepsy Behav 2002;3:249-54.

46. Fargo JD, Schefft BK, Szaflarski JP, Dulay MF, Testa SM, Privitera MD, Yeh H-S. Accuracy of selfreported neuropsychological functioning in individuals with epileptic of psychogenic nonepileptic seizures. Epilepsy Behav 2004;5:143-50.

47. Knyazeva MG, Jalili M, Frackowiak RS, Rossetti AO. Psychogenic seizures and frontal disconnection: EEG synchronisation study. J Neurol Neurosurg Psychiatry 2011;14:1-7.

48. Bautista RDC. Expanding the theory of symptom modelling in patients with psychogenic nonepileptic seizures. Epilepsy Behav 2008;13:407-9.

49. Moore PM, Baker GA. Non-epileptic attack disorder: a psychological perspective. Seizure 1997;6: 429-34. 
50. Vincentiis S, Valente KD, Thomé-Souza S, Kuczinsky E, Fiore LA, Negrao, N. Risk factors for psychogenic non-epileptic seizures in children and adolescents with epilepsy. Epilepsy Behav 2006;8:294-8.

51. Reuber M, House AO, Pukrop R, Bauer J, Elger CE. Somatization, dissociation and general psychopathology in patients with psychogenic non-epileptic seizures. Epilepsy Res 2003;57:159-67.

52. Mazza M, Della Marca G, Martini A, Scoppetta M, Vollono C, Azzurra MV, Vaccario ML, Bria P, Mazza S. Non-epileptic seizures (NES) are predicted by depressive and dissociative symptoms. Epilepsy Res 2009;84:91-6.

53. Aldenkamp AP, Mulder OG. Behavioural mechanisms involved in pseudo-epileptic seizures: a comparison between patients with epileptic seizures and patients with pseudo-epileptic seizures. Seizure 1997;6:275-82.

54. Moore PM, Baker GA, McDade G, Chadwick D, Brown S. Epilepsy, pseudoseizures and perceived family characteristics: a controlled study. Epilepsy Res 1994;18:75-83.

55. Baillès E, Pintor L, Torres X, Fernández-Egea E, De Pablo J, Arroyo S. Psychiatric disease in patients with psychogenic non-epileptic seizures referred from an epilepsy unit in a general hospital. Actas Esp Pisquiatr 2004;32:76-81.

56. Hill SW, Gale SD. Neuropsychological characteristics of nonepileptic seizure semiological subgroups. Epilepsy Behav 2011;22:255-60.

57. Cianci V, Ferlazzo E, Condino F, Mauvais H S, Farnier G, Labate A, Latella MA, Gasparini S, Branca D, Pucci F, Vazzana F, Gambardella A, Aguglia U. Rating scale for psychogenic nonepileptic seizures: scale development and clinimetric testing. Epilepsy Behav 2011;21:128-31.

58. Bodde NMG, Lazeron RHC, Wirken JMA, Van der Kruijs SJ, Aldenkamp AP, Boon PAJM. Patients with psychogenic non-epileptic seizures referred to a tertiary epilepsy centre: patient characteristics in relation to diagnostic delay. Clin Neurol Neurosurg 2012;114:217- 22.

59. Nijenhuis ERS, Van der Hart O, Kruger K. The psychometric characteristics of the Traumatic Experiences Checklist (TEC): first findings among psychiatric outpatients. Clin Psychol Psychother 2002,9:200-10.

60. Carlson EB. Trauma assessments: a clinician's guide. New York: Guilford; 1997.

61. Bracke D, Van Leeuwen K, Verhofstadt-Denève L. Comorbiditeit van zelfverwondend gedrag en dissociatieve symptomen bij vrouwelijke psychiatrische patienten. Tijdschr Psychiatr 2001;43:673-82.

62. Raven J, Raven JC, Court JH. Manual for Raven's Progressive Matrices and Vocabulary Scales. Section 3: The Standard Progressive Matrices. 2000 edition, updated 2004. San Antonio, TX: Harcourt Assessment.

63. Court JH, Raven J. Manual for Raven's progressive matrices and vocabulary scales. Section 7: research and references: summaries of normative, reliability, and validity studies and references to all sections. San Antonio, TX: Harcourt Assessment; 1995.

64. Reitan RM. Trail making test. Manual for administration and scoring. South Tucson, Arizona: Reitan Neuropsychology Laboratory; 1992.

65. Franzen, MD, Paul, D, Iverson GL. Reliability of alternate forms of the Trail Making Test. Clin Neuropsychol 1996;10:125-9.

66. Reitan RM. The validity of the Trail Making Test as an indicator of organic brain damage. Percept Mot Skills 1958;8:271-6.

67. Corrigan JD, Hinkeldey MS. Relationships between parts A and B of the Trail Making Test. J Clin Psychol 1987;43:402-9.

68. Gaudino EA, Geisler MW, Squires NK. Construct validity in the Trail Making Test: what makes Part B harder? J Clin Exp Neuropsychol 1995;17: 529-35.

69. Aldenkamp AP, Alpherts WC. The effect of the new antiepileptic drug rufinamide on cognitive functions. Epilepsia 2006;47:1153-9.

70. Duijsens IJ, Spinhoven Ph, Verschuur M, Eurlings-Bontekoe HM. De ontwikkeling van de Nederlandse verkorte temperament en karakter vragenlijst (TCI-105). Ned Tijdschr Psychol 1999;54:276-83.

71. Duijsens, IJ, Spinhoven, Ph, Goekoop, JG, Spermon, A, Eurelings-Bontekoe, EHM. The Dutch temperament and character inventory $(\mathrm{TCl})$ : dimensional structure, reliability and validity in a normal and psychiatric outpatient sample. Pers Individ Differ 2000;28:487-99.

72. Duijsens IJ, Spinhoven Ph. VTCI Handleiding. Handleiding van de Nederlandse Verkorte Temperament en Karakter Vragenlijst. Leiderdorp: Datec; 2001. 
$186 \mid$ Chapter 9

73. Cloninger CR. A systematic method for clinical description and classification of personality variants. A proposal. Arch Gen Psychiatry 1987;44:573-88.

74. Cloninger CR, Svrakic DM, Przybeck TR. A psychobiological model of temperament and character. Arch Gen Psychiatry 1993;50:975-90.

75. Cloninger CR, Przybeck TR, Svrakic DM, Wetzel RD. The temperament and character inventory (TCI): a guide to its development and use. St. Louis, MS: Center for Psychobiology of Personality Washington University; 1994.

76. Maesschalk C, Vertommen H. Nederlandse Verkorte Temperament en Karakter Vragenlijst (VTCI). Tijdschr Klin Psychol 2001;31:10-5.

77. Evers A, Zaal JN, Evers AK. Ontwikkelingen in het testgebruik van Nederlandse psychologen. De psycholoog 2002,37:54-61.

78. Luteijn F, Kok AR. Handleiding Nederlandse Verkorte MMPI Herziene Uitgave, 7. Lisse (The Netherlands): Swets and Zeitlinger;1985.

79. Eurelings-Bontekoe EHM, Duijsens IJ, Snellen WM, Diekstra RFW, Ouwersloot G. DSM-III-R and ICD-10 personality disorders and personality dimensions as assessed by the Dutch short form of the MMPI: preliminary results. Pers Individ Differ 1995;18:231-9.

80. Van der Hart O, Van Dijke A, Van Son MJM, Steele K. Somatoform dissociation in traumatized World War I combat soldiers: a neglected clinical heritage. J Trauma Dissociation 2000;1:33-66.

81. Lawton G, Baker GA, Brown JB. Comparison of two types of dissocation in epileptic and nonepileptic seizures. Epilepsy Behav 2008;13:333-6.

82. Van der Boom KJ, van den Hout MA, Huntjens R. Psychoform and somatoform dissociation, traumatic experiences, and fantasy proneness in somatoform disorders. Pers Individ Differ 2010;48:447-51.

83. Bernstein EM, Putman FW. Development, reliability, and validity of a dissociation scale. J Nerv Ment Dis 1986;174:727-35.

84. Sanders S. The perceptual alteration scale: a scale measuring dissociation. Am J Clin Hypn 1986; 29:95-102.

85. Riley KC. Measurement of dissociation. J Nerv Ment Dis 1988;176:449-50.

86. Vanderlinden J, Van Dyck R, Vandereycken W, Vertommen H. Dissociative experiences in the general population in The Netherlands and Belgium: a study with the Dissociative Questionnaire (DIS-Q). Dissociation 1991;180-4

87. Vanderlinden J, Van Dyck R, Vandereycken W, Vertommen H. Dissociatieve ervaringen bij Vlamingen en Nederlanders; een studie met de Dissociation Questionnaire. Dir Ther 1993;13:57-77.

88. Nijenhuis ERS, Spinhoven P, Van Dyck R, Van der Hart O, Vanderlinden J. The development and the psychometric characteristics of the Somatoform Dissociation Questionnaire (SDQ-20). J Nerv Ment Dis 1996;184:688-94.

89. Nijenhuis ERS. Somatoform dissociation. Phenomena, measurement, and theoretical issues. Assen: Van Gorcum; 1999.

90. Nijenhuis ERS, Spinhoven P, Van Dyck R, Van der Hart O, Vanderlinden J. Psychometric characteristics of the Somatoform Dissociation Questionnaire: a replication study. Psychother Psychosom 1998; 67:17-23.

91. Nijenhuis ERS, Spinhoven P, van Dyck R, Van der Hart O, Vanderlinden J. Degree of somatoform and psychological dissociation in dissociative disorders is correlated with reported trauma. J Trauma Stress 1998;11:711-30.

92. Sar V, Kundakci T, Kiziltan E, Bakim B, Bozkurt O. Differentiating dissociative disorders from other diagnostic groups through somatoform dissociation in Turkey. J Trauma Dissociation 2000;1:67-80.

93. El-Hage W, Darves-Bornoz JM, Allilaire JF, Gaillard P. Posttraumatic somatoform dissociation in French psychiatric outpatients. J Trauma and Dissociation 2002;3:59-73.

94. Vingerhoets AJJM, Jeninga AJ, Menges LJ. Het meten van chronische en alledaagse stressoren: eerste onderzoeksbevindingen met de Alledaagse Problemen Lijst (APL) II. Gedrag Gezond 1989;17:10-7.

95. Vingerhoets AJJM, Van Tilburg MAL. Alledaagse Problemenlijst (APL). Lisse: Swets en Zeitlinger; 1994.

96. Schreurs PJG, Van de Willige G, Brosschot JF, Tellegen B, Graus GMH. De Utrechtse Copinglijst: UCL; omgaan met problemen en gebeurtenissen. Herziene handleiding. Lisse: Swets en Zeitlinger Test Services; 1993.

97. Sanderman R, Ormel J. De Utrechtse Coping Lijst (UCL): validiteit en betrouwbaarheid. Gedrag Gezond 1992;20:32-7 
98. Garnefski N, Legerstee J, Kraaij V, van den Kommer T, Teerds J. Cognitive self-regulation strategies and emotional problems: differences between adolescents and adults. J Adolesc 2002;25:603-11.

99. Garnefski N, Kraaij V, Spinhoven Ph. Manual for the use of the Cognitive Emotion Regulation Questionnaire. Leiderdorp, The Netherlands: Datec; 2006.

100. Breslau N, Kessler RC, Chilcoat HD, Schultz LR, Davis GC, Andreski P. Trauma and posttraumatic stress disorder in the community: the 1996 Detroit Area Survey of Trauma. Arch Gen Psychiatry 1998;55: 626-32.

101. Wilkus RJ, Dodrill C, Thompson PM. Intensive EEG monitoring and psychological studies of patients with pseudoepileptic seizures. Epilepsia 1984;25:100-7.

102. Drake ME. Conversion hysteria and dominant hemisphere lesions. Psychosom J Consult Liaison Psychiat 1993;34:524-30.

103. Hermann BP. Neuropsychological assessment in the diagnosis of non-epileptic seizures. In: Rowan AJ, Gates JR, editors. Non-epileptic seizures. Boston: Butterworth-Heinemann; 1993:221-32.

104. Drane DL, Williamson DJ, Stroup ES, Holmes MD et al. Cognitive impairment is not equal in patients with epileptic and nonepileptic seizures. Epilepsia 2006;47:1879-86.

105. Goldstein LH, Drew C, Mellers J, Mitchell-O'Malley S, Oakley DA. Dissociation, hypnotisability, coping styles and health locus of control: characteristics of pseudoseizure patients. Seizure 2000,9:314-22.

106. Ito M, Adachi N, Okazaki M, Kato M, Onuma T. Evaluation of dissociative experiences and the clinical utility of the Dissociative Experience Scale in patients with coexisting epilepsy and psychogenic nonepileptic seizures. Epilepsy Behav 2009;16:491-4.

107. Frances PI, Baker GA. Appletoon PL. Stress and avoidance in pseudoseizures: testing the assumptions. Epilepsy Res 1999;34:241-9.

108. Bakvis P, Spinhoven P, Zitman FG, Roelofs K. Automatic avoidance tendencies in patients with psychogenic non-epileptic seizures. Seizure 2011;20:628-34.

109. Kuyk J, Leijten F, Meinardi H, Spinhoven P, Van Dyck R. The diagnosis of psychogenic nonepileptic seizures: a review. Seizure 1997;6:243-53.

110. Näring G, Nijenhuis ER. Relationships between self-reported potentially traumatizing events, psychoform and somatoform dissociation, and absorption, in two non-clinical populations. Aust $\mathrm{N} Z \mathrm{~J}$ Psychiatry 2005;39:982-8.

111. Karterud HN, Knizek BL, Nakken KO. Changing the diagnosis from epilepsy to PNES: patient's experiences and understanding of their new diagnosis. Seizure 2010;19:40-6.

112. Magaudda A, Gugliotta SC, Tallarico R, Buccheri T, Alfa R, Laganà A. Identification of three distinct groups of patients with both epilepsy and psychogenic nonepileptic seizures. Epilepsy Behav 2011;22:318-23.

113. Selkirk M, Duncan R, Oto M, Pelosi A. Clinical differences between patients with nonepileptic seizures who report antecedent sexual abuse and those who do not. Epilepsia 2008;49:1446-50.

114. Bakvis P, Spinhoven P, Giltay EJ, Kuyk J, Edelbroek PM, Zitman FG, Roelofs K. Basal hypercortisolism and trauma in patients with psychogenic nonepileptic seizures. Epilepsia 2010;51:752-9. 
188 


\section{Part 4}

Somatic vulnerability

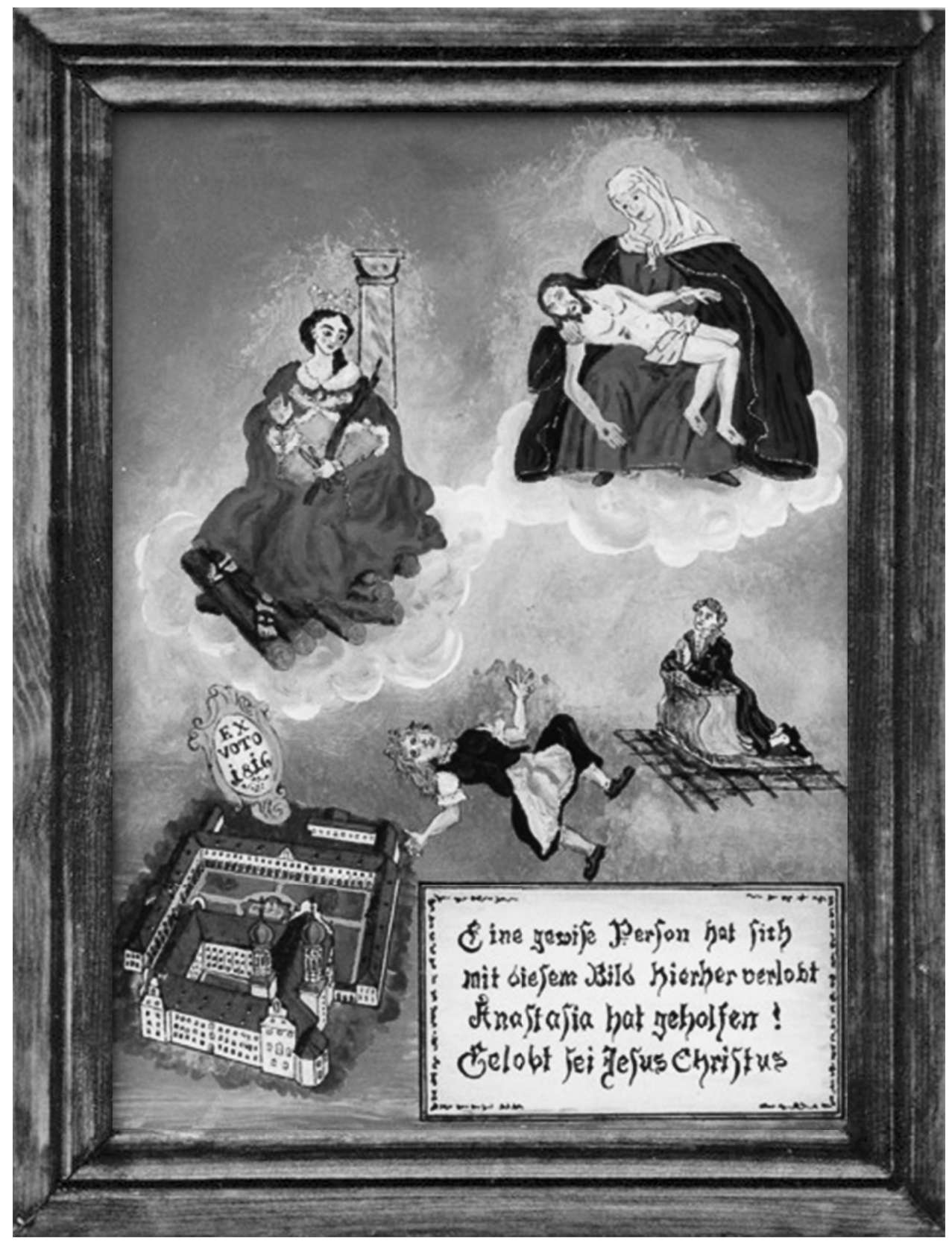


190 


\section{Chapter 10}

Psychophysiological biomarkers of dissociation in psychogenic non-epileptic seizures 
192 Chapter 10

\section{Abstract}

Misdiagnosis of patients with psychogenic non-epileptic seizures (PNES) as having epilepsy is a clinical relevant problem. Considerable problems for the patients, such as unnecessary anticonvulsant medication use and delay of suitable therapy, as well as a considerable economic burden are involved. Furthermore, after the diagnosis of PNES is confirmed, there is a lack of scientific evidence about the most efficient treatment for PNES. Evaluation of contributing factors is necessary. These factors should be implemented in explanatory models for the occurrence of PNES, which should be employed in diagnosis and treatment. Recent evidence suggests a role of deficiencies in neuronal information processing in multiple mental conditions. Although the focus in PNES research over the last two decades primarily has been on differential diagnosis and psychological and environmental factors, abnormalities in psychophysiological characteristics might also be involved in PNES. This review focuses on neurobiological substrates of PNES and dissociation, a trait which is often associated with PNES, to explore whether deviant information processing is involved in the aetiology of PNES. All studies examining the relationship between psychophysiological parameters and PNES have an exploratory character. However, the results suggest that neurophysiological characteristics, such as brain activity as visualized by functional MRI (fMRI), cardiovascular measurements and neuroendocrine functioning, may be abnormal in patients with PNES. Future investigations should therefore elucidate the exact role of neurophysiological abnormalities in the aetiology of PNES. 


\section{Introduction}

Psychogenic non-epileptic seizures (PNES) are epilepsy-like episodes of movement, sensations or behaviours that resemble epileptic seizures, but are not accompanied by epileptiform brain activity as seen on electroencephalogram (EEG). The underlying cause is assumed to be psychological; the episodes may be the somatic manifestations of emotional distress ${ }^{1}$. PNES is one of the most important differential diagnoses of epilepsy, and most patients with PNES are initially misdiagnosed as having epilepsy. The average period between the onset of seizures and the diagnosis of PNES is typically more than 6 years ${ }^{2}$. Misdiagnosis as epilepsy for patients with PNES has serious consequences for the patient, such as exposure to unnecessary anticonvulsant medication, and considerable delay to start the appropriate psychological therapy. In addition, a substantial economic burden is involved, as erroneous treatments for intractable epilepsy are expensive ${ }^{3}$. Evaluating the information described above, it is clear that differential diagnosis of PNES is clinically relevant. However, if the emphasis is only on excluding epilepsy, PNES may become a non-disease ${ }^{4}$. A positive diagnosis is necessary for appropriate treatment, therefore, the underlying mechanisms must be evaluated and results must be implemented in treatment. To gain more insight in the underlying mechanisms of psychogenic seizures, it is necessary to identify not only causal factors, such as traumatic experiences, but also predisposition factors, which elucidate why certain persons develop PNES symptoms after trauma and others do not. Such predisposition factors may be of influence in the stages of vulnerability, shaping, provocation and prolongation of PNES pathology, and have to be identified in order to organize an explanatory model of PNES.

An important predisposing factor for PNES is the tendency to dissociate ${ }^{1,5}$. The process of dissociation is a disruption of the usually integrated functions of identity, memory, consciousness or perceptions of the environment. It is regarded as a psychological defence mechanism from stressful events, by altering conscious experience ${ }^{6}$. Others assume dissociation to be a constitutional mental weakness that is activated by adverse events ${ }^{7}$. Dissociation is closely related to the process of hypnosis and essentially shows the ability to take distance from reality. People differ in their tendency to dissociate. The tendency to easily dissociate is considered an important factor in the provocation and possibly also the prolongation of PNES ${ }^{8}$.

Because the tendency to dissociate is such a prominent trait of a substantial group of PNES patients, investigation of biological correlates of dissociation is an important step in the attempt to generate an explanatory model for PNES. The psychophysiological mechanism underlying dissociation still remains to be elucidated. This review focuses on neurobiological substrates of PNES and dissociation associated with PNES, to explore whether deviant information processing is involved in the aetiology of PNES. 


\section{Methods}

Relevant studies were identified by searching the electronic databases PubMed and ScienceDirect. Articles included in this review were identified by searching the terms "MRI PNES", "fMRI PNES", "fMRI psychiatry", "fMRI hypnosis", "HRV PNES", and "cortisol PNES". Titles of articles and abstracts extracted during the search were reviewed for relevance, and if found to be applicable, the full-text article was retrieved. Case reports were not considered. Articles were included when published after 1980 up till 2010.

\section{Results}

\section{Structural MRI abnormalities}

Magnetic Resonance Imaging (MRI) of the brain provides the opportunity to investigate cerebral changes in a number of fundamentally different ways ${ }^{9}$. Structural $\mathrm{MRI}$ is one of the techniques most often employed for detection of anatomical brain abnormalities. Some investigations have related PNES with structural MRI abnormalities. For example, Reuber et al. ${ }^{10}$ found structural brain abnormalities more commonly in PNES patients than in the general population. They investigated the proportion of PNES patients having neurological abnormalities on structural magnetic resonance imaging, and found that $27 \%$ of PNES patients and $78 \%$ of patients with PNES and epilepsy showed anatomical irregularities. A wide variety of abnormalities was found in the PNES only group, including - in order of frequency - postoperative defects, arachnoid cyst, posttraumatic changes, generalized atrophy, gliotic change, white matter lesions, hippocampal sclerosis, and venous angioma. Abnormalities in the PNES plus epilepsy group included hippocampal sclerosis, postoperative defects, migration disorders, signs of previous stroke, gliosis, posttraumatic changes, hemiatrophy, white matter lesions, tumor, cavernoma, and venous angioma.

Devinsky et al. ${ }^{11}$ even report 65 percent of their sample of PNES patients (without comorbid epilepsy) having structural abnormalities on MRI. In their sample, neurological features also varied widely, but showed to be significantly more present in the right hemisphere of PNES patients compared to the distribution of pathologies in the brains of epilepsy patients. These results suggest that right hemisphere dysfunction may form a predisposition factor to development of PNES symptoms. This finding is consistent with previous evidence for right hemisphere dominance in emotional regulation and conversion reactions ${ }^{12,13}$. Thus, it is possible that neuropathology influences the neuropsychological performance of patients with PNES, and both may, in interaction, constitute the vulnerability factor in PNES patients. More research is needed to identify the exact role of structural brain abnormalities in the aetiology of PNES. 


\section{Functional MRI abnormalities}

Quantitative information about structural brain abnormalities provides minimal insight into functional organization and reorganization in patients with PNES. To investigate whether deviations in functional brain architecture are predictive of dissociation in patients with PNES, functional imaging is essential. Functional Magnetic Resonance Imaging ( $\mathrm{fMRI}$ ) is a technique frequently used to explore the relationship between brain activation and cognitive functioning. It measures changes in the bloodoxygen-level dependent (BOLD) signal, which are assumed to accompany neural activity in the brain ${ }^{14}$. $\mathrm{fMRI}$ abnormalities have been demonstrated to be related to abnormal information processing in several mental conditions, for example schizophrenia $^{15,16}$, panic disorders ${ }^{17}$, and bipolar disorder ${ }^{18}$.

Until now, fMRI techniques have not extensively been used to explain deviant neuronal processing in patients with PNES. However, some investigations have explored the relationship between hypnosis, a process closely linked to dissociation, and altered $\mathrm{FMRI}$ characteristics. In a fMRI investigation of McGeown et al. ${ }^{19}$, the authors demonstrate that induction of hypnosis in highly suggestible individuals causes decreased cerebral blood flow in the anterior parts of the default mode network during rest. Other authors, for example Egner et al. ${ }^{20}$ and Raz et al. ${ }^{21}$, have also associated decreased activation of frontal structures such as the anterior cingulate cortex (ACC) with high suggestibility. Because the process of hypnosis appears to be related to dissociation, similar activation patterns may be observed in patients with PNES with a high tendency to dissociate.

\section{Brain network abnormalities}

Cognitive and emotive functions result from the interactions of a number of differently localized brain regions rather than single (isolated) regions. In this context, novel brain connectivity analyses, which examine the integrity of cerebral networks, are most appropriate in evaluating information processing deficits of patients with psychiatric conditions such as PNES ${ }^{22}$. For example, fMRI facilitates the assessment of the functional connectivity of regional brain activity, based on correlations in dynamic spontaneous fluctuations ${ }^{23}$. This analysis can be applied both on task-related fMRI data, as well as on resting state fMRI ( $r s-f M R I)$ data where no explicit stimuli are presented $^{24}$. In addition, network analysis of diffusion tensor imaging (DTI) data, using measures of water directionality and diffusivity, can provide information regarding the integrity of structural connectivity of the entire brain ${ }^{25}$.

\section{Cardiovascular dysfunctioning}

It is hypothesized that patients with PNES (almost) continuously experience high levels of emotional stress. Emotional stress has been proven to be accompanied by physiological changes like increased heart rate, blood pressure, respiration rate and 
muscle tension, and decreased heart rate variability (HRV) ${ }^{26,27}$. HRV in particular is a measure of interest, because it reflects the functioning of the parasympathetic autonomic nervous system, the system responsible for stimulation of activities that occur when the body is at rest. HRV may be decreased in patients with PNES, suggesting a state of hypervigilance. Indeed, Bakvis et al. ${ }^{28}$ have examined the cardiovascular functioning of patients with PNES, and found that patients with PNES show lower HRV during baseline and recovery of stress compared to healthy controls. However, their study had an experimental design; ambulatory measurements during daily life (comprising psychogenic non-epileptic seizures) would provide additional and ecological valid information about the level of emotional arousal and cardiovascular condition of patients with PNES.

\section{Abnormal neuroendocrine functioning}

An increased state of threat vigilance was also confirmed with endocrinal measurements by Bakvis et al. ${ }^{29}$, who confirmed a state of hypercortisolism in patients with PNES. Increased cortisol levels are assumed to reflect greater activity of the hypothalamic-pituitary-adrenal (HPA) axis, a major part of the neuroendocrine system that controls reactions to stressors and regulates many body processes including mood and emotions ${ }^{30,31}$. The HPA-axis has been proven to be involved in the neurobiology of mood disorders such as anxiety disorder ${ }^{32,33}$, bipolar disorder ${ }^{34,35}$, post-traumatic stress disorder ${ }^{36}$, borderline personality disorder ${ }^{37}$, and major depressive disorder ${ }^{38,39}$. Antidepressants, which are routinely prescribed for many of these disorders, serve to regulate HPA axis function ${ }^{40}$. Recently, a pilot randomized controlled trial with Sertraline (a serotonine selective reuptake inhibitor) suggests this pharmacotherapy to be effective for seizure reduction, confirming involvement of the HPA-axis in the aetiology of PNES ${ }^{41}$.

\section{Conclusion}

To explore whether deviant information processing is involved in the aetiology of PNES, this review focused on neurobiological substrates of PNES and of dissociation associated with PNES. Demonstration of a relationship between PNES and deviant information processing would have substantial implications for the understanding of PNES aetiology. Better understanding of the mechanisms underlying PNES development could eventually improve the clinical management of PNES diagnosis and treatment. Nowadays, the time interval between seizure onset and PNES diagnosis still is more than 6 years on average, during which the patient is treated as having refractory epilepsy, which forms a heavy burden on the patient and society. Early recognition of vulnerability factors such as dissociation would offer a possibility 
of earlier diagnosis of PNES, diminishing delay of suitable therapy and unnecessary medical charges for epilepsy treatment.

Moreover, finding a neurobiological substrate of dissociation in PNES would change the concept of psychogenic seizures into being a psychophysiological phenomenon. This change of concept has implications for the development and evaluation of treatment, although direction of causality has to be examined in more detail. It will be difficult to position psychophysiological abnormalities definitely as a predisposition factor, because such abnormalities may both be the cause and the consequence of dissociation and psychogenic non-epileptic seizures. Longitudinal studies should clarify the exact contribution and interaction of dissociation and psychophysiological disturbances in PNES.

The most promising clinical consequence of such studies, in addition to improving knowledge about the aetiology of PNES, is the possibility of using neuroimaging data or other psychophysiological findings to identify subgroups of patients, which could allow treatments to be tailored. 


\section{References}

1. Bodde NM, Brooks JL, Baker GA, Boon PA, Hendriksen JG, Aldenkamp AP. Psychogenic non-epileptic seizures - definition, etiology, treatment and prognostic issues: a critical review. Seizure 2009;18:54353.

2. Alsaadi, TM, Marquez AV. Psychogenic non-epileptic seizures. Am Fam Physician 2005;2:849-56.

3. Martin RC, Gilliam FG, Kilgore M, Faught E, Kuzniecky R. Improved health care resource utilization following video-EEG-confirmed diagnosis of nonepileptic psychogenic seizures. Seizure 1998;7:38590.

4. Dekkers W, Van Domburg P. The role of doctor and patient in the construction of the pseudoepileptic attack disorder. Medical Health Care Phil 2000;3:29-38.

5. Kuyk J, Spinhoven P, Van Emde Boas W, Van Dyck R. Dissociation in temporal lobe epilepsy and pseudo-epileptic seizure patients. J Nerv Ment Dis 1999;12:731-20.

6. Erdelyi $\mathrm{MH}$. Subliminal perception and its cognates: theory, indeterminacy, and time. Conscious Cogn 2004;13:73-91.

7. Dell PF. Involuntariness in hypnotic responding and dissociative symptoms. J Trauma Dissociation 2010;11: 1-18.

8. Reuber $M$, Elger CE. Psychogenic non-epileptic seizures: review and update. Epilepsy Behav 2003;4:205-16

9. Tofts P. Quantitative MRI of the brain measuring changes caused by disease. Chichester, West Sussex; Hoboken, N.J.: John Wiley \& Sons Ltd.; 2003.

10. Reuber M, Fernandez G, Helmstaedter C, Qurishi A, Elger CE. Evidence of brain abnormality in patients with psychogenic non-epileptic seizures. Epilepsy Behav 2002;3:249-54.

11. Devinsky O, Mesad S, Alper K. Nondominant hemisphere lesions and conversion nonepileptic seizures. J Neuropsychiatry Clin Neurosci 2001;13:367-73.

12. Cancelliere AEB, Kertesz A. Lesion localization in acquired deficits of emotional expression and comprehension. Brain Cog 1990;13:133-47.

13. Stern, D.B. Handedness and the lateral distribution of conversion reactions. J Nerv Ment Dis 1997; 164:122-8.

14. Nair DG. About being BOLD. Brain Res Brain Res Rev 2005;50:229-43.

15. Hasenkamp W, James GA, Boshoven W, Duncan E. Altered engagement of attention and default networks during target detection in schizophrenia. Schizophr Res 2011;125:169-73.

16. Krawitz A, Braver TS, Barch DM, Brown JW. Impaired error-likelihood prediction in medial prefrontal cortex in schizophrenia. Neuroimage 2011;54:1506-17.

17. de Carvalho MR, Dias GP, Cosci F, de-Melo-Neto VL, Bevilaqua MC, et al. Current findings of $\mathrm{fMRI}$ in panic disorder: contributions for the fear neurocircuitry and CBT effects. Expert Rev Neurother 2010;10:291-303.

18. Dickstein DP, Gorrostieta C, Ombao H, Goldberg LD, Brazel AC, et al. Fronto-Temporal Spontaneous Resting State Functional Connectivity in Pediatric Bipolar Disorder. Biol Psychiatry 2010;68:839-46.

19. McGeown WJ, Mazzoni G, Venneri A, Kirsch I. Hypnotic induction decreases anterior default mode activity. Conscious Cogn 2009;18:848-55.

20. Egner T, Jamieson G, Gruzelier J. Hypnosis decouples cognitive control from conflict monitoring processes of the frontal lobe. Neuroimage 2005;27:969-78.

21. Raz A, Fan J, Posner MI. Hypnotic suggestion reduces conflict in the human brain. Proc Natl Acad Sci 2005; 102:9978-83.

22. Fusar-Poli P, Broome MR. Conceptual issues in psychiatric neuroimaging. Curr Opin Psychiatry 2006;19:608-12.

23. Rogers BP, Morgan VL, Newton AT, Gore JC. Assessing functional connectivity in the human brain by fMRI. Magn Reson Imaging 2007;25:1347-57.

24. Buckner RL, Vincent JL. Unrest at rest: default activity and spontaneous network correlations. Neuroimage 2007;37:1091-96.

25. Bullmore E, Sporns O. Complex brain networks: graph theoretical analysis of structural and functional systems. Nat Rev Neurosci 2009;10:186-98. 
26. Brosschot JF, Van Dijk E, Thayer JF. Daily worry is related to low heart rate variability during waking and the subsequent nocturnal sleep period. Int J Psychophysiol 2007;63:39-47.

27. Henje Blom E, Olsson EM, Serlachius E, Ericson M, Ingvar M. Heart rate variability (HRV) in adolescent females with anxiety disorders and major depressive disorder. Acta paediatrica 2010;4:604-11.

28. Bakvis P, Roelofs K, Kuyk J, Edelbroek PM, Swinkels WA, Spinhoven P. Trauma, stress, and preconscious threat processing in patients with psychogenic nonepileptic seizures. Epilepsia 2009; 50:1001-11.

29. Bakvis P, Spinhoven P, Giltay EJ, Kuyk J, Edelbroek PM, et al. Basal hypercortisolism and trauma in patients with psychogenic nonepileptic seizures. Epilepsia 2010;51:752-9.

30. Herman JP, Cullinan WE. Neurocircuitry of stress: central control of the hypothalamo-pituitaryadrenocortical axis. Trends Neurosci 1997;20:78-84.

31. McEwen BS. Physiology and Neurobiology of Stress and Adaptation: Central Role of the Brain. Physiol Rev 2007;87:873-904.

32. Mantella RC, Butters MA, Amico JA, Mazumdar S, Rollman BL, et al. Salivary cortisol is associated with diagnosis and severity of late-life generalized anxiety disorder. Psychoneuroendocrinology 2008;33:773-81.

33. Lenze EJ, Mantella RC, Shi P, Goate AM, Nowotny P, et al. Elevated cortisol in older adults with generalized anxiety disorder is reduced by treatment: a placebo-controlled evaluation of escitalopram. Am J Geriatr Psychiatry 2011;19:482-90.

34. Havermans R, Nicolson NA, Berkhof J, Devries MW. Patterns of salivary cortisol secretion and responses to daily events in patients with remitted bipolar disorder. Psychoneuroendocrinology 2011;36:258-65.

35. Chen $\mathrm{CH}$, Suckling J, Ooi $\mathrm{C}$, Jacob R, Lupson V, et al. A longitudinal fMRI study of the manic and euthymic states of bipolar disorder. Bipolar Disord 2010;12:344-7.

36. Pervanidou P, Chrousos GP. Neuroendocrinology of post-traumatic stress disorder. Prog Brain Res 2010;182:149-60.

37. Nater UM, Bohus M, Abbruzzese E, Ditzen B, Gaab J, et al. Increased psychological and attenuated cortisol and alpha-amylase responses to acute psychosocial stress in female patients with borderline personality disorder. Psychoneuroendocrinology 2010;35:1565-72.

38. Mclsaac SA, Young AH. The role of hypothalamic pituitary-adrenal axis dysfunction in the etiology of depressive disorders. Drugs Today (Barc) 2009;45:127-33.

39. Dedovic K, Engert V, Duchesne A, Lue SD, Andrews J, et al. Cortisol awakening response and hippocampal volume: vulnerability for major depressive disorder? Biol Psychiatry 2010;68:847-53.

40. Laakmann G, Wittmann M, Gugath M, Mueller OA, Treusch J, et al. Effects of psychotropic drugs (desimipramine, chlorimipramine, sulpiride and diazepam) on the human HPA axis. Psychopharmac (Berl) 1984;84:66-70.

41. Lafrance WC Jr, Keitner GI, Papandonatos GD, Blum AS, Machan JT, et al. Pilot pharmacologic randomized controlled trial for psychogenic non-epileptic seizures. Neurology 2010;75:1166-73. 
200 


\section{Chapter 11}

\section{Functional connectivity of dissociation in patients with psychogenic non-epileptic seizures}

SJM Van der Kruijs, NMG Bodde, MJ Vaessen, RHC Lazeron, KEJ Vonck, PAJM Boon, PAM Hofman, WH Backes, AP Aldenkamp, JFA Jansen

J Neurol Neurosurg Psychiatry 2012;83:239-47 


\section{Abstract}

\section{Introduction}

Psychogenic non-epileptic seizures (PNES) resemble epileptic seizures, but lack epileptiform brain activity. Instead, the cause is assumed to be psychogenic. An abnormal coping strategy may be exhibited by PNES patients, as indicated by their increased tendency to dissociate. Investigation of resting-state networks may reveal altered routes of information and emotion processing in PNES patients. The authors therefore investigated whether PNES patients differ from healthy controls in their resting-state functional connectivity characteristics and whether these connections are associated with the tendency to dissociate.

\section{Methods}

11 PNES patients without psychiatric comorbidity and 12 healthy controls underwent task-related paradigms (picture-encoding and Stroop paradigms) and resting-state functional MRI (rsfMRI). Global cognitive performance was tested using the Raven's Matrices test and participants completed questionnaires for evaluating dissociation. Functional connectivity analysis on rsfMRI was based on seed regions extracted from task-related fMRI activation maps.

\section{Results}

The patients displayed a significantly lower cognitive performance and significantly higher dissociation scores. No significant differences were found between the picture-encoding and Stroop colour-naming activation maps between controls and patients with PNES. However, functional connectivity maps from the rsfMRI were statistically different. For PNES patients, stronger connectivity values between areas involved in emotion (insula), executive control (inferior frontal gyrus and parietal cortex) and movement (precentral sulcus) were observed, which were significantly associated with dissociation scores.

\section{Conclusion}

The abnormal, strong functional connectivity in PNES patients provides a neurophysiological correlate for the underlying psychoform and somatoform dissociation mechanism where emotion can influence executive control, resulting in altered motor function (eg, seizure-like episodes). 


\section{Introduction}

Psychogenic non-epileptic seizures (PNES) are paroxysmal episodes that resemble epileptic seizures, but are not based on epileptiform brain activity as recorded by EEGs and have no clinical evidence for epilepsy. Furthermore, no evidence has been found for other somatic causes of the seizures. Instead, psychogenic factors are assumed to cause the seizures ${ }^{1}$.

PNES is one of the most important differential diagnoses of epilepsy. Although the differential diagnosis has been facilitated by the introduction of video EEG, there are as yet no real positive ictal features suggested to be pathognomonic for PNES. Most patients with PNES are initially misdiagnosed as having epilepsy, which has serious consequences for the patient, such as exposure to unnecessary anticonvulsant medication and considerable delay in starting the appropriate psychological therapy ${ }^{2}$. In addition, misdiagnosis of PNES as epilepsy has a substantial economic burden, as erroneous treatments for intractable epilepsy are expensive ${ }^{3}$.

More knowledge of PNES aetiology is needed to facilitate the process of PNES diagnosis and decide the nature of treatment ${ }^{4}$. Existing theories regarding the underlying psychological mechanisms of PNES are diverse and involve multiple factors that may play a role in the development and prolongation of PNES. One factor that is considered particularly important in most theories for PNES $^{5}$ and other functional symptoms $^{6,7}$ is dissociation. Dissociation is a broad concept that involves a variety of manifestations. In the literature on somatoform disorders, psychological and somatoform dissociation are often distinguished, but they can be seen as related constructs $^{8}$. The process of psychological dissociation is a disruption of the integration of a person's conscious functioning by severing the connection to thoughts, memories, feelings and sense of identity. Somatoform dissociation involves the loss of integration of somatic experiences, functions and responses ${ }^{9}$. Dissociation is postulated to be closely related to the process of hypnosis ${ }^{10}$ and is regarded as a coping strategy in the context of acute or chronic traumatization when the individual lacks the capacity to integrate adverse experiences ${ }^{11}$. PNES patients often demonstrate dissociative symptoms ${ }^{12}$ and high hypnotisability ${ }^{13}$, and dissociative disorders have been reported in over $90 \%$ of the PNES patients ${ }^{14}$. In fact, PNES may be considered as somatoform symptoms resulting from dissociated mental organization $^{11}$. Accordingly, the DSM-IV-TR and ICD-10 classifications of PNES as, respectively, conversion disorder and dissociative disorder are still a matter of debate ${ }^{15}$.

Since the tendency to dissociate is considered such an important mechanism in the aetiology of PNES, a better understanding of the neurobiological mechanism of dissociation might shed light on the pathophysiology of PNES and lead to more specific treatments. It might explain how information in patients with PNES or other functional symptoms is processed differently compared with non-affected individuals. A previous functional MRI ( $\mathrm{MMRI}$ ) study in patients with a motor conversion disorder 
identified abnormal functional connectivity (FC) between regions involved in emotion and motor preparation ${ }^{16}$. fMRI may identify a similar abnormality in patients with PNES, providing evidence for alternative neuronal routes of information and emotion processing in patients with PNES that probably result in dissociative seizure-like episodes $^{4,17,18}$. As yet, no fMRI study has been performed in patients with PNES.

We hypothesize that functional connections between networks involved in emotion, sensorimotor, and cognitive processes are abnormal in patients with PNES. Additionally, these abnormal connections are associated with the tendency to dissociate. To test these hypotheses, we performed an fMRI study in patients with PNES and healthy controls.

\section{Materials and methods}

\section{Participants}

Patients were selected by their clinical psychologist or neurologist $(>10$ years and $>9$ years experience, respectively), on the basis of their seizure characteristics ${ }^{5}$, tendency to dissociate, and the absence of mental retardation and comorbid psychiatric disorders (e.g., mood and anxiety disorders, schizophrenia and psychosis, and substance-related disorders), which were determined through (hetero-) anamnesis and extensive (neuro-) psychological assessment. Individuals with neurological comorbidity (including epilepsy) and malingering patients were excluded. Patients were only included after the PNES diagnosis was confirmed in a tertiary epilepsy centre by an experienced neurologist/epileptologist, using clinical description and, when available, additional (video) EEG investigations.

The total study population included 13 patients with PNES and 13 healthy volunteers. Two patients with PNES did not complete the study and one healthy control demonstrated periventricular heterotopia on MRI, because of which these patients were excluded from the analysis. The other subjects did not have clinically significant MRI abnormalities (Table 11.1). Analyses were performed on the data obtained from 11 patients and 12 healthy volunteers. All participants gave informed consent to participate in the investigation, which received ethical approval by the Medical Ethical Committee of Maastricht University (ref. 10-3-045). 
Functional connectivity of dissociation in patients with psychogenic non-epileptic seizures $\mid 205$

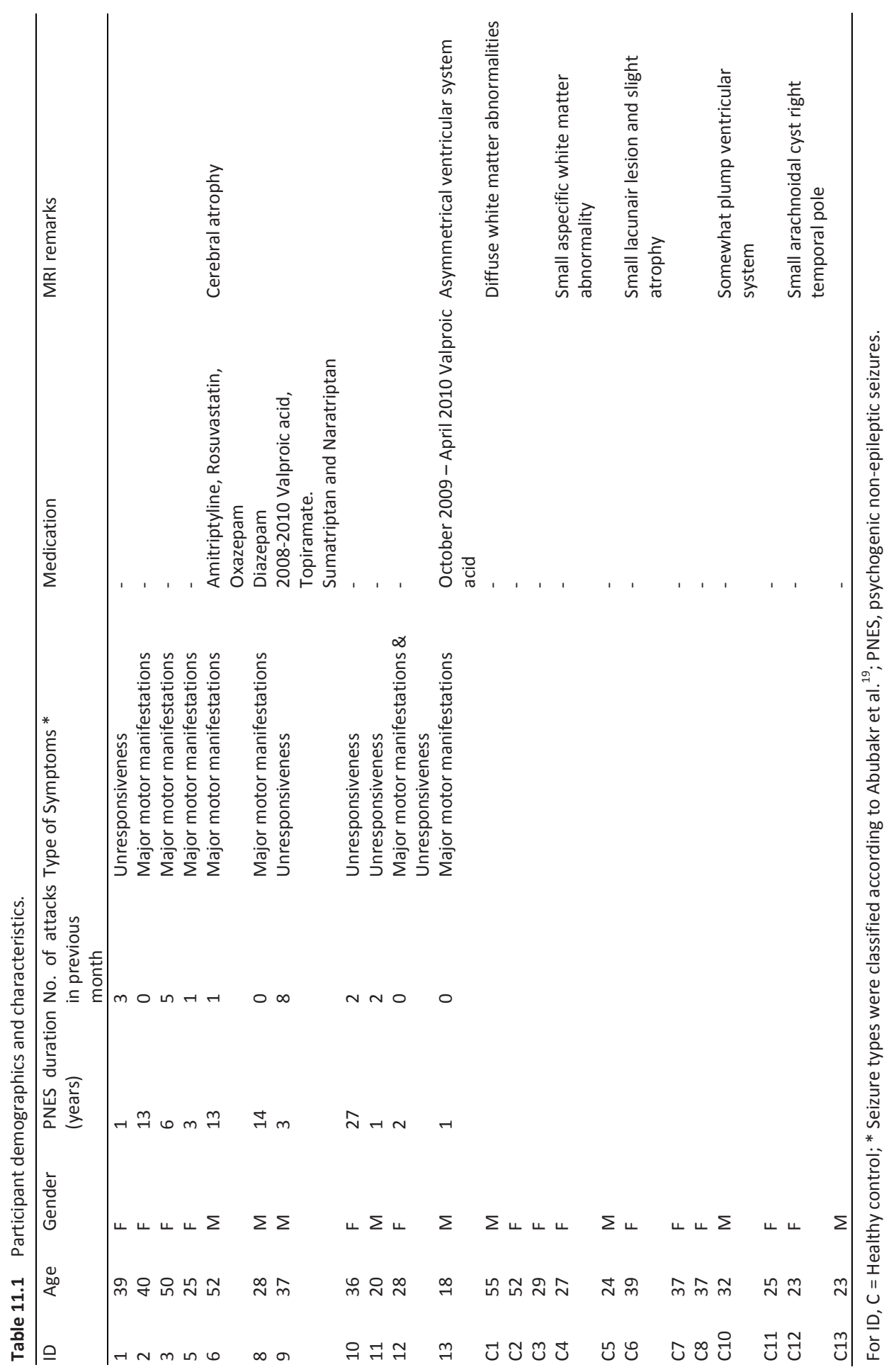




\section{Questionnaires and neuropsychological investigation}

All participants were asked to complete questionnaires to evaluate their dissociation tendency. These questionnaires included the Dissociation Questionnaire (DIS-Q), Dissociative Experiences Scale (DES) and the Somatoform Dissociation Questionnaire $(S D Q-20)^{20}$. Both the psychological forms of dissociation (DES and DIS-Q) and somatoform dissociation (SDQ-20) were assessed. Global cognitive performance was tested using the Raven's Progressive Matrices Test ${ }^{21}$. We obtained completed questionnaires from 10 patients with PNES and 12 healthy controls, as one patient did not return the questionnaires.

\section{Neuroimaging}

MRI was performed on a 3.0-tesla unit equipped with an 8-channel head coil (Philips Achieva, Philips Medical Systems, Best, The Netherlands). For anatomic reference, a T1-weigthed 3D turbo field echo was acquired with the following parameters: repetition time (TR) $8.2 \mathrm{~ms}$, echo time (TE) $3.7 \mathrm{~ms}$, flip angle $8^{\circ}$, matrix 240x240, field of view (FOV) $256 \times 256 \times 180 \mathrm{~mm}^{3}, 1 \mathrm{~mm}$ adjacent reconstructed coronal slices. fMRI data were acquired using a whole-brain single-shot multi-slice blood oxygen leveldependent echo-planar imaging sequence, with TR 2 s, TE $35 \mathrm{~ms}$, flip angle $90^{\circ}$, voxel size $2 \times 2 \times 4 \mathrm{~mm}^{3}$, matrix 128x128, 32 contiguous slices per volume and 195 volumes per acquisition.

For fMRI, four different scans were performed: (1) first resting-state fMRI (rsfMRI) session, (2) picture encoding, (3) Stroop colour naming, and (4) second rsfMRI session. During the rsfMRI sessions, subjects were instructed to close their eyes and think of nothing in particular. The rationale for including a second resting-state session after two task-related paradigms was that attentional effort may provoke dissociative phenomena, ${ }^{22-25}$ which thus may provoke dissociation during the second rsfMRI session.

The picture-encoding task was included in an attempt to stimulate the process of suggestibility by presenting pictures with a high positive sentimental value. During this task, subjects viewed five images of real-life outdoor scenes prior to the fMRI scans during acquisition of the T1-weighted $\operatorname{scan}^{26}$. Each picture was presented 25 times for 3 s. After approximately half an hour, an fMRI examination was performed while variable-length epochs of new pictures (new condition) were demonstrated mixed among variable-length epochs of the five old pictures (old condition). The epochs were mixed into a run of 195 stimuli. A total of 120 new pictures were shown. With each picture, the subjects had to decide whether it was old or new. The activation during the task was contrasted with the resting-state activation for further analysis. Previous studies with this task showed activation of the bilateral medial temporal lobes and other limbic structures ${ }^{26}$. 
The Stroop task was selected because susceptibility to hypnotic induction (associated with dissociation), has previously been related to Stroop performance and FC changes in the frontal attention system. ${ }^{27,} 28$ In the covert variation of the Stroop test, ${ }^{29,30}$ a word stimulus is presented in green, blue, yellow or red colour on a black background. Subjects were instructed to think of the colour in which the word was displayed. For example, the word 'blue' was written in red letters; the subject had to think 'red'. Each word was presented for $2 \mathrm{~s}$. In the baseline condition, subjects focused on a cross-hair. The paradigm consisted of seven baseline rest condition blocks (30s each) alternated with six activation blocks, consisting of 15 words. In total, 24 congruent and 66 incongruent stimuli were presented in random order. The contrast between the baseline condition and the activation condition was used for further analysis ${ }^{30}$.

\section{Neuroimaging analysis}

Structural MRI scans were reviewed by an experienced neuroradiologist ( $>10$ years experience). fMRI data analysis was performed in MATLAB (Mathworks, Natick, Massachusetts, USA) using the statistical parametric mapping software package (SPM8) (Wellcome Department of Cognitive Neurology, London, UK). Task-related paradigms were analyzed using brain activation contrasts according to the general linear model. The blood oxygen level-dependent images were realigned, transformed into the standardized Montreal Neurological Institute space and smoothed with an 8$\mathrm{mm}$ Gaussian kernel. In the general linear model, a standard discrete cosine set was used to correct for (low-frequency) signal drift. Additionally, the paradigms were convolved with the haemodynamic response function. To explore differences in activation between the PNES and control group, a random-effects analysis was performed. Results were thresholded at the $P<0.05$ level (corrected for family-wise multiple comparisons).

Subsequently, regions of interest with strong activation were defined (of approximately 300 voxels), based on the activation patterns during the tasks averaged for all subjects. This way, we ensured that the created masks were specific for this population, which is preferred over mask definitions available from the literature. ${ }^{31}$ The masks were created in MRIcro ${ }^{32}$.

For the resting-state FC analysis, the signal time-course data were filtered by applying a bandpass filter $(0.01-0.1 \mathrm{~Hz})$ and corrected for head movement effects by using the six motion correction parameters as a covariate. Seed time courses for each region and subject were then generated by averaging the signal within the region of interest at each time point. Each seed time course then was regressed against all brain voxel time courses to obtain an FC map, which was subsequently transformed using the Fisher-Z transformation ${ }^{31}$. Multiple regression was then performed with subject type (patient or control) and rsfMRI session (first or second) as covariates. The resulting contrasts were thresholded at the $p<0.05$ level (corrected for multiple comparisons using regional $\mathrm{FDR}^{33}$ ). Regions with significant differences in $\mathrm{FC}$ between patients and 
208 Chapter 11

controls (called FC regions hereafter) were identified, and corresponding masks were created in MRIcro ${ }^{32}$. Subsequently, for these regions individual functional connectivity values (called FC values hereafter) were computed by averaging the $\mathrm{FC}$ values over all voxels within each mask.

\section{Statistical analysis}

Statistical data analyses on summary values were performed in SPSS (PASW Statistics V.18.0, Chicago: SPSS Inc.), whereas analyses on a voxel-by-voxel level were performed in MATLAB (see previous section). Descriptive statistics of relevant variables were obtained, and Mann-Whitney $U$ tests were performed to examine differences between patients with PNES and controls. Additionally, correlation coefficients between dissociation scores, intelligence scores and FC values were obtained over all subjects using the non-parametric Spearman rank-correlation test. Finally, to gain insight into the predictive value of the tested variables for relevant significant correlations from the latter analysis, a linear regression was performed with FC as a dependent variable and dissociation and intelligence scores as independent variables. Statistical significance is denoted as $P<0.05$.

\section{Results}

\section{Clinical and neuropsychological assessments}

The study population comprised of 11 patients with PNES ( 6 women, 5 men, age $34 \pm 11$ years, number of seizures in previous month $2.0 \pm 2.5$ ), and 12 healthy volunteers ( 8 women, 4 men, age $34 \pm 11$ years) (Table 11.1). The patients displayed significantly lower performance on the Raven's Progressive Matrices test, and significantly higher dissociation tendency on the dissociation questionnaires, as assessed with Mann-Whitney $U$ tests $(P<0.05)$. The patients displayed high scores for both psychological and somatoform dissociations $(P<0.05)$.

\section{Neuroimaging analysis}

For both the PNES and control groups, the picture-encoding paradigm yielded significant activation within both hippocampi, the left lateral frontal cortex, the parahippocampal gyrus and fusiform gyrus. The Stroop paradigm activated the inferior frontal, precentral and parietal cortices. These results for both groups are typical activation maps, in accordance with the literature. ${ }^{26,30,34}$ Figure 11.1 displays the average activation for the picture-encoding and Stroop paradigms for both groups. The random-effects analysis did not reveal any significant differences for picture-encoding and Stroop colour-naming activation maps between controls and patients with PNES. 


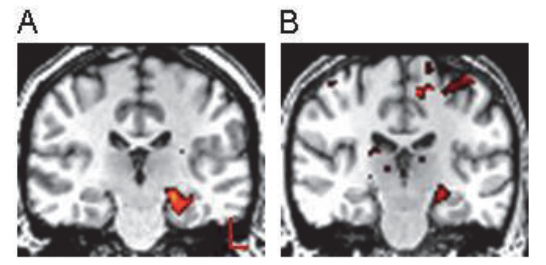

D

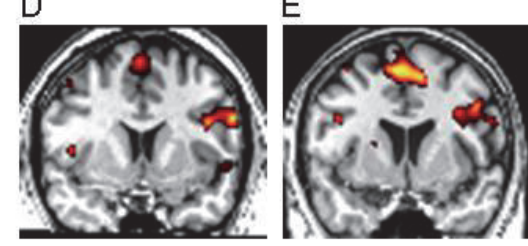

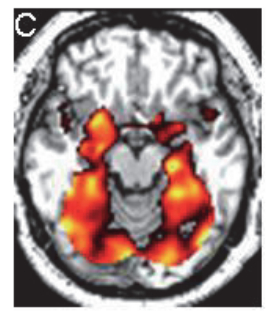
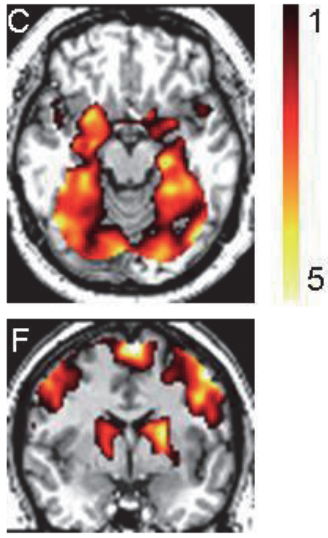

5

Figure 11.1 Group averaged fMRI activation maps superimposed on a normalized T1-weighted MR image. Mean activation patterns for PNES patients are shown in $A$ and $D$ and for healthy controls in $B$ and $\mathrm{E}$. Averaged activation patterns over all subjects are shown in $\mathrm{C}$ and $\mathrm{F}$. For the picture encoding paradigm the characteristic hippocampal activation is shown on coronal (A-B), and axial (C) slices. For the Stroop paradigm (D-F) the characteristic prefrontal activation is shown on coronal $(D, E, F)$ slices. The bar on the top right indicates the $t$-value of the activation level. Slice positions are specified in the MNI coordinate system: $y=-24 \mathrm{~mm}$ for $A$ and $B ; z=-18 \mathrm{~mm}$ for $C$, and $y=6 \mathrm{~mm}$ for $\mathrm{D}, \mathrm{E}$, and $\mathrm{F}$.

Based on the average activation for the task-related paradigms, nine seed regions of interest were created (Figure 11.2): left parahippocampal gyrus and right parahippocampal gyrus (based on the encode paradigm), and right inferior frontal gyrus, left inferior frontal gyrus, right intraparietal sulcus, left intraparietal sulcus, left supramarginal gyrus, anterior cingulate cortex, and left precentral sulcus (based on Stroop paradigm). The FC maps based on the seed regions left inferior frontal gyrus, left intraparietal sulcus, left supramarginal gyrus and left precental sulcus yielded significant group differences in connectivity values $(P<0.05$, corrected) (Table 11.3, Figure 11.3). The right intraparietal sulcus yielded similar results as the left intraparietal sulcus (data not shown). The other four seed regions did not yield significant differences in FC values. Multiple regression did not yield statistical significant differences between the two rsfMRI sessions ( $P>0.12)$.

Compared with healthy controls, patients had several significantly stronger functional correlations in the following FC regions: the anterior insular cortex, posterior insular cortex, central sulcus, posterior cingulate cortex, anterior cingulate cortex and parietal occipital fissure (Table 11.2). Interestingly, most FC regions were significantly different in FC maps from more than one seed region (Table 11.3). For example, the posterior insular cortex showed significantly higher correlation values with the precentral sulcus, the supramarginal gyrus as well as the intraparietal sulcus in PNES patients 
than in controls (average Fisher-Z transformed connectivity values: $0.37 \pm 0.12$ vs 0.25 $\pm 0.10,0.31 \pm 0.15$ vs $0.15 \pm 0.13$ and $0.30 \pm 0.15$ vs $0.17 \pm 0.13$, respectively) .

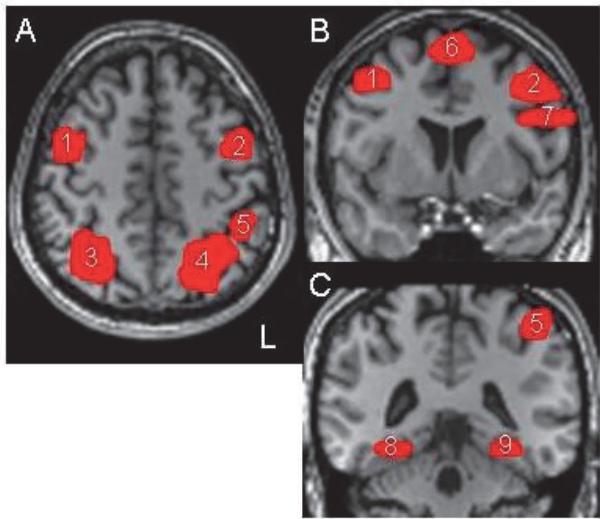

Figure 11.2 Seed regions obtained from the activation maps from the picture encoding $(8,9)$ and Stroop paradigms (1-7), superimposed on a normalized T1-weighted MR image. 1, right inferior frontal gyrus; 2, left inferior frontal gyrus; 3, right intraparietal sulcus; 4, left intraparietal sulcus; 5, left supramarginal gyrus; 6 , anterior cingulate cortex; 7, left precental sulcus; 8 , right parahippocampus; 9, left parahippocampus. MNI coordinate system: $z=+46 \mathrm{~mm}$ for $A$, $y=+6 \mathrm{~mm}$ for $\mathrm{B}$ and $\mathrm{y}=-42 \mathrm{~mm}$ for $\mathrm{C}$. MNI, Montreal Neurological Institute.

Table 11.2 Maximal Z-score and (cluster size) of regions with significant (positive) differences in FC between PNES patients and controls

\begin{tabular}{|c|c|c|c|c|c|c|}
\hline & \multicolumn{6}{|c|}{ FC REGION $(x, y, z)$} \\
\hline & $\begin{array}{c}\text { Anterior } \\
\text { insula (R) } \\
(-38,6,-12)\end{array}$ & $\begin{array}{l}\text { Posterior } \\
\text { insula (R) } \\
(-46,-12,6)\end{array}$ & $\begin{array}{c}\text { Central } \\
\text { sulcus (R) } \\
(-44,-20,30)\end{array}$ & $\begin{array}{l}\text { Posterior } \\
\text { cingulate } \\
\text { gyrus (R) } \\
(-2,-58,46)\end{array}$ & $\begin{array}{l}\text { Anterior } \\
\text { cingulate } \\
\text { gyrus (R) } \\
(-4,40,0)\end{array}$ & $\begin{array}{c}\text { Parietal } \\
\text { occipital } \\
\text { fissure (R) } \\
(-24,-56,14)\end{array}$ \\
\hline \multicolumn{7}{|l|}{ SEED REGION } \\
\hline \multicolumn{7}{|l|}{$(x, y, z)$} \\
\hline Inferior frontal gyrus (L) & & & 4.26 & 4.09 & 4.13 & 5.17 \\
\hline$(44,4,46)$ & & & $(250)$ & (890) & (579) & (723) \\
\hline Precentral sulcus (L) & 4.51 & 5.33 & 4.59 & & 4.28 & 4.49 \\
\hline$(46,6,26)$ & (64) & $(210)$ & (55) & & (789) & (634) \\
\hline Supramarginal gyrus (L) & & 6.20 & & 5.01 & & 6.30 \\
\hline$(46,-40,50)$ & & (512) & & (897) & & (713) \\
\hline Intraparietal sulcus (L) & & 4.86 & 5.29 & 6.90 & 4.40 & 4.99 \\
\hline$(28,-58,50)$ & & (313) & (79) & (795) & $(653)$ & $(806)$ \\
\hline
\end{tabular}

MNI coordinates are given in italics $(x, y, z)$. FC, functional connectivity value; L, left; MNI, Montreal Neurological Institute; PNES, psychogenic non-epileptic seizures; R, right. 

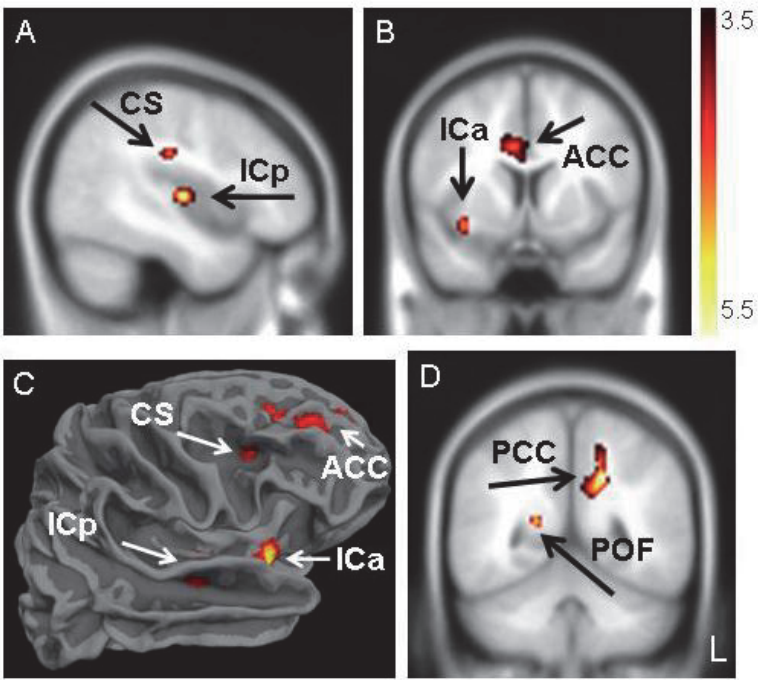

Figure 11.3 Regions of significant higher functional correlation for seed regions left precentral sulcus (A-C) and left inferior frontal gyrus (D) for PNES patients compared with controls during restingstate $\mathrm{fMRI}$, overlaid on an average normalized T1-weighted MR image generated using MRIcro $(A, B, D)$ or projected on an inflated right hemisphere surface map generated in Freesurfer (MGH, Massachusetts, USA) (C). Contrast is visible in the central sulcus (CS), anterior insular cortex (ICa), posterior insular cortex (ICp), anterior cingulate cortex (ACC), posterior cingulate cortex (PCC), and parietal occipital fissure (POF). The bar on the top right indicates the $t$-value of the FC map. MNI coordinate system: $x=-44 \mathrm{~mm}$ for $A, y=+8 \mathrm{~mm}$ for $B$ and $y=50 \mathrm{~mm}$ for D. FC, functional connectivity value; MNI, Montreal Neurological Institute; PNES, psychogenic non-epileptic seizures.

Table 11.3 Spearman's correlation coefficients (over all subjects) between FC values and scores on DISQs and Raven's test.

\begin{tabular}{lllll}
\hline & DES & DIS-Q & SDQ-20 & Raven \\
\hline FC precentral sulcus - anterior insula & $0.47^{*}$ & $0.51^{*}$ & 0.39 & $-0.48^{*}$ \\
FC precentral sulcus - posterior insula & $0.56^{* *}$ & $0.46^{*}$ & 0.42 & $-0.56^{*}$ \\
FC supramarginal gyrus - posterior insula & $0.45^{*}$ & $0.54 *$ & $0.45^{*}$ & -0.38 \\
FC intraparietal sulcus - posterior insula & 0.34 & $0.45^{*}$ & 0.37 & -0.32 \\
FC inferior frontal gyrus - central sulcus & $0.54 * *$ & $0.46^{*}$ & 0.39 & -0.24 \\
FC precentral sulcus - central sulcus & $0.58^{* *}$ & 0.39 & 0.34 & -0.27 \\
FC intraparietal sulcus - central sulcus & $0.64^{* *}$ & $0.53 *$ & $0.43^{*}$ & -0.30 \\
FC supramarginal gyrus - PCC & $0.46^{*}$ & 0.39 & 0.39 & $-0.50^{*}$ \\
FC intraparietal sulcus - PCC & $0.59 *$ & $0.53 *$ & $0.50 *$ & $-0.54 * *$ \\
FC inferior frontal gyrus - ACC & $0.43^{*}$ & 0.39 & 0.40 & -0.41 \\
FC intraparietal sulcus - ACC & $0.54 * *$ & $0.43 *$ & $0.49 *$ & $-0.47^{*}$ \\
FC inferior frontal gyrus - PO fissure & 0.40 & 0.39 & $0.46 *$ & $-0.57^{*}$ \\
FC precentral sulcus - PO fissure & 0.38 & 0.20 & $0.55^{* *}$ & $-0.43^{*}$ \\
FC supramarginal gyrus - PO fissure & $0.52 *$ & $0.46 *$ & $0.63 * *$ & $-0.48 *$ \\
FC intraparietal sulcus - PO fissure & 0.37 & 0.28 & $0.44 *$ & $-0.55^{*}$ \\
\hline
\end{tabular}

* Two-tailed $p$ value is statistically significant at the 0.05 level. ${ }^{* *}$ Two-tailed $p$ value is statistically significant at the 0.01 level. ACC, anterior cingulate cortex; DES, dissociative experiences scale; DISQ, dissociation questionnaire; FC, functional connectivity value (Fisher-Z transformed); PCC, posterior cingulate cortex; PO, parieto-occipital; SDQ, somatic dissociation questionnaire. 
212 Chapter 11

\section{Correlation analysis}

As the two rsfMRI sessions did not differ, FC values were averaged over the two sessions. Significant correlations $(P<0.05)$ were found between the abnormal FC values and DES, DISQ, SDQ and Raven scores (Table 11.3). We would like to highlight two correlations that were identified as related to dissociation, especially relevant from the perspective of PNES: precentral sulcus-anterior insula and precentral sulcusposterior insula. For example, the $\mathrm{FC}$ value of the precentral sulcus-posterior insula correlated significantly with the DES (Spearman's $P=0.56, P=0.007$; Figure 11.4). The FC value of the precentral sulcus-posterior insula connection also negatively correlated significantly with the Raven performance (Spearman's $P=-0.56, P=0.005$ ). A linear regression for this FC value as a dependent variable and DES and Raven test scores as independent variables yielded DES score as significant predictor $(\beta=0.066$, $P=0.046)$. Raven test score was not a significant predictor $(P=0.37)$.

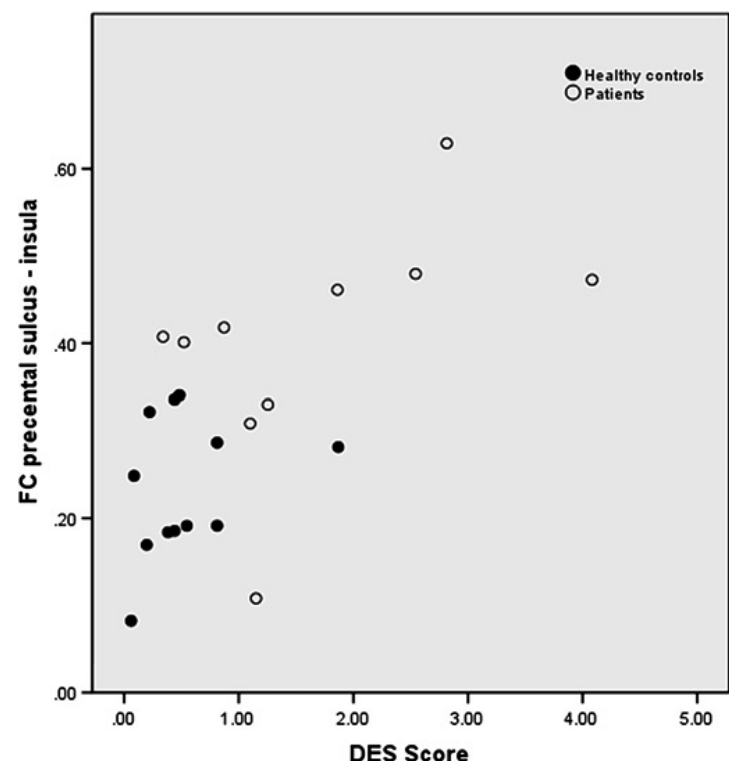

Figure 11.4 Scatter plot of distribution of the left precentral sulcus - right posterior insular FC values and DES scores in the whole population. Healthy controls are depicted by black dots, PNES patients are depicted by white dots (Spearmans' $\rho=0.56, p=0.007$ ). DES, Dissociative Experiences Scale; FC, functional connectivity value; PNES, psychogenic non-epileptic seizures. 


\section{Discussion}

In this study, we investigated resting-state networks in PNES patients and healthy controls to potentially reveal PNES-associated neurophysiology in terms of altered routes of information and emotion processing. First, a significantly higher dissociation tendency was observed in patients with PNES. Furthermore, an abnormal functional correlation was observed between the precentral sulcus, which resides in the motor cortex controlling voluntary muscle movement, and the insula, which is part of the limbic system and involved with emotion regulation, visceral sensory perception and self-awareness ${ }^{35}$. Additionally, significantly stronger correlations were found between the parietal lobe, which is involved in processing of sensory information and subsequent action organization ${ }^{36}$, and the insula. Moreover, a positive relationship between FC values and dissociation scores was found.

\section{Dissociation and PNES}

Our results reconfirm that patients with PNES have in general a higher tendency for dissociation than healthy individuals. This is a general effect concerning both psychological and somatoform dissociation ${ }^{14,28} 37$.

\section{Dissociation and fMRI}

The functional connections of the ACC are of interest as the ACC is an area that has been identified to be involved in dissociation and hypnosis ${ }^{38}$. The FC value of the IFG with ACC was significantly higher in the PNES group. Furthermore, the strength of this connection was significantly related to DES scores. This might have clinical_relevance in PNES, as this connection has been associated with cognitive integration and dissociation ${ }^{27}$.

Outside the domain of PNES, previous studies have related dissociation with FMRI outcomes. For example, Veltman et al. ${ }^{39}$ have demonstrated increased activation of the dorsolateral and ventrolateral prefrontal cortices, parietal cortex and supplementary motor area during working memory tasks in healthy, high-dissociative participants. Similarly, Elzinga et al. ${ }^{40}$ reported increased activation in anterior, dorsolateral and ventrolateral prefrontal cortices and parietal cortex during a working memory task in patients with dissociative disorder. These results suggest that dissociation is associated with an altered working-memory network.

In contrast, the results of the current study do not reveal differences in activation maps of the encoding task (working memory), or in FC based on seeds relevant to memory (hippocampi), between healthy controls and highly dissociative PNES patients. Also, although the picture encoding task employed emotional stimuli, the activation was related to processes of working memory instead of suggestibility. However, we did find abnormalities in FC in highly dissociative patients with PNES 
$214 \mid$ Chapter 11

based on seed regions obtained by the Stroop task. Previous studies in patients with PNES did indicate only a modest working memory deficiency ${ }^{41}$. We propose that the PNES pathology affects the neurobiology of executive control, which underlies dissociation, rather than the networks involved in memory processes.

\section{Dissociation and cognition in PNES}

Subjects with lower performance on the Raven's test scored significantly higher on the dissociation scales, which is in accordance with previous literature ${ }^{42}$. Dissociation might exert a perturbing action on individuals, which can negatively influence cognitive performance.

The FC values also correlated significantly with global cognitive functioning scores, as assessed using the Ravens' test. Previously, we showed in patients with chronic epilepsy that FC values, as assessed with fMRI, were strongly correlated with intelligence (i.e., performance on word fluency and text-reading tests). We hypothesized that a reduced performance was related to a reduced synchronization of activity in the brain ${ }^{43}$. In the current study, we observed the opposite effect, namely, a negative correlation of FC values with global cognitive performance. However, a linear regression analysis showed that global cognitive performance (i.e., intelligence) was not a significant predictor for FC values, whereas dissociation was. This emphasizes that dissociation, and not intelligence, is a key mechanism underlying abnormal FC values as observed in patients with PNES (Figure 11.4).

\section{Conversion disorders and fMRI}

It has been suggested that PNES share a pathophysiological mechanism with other conversion disorders ${ }^{4,18}$. An fMRI study in patients with motor conversion revealed that patients have a higher FC between the amygdala and the supplementary motor area during processing of positive and negative emotional stimuli ${ }^{16}$. It was suggested that this abnormal FC hints at a greater influence of limbic regions over motor preparatory regions ${ }^{18}$. Similarly, in dissociative amnesia, the relationship between memory-related areas and executive control areas may be affected, ${ }^{18,44}$ which also hints at a 'faulty' connection between executive control and areas specifically affected by dissociation.

As we found in PNES, higher FC values between regions involved in emotion and selfperception (insula) and motor preparation (precentral and the sulcus) between these two regions might underlie the pathophysiology for conversion disorders in general, including $\mathrm{PNES}^{4}$. The existence of such an unstable cognitive-emotional-motor 'hyperlink' is further supported by the fact that PNES is often accompanied by many diffuse psychological, psychiatric and somatoform symptoms ${ }^{18,45}$. In addition to the connection pair 'insula-precentral sulcus', we also identified other combinations of seed regions and FC regions (originating in the frontal, parietal and limbic cortices) 
with higher FC values for patients. The presence of higher FC in these regions strengthens the assumption that the whole network involved in sensory processing, executive control and emotion regulation in patients with PNES is abnormal. Figure 11.5 displays a schematic representation of the underlying dysfunctioning in this network in patients with PNES.

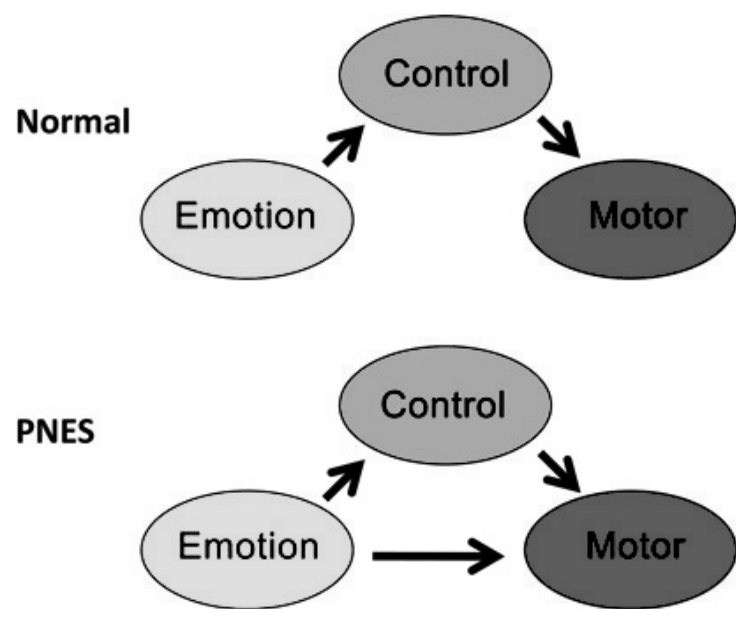

Figure 11.5 Schematic overview of the circuitry involved in cognitive-emotional executive control. In this study, we found significantly higher functional connectivity strengths between regions involved in emotion (insula) and motor planning (precentral sulcus) for patients with PNES. It appears that healthy controls can control their motor functions without strong influence of emotions, whereas in patients with PNES emotions can bypass executive control and cause involuntary movement. PNES, psychogenic non-epileptic seizures.

\section{Clinical implications}

Demonstration of a relationship between dissociation and deficient neuronal processing in PNES has substantial implications for the understanding of the aetiology. Dissociation is one of the mechanisms through which an emotional state can influence executive control, resulting in a seizure-like episode ${ }^{17,18}$ (Figure 11.5). Furthermore, the high FC identified in the current study has potential for the use of functional imaging to aid the differential diagnosis between PNES and epilepsy.

More knowledge of PNES aetiology is necessary for the clinical management of PNES diagnosis and treatment ${ }^{4}$. As such, a higher tendency to dissociate, associated with the hyperlink between regions involved in emotion (insula) and motor preparation (precentral sulcus), may be seen as an increased vulnerability to develop PNES. Moreover, identifying a neurobiological substrate of dissociation in PNES changes the concept of psychogenic seizures into being a biopsychological phenomenon, where a 
$216 \mid$ Chapter 11

psychogenic aetiology collides with a specific neurological vulnerability. This has implications for the development and evaluation of treatment, and may eventually improve the clinical management of PNES diagnosis. Moreover, it might aid the patient in accepting diagnosis of PNES. However, it is difficult to consider network abnormalities purely as a predisposition factor, as a diseased network connectivity could either be the cause or the consequence of dissociation and PNES.

\section{Study limitations and future considerations}

This study had a limited number of patients. However, even in this small population, statistically significant deviations were demonstrated. These findings should be validated in larger studies, to be able to identify the direction of causality between abnormalities in FC and dissociation and PNES.

Another limitation is that the effect of PNES cannot be disentangled from the effect of dissociation. All of our patients had both PNES and a high dissociation score. To resolve this problem, future studies should include a control group of PNES patients who are not highly dissociative and/or a control group of healthy normal subjects with a high dissociation.

Furthermore, it is not known whether FC abnormalities are accompanied by microstructural (white matter) abnormalities.

\section{Conclusion}

The abnormal strong FC found in patients with PNES hints at an underlying psychoform and somatoform dissociation mechanism where emotion can influence executive control, resulting in altered motor function (e.g., seizure-like episodes). Future studies should clarify the exact contribution and interaction of the process of dissociation and network disturbances in PNES. 


\section{References}

1. Bodde NMG, Brooks JL, Baker GA, Boon PAJM, Hendriksen JGM, Aldenkamp AP. Psychogenic nonepileptic seizures - Diagnostic issues: a critical review. Clin Neurol Neurosurg 2009;111:1-9.

2. Leis AA, Ross MA, Summers AK. Psychogenic seizures: ictal characteristics and diagnostic pitfalls. Neurology 1992;42:95-9.

3. Martin RC, Gilliam FG, Kilgore M, Faught E, Kuzniecky R. Improved health care resource utilization following video-EEG-confirmed diagnosis of nonepileptic psychogenic seizures. Seizure 1998;7: 385-90.

4. Devinsky O, Gazzola D, Lafrance WC Jr. Differentiating between nonepileptic and epileptic seizures. Nat Rev Neurol 2011;7:210-20.

5. Bodde NM, Brooks JL, Baker GA, Boon PA, Hendriksen JG, Mulder OG, Aldenkamp AP. Psychogenic non-epileptic seizures - definition, etiology, treatment and prognostic issues: a critical review. Seizure 2009;18:543-53.

6. Guz H, Doganay Z, Ozkan A, Colak E, Tomac A, Sarisoy G. Conversion and somatization disorders: dissociative symptoms and other characteristics. J Psychosom Res 2004;56:287-91.

7. Spitzer C, Spelsberg B, Grabe H-J, Mundt B, Freyberger HJ. Dissociative experiences and psychopathology in conversion disorders. J Psychosom Res 1999;46:291-4.

8. Maaranen $\mathrm{P}$, Tanskanen A, Haatainen $\mathrm{K}$, et al. The relationship between psychological and somatoform dissociation in the general population. J Nerv Ment Dis 2005;193:690-2.

9. Näring G, Nijenhuis ER. Relationships between self-reported potentially traumatizing events, psychoform and somatoform dissociation, and absorption, in two non-clinical populations. Aust $\mathrm{N} Z \mathrm{~J}$ psychiatry 2005;39:982-8.

10. Kihlstrom JF. Dissociations and dissociation theory in hypnosis: comment on Kirsch and Lynn (1998) Psychol Bull 1998;123:186-91.

11. Nijenhuis ER, van der Hart O. Dissociation in trauma: a new definition and comparison with previous formulations. J Trauma Dissociation 2011;12:416-45.

12. Goldstein LH, Mellers JDC. Ictal symptoms of anxiety, avoidance behaviour, and dissociation in patients with dissociative seizures. J Neurol Neurosurg Psychiatry 2006;77:616-21.

13. Dienes Z, Brown E, Hutton S, Kirsch I, Mazzoni G, Wright DB. Hypnotic suggestibility, cognitive inhibition, and dissociation. Conscious Cogn 2009;18:837-47.

14. Bowman ES, Markand ON. Psychodynamics and psychiatric diagnoses of pseudoseizure subjects. Am J Psychiatry 1996;153:57-63.

15. Brown RJ, Cardena E, Nijenhuis E, Sar V, van der Hart O. Should conversion disorder be reclassified as a dissociative disorder in DSM V? Psychosomatics 2007;48:369-78.

16. Voon V, Brezing C, Gallea C, et al. Emotional stimuli and motor conversion disorder. Brain 2010;133: 1526-36.

17. Van der Kruijs SJM, Bodde NMG, Aldenkamp, AP. Psychophysiological biomarkers of dissociation in psychogenic non-epileptic seizures. Acta Neurol Belg 2011;111:99-103.

18. Baslet G. Psychogenic non-epileptic seizures: a model of their pathogenic mechanism. Seizure 2011; 20:1-13.

19. Abubakr A, Kablinger A, Caldito G. Psychogenic seizures: clinical features and psychological analysis. Epilepsy Behav 2003;4:241-5.

20. Sno HN. Meetinstrumenten bij dissociatieve stoornissen. Tijdschrift voor psychiatrie 2004;46:697-700

21. Raven J, Raven JC, Court JH. Manual for Raven's Progressive Matrices and Vocabulary Scales. Court JH, San Antonio, 2003.

22. Leonard KN, Telch MJ, Harrington PJ. Dissociation in the laboratory: a comparison of strategies. Behav Res Ther 1999;37:49-61.

23. Castillo RJ. Depersonalization and meditation. Psychiatry 1990;53:158-68.

24. Cerezuela GP, Tejero P, Chóliz M, Chisvert M, Monteagudo MJ. Wertheim's hypothesis on `highway hypnosis': empirical evidence from a study on motorway and conventional road driving. Accid Anal Prev 2004;36:1045-54.

25. Vaitl D, Birbaumer N, Gruzelier J, et al. Psychobiology of altered states of consciousness. Psychol Bull 2005;131:98-127. 
218 Chapter 11

26. Vlooswijk MC, Jansen JF, Jeukens CR, Majoie HJ, Hofman PA, De Krom MC, Aldenkamp AP, Backes WH. Memory processes and prefrontal network dysfunction in cryptogenic epilepsy. Epilepsia 2011; 52:1467-75.

27. Egner T, Jamieson G, Gruzelier J. Hypnosis decouples cognitive control from conflict monitoring processes of the frontal lobe. Neuroimage 2005;27:969-78.

28. Kuyk J, Spinhoven P, van Emde Boas W, van Dyck R. Dissociation in temporal lobe epilepsy and pseudo-epileptic seizure patients. J Nerv Ment Dis 1999;187:713-20.

29. Stroop JR. Studies of interference in serial verbal reactions. J Exper Psychol 1935;18:643-62.

30. Jansen JFA, Vlooswijk MCG, De Baets MH, et al. Cognitive fMRI and soluble telencephalin assessment in patients with localization-related epilepsy. Acta Neurol Scand 2008;118:232-9.

31. Waites AB, Briellmann RS, Saling MM, Abbott DF, Jackson GD. Functional connectivity networks are disrupted in left temporal lobe epilepsy. Ann Neurol 2006;59:335-43.

32. Rorden C, Brett M. Stereotaxic display of brain lesions. Behav Neurol 2000;12:191-200.

33. Langers DRM, Jansen JFA, Backes $\mathrm{WH}$. Enhanced signal detection in neuroimaging by means of regional control of the global false discovery rate. Neuroimage 2007;38:43-56.

34. Mead LA, Mayer AR, Bobholz JA, et al. Neural basis of the Stroop interference task: Response competition or selective attention? J Int Neuropsychol Soc 2002;8:735-42.

35. Craig AD. How do you feel - now? The anterior insula and human awareness. Nat Rev Neurosci 2009; 10:59-70.

36. Fogassi L, Ferrari PF, Gesierich B, Rozzi S, Chersi F, Rizzolatti G. Parietal Lobe: From Action Organization to Intention Understanding. In, 2005: 662-7.

37. Fleisher W, Staley D, Krawetz P, Pillay N, Arnett JL, Maher J. Comparative study of trauma-related phenomena in subjects with pseudoseizures and subjects with epilepsy. Am J Psychiatry 2002;159: 660-3.

38. Lanius RA, Bluhm R, Lanius U, Pain C. A review of neuroimaging studies in PTSD: heterogeneity of response to symptom provocation. J Psychiatr Res 2006;40:709-29.

39. Veltman DJ, de Ruiter MB, Rombouts SA, et al. Neurophysiological correlates of increased verbal working memory in high-dissociative participants: a functional MRI study. Psychol Med 2005;35: 175-85.

40. Elzinga BM, Ardon AM, Heijnis MK, De Ruiter MB, Van Dyck R, Veltman DJ. Neural correlates of enhanced working-memory performance in dissociative disorder: a functional MRI study. Psychol Med 2007;37:235-45

41. Strutt AM, Hill SW, Scott BM, Uber-Zak L, Fogel TG. A comprehensive neuropsychological profile of women with psychogenic nonepileptic seizures. Epilepsy Behav 2011;20:24-8.

42. Gudjonsson GH. Suggestibility, intelligence, memory recall and personality: an experimental study. $\mathrm{Br}$ J Psychiatry 1983;142:35-7.

43. Vlooswijk MC, Jansen JF, Majoie HJ, et al. Functional connectivity and language impairment in cryptogenic localization-related epilepsy. Neurology 2010;75:395-402.

44. Kikuchi $\mathrm{H}$, Fujii $\mathrm{T}$, Abe $\mathrm{N}$, et al. Memory repression: brain mechanisms underlying dissociative amnesia. J Cogn Neurosci 2010;22:602-13.

45. Landgrebe M, Barta W, Rosengarth K, et al. Neuronal correlates of symptom formation in functional somatic syndromes: a fMRI study. Neuroimage 2008;41:1336-44. 


\section{Chapter 12}

General discussion 
220 Chapter 12 


\section{General discussion}

The quest towards a better understanding of the group of patients with PNES, specifically focussing on psychogenic aetiology and subgroups, has provided some answers, but also raised new questions. The key issue is whether PNES must be viewed as a separate disorder or, whether PNES are part of a continuum with other functional neurological symptoms (FNS) or even with the wider, related domain of functional somatic syndromes and symptoms (FSSS). The study findings in this thesis allow attempting answering some of the recurrent questions about PNES, focussing also on the relevance for clinical practice.

\section{1) Is the diagnosis 'psychogenic non-epileptic seizures' a valid diagnosis?}

There is consensus in literature that the differential diagnosis PNES versus epilepsy has greatly improved during the last thirty years and that video EEG is the golden standard (chapter 2 and 3). However, diagnosing 'non epilepsy' remains a clinical diagnosis and not in all cases video EEG is possible, for example due to infrequent seizures. PNES are - similar to epileptic seizures - paroxysmal events that may evade observation and recording. Also, seizures detected with video EEG in the clinic may not be typical for the seizures occurring in daily life. The patient group with PNES can be diagnostic non-compliant and many patients will not have seizures when they are in the EEG recording unit. As yet, there are no real positive ictal features suggested to be pathognomonic for PNES. This together implies that there may be no $100 \%$ guarantee for a PNES diagnosis. The same uncertainty also exists for other functional neurological symptoms (FNS). However, using advanced techniques in combination with the experience of a specialized epileptologist improves the accuracy of the diagnosis. An important misunderstanding, that often confuses the diagnosis, is the interpretation of results of psychological assessment. Once the diagnosis of PNES is firmly established, such assessment may provide insights in the specific psychogenic aetiology. This cannot be reversed; the existence of psychogenic factors (i.e. personality problems, emotional distress, a psychotrauma in the history) cannot be interpreted as evidence for PNES. Finding psychological or psychiatric problems does not eliminate having (comorbid) epilepsy.

The search for better techniques to diagnose PNES continues. Recent research approaching possible bioemotional factors (such as heart-rate variability) and neurobiological substrates for mechanisms involved in PNES (such as dissociation) may be useful for further improvement of the validity of the diagnosis. The findings of the fMRI study in this thesis (chapter 11) and other recent work by our group ${ }^{1}$ show that changes in brain activation and neuronal organisation may predispose to dissociation, a mechanism involved in the development of PNES. The abnormal, strong 
functional connectivity found in PNES patients provides a neurophysiological correlate for the underlying dissociation mechanism where emotion can influence executive control, resulting in altered motor function (e.g. seizure-like episodes). Heart-rate variability EEG and (functional) MRI seem to be sensitive methods to detect physiological changes related to dissociation and dissociative disorders such as FNS, and can possibly provide more information about the triggering factors involved. The use of such measures could eventually provide biomarkers for earlier identification of patients at risk and appropriate treatment of dissociative conditions ${ }^{1}$. However, up till now it is difficult to position psychophysiological abnormalities because they may be both the cause and the consequence of PNES.

In clinical practice it may be helpful to focus on possible subgroups in the differential diagnostic process. In some subgroups of PNES the diagnosis is more certain than in other groups, in which the neurologist has to work with a 'probability diagnosis'. This is in line with the classification of many other neurological disorders. Especially in patients with a complicated combined (frontal) epilepsy and PNES, distinguishing the seizures can be very difficult. In frontal epilepsy the lack of interictal epileptiform EEG activity may result in false negative conclusions. These difficult to diagnose groups of patients are often excluded from research. Pillai en Haut ${ }^{2}$ recently focused specifically on the group of patients with both diagnoses: PNES and epilepsy. They found that frontal lobe epilepsy was more common in patients with epilepsy and concomitant PNES than in patients with epilepsy alone. The results suggest that at least in the subgroup of comorbid epilepsy patients, PNES symptoms may be often associated with frontal seizures.

In general there is consensus in research on FNS that the risk to underdiagnose is probably larger than to overdiagnose. For clinicians, the potential misdiagnosis of an organic disorder is often a concern leading to reluctance in making a FNS diagnosis ${ }^{3}$. However, diagnostic accuracy is of great importance for therapeutic management ${ }^{4,5}$. A systematic review found that the frequency of misdiagnosis had been consistent and approximately $4 \%$ since $1970^{6}$. In the differential diagnosis epilepsy versus PNES overinterpretation of the EEG is an important reason why seizures are misdiagnosed as epilepsy so commonly ${ }^{5,7}$.

\section{2) How are PNES defined?}

Before the term PNES was more generally used, psychogenic seizures were labeled in relation to aetiological constructs such as conversion disorder and specifically hysteria. Both labels have a long history, even back to the ancient Greek. In the $20^{\text {th }}$ century psychodynamic visions, especially the psychoanalytic theory of Freud, were of great influence ${ }^{8}$. Freud considered PNES as a 'hysterical fit', being the expression of normal sexual desires, repressed from conscious awareness due to the unbearable 
affects with which they had become associated. The phenomenological similarity of many patients' seizures to movements common in the context of the sexual act was interpreted as evidence that the seizure was the symbolic expression of a repressed unconscious sexual conflict. After the abolition of the term 'hysterical neurosis' from the current diagnostic systems, PNES is no longer seen as related to one discrete disorder ('hysteria'). The term 'hysterical seizures' vanished from the literature, although a survey among British neurologists showed that in 1991 the term hysteria was still used in the 'informal contacts' (chapter 2).

In subsequent years the most common label for PNES used in epilepsy centres was "no epilepsy" ("pseudo seizures", "non epileptic attack disorder"). Nowadays, it is known that patients are not helped when presented with a "non-disease" or a "pseudo disease". The more neutral term 'psychogenic non-epileptic seizures' (PNES) is mostly used, avoiding the label pseudo, that may suggest that patients simulate the seizures. However, the term PNES is only used in the field of neurology, especially by neurologists involved in diagnosing epilepsy in general hospitals or specialized epilepsy centres. At least in the Netherlands a diagnosis of PNES is not well known in the broader context of medical practice (such as by general practitioners) or in mental health institutes. Also, the PNES definition clearly describes the somatic appearance of the seizures and the exclusion of other organic causes for the seizures. The underlying psychological or psychiatric problems are less well described, whereas patients with PNES are known to comprise a very heterogeneous group. The central question is whether the underlying pathology can be described in classification systems used in mental health care, such as the DSM-IV or the ICD 10, or that PNES are a unique and separate disorder or symptom unclassifiable in existing systems? Is PNES similar to other FNS or even the broader concept of FSSS, although the presentation of the symptoms is different, or is PNES a separate disorder?

In this thesis we found indications for both similarities and differences with related disorders described in the classification systems for mental health care. The study on personality factors using the MMPI-2 (chapter 7) showed no substantial difference in the personality profile of patients with PNES and patients with insomnia. There were relative differences in the extent of somatization and externalization; PNES patients seemed most similar to patients with a conversion disorder in general. This indicated that, seen from the personality profile, PNES do not substitute a unique disorder, but are part of the family of FSSS. The study on patient characteristics in relation to diagnostic delay (chapter 8) showed similarities between patients with PNES and patients with (different types of) a somatoform disorder such as classified in the DSMIV or patients described as having "medically unexplained physical symptoms". The majority of the patients with PNES had a patient history with many medical and diffuse psychological symptoms not limited to neurological disorders. It was hypothezid that especially the occurrence of a potential somatization disorder in PNES might be underestimated [see also ${ }^{9}$ ]. In the study on subgroups (chapter 9) a 
psychotrauma subgroup was identified with dissociative disorders, indicating similarity with the dissociation disorder (ICD10) and/or with a (subgroup of) post traumatic stress disorder (PTSD). The other two subgroups described in chapter 9 showed more similarity with FSSS (the high vulnerability somatising subgroup) and possible personality disorders (the high vulnerability sensitive personality problem subgroup). Describing a general profile seemed to conceal specific subgroups.

The results show, in line with other research, that there may be no term that fits all. PNES seem to be a general term concealing very diverse forms of underlying psychological and psychiatric problems. Characteristics found in some subgroups classify these in the continuum of FSN, FSSS and PTSD. In the forthcoming editions of ICD and DSM there will be revisions in this domain ${ }^{3}$, reflecting recent research on this area.

However, the type of symptom is of course important and different symptoms may have different impacts for both the patients and the family network. Having sleeping problems has probably a less profound impact on the social environment than seeing a PNES patient falling down at work. Not being able to walk because of conversion paralysis and arriving in a wheelchair has another impact than having sudden, unexpected seizures with the risk of falling down in dangerous places. The impact of having PNES in daily life is probably more similar to having epilepsy. Although similarities exist between PNES and other disorders in mental health care with respect to the underlying psychopathology, PNES also has unique characteristics due to the type of symptom, i.e. seizures. Furthermore, some specific elements in PNES are, as yet, not well understood. For example, the triggering factor, formulated in the theoretical model, to explain what triggers a seizure at a specific moment remains poorly understood. There may be a challenge for neurobiological research in here as mentioned before. There are indications that changing the "psychogenic" into "psychophysiological" seizures may be more suitable for some subgroups of patients with PNES.

\section{3) Treatment of PNES}

\section{a) What is the role for epilepsy centres or specialized hospitals?}

Many patients with PNES describe a medical history of having had epilepsy or having to deal with contradictory and/or unclear diagnoses, often indirectly sensing that some specialists were doubting an organic cause for the seizures. At the same time neurologists often consider PNES (and in general FNS) patients as "the most difficult to help ${ }^{\prime \prime}$. Since epilepsy centres have the facilities and expertise for the (complicated) medical PNES diagnosis, there seem to be a natural role for them in the subsequent diagnosis, referral and short-term treatment of PNES. 
In this thesis two consecutive phases are described in the diagnostic process of PNES. These phases include carefully timed multidisciplinary involvement, although not always simultaneously (chapter 3). In the first phase, the medical diagnosis "no epilepsy" must be established, including the exclusion of other organic factors. This is followed by a first intervention consisting of careful explaining the PNES diagnosis to the patient and her/his family. There is an important role here for the neurologist/ epileptologist (chapter 3). For a small group of patients this is sufficient to reduce seizure frequency or even to become seizure free (chapter 4). Clinical practice shows the importance of engaging PNES patients and their families in the diagnostic and treatment process as soon as possible. Without cooperation of the PNES patient, the diagnostic process can become very difficult; for example, the patient has no seizures during the clinical admission. This is also essential when antiepileptic medication is withdrawn. Also, timing of interventions is important. During the medical diagnosis a relatively short diagnostic delay is preferable. Diagnostic delay is still approximately about 6 years, although there are indications that there is an "active high speed referral group", who is referred within 2 years after seizure onset (chapter 8). However, patients also need time to get used to the idea of possible psychogenic factors playing a role in their seizures. Alper ${ }^{10}$ warned already in 1994 for a too early emphasis on pychogenic factors. In his experience it is far better that the PNES patient is told they do not have epilepsy by the neurologist than to be informed of psychogenesis by the psychologist in this first stage (chapter 3 ).

The second phase aims at establishing a positive diagnosis in which the underlying psychological and social factors are evaluated that can be used for treatment. This phase often involves thorough clinical (neuro)psychological assessment. Not only the first phase can be challenging, this second phase may be complicated as well. Clinical practice shows that this second phase cannot be entered without the consent of the patient to cooperate in the exploration of psychogenic factors. For many PNES patients this agreement can be difficult; they may need time to think this over. In line with the conversion reaction, most PNES patients do not experience a link between the medical symptoms and underlying emotional problems; they seem to be (partly) disconnected from their emotional experience. They may eventually accept the PNES diagnosis at a rational level, but probably feel emotional ambivalent. It may be hard to integrate the diagnosis in their self-image. Common statements in clinical practice are "this is not like me, I am a very stable and straightforward person, I'm not a stressful person".

After this second phase treatment indications can be determined. Some PNES patients can be directly referred for psychological assessment and treatment in mental health care. However, many patients need the medical environment and specific seizure experience of an epilepsy centre in this second phase. In this stage most patients still have to cope with many seizures which have an impact on their daily life and their 
social environment. Although symptom reduction is potentially possible after a clear diagnosis, depending on the complexity of the underlying pathology, seizures will continue during the process of assessment and start of subsequent therapy. Reducing the impact of the seizures on daily life by interventions aimed at school, work and/or the family is also important to break a potential vicious circle of prolongation factors. Other disciplines such as a social worker or educational specialist may be involved in coping with the symptoms on a practical level as well. Furthermore, many PNES patients need recognition for the helplessness they experience of not being able to control the seizures. They may have negative experiences in their social environment, for example when dealing with people that think they simulate. In focussing on symptom treatment, coping with seizures, there are many similarities in dealing with epilepsy in daily life.

In the Netherlands there seem to be different perspectives on the role of epilepsy centres in PNES. Perspectives range from no function at all (patients are confronted with the diagnosis "no epilepsy" and send back to their referrers) to a limited function with brief interventions after the PNES diagnosis to long-term inpatient treatment. Research consistently shows that presenting patients with the negative diagnosis of "no epilepsy" is not enough to guarantee consent with treatment. In fact, patients can experience this negative diagnosis as a denial of their symptoms (chapter 3, chapter 8).

On the other hand, long periods of inpatient treatments in the epilepsy centre may keep the patient in medical care too long, unintentionally confirming the medical attributions of the patients. Furthermore, the underlying psychogenic problems are so diverse that an epilepsy centre does not have all the necessary facilities available in specialized mental health care institutes. During the referral process for subsequent psychological treatment, neurologists face a number of obstacles [see ${ }^{11}$ ]. Access of treatment often is restricted in many areas and there may be long waiting periods or intervals between treatment sessions. Also, patients fail to engage, because they do not understand the relevance of psychological treatment for symptoms they perceive as physical. Referring PNES patients to mental health services too soon can have a high risk of drop out for further treatment and starting a new loop of searching for medical help (medical shopping) or even symptom shifts ${ }^{11-14}$.

Finding an optimized stepped care management pathway for patients with PNES is essential. In this way both the unique aspects of PNES are taken into account as well as the similarities with other FNS and FSSS. In this pathway the specific expertise of an epilepsy centre can be used in the diagnosis of PNES and the first management steps. PNES patients can be helped to pursue for treatment of the underlying pathology by referring them to mental health care institutes in their own social environment. Especially for the subgroup of patients with combined PNES and epilepsy, the role of the epilepsy centre may be more extended. Also, there may be a more extended consultancy role during the follow up treatment elsewhere, for example, when seizure 
type changes and/or there is a renewed uncertainty about a possible somatic cause of the seizures. Quick consultation may prevent unnecessary worries for the patient or extensive new medical investigations, diverting attention of the psychological treatment.

Recent research of Baxter et al. ${ }^{11}$ showed that even in this (more or less) intermediant function it is important to recognize subgroups in the epilepsy centre to carefully tailor the intervention package to individual needs. Also, cooperation between different professionals is important. In the Dutch system having a good working relationship with the general practitioner is specifically important. The general practitioner can help to motivate for follow up treatment and can help to prevent redundant medical investigations after symptom substitution or symptom shift ${ }^{15}$.

b) What is the current status of adequate follow-up treatment of the underlying pathology?

Since the underlying pathology of PNES is very diverse there is no standard psychological treatment for all PNES patients. Treatment interventions range from individual psychotherapy, hypnosis, to intensive multidisciplinary grouppsychotherapy. The Cochrane review in this thesis (chapter 5) showed there is no evidence-based support for the use of any specific treatment. However, there is consensus that variations of cognitive behavioral therapy showed to be the preferred type of treatment. In clinical practice this therapeutic background seems particularly important during the first phases of intervention. The associated directive and guiding attitude fits the needs of many patients with FNS or FSSS, often still in doubt about possible organic causes for their seizures and seeking advice. The exact choice of subsequent treatment should be based on individual differences and subgroups. In this thesis a theoretical model is proposed, which can be used for treatment indications. PNES seems to be a symptom of different underlying aetiological factors with specific accents in the model. Treatment is preferably focused on the bottom of the model, the underlying aetiology. The study on subgroups found for example the psychotrauma subgroup, having a clear underlying aetiological factor such as formulated in the diagnostic model. Subsequent treatment would be trauma processing. However, not everyone experiencing a trauma, develops seizures; other factors are important as well. Not all factors may be open for treatment, even when the underlying aetiology is clear. For many patients with PNES treatment in a first phase is focused on stress in daily life and extending coping strategies. Testa et al. ${ }^{16}$ recently confirmed that PNES patients have elevated levels of perceived distress and fewer action strategies to reduce the impact of a stressor.

In order for a referral from the epilepsy centre to a mental health institute to be effective, active commitment of the patient is essential. Clinical practice shows the importance of discussing treatment alternatives with PNES patients and strengthen 
the importance of making an own decision [see also ${ }^{15}$ ]. The experienced uncontrollability of the seizures is often one of the most difficult aspects for patients to handle. For some patients this may be related to major life events, in which they were not able to control or change their situation ${ }^{17}$. Giving patients with PNES control over alternatives, can help them direct their lives and take responsibility for it. For some patients clinical practice has shown this means choosing 'to learn to live with seizures' and make a well-considered decision to no longer engage in further treatment of underlying factors. This is in line with the consensus that effect measures of subsequent treatment should not only be seizure reduction, but also having less somatic symptoms in general, less medical consumption, improvement of the underlying pathology and quality of life.

In general, treatment settings and professionals with experience in and affinity with the treatment of FNS or FSSS are preferable for subsequent treatment. They can recognize and cope with recurring somatising tendencies, including the temporary return of PNES, which is 'normal' during the treatment process, but can interfere with on-going treatment if not handled properly. It is becoming increasingly clear that networks are necessary to form pathways for patients with FSSS. In the Netherlands there is an initiative to integrate both treatment and research from the perspective of NUMS (Network Unexplained Medical Symptoms, in Dutch NOLK). In the United Kingdom there was an initiative to discuss FNS within the country.

\section{C) What do the findings mean for future research?}

The major attention of scientific research has shifted from a focus on the differential diagnosis of PNES from epilepsy to a focus on finding subgroups with regard to the underlying psychological aetiology and treatment. It is widely recognized that evidence-based treatment research is very necessary, but difficult to accomplish. There are several complications for treatment research.

Firstly, most PNES research is initiated from a medical perspective, especially in tertiary epilepsy centres. Generalization of the findings may be limited to a tertiarycare population $^{18}$. Secondly, many PNES patients are eventually referred to other institutes and professionals for subsequent (psychological) treatment. As yet, treatment research focuses on the effect of interventions shortly after the PNES diagnosis in the epilepsy centres. For example, in 2010 Goldstein and colleges ${ }^{19}$ published a pilot study with class III evidence of the additional effect of cognitive behavioral therapy compared to standard care. Baxter et al. (2012) also showed the results of a brief intervention pathway after the diagnosis of PNES. More fundamental treatment research on PNES should involve long term follow up research after finishing additional treatment (see also chapter 4). Only when the underlying pathology is treated, the long term effects on PNES and psychological and social 
wellbeing will be clear. A long term follow up period is also necessary to prevent an exclusive focus on PNES reduction, whereas there may be symptom substitution or symptom shift to other disorders in the continuum of FNS and FSSS. Studying short term interventions may only illustrate a Pyrrhus victory, since the patient has no more seizures, but has developed other symptoms for which medical help is already sought in another circuit. For research this means collaboration with different institutes involved in the management pathway, such as NOLK.

Since subgroup analysis is considered important, criteria are needed to distinguish these subgroups and to replicate treatment-studies internationally. As yet comparing the results of different subgroup studies is difficult, because of the different psychological variables involved. Definition of terms can also be a problems. Terms such as "somatization" and "dissociation" can be too comprehensive to operationalize. Psychological tests are not always internationally used and comparable and are mostly assessed through self-report. In this thesis both patient characteristics and psychological variables were used to explore possible PNES subgroups. Seizure characteristics were also tested as a classification criterion, focusing on differences between major motor manifestations of PNES versus unresponsiveness. In line with other research on PNES semiology (chapter 9$)^{20}$ this was less useful.

Ideally, further treatment research should focus on well-designed randomized clinical trials using stratification techniques to identify the most suitable treatment for subgroups in the PNES population. To further entangle the continuum of PNES, FNS and FSSS, preferably control groups should be used with patients with other functional neurological and/or somatic symptoms in addition to "normal" controls. The results of the MMPI-2 study (chapter 7) suggest that patients with other conversion disorders might be an interesting first control group, having much similarities with PNES. Also, for subgroup research a comparison of the patients of the 'psychotrauma subgroup' with patients with an PTSD is recommendable.

Finally, the patient inclusion requires attention, especially the common exclusion of patients with comorbid epilepsy and/or patients in which the PNES diagnosis is very plausible but difficult to diagnose more firmly. Maybe subgroups of these types of patients should be involved in future research as well. Interesting for the combined group of epilepsy and PNES patients is research focusing on a possible connection between stress and epilepsy. Still, treatment research remains clinical work with the methodological and ethical complications. Most research is retrospectively and for convenience epilepsy patients are easily used as a control group. It is becoming increasingly clear that randomised clinical treatment trials regarding PNES as a unique disorder are not possible neither very helpful. Also, the efficacy of treatment needs a long follow up period from the scientific point of view, but there may ethical and 
230 Chapter 12

treatment considerations not to contact PNES patients after they were referred to another institute, since this might interfere with their on-going treatment process. 


\section{References}

1. Van der Kruijs SJM, Bodde NMG, Carrette E, Lazeron RHC, Vonck KEJ, Boon PAJM, Langereis GR, Cluitmans PJM, Feijs LMG, Hofman PAM, Backes WH, Jansen JFA, Aldenkamp AP. Neurophysiological correlates of dissociative symptoms. J Neurol Neurosurg Psychiatry 2012;22. [Epub ahead of print] PubMed PMID: 23175855.

2. Pillai JA, Haut SR. Patients with epilepsy and psychogenic non-epileptic seizures: an inpatient videoEEG monitoring study. Seizure 2012:21:24-7.

3. Carson JA, Brown R, David AS, Duncan R, Edwards MJ, Goldstein LH, Grunewald R, Howlett S, Kanaan R, Mellers J, Nicholson TR, Reuber M, Schrag A-E, Stone J, Voon V. Functional (conversion) neurological symptoms: research since the millennium. J Neurol Neurosurg Psychiatry 2012;13:1-9.

4. Rotge JY, Lambrecq V, Marchal C, Pedespan JM, Burbaud P, Rougier A, Michel V. Conversion disorder and coexisting non-epileptic seizures in patients with refractory seizures. Epilepsy Behav 2009;16: 350-2.

5. Brown RJ, Syed TU, Benbadis S, LaFrance WC, Reuber M. Psychogenic non-epileptic seizures. Epilepsy Behav 2011;22:85-93.

6. Stone J, Smyth R, Carson A et al. Systematic review of misdiagnosis of conversion symptoms and "hysteria". BMJ 2005;331:989.

7. Arain AM, Song Y, Bangalore-Vittal N, Ali S, Jabeen S, Azar NJ. Long term video/EEG prevents unnecessary vagus nerve stimulator implantation in patients with psychogenic non-epileptic seizures. Epilepsy Behav 2011;21:364-6

8. Kozlowska K. Healing the disembodied mind: contemporary models of conversion disorder. Harv Rev Psychiatry 2005;13:1-13.

9. O’Sullivan SS, Spillane JE, McMahon EM, Sweeney BJ, Galvin RJ, McNamara B, Cassidy EM. Clinical characteristics and outcome of patients diagnosed with psychogenic non-epileptic seizures: a 5-year review. Epilepsy Behav 2007;11:77-84.

10. Alper K. Non-epileptic seizures. Neurologic Clinics (Epilepsy II: special issues) 1994(12):153-73.

11. Baxter S, Mayor R, Baird W, Brown R, Cock H, Howlett S, House A, Messina J, Smith P, Reuber M. Understanding patient perceptions following a psycho-educational intervention for psychogenic nonepileptic seizures. Epilepsy Behav 2012;23:487-93.

12. Howlett S, Grunewald R, Khan A, Reuber M. Engagement in psychological treatment for functional neurological symptoms - barriers and solutions. Psychother Theory Res Prac Train 2007;44;354-60.

13. Thompson R, Isaac C, Rowse G, Tooth CL, Reuber M. What is it like to receive a diagnosis of nonepileptic seizures? Epilepsy Behav 2009;14:508-15.

14. McKenzie PS, Oto M, Graham CD, Duncan R. Do patients whose psychogenic non-epileptic seizures resolve, 'replace' them with other medically unexplained symptoms? Medically unexplained symptoms arising after a diagnosis of psychogenic non-epileptic seizures. J Neurol Neurosurg Psychiatry 2011;82:967-69.

15. Olde Hartman T. Persistent medically unexplained symptoms in primary care. The patient, the doctor and the consultation. Phd thesis Nijmegen 2011, the Netherlands.

16. Testa SM, Krauss GL, Lesser RP, Brandt J. Stressful life event appraisal and coping in patients with psychogenic seizures and those with epilepsy. Seizure 2012;21:282-7.

17. Prigatano GP, Stonnington CM, Fisher RS. Psychological factors in the genesis and management of non-epileptic seizures: clinical observations. Epilepsy Behav 2002;3:343-9.

18. Bowman ES, Markand ON. Psychodynamics and psychiatric diagnoses of pseudoseizure subjects. Am J Psychiatry 1996;153:57-63.

19. Goldstein LH, Chalder T, Chigwedere C, Khondoker MR, Moriarty J, Toone BK, Mellers JD. Cognitivebehavioral therapy for psychogenic nonepileptic seizures: a pilot RCT. Neurology 2010;74:1986-94.

20. Hill SW, Gale SD. Neuropsychological characteristics of non-epileptic seizure semiological subgroups. Epilepsy Behav 2011;22:255-60. 
232 
234 


\section{Summary}

A psychogenic non-epileptic seizure (PNES) is defined as a clinically observable paroxysmal change in behaviour or consciousness, that resembles an epileptic seizure, but is not accompanied by the typical electrophysiological changes that accompany an epileptic seizure. In these patients there is an absence of any known organic aetiology of the seizures, whereas there is positive evidence or a strong suspicion for the existence of psychogenic factors. The incidence of PNES in the general population is relatively low, estimated at about 1.5/ 100,000 persons per year. The actual incidence may be higher because of difficulties in epidemiological studies. Tertiary referral centres, especially epilepsy centres, estimate a much higher incidence rate. Twentyfive to thirty percent of the patients referred to tertiary epilepsy centres for refractory epilepsy are diagnosed with PNES, with or without (comorbid) epilepsy.

Although the correct medical differential diagnosis of PNES versus epilepsy can be challenging, in the past thirty years the differential diagnosis has greatly improved. Differentiating PNES from epilepsy is important, since misdiagnosing PNES as epilepsy may potentially expose patients to unnecessary antiepileptic medications and other iatrogenic consequences of unnecessary medical treatments. However, once the medical diagnosis has been made, it appears not easy to treat these patients adequately and prognosis for at least part of the patients is not that well. With their somatic appearance and underlying psychological or psychiatric problems, PNES patients present on the boundaries of the medical and mental health services. There are potential risks that PNES patients 'shop' through the medical circuit or remain in a 'No Man's Land' without the necessary realization of appropriate psychological or psychiatric treatment. Meanwhile, the impact on daily life is substantial, including not being able to engage in society, leading to psychological burden and economic costs.

The studies in this thesis aim at exploring the psychological aetiology after the medical diagnosis of PNES has been confirmed. A focus that is in line with recent studies of PNES in the international field. Firstly, the research questions focus on finding psychogenic factors that underlie the onset and the prolongation of PNES. Finding underlying psychological mechanisms is essential to engage in treatment. Secondly, the research questions aim at exploring possible sub-classifications of PNES that may be helpful to specify treatment for subgroups and to establish prognosis. The studies are mostly based on clinical work with patients with PNES diagnosed in the specialised Epilepsy Centre Kempenhaeghe and referred to a multidisciplinary expert team involved in the treatment of PNES.

Part 1 gives an overview of the existing knowledge in this field. In chapter $\mathbf{2}$ we review the literature on the medical differential diagnosis of PNES and epilepsy. There is consensus in literature that the differential diagnosis PNES versus epilepsy has greatly 
improved and that video EEG is the golden standard. However, diagnosing 'non epilepsy' remains a clinical diagnosis and not in all cases video EEG is possible. An important misunderstanding, that often confuses the diagnosis, is the interpretation of results of psychological assessment. Once the diagnosis of PNES is firmly established, such assessment (and especially personality assessment) may provide insights in the psychogenic aetiology. This cannot be reversed; the existence of psychogenic factors cannot be interpreted as evidence for PNES. Finding psychological or psychiatric problems does not eliminate having (comorbid) epilepsy. In addition, in chapter $\mathbf{3}$ the review is focused on psychological aetiology, treatment issues and prognosis. PNES patients comprise a very heterogeneous patient group with regard to the psychological aetiology. It appears not easy to treat these patients adequately and prognosis for at least part of the patients is not that well. Based on these reviews a model is proposed of factors involved in the causation, provocation and prolongation of PNES. This model helped to interpret the findings of the later studies. Although this model resembles other models of somatoform disorders, specific factors, such as "triggering factors", were added presenting PNES as a unique disorder.

In part $\mathbf{2}$ the current status of subsequent treatment of PNES is explored. Chapter $\mathbf{4}$ describes a clinical non-randomized study on the long-term outcome of a group of 22 patients diagnosed with PNES in the epilepsy centre, 4 to 6 years after the diagnosis. Seizure frequency shows statistically significant reduction. It cannot be fully clarified which factors caused this improvement, but one may speculate that a definitive expert diagnosis made in a tertiary center and the efforts to inform the patient in a respectful manner about the diagnosis are crucial factors. However, in addition to seizure reduction, there is improvement on different levels of psychological function, showing reduction in psychological distress, reduction in dissociative features, increased self-control, reduction in feelings of dissatisfaction and passive avoidant behavior, and a more active attitude towards social contact. This does not necessary reflect a causal relationship with the observed seizure reduction. Nonetheless, it is noteworthy that, post aut propter, seizure remission is associated with a more confident social and personal attitude. Chapter 5 and chapter 6 present the results of a Cochrane review on treatment effects in collaboration with the University of Liverpool. The main results show that only three small treatment studies met the Cochrane inclusion criteria at that moment, and these studies are of poor methodological quality. Two studies assessed hypnosis and the other study paradoxical therapy as treatment for PNES. The conclusion is that, in view of the methodological limitations and the small number of studies, there is at that moment no reliable evidence to support the use of any specific treatment, including hypnosis or paradoxical injunction therapy, in the treatment of PNES. Randomized studies of these and other interventions are needed. 
Part 3 challenges both the usefulness of the PNES diagnosis for such a heterogeneous patient group and the opinion of PNES as a unique disorder. Patients with PNES may have similar characteristics as patients with other functional neurological symptoms (FNS) or even the broader group of patients with functional somatic symptoms and syndromes (FSSS). In chapter 7 the personality profile of 41 PNES patients is compared with the profile of 43 patients with insomnia. The personality profile was assessed with the Minnesota Multiphasic Personality Inventory 2 (MMPI-2). The MMPI-2 profile showed no statistically significant quantitative scoring differences on the main clinical scales, indicating that there is no substantial difference in "personality make-up" between these two groups. Additional subscale analysis indicated that patients with PNES reported significantly more somatic complaints and bizarre sensory experiences. Further profile analysis revealed that the personality pattern of patients with PNES was characterized by a strong tendency toward "conversion V, a lack of control pattern and less excessive worries", as compared with patients with insomnia. Patients with PNES are characterized by a stronger tendency towards somatization and externalization, which has treatment implications. Chapter $\mathbf{8}$ includes a descriptive study providing patient characteristics in 90 PNEA patients newly referred to the epilepsy centre in a 2-year period, focusing on the medical and psychological patient history before seizure onset. The majority of the patients showed a patient history with many medical symptoms (other than seizures) and they were or had been in treatment by other medical specialists than neurologists. Furthermore, diffuse psychological or psychiatric symptoms and subsequent treatments were also remarkably common, in general without a clear psychological diagnosis. The average time between seizure onset and referral to an epilepsy centre was relatively short (4.29 years), compared to data in literature. About $50 \%$ of the patients were referred within 2 years of seizure onset. This 'active high speed referral group' had significantly more previous psychological complaints, significantly more previous psychological/ psychiatric treatments and a trend towards more previous medical investigations. The conclusion is that there possibly is a new subgroup of PNES patients, characterized by a relative more active attitude towards examination of symptoms in combination with an active attitude to apply for treatment. The PNES cohort as a whole is characterized by having somatoform symptoms based on a process of somatization.

In chapter 9 the theoretical model derived from the reviews is used to describe subgroups in a prospective study. The results showed that the total PNES group $(n=40)$ was characterized by multiple trauma, personality vulnerability (in a lesser extent, neuropsychological vulnerabilities), no increased dissociation, many complaints about daily hassles that may trigger seizures, and negative coping strategies that may contribute to prolongation of the seizures. Using factor analysis, three specific subgroups were revealed: a 'psychotrauma subgroup', a 'high vulnerability somatizing subgroup' (with high and low cognitive levels) and a 'high vulnerability sensitive personality problem subgroup'. The conclusion is that using a theoretical model, PNES seem to be a symptom of distinct underlying aetiological factors with different 
accents in the model. Hence, describing a general profile seems to conceal specific subgroups with subsequent treatment implications. This study identified three factors, representing two dimensions of the model, that are essential for subgroup classification: psychological etiology (psychotrauma or not) and vulnerability, e.g., the somatization tendency, and sensitive personality problems/characteristics ('novelty seeking'). For treatment this means that interventions could be tailored to the main underlying etiological problem. Also, further research could focus on differentiating subgroups with subsequent treatment indications and possible different prognoses.

In the model a specific vulnerability to develop PNES is suggested. This predisposition may involve psychological factors, such as personality characteristics. However, biological vulnerability may also be involved in the development of PNES. This is studied and described in part 4 . Such a vulnerability may not be the single cause of the symptoms, but may contribute to the development of PNES. This is in line with the perspectives of the biopsychological model in somatoform disorders. In chapter 10 a specific review is presented, focusing on psychobiological markers for dissociation, one mechanism or process that may cause psychogenic seizures. In a final study, described in chapter 11, functional MRI is used to demonstrate such biological vulnerability. The findings of the fMRI study show that changes in brain activation and neuronal organisation may predispose to dissociation, a mechanism involved in the development of PNES. The abnormal, strong functional connectivity found in PNES patients provides a neurophysiological correlate for the underlying dissociation mechanism where emotion can influence executive control, resulting in altered motor function (e.g., seizure-like episodes). Heart-rate variability (HRV) measures, EEG and (functional) MRI seem to be sensitive methods to detect physiological changes related to dissociation and dissociative disorders such as FNSS, and can possibly provide more information about the specific biological vulnerability. The use of such measures could eventually provide biomarkers for earlier identification of patients at risk and appropriate treatment of dissociative conditions. However, up till now it is difficult to position psychophysiological abnormalities, because they may be both the cause and the consequence of dissociation and PNES.

Finally, in chapter 12, general discussion, the results of all studies are discussed by attempting to answer some of the recurring questions about PNES. Central focus of the discussion is whether PNES must be viewed as a separate disorder or part of a continuum with other functional somatic (neurological) symptoms. Also, the discussion is focused on the implication of the study findings, together with clinical practice experience, for the role of epilepsy centres in the diagnosis and treatment of PNES. 
Samenvatting 
240 


\section{Samenvatting}

Een psychogene niet epileptische aanval (PNEA) wordt gedefinieerd als een klinisch observeerbare paroxysmale verandering in gedrag of bewustzijn, die lijkt op een epileptische aanval, maar die niet samengaat met de typische elektrofysiologische veranderingen die samengaan met een epileptische aanval. Bij deze patiënten is geen sprake van een organische etiologie voor de aanvallen, terwijl er positief bewijs is voor of een sterk vermoeden op de aanwezigheid van psychogene factoren. De incidentie van PNEA in de algemene bevolking is relatief laag en wordt geschat op ongeveer 1,5 / 100.000 personen per jaar. De werkelijke incidentie kan hoger zijn, omdat epidemiologische studies moeilijk uitvoerbaar zijn. Tertiaire instellingen, en met name epilepsiecentra, schatten een veel hogere incidentie in. Vijfentwintig tot dertig procent van de patiënten die verwezen worden naar tertiaire epilepsie centra voor refractaire epilepsie, worden gediagnostiseerd met PNEA, met of zonder (comorbide) epilepsie.

Hoewel het stellen van een goede medische differentiaal diagnose van PNEA versus epilepsie gecompliceerd kan zijn, is deze differentiaal diagnostiek in de afgelopen dertig jaar zeer verbeterd. Het differentiëren tussen PNEA en epileptische aanvallen is belangrijk. Een verkeerde diagnose van PNEA als epilepsie stelt patiënten namelijk potentieel bloot aan onnodige anti-epileptische medicatie en kan andere iatrogene consequenties hebben van onnodig medisch handelen. Echter, wanneer de medische diagnose is gesteld, blijkt het niet gemakkelijk deze patiënten adequaat te behandelen. Ook is de prognose, op z'n minst voor een deel van de patiënten, minder goed. Door de somatische verschijningsvorm enerzijds en de onderliggende psychologische of psychiatrische problemen anderzijds, presenteren PNEA patiënten zich op de grenzen van zowel de medische als de geestelijke gezondheidszorg instellingen. Er zijn potentiële risico's dat PNEA patiënten gaan "shoppen" door het medische circuit of in een "niemandsland" verblijven, zonder dat de noodzakelijke adequate psychologische of psychiatrische behandeling wordt ingezet. Ondertussen is de impact op het dagelijks leven aanzienlijk, inclusief niet in staat zijn deel te nemen aan de maatschappij, hetgeen kan leiden tot psychologische belasting en onnodige economische kosten.

De studies in dit proefschrift hebben als doel het onderzoeken van de psychogene factoren, nadat de medische diagnose PNEA is bevestigd. Dit doel komt overeen met recente internationale studies naar PNEA. Ten eerste richten de onderzoeksvragen zich op het vinden van psychogene factoren, die ten grondslag liggen aan het ontstaan en het persisteren van PNEA. Het vinden van onderliggende psychologische mechanismen is essentieel voor het kunnen inzetten van adequate behandeling. Ten tweede hebben de onderzoeksvragen tot doel mogelijke PNEA subgroepen te verkennen, hetgeen behulpzaam kan zijn bij het specificeren van behandeling voor 
subgroepen en het vaststellen van daarbij horende prognoses. De studies zijn overwegend gebaseerd op de klinische praktijk met PNEA patiënten, die gediagnostiseerd zijn in het gespecialiseerde epilepsiecentrum Kempenhaeghe en die verwezen zijn naar een multidisciplinair expert team dat zich bezig houdt met de behandeling van PNEA.

Deel 1 geeft een theoretische samenvatting van de literatuur over dit onderwerp. Hoofdstuk 2 is een review van de literatuur over de differentiaal diagnostiek PNEA versus epilepsie. De review laat zien dat consensus bestaat dat de diagnosemogelijkheden van PNEA - met het video-EEG als gouden standaard- aanzienlijk verbeterd zijn. Echter, 'niet-epilepsie' blijft een klinische diagnose en niet in alle omstandigheden is het video-EEG mogelijk. Een belangrijk misverstand, vaak leidend tot misinterpretaties, is de interpretatie van de resultaten van psychologisch onderzoek. Wanneer eenmaal de diagnose PNEA is bevestigd, heeft psychologisch onderzoek (en dan met name persoonlijkheidsdiagnostiek) een essentiële rol bij het vaststellen van onderliggende psychogene factoren. Deze volgorde kan echter niet omgedraaid worden. Het bestaan van psychogene factoren is geen bewijs dat sprake is van PNEA. Het vinden van psychologische of psychiatrische problemen sluit immers niet uit dat sprake is van (comorbide) epilepsie. In aanvulling hierop richt hoofdstuk $\mathbf{3}$ zich op de literatuur over psychologische etiologie, behandelzaken en prognose. Patiënten met PNEA vormen een zeer heterogene patiëntengroep met betrekking tot de psychologische etiologie. Het blijkt niet gemakkelijk deze patiënten adequaat te behandelen. Ook is de prognose voor minstens een deel van de patiënten niet goed. Gebaseerd op de reviews is een model opgesteld, waarin de verschillende factoren zijn opgenomen, die verantwoordelijk zijn voor het veroorzaken van PNEA, het uitlokken van de aanvallen en het in stand houden van de symptomen. Dit model wordt ook gebruikt om de resultaten van de vervolgstudies te interpreteren. Het model komt overeen met modellen die ook gebruikt worden bij de verklaring van andere somatoforme stoornissen, maar is door het invoegen van bepaalde factoren, bijvoorbeeld "trigger" factoren, uniek voor PNEA.

Deel 2 richt zich op de huidige kennis over de behandeling van PNEA. Hoofdstuk 4 beschrijft een klinische studie, waarin de langere termijn effecten van de diagnose PNEA, vastgesteld in een epilepsiecentrum, werden geëvalueerd. Een groep van 22 patiënten met PNEA werd onderzocht, 4 tot 6 jaar nadat de diagnose was vastgesteld. De analyse toont een significante verlaging van de aanvalsfrequentie. Het is niet geheel duidelijk welke factoren hebben bijgedragen aan dit resultaat. Mogelijk heeft de duidelijke diagnose bijgedragen, evenals het feit dat die vastgesteld werd door een expertteam in een expertise centrum. Mogelijk is ook de manier waarop de diagnose met de patiënt is gecommuniceerd van belang, met veel aandacht voor respectvolle communicatie. Naast de aanvalsvermindering is ook sprake van verbetering van verschillende onderzochte psychische functies. Het psychologisch onderzoek toont 
vermindering van psychische stress, verminderde neiging tot dissociatie, toename van zelfcontrole, afname van gevoelens van onvrede en van passief vermijdend gedrag en een meer actieve sociale houding. Deze studie heeft niet vastgesteld of de reductie in aanvalsfrequentie veroorzaakt werd of gevolgd werd door de verbetering in psychisch functioneren. Ondanks deze onduidelijkheid is het echter opmerkelijk dat het verdwijnen van een symptoom (aanvallen) met sociale consequenties geassocieerd is met een verbeterde sociale en persoonlijke attitude. Hoofdstuk 5 en hoofdstuk 6 presenteren de resultaten van een Cochrane review over behandel-effecten, tot stand gekomen in samenwerking met de universiteit van Liverpool. De resultaten tonen aan dat slechts drie studies op dat moment voldeden aan de Cochrane inclusie criteria. Alle drie de studies hebben ernstige methodologische tekortkomingen. Twee studies onderzochten het effect van hypnose en één studie het effect van paradoxale behandeling op PNEA. De analyse van de gehele literatuur leidt tot de conclusie dat er op dat moment geen 'evidence-based' aanbevelingen te geven zijn over het gebruik van specifieke behandelingen bij PNEA. Gerandomiseerde interventiestudies zijn nodig.

Deel 3 richt zich op de zinvolheid van de diagnose PNEA als dé overkoepelende term voor een zeer heterogene aandoening. Bovendien wordt ingegaan op de vraag of PNEA gezien kan worden als een aparte stoornis of dat sprake is van een stoornis in een continuüm van psychische aandoeningen. PNEA patiënten hebben mogelijk vergelijkbare kenmerken met patiënten met andere functionele neurologische symptomen (FNS) of zelfs vergelijkbare kenmerken met de grotere groep van patiënten met functionele somatische symptomen en syndromen (FSSS). In Hoofdstuk 7 wordt het persoonlijkheidsprofiel van 41 patiënten met PNEA vergeleken met het profiel van 43 patiënten met insomnie. Het persoonlijkheidsprofiel werd vastgesteld met de Minnesota Multiphasic Personality Inventory 2 (MMPI-2). Het MMPI-2 profiel toonde geen statistisch significante kwantitatieve verschillen op de scores op de hoofdschalen, hetgeen betekent dat de 'personality make-up' van deze twee groepen niet wezenlijk verschillend is. Aanvullende analyses van de subschalen toonden wel enkele verschillen. De patiënten met PNEA rapporteerden significant meer somatische klachten en bizarre zintuiglijke ervaringen. Een profiel analyse toonde verder voor de patiënten met PNEA een sterke neiging tot "het karakteristieke 'conversie $V^{\prime}$ profiel, een patroon van gebrek aan controle en minder overmatige zorgen" in vergelijking met patiënten met insomnie. In het algemeen kan gezegd worden dat de patiënten met PNEA een sterkere neiging blijken te hebben tot somatisatie en externalisatie, hetgeen van belang is voor de behandeling van deze patiënten. Hoofdstuk 8 beschrijft een klinische studie naar de patiënt karakteristieken van 90 PNEA patiënten, die gedurende een 2-jarige periode verwezen werden naar het epilepsiecentrum Kempenhaeghe en die gezien waren door een expertteam. Ook de medische en psychologische voorgeschiedenis van deze patiënten werd in de studie onderzocht. De meerderheid van de patiënten had een voorgeschiedenis met 
veel medische symptomen (anders dan de aanvallen) en was in behandeling (geweest) bij andere medische specialisten dan neurologen. Verder waren vrij diffuse psychische en psychiatrische symptomen algemeen voorkomend, inclusief daarop gerichte behandelingen. Daarbij viel op dat veel psychische behandelingen gestart waren zonder duidelijke psychologische diagnose. De gemiddelde periode tussen het debuut van de aanvallen en de verwijzing naar een epilepsiecentrum was relatief kort in deze groep (gemiddeld 4.29 jaar), althans in vergelijking met de gepubliceerde data over deze 'diagnostic delay'. Ongeveer $50 \%$ van de patiënten was zelfs zeer snel verwezen (binnen 2 jaar na het aanvalsdebuut). Deze snel verwezen groep ("the active high speed referral group") werd gekarakteriseerd door een voorgeschiedenis met significant meer psychische klachten dan de overige patiënten. Tevens hadden zij in hun voorgeschiedenis significant meer psychische/psychiatrische behandelingen ondergaan en toonden zij een sterke tendens tot het verzoeken om medische onderzoeken. Er wordt geconcludeerd dat mogelijk sprake is van een nieuwe subgroep van PNEA patiënten, gekenmerkt door een relatief actieve houding ten opzichte van het laten onderzoeken van symptomen in combinatie met een actieve houding behandeling aan te vragen. Het gehele PNEA cohort wordt gekenmerkt door het hebben van somatoforme symptomen gebaseerd op een proces van somatisatie.

Het eerder beschreven theoretische model is in hoofdstuk 9 gebruikt voor een prospectieve vergelijkende studie naar subgroepen van PNEA patiënten. De resultaten toonden dat de groep als totaal $(n=40)$ werd gekenmerkt door meervoudige psychotraumata, kwetsbaarheid door persoonlijkheidsfactoren (in mindere mate een neuropsychologische kwetsbaarheid), geen toegenomen dissociatie, veel klachten over dagelijkse zorgen, die aanvallen kunnen triggeren en negatieve coping strategieën, die kunnen bijdragen aan het in stand houden van de aanvallen. Factor analyse toonde drie subgroepen: een 'psycho-trauma subgroep', 'een 'somatisatie subgroep' (met een hoog en laag cognitief niveau) en een subgroep gekenmerkt door 'persoonlijkheidsproblemen' ('sensitiviteit'). De conclusie is, dat door gebruik te maken van het gehanteerde theoretische model, PNEA een symptoom is van verschillende onderliggende etiologische factoren met verschillende accenten in het model. Het beschrijven van een algemeen profiel lijkt te verhullen dat sprake is van specifieke subgroepen met daarop toegespitste behandelmogelijkheden. De studie identificeerde drie essentiële factoren voor subgroep classificatie, die twee dimensies van het model vertegenwoordigen: psychologische etiologie (psychotrauma of niet) en kwetsbaarheid (voor somatiseren en voor het ontwikkelen van persoonlijkheidsproblemen). Voor behandeling betekent dit dat interventies specifiek gericht kunnen worden op het belangrijkste onderliggende etiologische probleem. Ook zou verder onderzoek aan te raden zijn, gericht op het differentiëren van subgroepen met daarbij passende behandelindicaties en mogelijk andere prognoses.

In het gehanteerde model wordt verondersteld dat PNEA mede kan ontstaan door een specifieke kwetsbaarheid of predispositie. Predisponerende factoren kunnen 
persoonlijkheidskenmerken zijn, maar ook biologische factoren zouden een rol kunnen spelen in de ontwikkeling van PNEA. Dit is bestudeerd en de resultaten worden beschreven in deel 4. Biologische predisposities zullen nooit de enige oorzaak zijn voor PNEA, maar kunnen de kans verhogen dat zich gedurende het leven PNEA ontwikkelt. Ook voor andere somatoforme stoornissen zijn zulke biopsychologische modellen geopperd. Hoofdstuk 10 bevat de review gericht op psychobiologische factoren die van invloed zijn op een belangrijk proces of mechanisme dat kan bijdragen aan het ontstaan van PNEA, namelijk dissociatie. In een laatste studie, beschreven in hoofdstuk 11, wordt functional MRI gebruikt om een dergelijke biologische kwetsbaarheid aan te tonen. De resultaten tonen een dergelijke psychobiologische marker in de vorm van specifieke kenmerken van de neuronale functionele connectiviteit bij patiënten met PNEA. De aangetoonde netwerk veranderingen verhogen de kans op dissociatie en kunnen verklaren waarom emoties bij deze patiënten sneller kunnen leiden tot een motorische reactie (in dit geval een aanval). Het gebruik van deze methode, maar mogelijk ook heart-rate variability (HRV) maten (cardiale signalen gerelateerd aan stress) en EEG, kunnen eveneens biomarkers vormen die aangeven welke mensen een verhoogd risico vormen dissociatieve stoornissen en uiteindelijk ook PNEA te ontwikkelen. Een groot probleem met de huidig maten is het post aut propter dilemma, waardoor geen causale relaties gelegd kunnen worden.

Tenslotte bevat hoofdstuk 12 de discussie. Gepoogd is de resultaten van de verrichtte studies, maar ook de praktijkervaring, te gebruiken om te proberen enkele van de klinisch relevante vragen - die ook keer op keer opduiken- te beantwoorden. Eén van de centrale vragen is of we PNEA moeten beschouwen als een unieke aandoening of dat het zich laat rangschikken in een continuüm met andere functionele somatische (of neurologische) symptomen. Ook op de rol van de epilepsiecentra in de diagnose en behandeling van PNEA wordt ingegaan. 
246 
Dankwoord 
248 


\section{Dankwoord}

Op het moment van schrijven van dit dankwoord overheerst nog het niet te bevatten gevoel dat na al die jaren dit proefschrift tot een afronding is gekomen. En tegelijkertijd merk ik nog lang niet uitgekeken te zijn op zowel het wetenschappelijk onderzoek als de patiëntenzorg bij mensen met psychogene niet-epileptische aanvallen. Het blijft een uitdaging te proberen de diagnostiek en behandeling steeds beter vorm te geven en we zijn er nog niet.

Het schrijven van het proefschrift, uitwerken van data, is in het geheel iets wat zich solitair afspeelt. Echter, wanneer je onderzoek doet op een breed terrein dat diverse disciplines omvat, betekent dit ook veel samenwerken, netwerken en je verdiepen in de bijdragen van andere specialisten. Mede vanuit mijn achtergrond binnen de GGZ en door de postdoctorale opleiding was ik al doordrongen van het belang van multidisciplinaire samenwerking. Het bleek een goed uitgangspunt voor de huidige werkzaamheden. Deze constatering vormt tevens een excuus dan wel verantwoording voor het lange dankwoord dat gaat volgen.

Te beginnen met de mensen met psychogene niet-epileptische aanvallen die de afgelopen jaren hebben meegewerkt aan het wetenschappelijk onderzoek. Het viel me op hoeveel patiënten daartoe uiteindelijk bereid bleken te zijn. Dit terwijl de aard van het onderzoek, zoals deelnemen aan een fMRI studie, niet voor alle patiënten, met bijvoorbeeld een traumatische achtergrond, even gemakkelijk was. Verschillende mensen gaven aan dat zij de deelname als een erkenning ervaren hebben voor hun aanvallen. Wij leerden er vervolgens van nog meer gebruik te maken van patiënt ervaringen binnen de behandeling van PNEA patiënten. Hartelijk dank aan alle deelnemers aan het onderzoek, ook de vrijwillige controle personen, zonder wie dit proefschrift niet tot stand gekomen was.

Een speciaal woord van dank gaat uit naar degenen die mijn promotie begeleid hebben.

Allereerst prof. dr. R.J. van Oostenbrugge, hoogleraar Neurologie, MUMC, beste Robert. Hartelijk dank dat je later in het promotietraject wilde instappen en de essentiële voorwaarden hebt gecreëerd om daadwerkelijk te kunnen promoveren in Maastricht. Ik heb je kordate, betrokken handelen en kritische feedback met veel gevoel voor (cynische) humor erg gewaardeerd. Dat heeft ook gemaakt dat ik mij goed voorbereid voel voor de promotiedag.

Prof. dr. K.E. Vonck, hoogleraar Epileptologie UZ Gent, beste Kristl. Hartelijk dank voor de waardevolle ondersteuning en zorgvuldige terugkoppeling op de artikelen in de afgelopen jaren. Ik heb veel geleerd van de creatieve manier waarop jij het PNEA onderwerp benadert en je faciliteert wetenschappelijk onderzoek op inspirerende 
wijze. De samenwerking met Gent is heel belangrijk gebleken, ook voor de vervolgstudies die momenteel lopen. Hartelijk dank daarvoor.

Dr. R.H.C. Lazeron, dienst Neurologie Kempenhaeghe, beste Richard. Hartelijk dank voor de zeer precieze en kritische feedback op de manuscripten van dit proefschrift. De afgelopen jaren hebben we intensief samengewerkt binnen zowel de patiëntenzorg als het wetenschappelijk onderzoek. Vele patiënten hebben we samen gezien. Het heeft mij gesteund dat we hierin op beide fronten goed hebben kunnen samenwerken, met alle ruimte voor een open discussie. Ik waardeer je integriteit en betrokkenheid zeer.

Dr. A.J.A. de Louw, medisch diensthoofd Neurologie Kempenhaeghe, beste Anton. Veel dank voor de support, vaak met een kwinkslag, en de gedegen terugkoppeling in de afgelopen periode. Je gaf niet alleen feedback op de manuscripten, maar bent ook zeer betrokken bij de inhoudelijke discussies over de manier waarop de patiëntenzorg voor PNEA binnen Kempenhaeghe nog beter vorm gegeven kan worden. Dank ook voor het creëren van de faciliteiten om deze zorg te verbeteren.

Prof. dr. P.A.J.M. Boon, diensthoofd Neurologie UZ Gent, directeur Onderzoek \& Ontwikkeling Kempenhaeghe, beste Paul. Hartelijk dank voor alle ondersteuning, de intellectuele uitdaging en stimulans in de afgelopen jaren, hetgeen mij ook geholpen heeft een aantal moeilijke hobbels tijdens het traject te nemen. Het is geen promotie in Gent geworden, maar je bijdragen hebben essentiële accenten op dit proefschrift gelegd.

Prof. dr. A.P. Aldenkamp, hoogleraar Epilepsie \& Neuropsychologie MUMC, diensthoofd Gedragswetenschappelijke Dienst (GWD), Kempenhaeghe. Beste Bert, je bent de initiator geweest van dit onderzoek en tevens steeds een drijvende kracht in het blijven volhouden van alle studies, zoeken naar oplossingen bij tegenslag en bedenken van interessante en creatieve invalshoeken. Ik heb daar veel van geleerd en ervaren dat het daar in onderzoek doen ook vaak omgaat. Heel veel dank daarvoor.

Ook wil ik graag speciale dank betuigen aan de leden van de beoordelingscommissie voor de tijd en energie, die zij gestoken hebben in de beoordeling van dit proefschrift. Dank aan prof. dr. F.R.J. Verhey, hoogleraar Neuropsychiatrie en Ouderenpsychiatrie, MUMC (voorzitter); prof. dr. G.A. Baker, professor of Clinical Psychology and Neuropsychology of epilepsy, University of Liverpool, UK; prof. dr. E. Thiery, emeritus hoogleraar Neuropsychiatrie en Neuropsychologie, Universiteit Gent, België en dr. M.C.G Vlooswijk, dienst Neurologie, Maastricht MUMC.

Dank ook aan het expertisecentrum Kempenhaeghe, de leden van de raad van bestuur, ir. N. Bomer en dr. M. Chatrou, voor het stimuleren van wetenschappelijk 
onderzoek ten dienste van het verbeteren van de patiëntenzorg, inclusief het creëren van goede faciliteiten hiervoor. Ook de twee betrokken onderzoekscholen wil ik bedanken. De School for Mental Health and Neuroscience, Maastricht University (MHeNS UM) en de sector Onderzoek \& Ontwikkeling vanuit Kempenhaeghe. In het bijzonder de betrokken managers, die hebben bijgedragen aan het organiseren van een goed onderzoeks- en wetenschappelijk klimaat met ruimte voor het volgen van specifieke cursussen. Dank aan Laurent Louwies, Managing Director MHeNS UM en Laura Gottmer-Welschen, manager Onderzoek \& Ontwikkeling Kempenhaeghe. Ook dank aan de voorganger, Juliette Duisterwinkel. Juliette, je hebt nog een sleutel van me te goed, vanuit een poging het schrijven te stimuleren op een meer afgezonderde plek in de Boondert!

Dr. J.G. Hendriksen, eerste psycholoog GWD, Kempenhaeghe. Beste Jos, dank je voor de support bij het creëren van voorwaarden voor het uitvoeren van wetenschappelijk werk (het moest soms stevig met mij afgesproken worden). Dank ook voor je zorgvuldige wetenschappelijke bijdragen aan de reviews.

Dank ook aan alle andere betrokken coauteurs voor de waardevolle bijdragen aan de artikelen in dit proefschrift. Tiny Wouters, bedankt voor het zorgvuldig omzetten van het manuscript naar een proefschrift. En Geke Overvliet, bedankt voor de goede tip!

Dr. A.M.A.J. Janssen, drs. C. Theuns en dhr. J.F. Vanhoutvin. Beste Guus, Cees en Jos, jullie vormen de basis van de huidige multidisciplinaire samenwerking op het gebied van PNEA; jullie waren het eerste "PNEA" team binnen Kempenhaeghe. Ik heb veel van jullie kunnen leren in de intensieve gesprekken, die we over de PNEA patiënten voerden, onder andere over het belang van duidelijke communicatie van de diagnose en het betrekken van het systeem. Dank daarvoor. Jullie zijn niet meer werkzaam op Kempenhaeghe, maar we houden contact.

Richard Lazeron, Renée Dabekaussen-Spiering, Jacqueline van Nes, Nora de la Parra, Trudy Beijk en Aleida Smits-van de Velden, de huidige leden van het multidisciplinaire PNEA team in Kempenhaeghe. Veel dank voor de fijne samenwerking en de ondersteuning bij de totstandkoming van dit proefschrift. Samen patiënten zien, bespreken, nadenken over vervolgstrategieën, vormt voor mij een heel leuk en ondersteunend onderdeel van de patiëntenzorg. De wekelijkse vergaderingen verlopen vaak met veel humor en extraatjes en worden door ons allen trouw bezocht.

Sandra Boelen en opnieuw Jacqueline en zeker ook Nora, dank jullie wel voor het overnemen van intakes, andere patiëntencontacten, vergaderingen, op momenten dat er echt even doorgewerkt moest worden aan het proefschrift. Het bleek voor mij in de praktijk niet altijd makkelijk tijd te maken voor de wetenschap binnen de vaak intensieve patiëntenzorg, die gepaard kan gaan met veel telefoontjes, spoed- 
aanvragen e.d. Veel dank dat jullie mij daarin hebben bijgestaan. En Nora, mijn enthousiaste 'overbuurvrouw', wat zou ik het leuk vinden wanneer je zou kunnen starten met die (gecombineerde) specialistische opleidingsplek!

Dimona Bartelet, José Wirken, Els van der Horst en Dominique IJff. Tijdens jullie stageen opleidingsperioden zijn jullie ook bij mij ingesprongen om data te bewerken voor dit proefschrift. Dimona en José hebben er zelfs een scriptie aan gewijd. Veel dank voor jullie hulp.

Dr. Jane Brooks, dr. Laura Goodfellow and prof dr. Gus Baker, thank you for the inspiring cooperation and your hard work on the (Cochrane) Reviews. I enjoyed the visits to Liverpool and it was an educational experience to participate in your nonepileptic attack clinic. The language was different, but there were many similarities in the presentation and difficulties we encounter in diagnosing and treating these patients.

Dr. O. Mulder, gepensioneerd neuroloog en psychotherapeut, een bijzondere combinatie. Beste Olaf, hartelijk dank voor de discussies over PNEA, de samenwerking bij de review en de stimulerende woorden. Je hebt, samen met prof. dr. Aldenkamp, aan de voet gestaan van deze promotiestudie.

Beste Sylvie Kolfschoten van der Kruijs, vanuit je achtergrond als neurowetenschapper ben jij een meer "technisch" promotietraject binnen PNEA gestart naar biofysiologische parameters. Het is erg leuk en stimulerend om samen vanuit verschillende invalshoeken op te trekken. Tijdens de fMRI studie zaten we vaak samen achter de scan met dr. Jaap Jansen en Remco Berting, MRI laborant. Het was in het begin spannend hoe dat zou gaan lopen bij deze patiëntengroep. Zou men niet direct een aanval krijgen tijdens de scan? Het bleek allemaal boven verwachting goed te gaan. Ik heb het als heel gezellig en leerzaam ervaren om met jullie samen te werken. Dank daarvoor! En Sylvie, veel succes met de afronding van je eigen promotie.

Collega's binnen de GWD, psychologen en psychologisch assistenten, dank jullie wel voor jullie belangstelling en steun in de afgelopen jaren. Caroline van der Linden, jouw humor en energie helpen bij elke tegenslag. Misschien kunnen we onze Koefnoen sketches nog eens gaan uitschrijven, anoniem uiteraard! Dank ook voor je hulp bij de feestelijke organisatie rondom de promotie. Lisette, mijn kamergenoot, Debby , Els, Lisanne en ook de andere en nieuwe collega's, dank voor de aanhoudende belangstelling en bemoedigende woorden bij het schrijven van dit proefschrift.

Annemarie, Christie en Thérèse en zeker ook Aleida: mijn agenda beheren, dat valt niet mee, maar gelukkig zijn jullie flexibel. Dank voor alle ondersteuning, ook al omdat 
jullie het eerste contact zijn voor de patiënten als zij persoonlijk of telefonisch contact zoeken.

De gehele neurologenstaf binnen Kempenhaeghe, zoals o.a. mijn copromotoren, dr. Mariette Debeij-van Hall, dr. Marian Majoie, Saskia Ebus en Inge Gommans, met wie ik de afgelopen jaren veel heb samengewerkt op het gebied van PNEA, epilepsie en het verbeteren van de patiëntenzorg. Dank voor jullie ondersteuning en voor de open houding ten opzichte van multidisciplinair werken.

Mijn praktijkopleiders en supervisoren tijdens de opleiding, in het bijzonder drs. C. de Haan en drs. M. Cluysenaer-Lauwers. Beste Cor en Miriam, ik was nog relatief jong toen ik aan de postdoctorale opleiding begon, maar toch gaven jullie mij de kans en daarvoor ben ik jullie zeer dankbaar. Beiden hebben jullie ook altijd aangeven dat een combinatie met wetenschap voor mij geschikt zou kunnen zijn. En zie daar, vele jaren later, blijkt dat inderdaad het geval en dan ook nog binnen de affiniteiten, die er altijd al lagen, multidisciplinair werken met "moeilijke mensen". Dank voor jullie begeleiding en de essentiële basis, die jullie voor mijn beroepsuitoefening hebben gelegd. Ook dank aan Ingeborg Hopman, destijds supervisor en "baas", zij leerde me de fijne kneepjes van de gedragstherapie. Altijd hebben we contact gehouden.

Ook de opleidingsgroep tot klinisch psycholoog en psychotherapeut, de "KP 95-club", wil ik bedanken. Marianne, Sylvie, Rolf, Ingrid, Hans, Larissa, Marian, Suzan, Ellen, Mirjam en Jan, we hebben een intensieve periode met elkaar opgetrokken en dat schept een band; we delen een zelfde opleidingsachtergrond en begrijpen elkaars werkzaamheden en positie. We zijn uitgewaaierd over het land, maar houden ook altijd weer contact.

Carol en Ronnet, we gaan inmiddels al lang terug. Trouw zijn we aan onze etentjes, waarbij Utrecht zo ongeveer het midden voor ons is, en we alles kunnen delen wat er op ons levenspad komt. We hebben zelfs een vaste stek in "Het Zuiden" weten te bemachtigen. Jullie vertegenwoordigen mijn roots binnen de (klinische) psychotherapie (een intense leerperiode), maar inmiddels ook zoveel meer dan dat. Jullie hebben erg meegeleefd tijdens het promotietraject. Ik ben heel blij dat jullie mijn paranimfen willen zijn!

Anja en Isolde, als vriendinnen gelukkig al heel lang in mijn leven. We startten ieder met een totaal andere studie in Nijmegen, maar smeedden een band voor het leven. Jullie waren getuigen op ons huwelijk. Dank jullie wel voor de mij dierbare vriendschap en de ondersteuning tijdens het promotietraject en de vele leuke momenten, die we samen, maar ook met onze gezinnen beleven. Dat er nog vele van zulke momenten mogen volgen. 
De jaarclubgenoten, Marjan, Ilse, Iris, Ellis, Marit en Sabina wil ik bedanken voor hun steun, belangstelling en gezelligheid. Marjan en Ellis, jullie weten hoe het is om te promoveren. De jaarclubnaam verzwijgen we al jaren, dat was in de jaren 80, maar altijd weer volgen er leuke etentjes en uitstapjes. En wat heb ik daar nu weer tijd voor...!

Maria, vriendin, oud collega en coauteur, dank je wel voor alle ondersteuning en de plezierige gezamenlijke ontmoetingen, ook met onze beide gezinnen, hier of in Spanje.

Ook alle andere vrienden en kennissen wil ik danken voor zowel de steun als soms ook broodnodige afleiding. Door de verschillende verhuizingen is ons netwerk erg verspreid over het land, maar gelukkig staat de moderne techniek voor niets (toegeven, ik ben ik niet de allerhandigste techneut, maar leer wel bij...!)

Tineke, Ingrid en Marioline, zonder jullie hulp zou het in dit drukke leven niet mogelijk geweest zijn te kunnen promoveren. Dankzij jullie weet ik dat het thuis goed geregeld is wanneer ik er niet ben. De kinderen zijn ook dol op jullie. Veel dank daarvoor. Dat geldt ook voor alle gezellige en steunende contacten in onze kinderrijke buurt, waar het mede daardoor heel fijn wonen is. In het bijzonder mijn kordate "buurvrouw" Natalie, die ondertussen het nodige afweet van promoveren. En ook Annelyn, de flexibele grote zus en oppas. Die avondvierdaagse lopen komt nog wel een keer!

Familie en schoonfamilie. Doorzettingsvermogen, nieuwsgierigheid en de behoefte je verder te ontwikkelen heb ik als kind goed meegekregen. En eerlijk is eerlijk, dat kwam tijdens dit proces goed van pas. Mijn ouders hebben mij mede gebracht waar ik nu sta. Zonder mijn vader was de hele vacature in Kempenhaeghe mij aanvankelijk waarschijnlijk ontgaan. Hij heeft een goed inzicht gehad in wat mij zou passen. Inmiddels heb ik er een grote, warme (schoon)familie bij gekregen, met de grote broers Arnoud en Adrian, Annelyn, neven en nichten, waarbij ik ook mijn schoonouders niet kan missen. Dat heeft mijn leven verrijkt en al vele leuke momenten gebracht. Dank jullie wel voor jullie belangstelling, support en doortastende, doch confronterende, vragen (Anneke en Erica, jarenlang, liefst tijdens het kerstdiner: "kunnen we al vragen wanneer de promotiedatum is...?!!"). Hopelijk volgen er nog vele mooie momenten.

Mijn basis, mijn alles, lieve Bert, Edar, Julien en Anna. Ik houd heel veel van jullie en kan me geen leven zonder jullie voorstellen. Jullie hebben het vele werken voor mij in een ander perspectief geplaatst, al is het werk van mama wel moeilijk uit te leggen ("ze praat een beetje en dan worden de mensen beter toch..?!"). Bert, jij hebt altijd vertrouwen gehouden, mij uitgedaagd met je intellect en humor en veel geduld gehad. Ik kan je niet genoeg bedanken! We gaan een feestje vieren! 
Curriculum Vitae 
256 


\section{Curriculum Vitae}

Nynke Maria Gerharda Bodde werd geboren op 16 september 1971 te Geldrop. In 1989 behaalde zij het atheneum diploma aan het Van der Puttlyceum te Eindhoven. Aansluitend startte zij met de studie psychologie aan de Radboud Universiteit Nijmegen. In 1990 behaalde zij het propedeuse diploma cum laude. Vervolgens volgde zij de doctoraal opleiding vanuit de afstudeerrichtingen Gerontologie en Klinische Psychologie. Als student assistent leidde zij ondersteuningsgroepen voor ouderen en deed vrijwilligerswerk in het verzorgingstehuis. Tijdens de lange stage periode binnen de psychiatrische - en opname afdelingen van Pro Persona GGZ raakte zij toenemend geïnteresseerd in diagnostiek en behandeling van complexe psychologische en psychiatrische problematiek. In juni 1995 rondde zij cum laude de psychologie opleiding af. In datzelfde jaar startte zij met de postdoctorale specialistische opleiding tot klinisch psycholoog en psychotherapeut, eveneens vanuit de Radboud Universiteit Nijmegen. Vanuit deze postdoctorale opleiding was zij verbonden aan diverse opleidingscentra. Zij startte binnen de eerstelijnspraktijk, allereerst Psychologenpraktijk Derksen \& Klein Herenbrink te Bemmel en later Hopman Praktijk voor Cognitieve Gedragstherapie te Nijmegen. Ook was zij werkzaam op de Psychiatrische Deeltijdbehandeling verbonden aan GGNet te Apeldoorn, de Angstpolikliniek vanuit Pro Persona GGZ te Nijmegen en tot slot het Centrum voor Psychotherapie (deeltijd klinische - en klinische afdelingen) te Lunteren, inmiddels eveneens verbonden aan Pro Persona GGZ. In 2001 behaalde zij de BIG registraties tot GZ psycholoog, klinisch psycholoog en psychotherapeut. Ook werd zij in dat jaar geregistreerd als cognitief gedragstherapeut bij de Vereniging voor Gedragstherapie en Cognitieve Therapie (VGCT). Zij vervolgde haar werkzaamheden als hoofdbehandelaar binnen de Psychotherapeutische Deeltijdbehandeling verbonden aan de GGZ in Breda. In 2003 trad zij in dienst van Kempenhaeghe, Expertisecentrum voor epileptologie, slaapgeneeskunde en neurocognitie. Zij is verbonden aan de Gedragswetenschappelijke Dienst. De afgelopen jaren heeft zij een functie binnen de patiëntenzorg gecombineerd met een promotietraject gericht op psychogene niet epileptische aanvallen. In deze functie komen de eerdere interesses samen met het uitdagende gebied van de medisch onverklaarde somatische klachten.

Nynke Maria Gerharda Bodde was born on September 16th 1971 in Geldrop, the Netherlands. In 1989 she finished her secondary school at the Van der Puttlyceum in Eindhoven. Subsequently, she started studying psychology at the Radboud University Nijmegen in the Netherlands. In 1990 she finished her Bachelor psychology cum laude. She then followed the Masters training psychology in both Gerontology and Clinical Psychology. As a student assistant she led support groups for elderly and she was a volunteer in an elderly home. During a long internship in a psychiatric ward and admission centre of "Pro Persona GGZ", she became interested in the diagnosis and 
treatment of complex psychological and psychiatric problems. In June 1995 she graduated cum laude as a psychologist. In the same year she enrolled the Postdoc Education towards Clinical Psychologist and Psychotherapist, again at the Radboud University Nijmegen. During this training she worked at several training institutes. Starting within the so called primary care, the Psychology Practice Derksen \& Klein Herenbrink in Bemmel and, later at Hopman Practice for Cognitive Behavioral Therapy in Nijmegen. She also worked at the Psychiatric Treatment Unit of "GGNet" in Apeldoorn, the Treatment Unit for Anxiety Disorders of "Pro Persona GGZ" in Nijmegen and finally the Centre for Psychotherapy in Lunteren, also of "Pro Persona GGZ". In 2001 she is enlisted in the registry as healthcare psychologist, clinical psychologist and psychotherapist. In the same year she was also registered as a cognitive behavioral therapist at the Dutch Association for Behavioral and Cognitive Therapy (VGCT). She subsequently worked as a leading counsellor in the Psychotherapeutic Treatment Centre of the "GGZ" in Breda. In 2003 she joined Kempenhaeghe, Centre of expertise in epileptology, sleep medicine and neurocognition. She is working at the Department for Behavioural Sciences. In the past years she combined a function in patient care with a PhD program focussed at psychogenic non-epileptic seizures. In this function the former interests combine with the challenging field of medically unexplained somatic symptoms. 